\title{
Vitamin and mineral supplementation for maintaining cognitive function in cognitively healthy people in mid and late life (Review)
}

Rutjes AWS, Denton DA, Di Nisio M, Chong LY, Abraham RP, Al-Assaf AS, Anderson JL, Malik MA, Vernooij RWM, Martínez G, Tabet N, McCleery J

Rutjes AWS, Denton DA, Di Nisio M, Chong LY, Abraham RP, Al-Assaf AS, Anderson JL, Malik MA, Vernooij RWM, Martínez G, Tabet N, McCleery J.

Vitamin and mineral supplementation for maintaining cognitive function in cognitively healthy people in mid and late life. Cochrane Database of Systematic Reviews 2018, Issue 12. Art. No.: CD011906.

DOI: 10.1002/14651858.CD011906.pub2.

www.cochranelibrary.com

Vitamin and mineral supplementation for maintaining cognitive function in cognitively healthy people in mid and late life (Review) 
TABLE OF CONTENTS

HEADER

ABSTRACT

PLAIN LANGUAGE SUMMARY

SUMMARY OF FINDINGS

BACKGROUND

OBJECTIVES

METHODS

RESULTS

Figure 1.

Figure 2.

Figure 3.

Figure 4.

Figure 5.

DISCUSSION

AUTHORS' CONCLUSIONS

ACKNOWLEDGEMENTS

REFERENCES

CHARACTERISTICS OF STUDIES

DATA AND ANALYSES

Analysis 1.1. Comparison $1 \mathrm{~B}$ vitamins versus control, Outcome 1 Overall cognitive functioning.

Analysis 1.2. Comparison $1 \mathrm{~B}$ vitamins versus control, Outcome 2 Episodic memory.

Analysis 1.3. Comparison $1 \mathrm{~B}$ vitamins versus control, Outcome 3 Executive function.

Analysis 1.4. Comparison $1 \mathrm{~B}$ vitamins versus control, Outcome 4 Speed of processing.

Analysis 1.5. Comparison $1 \mathrm{~B}$ vitamins versus control, Outcome 5 Incidence of $\mathrm{MCl}$ or dementia.

Analysis 1.6. Comparison $1 \mathrm{~B}$ vitamins versus control, Outcome 6 All-cause mortality.

Analysis 2.1. Comparison 2 Antioxidants versus control, Outcome 1 Overall cognitive functioning.

Analysis 2.2. Comparison 2 Antioxidants versus control, Outcome 2 Episodic memory.

Analysis 2.3. Comparison 2 Antioxidants versus control, Outcome 3 Executive function.

Analysis 2.4. Comparison 2 Antioxidants versus control, Outcome 4 Incidence of dementia.

Analysis 2.5. Comparison 2 Antioxidants versus control, Outcome 5 All-cause mortality.

Analysis 3.1. Comparison 3 Vitamin D3 versus placebo, Outcome 1 Overall cognitive functioning.

Analysis 3.2. Comparison 3 Vitamin D3 versus placebo, Outcome 2 Episodic memory.

Analysis 3.3. Comparison 3 Vitamin D3 versus placebo, Outcome 3 Executive function.

Analysis 3.4. Comparison 3 Vitamin D3 versus placebo, Outcome 4 Speed of processing.

Analysis 3.5. Comparison 3 Vitamin D3 versus placebo, Outcome 5 Incident $\mathrm{MCl}$.

Analysis 3.6. Comparison 3 Vitamin D3 versus placebo, Outcome 6 Incident all-cause dementia.

Analysis 4.1. Comparison 4 Zinc + copper versus placebo, Outcome 1 Overall cognitive functioning.

Analysis 4.2. Comparison 4 Zinc + copper versus placebo, Outcome 2 Episodic memory.

Analysis 4.3. Comparison 4 Zinc + copper versus placebo, Outcome 3 Executive function.

Analysis 5.1. Comparison 5 Complex multivitamin versus control, Outcome 1 Overall cognitive functioning.

Analysis 5.2. Comparison 5 Complex multivitamin versus control, Outcome 2 Episodic memory.

Analysis 5.3. Comparison 5 Complex multivitamin versus control, Outcome 3 Executive function.

Analysis 5.4. Comparison 5 Complex multivitamin versus control, Outcome 4 Speed of processing. 
[Intervention Review]

\title{
Vitamin and mineral supplementation for maintaining cognitive function in cognitively healthy people in mid and late life
}

\author{
Anne WS Rutjes 1,2, David A Denton³, Marcello Di Nisio4, Lee-Yee Chong5, Rajesh P Abraham6, Aalya S Al-Assaf7, John L Anderson8, \\ Muzaffar A Malik ${ }^{9}$, Robin WM Vernooij ${ }^{10}$, Gabriel Martínez ${ }^{11}$, Naji Tabet ${ }^{12}$, Jenny McCleery ${ }^{13}$ \\ 1Institute of Social and Preventive Medicine (ISPM), University of Bern, Bern, Switzerland. 2Institute of Primary Health Care (BIHAM), \\ University of Bern, Bern, Switzerland. 3Specialist Older People's Services, Sussex Partnership NHS Foundation Trust, Uckfield, UK. \\ 4Department of Medicine and Ageing Sciences, University "G. D'Annunzio" of Chieti-Pescara, Chieti Scalo, Italy. ${ }^{5}$ UK Cochrane Centre, \\ Oxford, UK. ${ }^{6}$ Community Mental Health Team for Older People:Waverley, Surrey and Borders Partnership NHS Foundation Trust, \\ Guildford, UK. ${ }^{7}$ NIHR Innovation Observatory, Newcastle University, Newcastle Upon Tyne, UK. 8Department of Medical Education, \\ Brighton and Sussex Medical School, University of Brighton, Falmer, UK. ${ }^{9}$ Department of Medical Education (Postgraduate), Brighton and \\ Sussex Medical School, University of Brighton, Falmer, UK. 10/beroamerican Cochrane Centre, Barcelona, Spain. ${ }^{11}$ Faculty of Medicine \\ and Dentistry, Universidad de Antofagasta, Antofagasta, Chile. ${ }^{12}$ Centre for Dementia Studies, Brighton and Sussex Medical School, \\ Brighton, UK. ${ }^{13}$ Oxford Health NHS Foundation Trust, Banbury, UK
}

Contact address: Naji Tabet, Centre for Dementia Studies, Brighton and Sussex Medical School, Mayfield House, University of Brighton, Falmer, Brighton, BN1 9PH, UK. n.tabet@bsms.ac.uk.

Editorial group: Cochrane Dementia and Cognitive Improvement Group.

Publication status and date: Edited (no change to conclusions), published in Issue 1, 2019.

Citation: Rutjes AWS, Denton DA, Di Nisio M, Chong LY, Abraham RP, Al-Assaf AS, Anderson JL, Malik MA, Vernooij RWM, Martínez G, Tabet N, McCleery J. Vitamin and mineral supplementation for maintaining cognitive function in cognitively healthy people in mid and late life. Cochrane Database of Systematic Reviews 2018, Issue 12. Art. No.: CD011906. DOI: 10.1002/14651858.CD011906.pub2.

Copyright (c) 2019 The Cochrane Collaboration. Published by John Wiley \& Sons, Ltd.

\section{A B S T R A C T}

\section{Background}

Vitamins and minerals play multiple functions within the central nervous system which may help to maintain brain health and optimal cognitive functioning. Supplementation of the diet with various vitamins and minerals has been suggested as a means of maintaining cognitive function, or even of preventing dementia, in later life.

\section{Objectives}

To evaluate the effects of vitamin and mineral supplementation on cognitive function in cognitively healthy people aged 40 years or more.

\section{Search methods}

We searched ALOIS, the Cochrane Dementia and Cognitive Improvement Group's (CDCIG) specialised register, as well as MEDLINE, Embase, PsycINFO, CINAHL, ClinicalTrials.gov and the WHO Portal/ICTRP from inception to 26th January 2018.

\section{Selection criteria}

We included randomised controlled trials that evaluated the cognitive effects on people aged 40 years or more of any vitamin or mineral supplements taken by mouth for at least three months.

\section{Data collection and analysis}

Study selection, data extraction, and quality assessments were done in duplicate. Vitamins were considered broadly in the categories of $B$ vitamins, antioxidant vitamins, and combinations of both. Minerals were considered separately, where possible. If interventions and outcomes were considered sufficiently similar, then data were pooled. In order to separate short-term cognitive effects from possible 
longer-term effects on the trajectory of cognitive decline, data were pooled for various treatment durations from 3 months to 12 months and up to 10 years or more.

\section{Main results}

In total, we included 28 studies with more than 83,000 participants. There were some general limitations of the evidence. Most participants were enrolled in studies which were not designed primarily to assess cognition. These studies often had no baseline cognitive assessment and used only brief cognitive assessments at follow-up. Very few studies assessed the incidence of dementia. Most study reports did not mention adverse events or made only very general statements about them. Only 10 studies had a mean follow-up $>5$ years. Only two studies had participants whose mean age was $<60$ years at baseline. The risk of bias in the included studies was generally low, other than a risk of attrition bias for longer-term outcomes. We considered the certainty of the evidence behind almost all results to be moderate or low.

We included 14 studies with 27,882 participants which compared folic acid, vitamin B12, vitamin B6, or a combination of these to placebo. The majority of participants were aged over 60 years and had a history of cardio- or cerebrovascular disease. We found that giving B vitamin supplements to cognitively healthy adults, mainly in their $60 \mathrm{~s}$ and 70 s, probably has little or no effect on global cognitive function at any time point up to 5 years (SMD values from -0.03 to 0.06 ) and may also have no effect at 5-10 years (SMD -0.01). There were very sparse data on adverse effects or on incidence of cognitive impairment or dementia.

We included 8 studies with 47,840 participants in which the active intervention was one or more of the antioxidant vitamins: $ß$-carotene, vitamin C or vitamin E. Results were mixed. For overall cognitive function, there was low-certainty evidence of benefit associated with $B$ carotene after a mean of 18 years of treatment (MD 0.18 TICS points, $95 \% \mathrm{Cl} 0.01$ to 0.35 ) and of vitamin C after 5 years to 10 years (MD 0.46 TICS points, $95 \% \mathrm{CI} 0.14$ to 0.78 ), but not at earlier time points. From two studies which reported on dementia incidence, there was lowcertainty evidence of no effect of an antioxidant vitamin combination or of vitamin $\mathrm{E}$, either alone or combined with selenium. One of the included studies had been designed to look for effects on the incidence of prostate cancer; it found a statistically significant increase in prostate cancer diagnoses among men taking vitamin $\mathrm{E}$.

One trial with 4143 participants compared vitamin D3 (400 IU/day) and calcium supplements to placebo. We found low- to moderatecertainty evidence of no effect of vitamin D3 and calcium supplements at any time-point up to 10 years on overall cognitive function (MD after a mean of 7.8 years -0.1 MMSE points, $95 \% \mathrm{Cl}-0.81$ to 0.61 ) or the incidence of dementia (HR $0.94,95 \% \mathrm{Cl} 0.72$ to 1.24 ). A pilot study with 60 participants used a higher dose of vitamin D3 (4000 IU on alternate days) and found preliminary evidence that this dose probably has no effect on cognitive function over six months.

We included data from one trial of zinc and copper supplementation with 1072 participants. There was moderate-certainty evidence of little or no effect on overall cognitive function (MD 0.6 MMSE points, $95 \% \mathrm{Cl}-0.19$ to 1.39 ) or on the incidence of cognitive impairment after 5 years to 10 years. A second smaller trial provided no usable data, but reported no cognitive effects of six months of supplementation with zinc gluconate.

From one study with 3711 participants, there was low-certainty evidence of no effect of approximately five years of selenium supplementation on the incidence of dementia ( $\mathrm{HR} 0.83,95 \% \mathrm{Cl} 0.61$ to 1.13 ).

Finally, we included three trials of complex supplements (combinations of B vitamins, antioxidant vitamins, and minerals) with 6306 participants. From the one trial which assessed overall cognitive function, there was low-certainty evidence of little or no effect on the TICS (MD after a mean of 8.5 years $0.12,95 \% \mathrm{Cl}-0.14$ to 0.38 ).

\section{Authors' conclusions}

We did not find evidence that any vitamin or mineral supplementation strategy for cognitively healthy adults in mid or late life has a meaningful effect on cognitive decline or dementia, although the evidence does not permit definitive conclusions. There were very few data on supplementation starting in midlife (<60 years); studies designed to assess cognitive outcomes tended to be too short to assess maintenance of cognitive function; longer studies often had other primary outcomes and used cognitive measures which may have lacked sensitivity. The only positive signals of effect came from studies of long-term supplementation with antioxidant vitamins. These may be the most promising for further research.

\section{PLAIN LANGUAGE SUMMARY}

\section{Vitamin and mineral supplementation for preventing cognitive deterioration in cognitively healthy people in mid and late life}

\section{Review question}

This review aimed to find out whether people aged 40 years or older could maintain their mental abilities or reduce their risk of dementia by taking vitamin or mineral supplements.

\section{Background}


There is great interest in anything people might do to keep themselves mentally healthy as they age and, especially, to reduce their risk of developing dementia. Various vitamin and mineral supplements have been suggested as ways to do this. Vitamins and minerals have many functions in the body and the ways they might affect brain health are not well understood. Therefore, we were interested in the effects of any vitamins or minerals, either alone or in combination.

\section{What we did}

We searched up to January 2018 for all trials which had studied the effect on cognition (thinking and remembering) of any vitamin or mineral supplements in people aged 40 years or more who had no cognitive problems at the beginning of the study. The studies had to include a comparison group which had not taken the supplement being studied and, to be sure the comparison was fair, it should have been decided at random whether people got the supplement or not.

\section{What we found}

We grouped the 28 included trials according to the kind of supplement they used and how it might work.

Most of the trials were not originally designed to study cognition or dementia and used only simple measures of cognition. Very few studies investigated whether participants developed dementia. Long-term studies are probably needed to find effects on the risk of dementia or cognitive decline but only 10 studies had an average length of follow-up longer than five years. The studies were generally well-conducted although the longer trials had difficulty following up all of the participants and this could have biased some of the longer-term results.

There were 14 trials of B vitamins (folic acid, vitamin B6, vitamin B12) with nearly 28,000 participants, mainly in their 60 s and 70s. Most of these trials were quite short (less than two years). We found no evidence that $B$ vitamins had any effect on cognition.

There were 8 trials of antioxidant vitamins (beta-carotene/vitamin A, vitamin C, vitamin E) with approximately 47,000 participants. These trials tended to be longer than the B vitamin trials so may have had more chance of detecting effects on dementia and cognitive decline. The results were mixed. We found low-certainty evidence of better overall cognitive function after an average of 18 years taking beta-carotene and after five years to 10 years taking vitamin C, but no effects after shorter periods of treatment. There were also small benefits of betacarotene, vitamin C, and antioxidant combinations on memory at some time points but not others. There was no evidence of any benefits from vitamin E alone. Two studies examined the risk of developing dementia. One found no effect of a combination of antioxidant vitamins and the other found no effect of vitamin E, either alone or combined with the mineral selenium. Most of the studies did not report any information about harmful effects. One included trial was designed to look for an effect on the risk of prostate cancer; it found a higher risk among the men taking vitamin $\mathrm{E}$.

There was a small trial of vitamin D supplements which found they probably had no effect on cognition over six months. There were longer trials of vitamin D with calcium (one trial), zinc and copper (one trial), and complex multivitamins (three trials). All lasted between five and 10 years, but none of them found any evidence of beneficial effects on cognition. One trial found no effect of selenium taken for approximately five years on the risk of developing dementia.

\section{Conclusions}

We found no good evidence to suggest that middle-aged or older people can preserve cognitive function or prevent dementia by taking vitamin or mineral supplements. There were a few positive results associated with long-term use of antioxidant vitamins, particularly betacarotene and vitamin C, although the effects were small. Further research into the effects of these vitamins may be worthwhile. 
SUMMARY OF FINDINGS

Summary of findings for the main comparison. B vitamins compared to placebo for maintaining cognitive function in cognitively healthy people in mid and late life

B Vitamins compared to placebo for maintaining cognitive function in cognitively healthy people in mid and late life

Patient or population: cognitively healthy people in mid and late life

Setting: community

Intervention: B Vitamins (folic acid, vitamins B6 and vitamin B12, alone or in combination)

Comparison: placebo

\begin{tabular}{|c|c|c|c|c|c|c|}
\hline \multirow[t]{2}{*}{ Outcomes } & \multicolumn{2}{|c|}{ Anticipated absolute effects* $(95 \% \mathrm{Cl})$} & \multirow{2}{*}{$\begin{array}{l}\text { Relative effect } \\
(95 \% \mathrm{Cl})\end{array}$} & \multirow{2}{*}{$\begin{array}{l}\text { № of partici- } \\
\text { pants } \\
\text { (studies) }\end{array}$} & \multirow{2}{*}{$\begin{array}{l}\text { Certainty of } \\
\text { the evidence } \\
\text { (GRADE) }\end{array}$} & \multirow[t]{2}{*}{ Comment: } \\
\hline & $\begin{array}{l}\text { Risk with } \\
\text { placebo }\end{array}$ & Risk with B Vitamins & & & & \\
\hline $\begin{array}{l}\text { Overall cognitive functioning } 3 \text { to } 12 \text { months of } \\
\text { supplementation (final measurement data) } \\
\text { assessed with: MMSE or TICSm }\end{array}$ & - & $\begin{array}{l}\text { SMD } 0 \\
\text { (0.08 lower to } 0.08 \\
\text { higher) }\end{array}$ & - & $\begin{array}{l}2556 \\
\text { (3 RCTs) }\end{array}$ & $\begin{array}{l}\oplus \oplus \oplus \ominus \\
\text { MODERATE } 1\end{array}$ & \\
\hline $\begin{array}{l}\text { Overall cognitive functioning } 3 \text { to } 12 \text { months of } \\
\text { supplementation (change from baseline data) } \\
\text { assessed with: MMSE or TICSm }\end{array}$ & - & $\begin{array}{l}\text { SMD } 0.03 \text { lower } \\
\text { (0.26 lower to } 0.19 \\
\text { higher) }\end{array}$ & - & $\begin{array}{l}317 \\
(2 \mathrm{RCTs})\end{array}$ & $\begin{array}{l}\oplus \oplus \ominus \ominus \\
\text { LOW } 12\end{array}$ & \\
\hline $\begin{array}{l}\text { Overall cognitive functioning > } 1 \text { to } 2 \text { years of } \\
\text { supplementation (final measurement data) } \\
\text { assessed with: MMSE, TICS, or TICSm }\end{array}$ & - & $\begin{array}{l}\text { SMD } 0.15 \text { higher } \\
\text { ( } 0.17 \text { lower to } 0.47 \\
\text { higher) }\end{array}$ & - & $\begin{array}{l}6956 \\
(5 \mathrm{RCTs})\end{array}$ & $\begin{array}{l}\oplus \oplus \oplus \ominus \\
\text { MODERATE } 1\end{array}$ & \\
\hline $\begin{array}{l}\text { Overall cognitive functioning }>2 \text { to } 5 \text { years of } \\
\text { supplementation (final measurement data) } \\
\text { assessed with MMSE, TICS, F-TICSm or a compos- } \\
\text { ite score }\end{array}$ & - & $\begin{array}{l}\text { SMD } 0.01 \text { lower } \\
\text { (0.11 lower to } 0.09 \\
\text { higher) }\end{array}$ & - & $\begin{array}{l}3985 \\
(4 \mathrm{RCTs})\end{array}$ & $\begin{array}{l}\oplus \oplus \oplus \ominus \\
\text { MODERATE } 1\end{array}$ & \\
\hline $\begin{array}{l}\text { Overall cognitive functioning - > 5-10 years of } \\
\text { supplementation (final measurement data) }\end{array}$ & - & SMD 0.01 lower & - & $\begin{array}{l}10249 \\
\text { (3 RCTs) }\end{array}$ & $\begin{array}{l}\oplus \oplus \ominus \ominus \\
\text { LOW } 13\end{array}$ & \\
\hline
\end{tabular}

$\rightarrow$

(3 RCTs)

LOW 13 
Incidence of $\mathrm{MCl}$ or dementia $>2$ to 5 years of supplementation

Study population

RR 0.89

1803

$\oplus \oplus \oplus \ominus$

assessed with: MMSE $<24$ on 2 or more occa-

103 per 1.000

(0.67 to 1.18$)$

1803

MODERATE

sions

91 per 1.000

(69 to 121$)$

follow-up: median 2.8 years

${ }^{*}$ The risk in the intervention group (and its 95\% confidence interval) is based on the assumed risk in the comparison group and the relative effect of the intervention (and its $95 \% \mathrm{Cl}$ ).

Cl: Confidence interval; RR: Risk ratio; OR: Odds ratio;

\section{GRADE Working Group grades of evidence}

High certainty: We are very confident that the true effect lies close to that of the estimate of the effect

Moderate certainty: We are moderately confident in the effect estimate: The true effect is likely to be close to the estimate of the effect, but there is a possibility that it is substantially different

Low certainty: Our confidence in the effect estimate is limited: The true effect may be substantially different from the estimate of the effect

Very low certainty: We have very little confidence in the effect estimate: The true effect is likely to be substantially different from the estimate of effect

1 Downgraded for indirectness due to restricted inclusion criteria for participants in included studies

2 Downgraded for imprecision due to small sample size and wide confidence intervals

3 Downgraded for study limitations due to missing data from 26\% of participants in SEARCH 2010

MMSE: Mini Mental State Examination

TICS: Telephone Interview for Cognitive Status

TICSm: modified Telephone Interview for Cognitive Status

F-TICSm: modified Telephone Interveiw for Cognitive Status (French version)

\section{Summary of findings 2 . Antioxidants compared to placebo for maintaining cognitive function in cognitively healthy people in mid and late life}

\section{Antioxidants compared to placebo for maintaining cognitive function in cognitively healthy people in mid and late life}

Patient or population: cognitively healthy people in mid and late life

Setting: community

Intervention: antioxidant vitamins (vitamins C, E, and beta-carotene, alone or in combination)

Comparison: placebo

\begin{tabular}{l|l|lll}
\hline Outcomes & $\begin{array}{l}\text { Anticipated absolute effects } \\
\text { CI) }(95 \%\end{array}$ & $\begin{array}{l}\text { Relative effect } \\
(95 \% \mathrm{Cl})\end{array}$ & $\begin{array}{l}\text { № of partici- } \\
\text { pants } \\
\text { (studies) }\end{array}$ & $\begin{array}{l}\text { Certainty of } \\
\text { the evidence } \\
\text { (GRADE) }\end{array}$
\end{tabular}




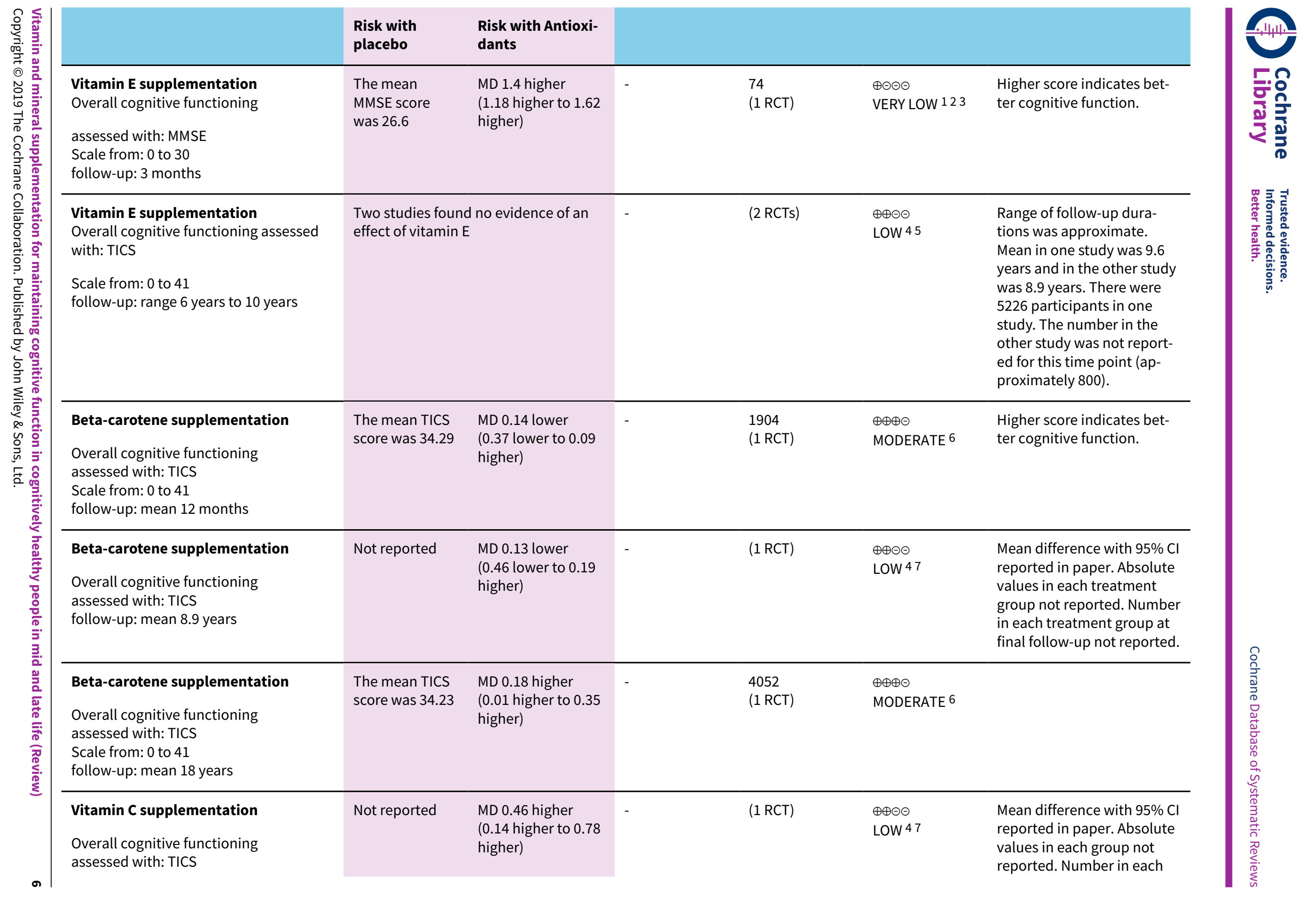




\begin{tabular}{|c|c|c|c|c|c|c|}
\hline 厄) & follow-up: mean 8.9 years & & & & & $\begin{array}{l}\text { treatment group at final fol- } \\
\text { low-up not reported. }\end{array}$ \\
\hline 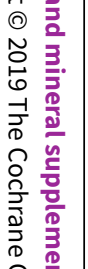 & $\begin{array}{l}\text { Supplementation with beta-carotene } \\
\text { + vit C + vit E } \\
\text { Overall cognitive functioning } \\
\text { assessed with: TICSm } \\
\text { Scale from: } 0 \text { to } 39 \\
\text { follow-up: mean } 5 \text { years }\end{array}$ & $\begin{array}{l}\text { The mean } \\
\text { TICSm score } \\
\text { was } 24.02\end{array}$ & $\begin{array}{l}\text { MD } 0.09 \text { higher } \\
\text { ( } 0.05 \text { lower to } 0.23 \\
\text { higher) }\end{array}$ & $\begin{array}{l}20536 \\
(1 \mathrm{RCT})\end{array}$ & $\begin{array}{l}\oplus \oplus \oplus \ominus \\
\text { MODERATE } 8\end{array}$ & \\
\hline 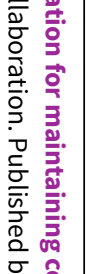 & $\begin{array}{l}\text { Supplementation with beta-carotene } \\
\text { + vit C + vit E } \\
\text { Overall cognitive functioning } \\
\text { assessed with: } 3 \mathrm{MS} \text { (modified MMSE) } \\
\text { Scale from: } 0 \text { to } 100 \\
\text { follow-up: median } 6.9 \text { years }\end{array}$ & $\begin{array}{l}\text { The mean 3MS } \\
\text { score was } 92.1\end{array}$ & $\begin{array}{l}\text { MD } 0.6 \text { higher } \\
(0.2 \text { lower to } 1.4 \\
\text { higher) }\end{array}$ & $\begin{array}{l}1100 \\
(1 \mathrm{RCT})\end{array}$ & $\begin{array}{l}\oplus \oplus \oplus \ominus \\
\text { MODERATE } 4\end{array}$ & $\begin{array}{l}\text { Higher score indicates bet- } \\
\text { ter cognitive function. }\end{array}$ \\
\hline 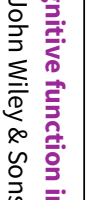 & $\begin{array}{l}\text { Incidence of all-cause dementia } \\
\text { follow-up: mean approximately } 5 \text { years }\end{array}$ & $\begin{array}{l}\text { Two studies, on } \\
\text { of beta-caroten } \\
\text { one using vit } E \text { - } \\
\text { significant diffe } \\
\text { of dementia. }\end{array}$ & $\begin{array}{l}\text { using a combination } \\
\text { vit } C \text { and vit } E \text { and } \\
\text { elenium, found no } \\
\text { ece in the incidence }\end{array}$ & $\begin{array}{l}25993 \\
\text { (2 RCTs) }\end{array}$ & $\begin{array}{l}\oplus \oplus \ominus \ominus \\
\text { LOW } 89\end{array}$ & \\
\hline 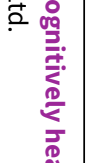 & $\begin{array}{l}{ }^{*} \text { The risk in the intervention group (an } \\
\text { its } 95 \% \mathrm{Cl}) . \\
\text { Cl: Confidence interval; RR: Risk ratio; } 0\end{array}$ & $\begin{array}{l}\text { ts } 95 \% \text { confiden } \\
\text { Odds ratio; }\end{array}$ & nterval) is based on & assumed risk in the compar & $p$ and the rela & effect of the intervention (and \\
\hline 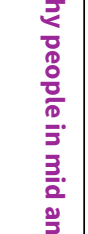 & $\begin{array}{l}\text { GRADE Working Group grades of evide } \\
\text { High certainty: We are very confident th } \\
\text { Moderate certainty: We are moderately } \\
\text { substantially different } \\
\text { Low certainty: Our confidence in the ef } \\
\text { Very low certainty: We have very little }\end{array}$ & $\begin{array}{l}\text { the true effect li } \\
\text { nfident in the ef } \\
\text { t estimate is limi } \\
\text { fidence in the ef }\end{array}$ & $\begin{array}{l}\text { close to that of the e } \\
\text { t estimate: The true } \\
\text { the true effect ma } \\
\text { t estimate: The true }\end{array}$ & $\begin{array}{l}\text { mate of the effect } \\
\text { ect is likely to be close to the } \\
\text { e substantially different from } \\
\text { ect is likely to be substantiall }\end{array}$ & $\begin{array}{l}\text { of the effect, b } \\
\text { nate of the effe } \\
t \text { from the estin }\end{array}$ & ere is a possibility that it is \\
\hline 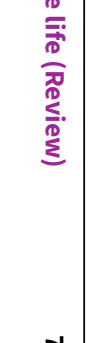 & $\begin{array}{l}1 \text { Downgraded for risk of bias due to lack } \\
2 \text { Downgraded for indirectness (diabetic } p \\
3 \text { Downgraded for imprecision due to sma } \\
4 \text { Downgraded for risk of bias due to incon } \\
5 \text { Downgraded for indirectness (both stud } \\
6 \text { Downgraded for indirectness (included } \\
7 \text { Downgraded for indirectness (included } \\
8 \text { Downgraded for indirectness (all partici }\end{array}$ & $\begin{array}{l}\text { linding (open-la } \\
\text { icipants only) } \\
\text { ample size } \\
\text { lete outcome dat } \\
\text { included only w } \\
\text { n only) } \\
\text { y women with ca } \\
\text { its had high risk }\end{array}$ & $\begin{array}{l}\text { study) } \\
\text { en and in one study } \\
\text { iovascular disease or } \\
\text { coronary heart disea }\end{array}$ & $\begin{array}{l}\text { participants also had cardiov } \\
3 \text { coronary risk factors) } \\
\text { death over the next } 5 \text { years) }\end{array}$ & sease or 3 or $n$ & coronary risk factors) \\
\hline
\end{tabular}




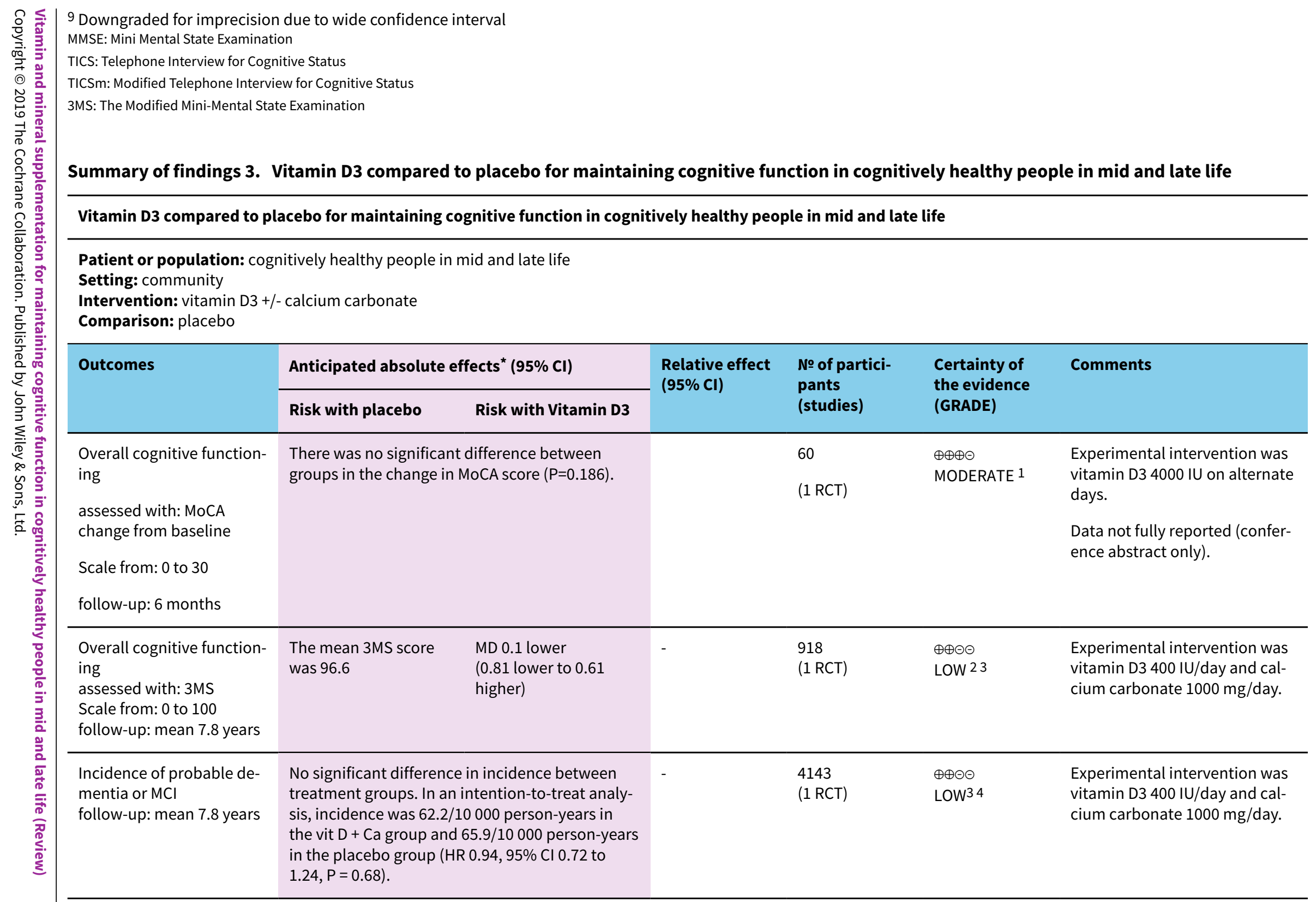

${ }^{\star}$ The risk in the intervention group (and its $95 \%$ confidence interval) is based on the assumed risk in the comparison group and the relative effect of the intervention (and its $95 \% \mathrm{Cl}$ ). 
GRADE Working Group grades of evidence

High certainty: We are very confident that the true effect lies close to that of the estimate of the effect

Moderate certainty: We are moderately confident in the effect estimate: The true effect is likely to be close to the estimate of the effect, but there is a possibility that it is substantially different

Low certainty: Our confidence in the effect estimate is limited: The true effect may be substantially different from the estimate of the effect

Very low certainty: We have very little confidence in the effect estimate: The true effect is likely to be substantially different from the estimate of effect

1 Downgraded for imprecision (small sample size)

2 Downgraded for risk of bias due to incomplete outcome data

3 Downgraded for indirectness (study included women only)

4 Downgraded for imprecision due to wide confidence interval

MCl: Mild Cognitive Impairment

MOCA: Montreal cognitive assessment

3MS: The Modified Mini-Mental State Examination

\section{Summary of findings 4. Zinc + copper compared to placebo for maintaining cognitive function in cognitively healthy people in mid and late life}

Zinc + copper compared to placebo for maintaining cognitive function in cognitively healthy people in mid and late life

Patient or population:cognitively healthy people in mid and late life

Setting: Community

Intervention: Zinc + copper oxides

Comparison: Placebo

\begin{tabular}{|c|c|c|c|c|c|c|}
\hline \multirow[t]{2}{*}{ Outcomes } & \multicolumn{2}{|c|}{ Anticipated absolute effects ${ }^{\star}(95 \% \mathrm{Cl})$} & \multirow{2}{*}{$\begin{array}{l}\text { Relative effect } \\
(95 \% \mathrm{Cl})\end{array}$} & \multirow{2}{*}{$\begin{array}{l}\text { № of partici- } \\
\text { pants } \\
\text { (studies) }\end{array}$} & \multirow{2}{*}{$\begin{array}{l}\text { Certainty of } \\
\text { the evidence } \\
\text { (GRADE) }\end{array}$} & \multirow[t]{2}{*}{ Comments } \\
\hline & Risk with placebo & Risk with Zinc + copper & & & & \\
\hline $\begin{array}{l}\text { Overall cognitive functioning } \\
\text { assessed with: } 3 \mathrm{MS} \\
\text { Scale from: } 0 \text { to } 100 \\
\text { follow-up: median } 6.9 \text { years }\end{array}$ & $\begin{array}{l}\text { The mean 3MS score was } \\
92.1\end{array}$ & $\begin{array}{l}\text { MD } 0.6 \text { higher } \\
\text { (0.19 lower to } 1.39 \text { higher) }\end{array}$ & - & $\begin{array}{l}1072 \\
(1 \mathrm{RCT})\end{array}$ & $\begin{array}{l}\oplus \oplus \oplus \ominus \\
\text { MODERATE } 12\end{array}$ & \\
\hline $\begin{array}{l}\text { Incidence of dementia or } \mathrm{MCl} \\
\text { assessed with: } 3 \mathrm{MS} \text { score }<80 \\
\text { follow-up: median } 6.9 \text { years }\end{array}$ & \multicolumn{2}{|c|}{$\begin{array}{l}4.5 \% \text { of participants met the authors' definition of cogni- } \\
\text { tive impairment }(3 \mathrm{MS}<80) \text { and "there was no significant } \\
\text { effect of treatment group on likelihood of having cogni- } \\
\text { tive impairment." }\end{array}$} & - & $\begin{array}{l}1072 \\
(1 \mathrm{RCT})\end{array}$ & $\begin{array}{l}\oplus \oplus \ominus \ominus \\
\text { LOW }^{3}\end{array}$ & \\
\hline
\end{tabular}

${ }^{*}$ The risk in the intervention group (and its $95 \%$ confidence interval) is based on the assumed risk in the comparison group and the relative effect of the intervention (and its $95 \% \mathrm{Cl}$ ). 


\begin{tabular}{|c|c|c|c|c|c|c|}
\hline \\
\hline \multicolumn{7}{|c|}{$\begin{array}{l}\text { GRADE Working Group grades of evidence } \\
\text { High certainty: We are very confident that the true effect lies close to that of the estimate of the effect } \\
\text { Moderate certainty: We are moderately confident in the effect estimate: The true effect is likely to be close to the estimate of the effect, but there is a possibility that it is } \\
\text { substantially different } \\
\text { Low certainty: Our confidence in the effect estimate is limited: The true effect may be substantially different from the estimate of the effect } \\
\text { Very low certainty: We have very little confidence in the effect estimate: The true effect is likely to be substantially different from the estimate of effect }\end{array}$} \\
\hline \multicolumn{7}{|c|}{$\begin{array}{l}1 \text { Downgraded for risk of bias due to unclear selective reporting and high risk of bias due to incomplete outcome data } \\
2 \text { Downgraded for indirectness (Yaffe } 2004 \text { included participants with age-related macular degeneration) } \\
3 \text { Downgraded two levels for study limitations due to incomplete outcome data and selective reporting } \\
\text { 3MS: The Modified Mini-Mental State Examination } \\
\text { MCI: Mild cognitive impairment }\end{array}$} \\
\hline \multicolumn{7}{|c|}{ Complex multivitamin compared to control for maintaining cognitive function in cognitively healthy people in mid and late life } \\
\hline \multicolumn{7}{|c|}{$\begin{array}{l}\text { Patient or population: cognitively healthy people in mid and late life } \\
\text { Setting: community } \\
\text { Intervention: complex multivitamins (combinations of B vitamins and antioxidant vitamins +/- minerals) } \\
\text { Comparison: placebo }\end{array}$} \\
\hline \multirow[t]{2}{*}{ Outcomes } & \multicolumn{2}{|c|}{ Anticipated absolute effects ${ }^{*}(95 \% \mathrm{Cl})$} & \multirow{2}{*}{$\begin{array}{l}\text { Relative effect } \\
(95 \% \mathrm{CI})\end{array}$} & \multirow{2}{*}{$\begin{array}{l}\text { № of partici- } \\
\text { pants } \\
\text { (studies) }\end{array}$} & \multirow{2}{*}{$\begin{array}{l}\text { Certainty of } \\
\text { the evidence } \\
\text { (GRADE) }\end{array}$} & \multirow[t]{2}{*}{ Comments } \\
\hline & $\begin{array}{l}\text { Risk with con- } \\
\text { trol }\end{array}$ & $\begin{array}{l}\text { Risk with Complex } \\
\text { multivitamin }\end{array}$ & & & & \\
\hline $\begin{array}{l}\text { Overall cognitive functioning } \\
\text { assessed with: TICS } \\
\text { Scale from: } 0 \text { to } 41 \\
\text { follow-up: mean } 2.5 \text { years }\end{array}$ & $\begin{array}{l}\text { The mean TICS } \\
\text { score was } 34.3\end{array}$ & $\begin{array}{l}\text { MD } 0.04 \text { higher } \\
\text { (0.09 lower to } 0.18 \text { high- } \\
\text { er) }\end{array}$ & - & $\begin{array}{l}5947 \\
(1 \mathrm{RCT})\end{array}$ & $\begin{array}{l}\oplus \oplus \ominus \ominus \\
\text { LOW } 12\end{array}$ & $\begin{array}{l}\text { Follow-up } \\
\text { ranged from } \\
0.18 \text { to } 5.3 \\
\text { years. }\end{array}$ \\
\hline $\begin{array}{l}\text { Overall cognitive functioning } \\
\text { assessed with: TICS } \\
\text { Scale from: } 0 \text { to } 41 \\
\text { follow-up: mean } 8.5 \text { years }\end{array}$ & $\begin{array}{l}\text { The mean TICS } \\
\text { score was } 33.1\end{array}$ & $\begin{array}{l}\text { MD } 0.12 \text { higher } \\
\text { ( } 0.14 \text { lower to } 0.38 \text { high- } \\
\text { er) }\end{array}$ & - & $\begin{array}{l}2324 \\
(1 \mathrm{RCT})\end{array}$ & $\begin{array}{l}\oplus \oplus \Theta \Theta \\
\text { LOW } 12\end{array}$ & $\begin{array}{l}\text { Follow-up } \\
\text { ranged from } 0.3 \\
\text { to } 14.2 \text { years. }\end{array}$ \\
\hline
\end{tabular}




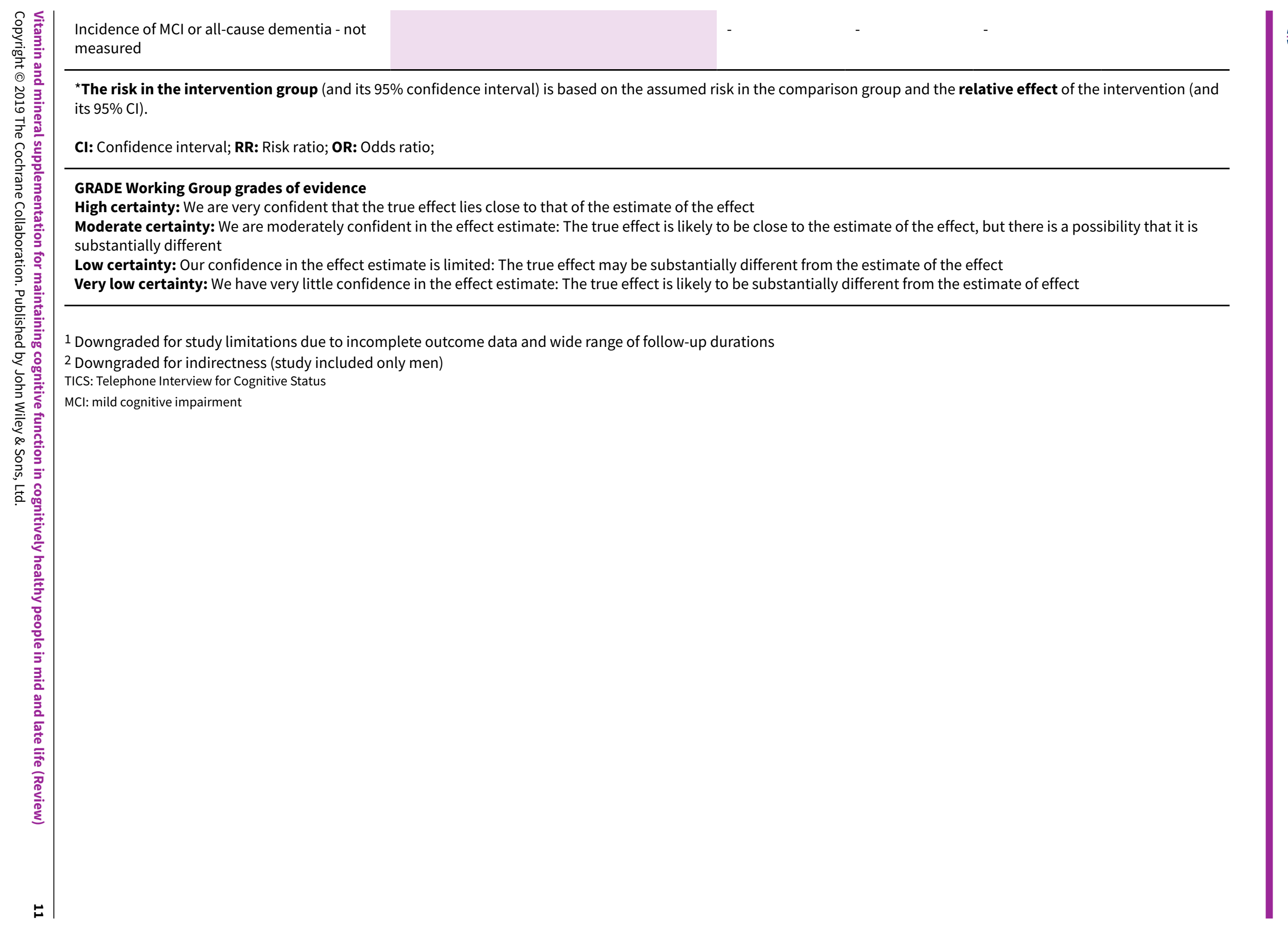




\section{B A C K G R O U N D}

\section{Description of the condition}

\section{Cognitive health, mild cognitive impairment, and dementia}

There is no consensus definition of cognitive health or successful cognitive ageing, but it has been described as "not just the absence of cognitive impairment, but the development and preservation of the multidimensional cognitive structure that allows the older adult to maintain social connectedness, an ongoing sense of purpose, and the abilities to function independently, to permit functional recovery from illness and injury, and to cope with residual cognitive deficits" (Depp 2012; Hendrie 2006). Successful cognitive ageing is distinct from mild cognitive impairment $(\mathrm{MCl})$ and dementia.

Dementia is a syndrome of cognitive and functional decline that is usually progressive. It affects multiple cognitive domains, among which memory is usually prominent, but orientation, executive function, language, perception, and social cognition are also often affected. In most cases, the onset of dementia is gradual. It is usually preceded by a stage of mild cognitive impairment when cognitive deficits beyond those of normal ageing are detectable, but function is not significantly impaired. The term dementia is used once the cognitive deficits begin to have a significant effect on daily activities. As the syndrome progresses, those affected become increasingly dependent on others for all activities of daily living.

\section{Types of $\mathrm{MCl}$ and dementia}

Subtypes of dementia are distinguished by the underlying pathology. The four most common subtypes are Alzheimer's disease dementia (AD) (accounting for an estimated 60\% to $70 \%$ of all dementia cases); vascular dementia (VaD); dementia with Lewy Bodies (DLB); and frontotemporal dementia (FTD). Accurate diagnosis of the subtypes may be difficult. Mixed pathology is common, with more than $80 \%$ of cases having some features of Alzheimer's disease (Jellinger 2006; WHO 2012). However, the proportion of dementia attributable to Alzheimer's disease reduces with age (Savva 2009).

There are numerous different operational definitions of $\mathrm{MCl}$, with different scope (e.g. memory or non-memory impairments) (Matthews 2007), prevalence (Stephan 2007), and risk of progression to dementia (Matthews 2008). Currently, there is no single, universally accepted definition of $\mathrm{MCl}$ (Stephan 2013), but adaptations of the criteria suggested by Petersen 1999 are commonly used in clinical trials. Categorisation of $\mathrm{MCI}$ may also be based on the suspected underlying cause of the cognitive deficits, e.g. $\mathrm{MCl}$ due to Alzheimer's disease and $\mathrm{MCl}$ due to vascular disease (termed 'vascular cognitive impairment, no dementia': VCIND).

It is increasingly recognised that some dementia syndromes, including $A D$, have a very long preclinical phase with pathological changes beginning years, or even decades, before the onset of symptoms (Sperling 2011). Attempts have been made to develop criteria to capture preclinical states as early as possible. For example, the label 'pre-MCl' has been applied to people with impaired executive function and language, elevated apathy scores, and reduced volumes of left brain areas of the hippocampus, an area involved in consolidation of information from short-term memory to long-term memory but also spatial memory, enabling orientation. (Duara 2011). It is likely that biomarker tests, tests that measure some biological state, will be needed to identify people in the earliest stages of dementing illnesses.

\section{Prevalence of $\mathrm{MCl}$ and dementia}

In the UK Medical Research Council's population-based Cognitive Function and Ageing Study (CFAS), which mapped 18 different definitions of $\mathrm{MCl}$, the range of prevalence estimates was found to be variable $(0.1 \%$ to $42.0 \%)$, and conversion rates to dementia generally low (Stephan 2007). Prevalence rates and rates of conversion to dementia have been reported to be higher in specialist settings than in population-based studies (adjusted conversion rate from $\mathrm{MCl}$ to dementia $9.6 \%$ versus $4.9 \%$ ) (Mitchell 2009).

The risk of dementia increases with age. According to a World Health Organization (WHO) report, only $2 \%$ to $10 \%$ of cases start before the age of 65 years (WHO 2012). The same report estimated that there were 35.6 million people with dementia in the world in 2010, and that this figure would double every 20 years to reach 65.7 million in 2030 (WHO 2012). However, there is a degree of uncertainty about the expected increase in prevalence of dementia. Recent research by Matthews 2013 in the UK and by Christensen 2013 in Denmark indicates that age-specific prevalence of dementia may be falling in developed countries, suggesting the possibility that dementia risk may be modifiable. Nevertheless, because of population ageing, the overall prevalence continues to rise.

\section{Risk factors}

Generally, risk factors for dementia can be divided into modifiable and non-modifiable categories. Non-modifiable risk factors include age, genetic factors, and gender (females are at higher risk). At a population level, age is the most significant risk factor. In people older than 65 years, the risk of $A D$ (the commonest cause of dementia) doubles every five years (Launer 1999; McCullagh 2001; Van den Berg 2012; Van der Flier 2005). A pooled analysis of four prospective studies in Europe found that the incidence of AD among people aged 90 years and over was 63.5/1000 person-years (Launer 1999). Genetics plays a major role in early onset $A D$, but a lesser role in the much commoner late onset disease.

Many potentially modifiable risk factors are common to $A D$ and vascular dementia. These include diabetes mellitus, midlife obesity, midlife hypertension, smoking,,and physical inactivity (Prince 2014; WHO 2012). The fact that risk factors are active in midlife is consistent with what is known of the long preclinical phase of dementia and implies that there is a long period in which preventive efforts could be effective.

At present, there is no cure for any subtype of dementia, but identifying and targeting modifiable risk factors might offer opportunities to modify its onset and course. Studies to test this hypothesis have investigated cognitive stimulation, exercise, diet, and other nutritional interventions, and the management of vascular risk factors, such as hypertension, diabetes, obesity, smoking, and physical inactivity (Lindsay 2002; Lourida 2013; Norton 2014; Wilson 2002).

\section{Description of the intervention}

This review focusses on the effect of vitamins or minerals (or both) on cognitive functioning. Vitamins are organic compounds that 
are essential for the normal physiological process in the body and play important roles in growth and development (Kennedy 2011). MInerals are inorganic elements and as nutrients are also needed by the body to grow and develop normally (Centers for Disease Control and Prevention 2014). Most of these essential nutrients are available naturally in the diet. Dietary supplements are any consumed products that aim to provide nutrients additional to those obtained in the regular diet.

\section{How the intervention might work}

Vitamins and minerals have numerous important roles in human physiology. Recognised biological roles of all those considered for this review are summarised briefly in Appendix 1.

The most commonly cited mechanisms by which vitamins and minerals may influence cognitive function are (1) via effects on specific plasma amino-acids called homocysteine for $B$ vitamins (folic acid, vitamin B6, and vitamin B12) and (2) via antioxidant effects, reducing the concentration of free radicals that may damage human cells, for vitamins C, E, and ß-carotene, possibly vitamin $D$, and some minerals such as selenium. These hypotheses about possible mechanisms are based largely on preclinical studies and on observations of associations between elevated homocysteine levels or elevated markers of oxidative stress and cognitive decline or dementia (Clarke 2007a, Bennett 2009). Detailed understanding of mechanisms is, however, lacking.

\section{Why it is important to do this review}

The prevalence and high societal costs of dementia are such that even small reductions in its age-specific incidence would have a large impact on healthcare costs and on the overall burden it causes to patients, their families, and communities. In order to decide where preventive efforts should be concentrated, robust assessments are needed of the effects of interventions and of the 'dose' and duration of intervention necessary to achieve an effect.

For individuals, fear of cognitive decline and dementia may be powerful motivators to seek preventive interventions. Vitamin and mineral supplementation and cognitive activities (e.g. computerised 'brain training' games), in particular, are subject to promotion by those with commercial interests. It is important for people to know whether time, effort, and money they might invest to prevent cognitive decline is likely to be well spent. Information about adverse effects is also important. Although nutritional and behavioural interventions are often perceived to be 'low risk', they are not necessarily without the potential to cause harm. For example, trials have found high doses of vitamin $\mathrm{E}$ to be associated with higher rates of side effects than placebo (Bjelakovic 2012; Brigelius-Flohe 2007; Miller 2005).

\section{O B JECT IVES}

To evaluate the effects of vitamin and mineral supplementation on cognitive function in cognitively healthy people aged 40 years or more.

\section{METHODS}

\section{Criteria for considering studies for this review}

\section{Types of studies}

We included randomised or quasi-randomised controlled trials, published or unpublished, reported in any language. We included trials with a duration of intervention of 12 weeks or more. Trials in cognitively healthy people with a duration as short as 12 weeks typically investigate cognitive enhancement rather than maintenance of cognitive function. We included these trials in order to give a full picture of the data, although it is recognised that the relationship between short-term cognitive enhancement and maintenance of cognitive function over longer periods of time, or incidence of dementia, is unclear.

\section{Types of participants}

We included trials in which the participants were cognitively healthy people from midlife onwards, i.e. participants aged 40 years and over without a dementia diagnosis or cognitive impairment at baseline ('midlife' was defined for the purposes of disease classification, in DSM-IV 1994, as between 40 years and 65 years).The cognitive status of participants was determined by the trialists' own definitions of 'cognitively healthy'. These definitions were recorded. We contacted trialists if further clarification was needed to determine health status. If trials included a cognitively mixed population, we required at least $80 \%$ of participants to be free of cognitive impairment (including subjective cognitive impairment) at baseline.

\section{Types of interventions}

We included studies comparing the effect of orally-administered vitamin or mineral supplements (or vitamin and mineral supplements) with control interventions which were not expected to have an effect on cognition (placebo or no intervention/usual care). Eligible vitamins and minerals are listed in Appendix 1. These vitamins and minerals could be given singly or in combination and at any dose, for a minimum of 12 weeks. Trials of vitamins or minerals (or vitamins and minerals) given in combination with other nutrients (e.g. fatty acids, amino acids) or with drugs were excluded unless the design allowed the effects of vitamins or minerals to be isolated. For example, a trial comparing vitamin $X$ to amino acid $Y$ was ineligible, but a trial comparing vitamin $X$ and amino acid $Y$ to amino acid $Y$ only was eligible.

\section{Types of outcome measures}

\section{Primary outcomes}

Mean overall cognitive functioning measured with any internationally accepted and validated measure: for example, Alzheimer's Disease Assessment Scale - cognitive subscale (ADAScog); Mini Mental State Examination (MMSE); Repeatable Battery for the Assessment of Neuropsychological Status (RBANS); Cambridge Cognition Examination (CAMCOG).

\section{Secondary outcomes}

Any internationally accepted and validated measures of:

- specific cognitive functioning subdomain: episodic memory;

- specific cognitive functioning subdomain: executive functioning; 
- specific cognitive functioning subdomain: speed of processing;

- incidence of $\mathrm{MCl}$ or all-cause dementia;

- quality of life, either generic or disease-specific;

- clinical global impression (a scale measuring a clinician's judgement on overall symptom severity);

- functional performance;

- number of participants experiencing one or more serious adverse events (SAE);

- mortality.

If a trial provided data on more than one cognitive scale for a specific outcome, we applied a hierarchy of cognition-related outcomes and used data on the cognitive scale that was highest on this hierarchy. For example, if a trial reported results on both the Mini Mental State Examination and the Clinical Dementia Rating scale (CDR), we used the outcome data from MMSE in our quantitative analyses. The rank of a scale in the hierarchy was determined by the frequency of its use in a large set of 79 trials, evaluating vitamin and mineral supplementation, dietary interventions, and physical exercise interventions.

\section{Search methods for identification of studies}

\section{Electronic searches}

We searched ALOIS (www.medicine.ox.ac.uk/alois), the Cochrane Dementia and Cognitive Improvement Group's (CDCIG) specialised register.

ALOIS is maintained by the Information Specialist for the CDCIG, and contains studies that fall within the areas of dementia prevention, dementia treatment and management, and cognitive enhancement in healthy elderly populations. The studies are identified through:

1. Monthly searches of a number of major healthcare databases: MEDLINE, Embase, CINAHL, PsycINFO and LILACS;

2. Monthly searches of a number of trial registers: ISRCTN; UMIN (Japan's Trial Register); the WHO portal (which covers ClinicalTrials.gov; ISRCTN; the Chinese Clinical Trials Register; the German Clinical Trials Register; the Iranian Registry of Clinical Trials and the Netherlands National Trials Register, plus others);

3. Quarterly search of The Cochrane Library's Central Register of Controlled Trials (CENTRAL);

4. Six-monthly searches of a number of grey literature sources: ISI Web of Knowledge Conference Proceedings; Index to Theses; Australasian Digital Theses.

To view a list of all sources searched for ALOIS see About ALOIS on the ALOIS website (www.medicine.ox.ac.uk/alois).

Details of the search strategies run in healthcare bibliographic databases, used for the retrieval of reports of dementia, cognitive improvement, and cognitive enhancement trials, can be viewed in the 'methods used in reviews' section within the editorial information about the Cochrane Dementia and Cognitive Improvement Group.

We ran additional searches in MEDLINE, Embase, PsycINFO, CINAHL, ClinicalTrials.gov and the WHO Portal/ICTRP to ensure that the searches for each suite of reviews was as comprehensive and as up-to-date as possible to identify published, unpublished, and ongoing trials. The search strategies that we created and used can be seen in Appendix 2.

\section{Searching other resources}

We screened reference lists of all included trials. In addition, we screened reference lists of recent systematic reviews, health technology assessment reports, and subject-specific guidelines identified through www.guideline.gov. The search was restricted to those guidelines meeting National Guideline Clearinghouse's (NGC) 2013 inclusion criteria published in this year or later.

We contacted experts in the field and companies marketing included interventions, in order to provide additional randomised trial reports that were not identified by the database search.

\section{Data collection and analysis}

\section{Selection of studies}

We used crowdsourcing to screen the search results. Details of this have been described here: http://www.medicine.ox.ac.uk/ alois/content/modifiable-risk-factors. In brief, teams of volunteers performed a 'first assessment' on the search results. The volunteers were recruited through the author team's institutions. They screened the results using an online tool developed for Cochrane Embase project but tailored for this programme of work. The crowd decided, based on a reading of title and abstract, whether the citation was describing a randomised or quasi-randomised trial, irrespective of the citations topic. It is estimated that this removes $75 \%$ to $90 \%$ of results retrieved. The remaining titles and abstracts were then screened by the author team, followed by full text screening. Two clinicians in the author team screened independently (AA, DD, RA). In the event of disagreement that could not be resolved by discussion, a methodologist (LYC) and additional clinician (NT or JA) arbitrated on eligibility and reasons for exclusion. All consensus rulings and reasons for exclusion were subsequently verified by methodologists (AR and MdN or LYC). Citations and full text papers from the update searches conducted in 2017 and 2018 were screened independently by two clinicians (JM and GM), who reached consensus through discussion if necessary.

\section{Data extraction and management}

Two review authors, working independently, extracted trial information using a structured data extraction form. Discrepancies were resolved by discussion, or by the involvement of a third reviewer. Where possible, we extracted (as a minimum) the following information related to characteristics of participants, intervention, and study design:

\section{Participant characteristics:}

- gender;

- baseline age (range, median, mean);

- baseline cognitive function;

- cognitive diagnostic status.

Intervention characteristics:

- nature of the intervention; generic and trade name of intervention; 
- description of the control condition;

- duration of treatment;

- dosage and frequency;

- any concomitant treatments;

- treatment adherence.

Methodological characteristics:

- trial design (individual or cluster randomisation; parallel group, factorial, or crossover design);

- number of participants;

- outcome measures used;

- duration of follow-up as measured from randomisation;

- duration of follow-up as measured from end of treatment;

- source of financial support;

- publication status.

If eligible cognitive outcome data were available at multiple time points, we grouped outcomes into short-term (12 weeks/three months to one year), medium-term (> one year to two years) and longer-term results ( $>$ two to five years, $>$ five to 10 years and $>10$ years). For the secondary outcome all-cause dementia, only outcome data after one or more years of follow-up were considered. Within these time periods, the longest available data reported by the study were extracted (for example, if study reported data at six months, 9 months and one year, only the one-year data were extracted and analysed for the short-term time point.

For dichotomous outcomes (such as incident dementia or mortality), we extracted from each trial the number of participants with each outcome.

For continuous outcomes, we extracted the number of participants in whom the outcome was measured, and the mean and standard deviation of the change from baseline or of the mean value at each relevant time point. When necessary, means and measures of dispersion were approximated from figures in the reports.

For crossover trials, we extracted data on the first treatment period only.

Whenever possible, we extracted intention-to-treat data i.e. analysing all patients according to the group randomisation. If this was not available, then we extracted and reported data from available case analyses. If these data were also not available, we considered data from 'per protocol' analyses. We contacted the trialists if we could not obtain the necessary data from the trial report.

\section{Assessment of risk of bias in included studies}

Two authors independently assessed the risk of bias in each of the included trials using Cochrane's 'Risk of bias' tool (Higgins 2011). We resolved disagreements by consensus. We assessed the risk of bias potentially introduced by suboptimal design or conduct in the domains of sequence generation, concealment of allocation, blinding of participants and caregivers, blinding of outcome assessors, selective outcome reporting, and incomplete outcome data, including the type of statistical analyses used (true intention-to-treat versus other). The general definitions that were used are reported in the Cochrane Handbook for Systematic Reviews of Interventions (Higgins 2011); the review-specific definitions described in Appendix 3 are in part derived from a previously published systematic review (Rutjes 2012).

\section{Measures of treatment effect}

The measure of treatment effect for continuous outcomes was a mean difference (MD) if all studies measuring that outcome used the same scale and a standardised mean difference (SMD), defined as the between-group difference in mean values divided by the pooled standard deviation (SD), if an outcome was measured with a variety of scales. The treatment effect for dichotomous outcomes was expressed as a relative risk (RR).

\section{Unit of analysis issues}

We included no cluster-randomised trials and identified no other unit of analysis issues.

\section{Dealing with missing data}

Missing data in the individual trials may put the study estimates of effects at a high risk of bias, and may lower the overall certainty of the evidence according to GRADE (Higgins 2011). We dealt with missing data in our 'Risk of bias' assessments and planned to evaluate attrition bias in stratified analyses of the primary outcomes (Appendix 3). We thus analysed the available information and did not contact authors with a request to provide missing information. We did not impute missing data ourselves.

\section{Assessment of heterogeneity}

We considered differences in trial populations, interventions (including duration of treatment), and outcomes when assessing clinical heterogeneity and deciding which data to pool. We used visual inspection of forest plots and the tau ${ }^{2}$ and $\mathrm{I}^{2}$ statistics when considering whether to downgrade our confidence in results for inconsistency between trials, see also Data synthesis.

\section{Assessment of reporting biases}

Due to the low number of studies included in meta-analyses, we did not perform any funnel plot analyses to explore possible reporting biases.

\section{Data synthesis}

We pooled interventions which have been postulated to share a main mechanism of action in preventing development of dementia. Specifically, we pooled data from trials of:

- the antioxidant vitamins C, E, and ß-carotene, and

- B vitamins (thiamine (B1), pyridoxine (B6), folic acid (B9) and cobalamin (B12)) on the grounds that these are cofactors for key metabolic processes and are involved in reducing high homocysteine levels.

Whenever possible, we used standard inverse-variance randomeffects meta-analysis to combine outcome data across the trials (DerSimonian 1986) (see Data extraction and management for definitions of time points). When indicated, we converted scales to a consistent direction of effect across all trials, so that negative estimates of effect referred to those favouring active supplementation, while positive estimates referred to those favouring control. We visually inspected forest plots for the presence of heterogeneity and calculated the variance estimate $\operatorname{tau}^{2}$ as a measure of between-trial heterogeneity (DerSimonian 
1986). We prespecified $\mathrm{atau}^{2}$ of 0.04 to represent low heterogeneity, 0.09 to represent moderate heterogeneity, and 0.16 to represent high heterogeneity between trials (Spiegelhalter 2004). The $I^{2}$ statistic and the corresponding $\mathrm{Chi}^{2}$ test were depicted in addition (Higgins 2003) for the benefit of readers more familiar with this statistic. $\mathrm{I}^{2}$ describes the percentage of variation across trials attributable to heterogeneity rather than chance, with values of $25 \%, 50 \%$, and $75 \%$ typically being interpreted as low, moderate, and high between-trial heterogeneity. Tau ${ }^{2}$ was preferred over $\mathrm{I}^{2}$ in the interpretation of between-trial heterogeneity, as the interpretation of $\mathrm{I}^{2}$ can be affected by the precision of trials included in the meta-analysis (Rücker 2008). All P values were two-sided. Statistical analysis was done in Review Manager 5 (Review Manager 2014); and in STATA, release 13 (StataCorp, College Station, Texas).

\section{Subgroup analysis and investigation of heterogeneity}

Where we identified substantial inconsistency between trials in a meta-analysis, we inspected forest plots to look for obvious sources of inconsistency and reviewed the trials for clinical heterogeneity. Because of the small numbers of trials from which data could be pooled, we conducted no subgroup analyses.

\section{Sensitivity analysis}

We did not conduct any sensitivity analyses.

\section{GRADE and summary of findings table}

We constructed 'Summary of Findings' (SoF) tables for comparisons of B vitamins, antioxidant vitamins, Vitamin D + calcium, Zinc + Copper and complex multivitamins with placebo. For each comparison, we included in the SoF tables results related to overall cognitive function and the incidence of dementia at each time point. If a study presented results for the same participants at different time points, and these could not be pooled with results from other studies, then we presented in the SoF table only the results from the longest period of follow-up.
We used GRADE to describe the certainty of the overall body of evidence for each outcome in the 'Summary of findings' table (Higgins 2011; Guyatt 2008).

Certainty refers to the degree of confidence which can be placed in the estimates of treatment benefits and harms. There are four possible ratings: 'high', 'moderate', 'low' and 'very low'. The GRADE approach rates evidence from RCTs which do not have serious limitations as 'high-certainty'. However, several factors can lead to the downgrading of the evidence to 'moderate', 'low' or 'very low'. The degree of downgrading is determined by the seriousness of these factors: study limitations (risk of bias); inconsistency; indirectness of evidence; imprecision; and publication bias (Higgins 2011; Guyatt 2008). Rating evidence 'high-certainty' implies that we are confident in our estimate of the effect, and further research is very unlikely to change this. A rating of 'very low'-certainty indicates that we are very uncertain about the obtained summary estimate of the effect.

\section{RES U L T S}

\section{Description of studies}

See Characteristics of included studies and Characteristics of excluded studies.

\section{Results of the search}

We conducted searches in December 2014, July 2015, March 2016, August 2016, March 2017, and January 2018. In total, we retrieved 7,257 records from the six searches. After de-duplication, 5211 records remained. A Crowd and the CDCIG information specialist assessed these at title and abstract level. In total, 725 results remained after this assessment. The review team then screened these records. Of these, we assessed 74 full-text articles for eligibility and included 28 studies. One study was placed in the section 'Awaiting classification'; although it was marked as 'completed' in the trial registry, we were unable to find any results or to get any response from the authors. This process is depicted in Figure 1. 
Figure 1. Study flow diagram.

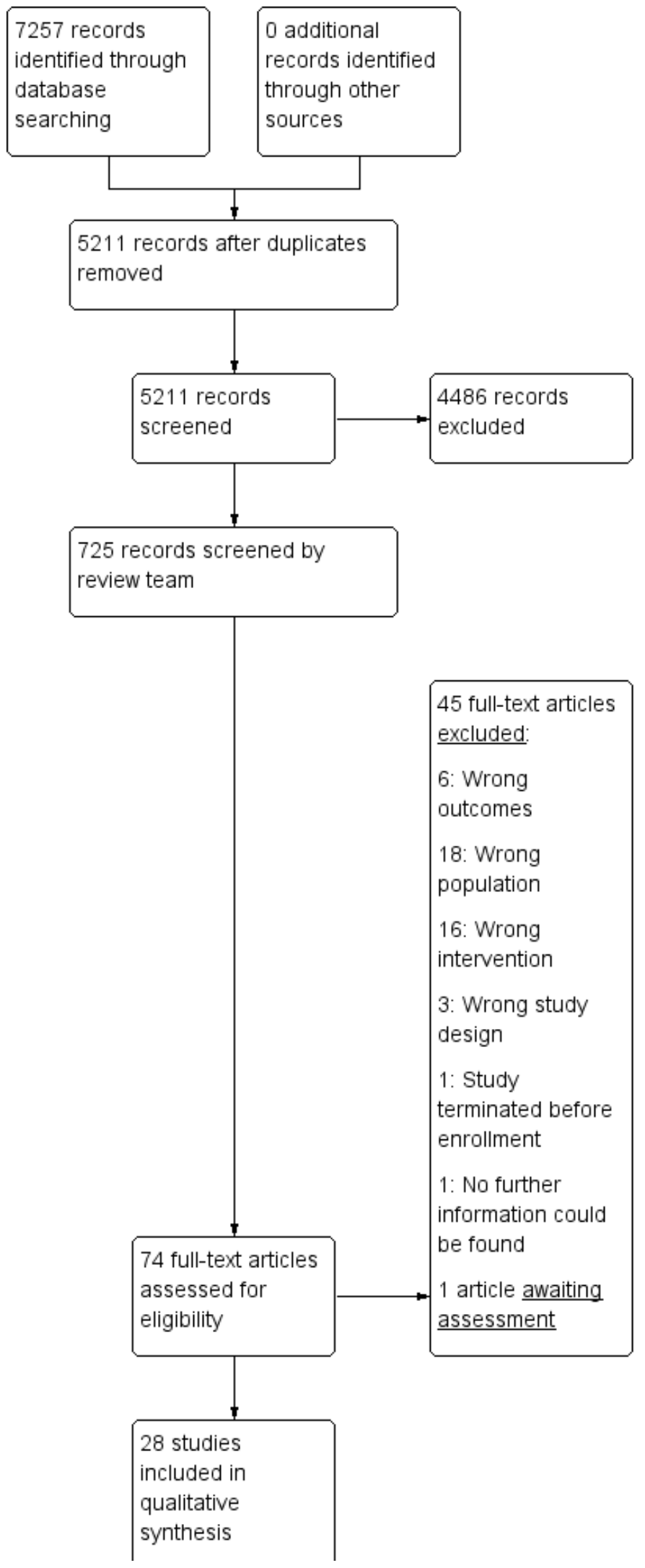


Figure 1. (Continued)

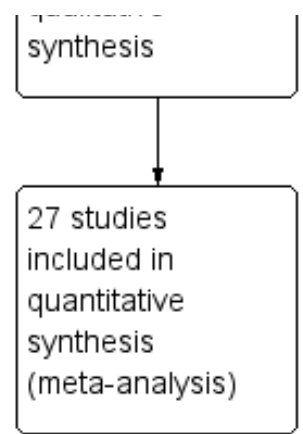

\section{Included studies}

We included 28 studies with a total of more than 83,000 participants in the review.

\section{Studies of B vitamins}

We included 14 studies with 27,882 participants in which the active intervention was folic acid, vitamin B12, vitamin B6, or a combination of these (Andreeva 2011; Dangour 2015; Durga 2007; Eussen 2006; Ford 2010; Hankey 2013; Kang 2008; Lewerin 2005; McMahon 2006; SEARCH 2010; Stott 2005; Toole 2004; Van der Zwaluw 2014; Walker 2012). Seven of the 14 studies had been designed with cognition as a primary outcome.

- Study design. Nine studies compared the B vitamin or B vitamin combination to placebo in a two-arm, parallel group design. In one two-arm, parallel group study (Toole 2004), the intervention was a multivitamin containing the United States' Food and Drug Administration (FDA) recommended daily allowances (RDA) of vitamins supplemented with high doses of folic acid, vitamin B6, and vitamin B12 while the comparator arm was a multivitamin containing the RDAs only. One study (Eussen 2006) had a threearm, parallel group design with active intervention groups receiving $B 12$ and (folic acid $+B 12$ ); we combined these to make a single active intervention group. Four studies had factorial designs with placebo controls. SEARCH 2010 had a $2 \times 2$ factorial design including (folic acid + B12) and simvastatin. Andreeva 2011 had a $2 \times 2$ factorial design including (folic acid + B6 + B12) and omega fatty acids. Stott 2005 had a $2 \times 2 \times 2$ factorial design including (folic acid + B12), B2, and B6 and reported results for all eight groups separately; for comparability with other studies, we included the (folic acid + B12) and the (folic acid + B12 + B6 groups), combining these to make a single active intervention group. Kang 2008 had a $2 \times 2 \times 2 \times 2$ factorial design. It reported on a cognitive substudy of the Women's Antioxidant and Folic Acid Cardiovascular Study (WAFACS), which was established by adding a fourth arm - (folic acid + B6 + B12) - to the Women's Antioxidant Cardiovascular Study (WACS). The active interventions in WAFACS were therefore (folic acid + B6 + B12), vitamin $E$, vitamin $C$, and $B$-carotene. Kang 2008 reported on the effects of the $B$ vitamins.

- Interventions. The active interventions varied in their constituents and dose. In one trial, the active intervention of interest was folic acid alone; in one trial, it was B12 alone. In five trials, the active intervention was (folic acid + B12) and in six trials (folic acid $+B 12+B 6$ ), although in one of these trials the B12 dose was minimal. Daily doses of folic acid ranged from 0.4 $\mathrm{mg}$ to $2.5 \mathrm{mg}$, of B6 from $3 \mathrm{mg}$ to $50 \mathrm{mg}$ and of B12 from $0.02 \mathrm{mg}$ to $1 \mathrm{mg}$. All studies had a placebo control, although for most of the factorial studies the comparison was ' $B$ vitamin' versus 'no $B$ vitamin' where the 'no B vitamin' group were taking a variety of other interventions. In one trial, all participants were also given 600 IU of vitamin D3 daily.

- Population. The study populations varied.

* Six studies recruited participants with a history of cardioor cerebrovascular disease (Andreeva 2011, Hankey 2013; MRC/BHF 2002, SEARCH 2010, Stott 2005, Toole 2004) and one recruited men with hypertension (Ford 2010). Three studies included only participants with elevated serum homocysteine levels (> 12 or $13 \mu \mathrm{mol} / \mathrm{L}$ ) at baseline (Durga 2007, McMahon 2006, Van der Zwaluw 2014). Two studies included only participants with mild to moderate B12 deficiency (Dangour 2015; Eussen 2006). One study included only diabetic participants (Anand 2011). In one study, participants were selected on the basis of elevated psychological distress (Walker 2012).

* In all studies, there was evidence that most participants were cognitively healthy at baseline, but inclusion of small numbers of participants with cognitive impairment was possible. The inclusion decision was marginal for two studies. Stott 2005 reported median MMSE at baseline of 28 with an IQR of 26 to 29 ; hence $25 \%$ of participants in this UK study had an MMSE < 26. In Toole 2004, all participants had had a 'non-disabling' ischaemic stroke and baseline MMSE was 26.9 (SD 3.4) so it is likely that some participants had a degree of cognitive impairment at baseline. Only participants with 'severe cognitive impairment' were excluded. We decided to include both of these studies, but to consider the population as a possible source of heterogeneity.

* The age of participants also varied. In six studies, the mean age at the onset of supplementation was between 60 years and 70 years; in eight studies the mean age was between 70 years and 80 years.

\section{Studies of antioxidant vitamins}

We included eight studies with 47,840 participants in which the active intervention was one or more of the antioxidant vitamins: vitamin E, vitamin C, ß-carotene (Anand 2011; Grodstein 2007; Kang 2006; Kang 2009; Kesse-Guyot 2011; Kryscio 2017; MRC/BHF 2002; Yaffe 2004). Only one of these studies had been designed primarily to assess cognition.

- Study design. One study (Anand 2011) compared vitamin E to no vitamin $E$ in a randomised, open-label design. The remaining studies were placebo-controlled. One (Kang 2006) was a 2 × 2 
factorial comparison of vitamin $\mathrm{E}$ and low dose aspirin. One (Kryscio 2017) was a $2 \times 2$ factorial comparison of vitamin $E$ and selenium supplements (this trial was also included in a comparison of selenium with placebo, below). Grodstein 2007 reported data on ß-carotene. It started as a two-arm parallel group study (ß-carotene and placebo, the Physicians' Health Study I (PHS-I)) which lasted for 13 years. After a gap of up to 18 months in some cases, approximately half the participants in PHS-I and some new recruits entered the Physicians' Health Study II (PHS-II) and a cognitive assessment was added. The original randomisation of participants in PHS-I to ß-carotene or placebo was retained in PHS-II while vitamin C, vitamin E, and a complex multivitamin were added in a factorial design. The paper therefore reported data after both long-term (mean 18 years, range 15 to 20 years) and shorter-term (mean one year, range three months to three years) treatment with ß-carotene. Kang 2009 studied vitamin E, vitamin C, and B-carotene in a $2 \times 2 \times 2$ factorial design. In the remaining three studies, the active intervention was a combination of antioxidant vitamins. MRC/BHF 2002 had a $2 \times 2$ factorial design comparing (vitamin $\mathrm{E}+$ vitamin $\mathrm{C}+$ B-carotene) and simvastatin. Yaffe 2004 was a four-arm parallel group study; in this comparison, we included the (vitamin E + vitamin C + B-carotene) and placebo arms (Yaffe 2004 had two additional arms: one treated with zinc and cupric oxide, which we included in another comparison, and one treated with the antioxidant combination plus zinc and cupric oxide, which we excluded). Finally, Kesse-Guyot 2011 compared a combination of vitamin E, vitamin C, ß-carotene, zinc, and selenium to placebo. In this case, it was not possible to separate the antioxidant vitamins from the minerals. This study also differed in the timing of the cognitive assessment which took place six years after the end of the eight-year supplementation period.

- Interventions. There were data on vitamin E from four trials, on vitamin C from one trial, and on ß-carotene from two trials. Most of these data were from factorial trials in which the comparison group was receiving a variety of interventions. In two trials, the active intervention was the antioxidant combination (vitamin $\mathrm{E}+$ vitamin $\mathrm{C}+\mathrm{B}$-carotene), in one trial, it was the same combination with zinc and selenium and in one trial there were both vitamin E and (vitamin E + selenium) arms. All vitamin E was given as alpha-tocopherol. Doses of vitamin $C$ ranged from 120 $\mathrm{mg}$ to $500 \mathrm{mg}$ daily, of vitamin $\mathrm{E}$ from $600 \mathrm{IU}$ on alternate days to 660 IU daily (except in Kesse-Guyot 2011 in which the vitamin E dose in the combined antioxidant was only $45 \mathrm{IU}$ daily) and of $B$ carotene from $6 \mathrm{mg}$ to $50 \mathrm{mg}$ daily.

- Population. The study populations varied.

* Two studies included women only (Kang 2006, Kang 2009) and two studies included men only (Grodstein 2007; Kryscio 2017). In Anand 2011, all participants had type 2 diabetes and were taking oral hypoglycaemics. In Kang 2009, all participants had cardiovascular disease or three or more coronary risk factors. In MRC/BHF 2002, participants were recruited on the basis of a high risk of coronary heart disease death over the next five years. In Yaffe 2004, all participants had age-related macular degeneration.

* Reflecting the fact that these studies were overwhelmingly cognitive 'add-ons' to studies with other purposes, only one study (Anand 2011) conducted any cognitive assessment at baseline. In this study, which was conducted in an economically-deprived population in India, a score of 24 or more on the Tamil version of the MMSE was considered normal cognition. Although we could not be sure that the other studies did not include some participants with cognitive impairment, we considered it likely in all cases that the study populations were very largely free of dementia or significant cognitive impairment and that the data were informative for our review question.

* The age of participants included in this comparison was generally lower than in the $B$ vitamin comparison. In three studies (Anand 2011, the long-term component of Grodstein 2007 and Kesse-Guyot 2011), the mean age at randomisation was between 50 and 60 years. In four studies, the mean or median age at randomisation was between 60 and 70 years. For the shorter-term component of Grodstein 2007, the mean age at randomisation was 71 years. MRC/BHF 2002 did not report a mean age of participants; the range at baseline was 40 years to 80 years.

\section{Studies of vitamin D}

We included one trial with 4143 participants which compared (vitamin D3 + calcium carbonate) with placebo (Rossom 2012, the Women's Health Initiative Memory Study, or WHIMS) and a small pilot study with 60 participants comparing vitamin D3 and placebo (Aspell 2017). Cognition was a primary outcome in Aspell 2017. Although Rossom 2012 was an ancillary study to a larger study with different primary aims, participants did have a detailed assessment to exclude dementia or cognitive impairment prior to enrolment in WHIMS.

- Study design. Both studies were two-arm parallel group studies. The mean duration of treatment and follow-up in Rossom 2012 was 7.8 years; in Aspell 2017, it was six months.

- Intervention. The doses differed markedly in these two studies. In Rossom 2012, the experimental intervention was 400 IU vitamin D3 and $1000 \mathrm{mg}$ calcium carbonate daily. Use of personal supplemental vitamin D up to $600 \mathrm{IU}$ (later $1000 \mathrm{IU}$ ) and of calcium up to $1000 \mathrm{mg}$ was also permitted. All participants were also enrolled in WHI Hormone Therapy trials and may have been taking estrogen with or without progestin under those protocols. In Aspell 2017, the experimental intervention was 4000 IU of vitamin D3 on alternate days.

- Population. The participants in Rossom 2012 were 4143 women with a mean age of 71 years (range 65 to 80 years). The participants in Aspell 2017 were 60 community-dwelling men and women with a mean age of 68.5 years.

\section{Studies of zinc and copper}

We included two trials comparing zinc or zinc and copper supplements with placebo (Maylor 2006, Yaffe 2004), but only Yaffe 2004 with 1072 participants reported usable data. Maylor 2006 was designed to assess cognitive function, but Yaffe 2004 was part of a trial whose primary outcome was the effect of supplementation on age-related macular degeneration.

- Study design and interventions. Maylor 2006 was a three-arm, parallel-group trial with 232 participants which compared two doses of zinc gluconate (15 mg and $30 \mathrm{mg}$ a day) with placebo over six months. This study was eligible for inclusion, but did not report data in sufficient detail for extraction and inclusion in analyses. Yaffe 2004 was a four-arm, parallel group trial in which participants were treated for a median of 6.9 years. For 
this comparison, we used data from the active intervention arm in which participants were treated with $80 \mathrm{mg}$ of zinc as zinc oxide and $2 \mathrm{mg}$ of copper as cupric oxide.

- Population. The participants in Maylor 2006 were 387 people aged 55 to 87 years. The cognitive inclusion criterion was MMSE > 23 , but in fact mean MMSE among participants was $>28$ with low variability.The participants in Yaffe 2004 were 2166 people with age-related macular degeneration. Their median age at baseline was 69 years (range 55 to 80 years). There was no baseline cognitive assessment.

\section{Studies of selenium}

Kryscio 2017 (PREADVISE) was a $2 \times 2$ factorial study of vitamin $\mathrm{E}$ and selenium supplements. For this comparison (selenium versus placebo), we considered only the 3711 participants in the selenium only and placebo only groups. The participants who received vitamin $\mathrm{E}$ and (vitamin $\mathrm{E}+$ selenium) were considered in the antioxidant vitamins versus placebo comparison. This was an ancillary trial to SELECT, the primary aim of which was the prevention of prostate cancer.

\section{Studies of supplementation with B vitamin, antioxidant vitamin and mineral combinations ('complex multivitamins')}

We included three studies with 6306 participants in which the interventions were supplements which included both B vitamins and antioxidant vitamins, with or without additional minerals (Cockle 2000, Grodstein 2013, Wolters 2005). For ease of reference, we called these 'complex multivitamins'. Only the two smaller trials (Cockle 2000, Wolters 2005, combined $n=359$ ) were designed to assess cognition.

- Study design. Cockle 2000 and Wolters 2005 were small, twoarm, placebo-controlled, parallel group studies lasting 24 weeks and six months respectively. Grodstein 2013 reported the multivitamin data from a cognitive substudy $(n=5947)$ of the large Physicians' Health Study II (PHS-II), which is described under 'antioxidant vitamins' above. It had a $2 \times 2 \times 2 \times 2$ factorial design. The mean time from randomisation to first cognitive assessment was 2.5 years (range 0.18 to 5.3 years) and to final cognitive assessment 8.5 years (range 0.3 to 14.2 years).

- Interventions.

* In Cockle 2000, the daily dose of the experimental intervention contained: vitamin A palmitate $3334 \mathrm{IU}$, thiamine mononitrate (B1) $14 \mathrm{mg}$, riboflavin (B2) $16 \mathrm{mg}$, pyridoxine (B6) $22 \mathrm{mg}$, vitamin B12 $0.03 \mathrm{mg}$, vitamin C 600 $\mathrm{mg}$, dl-alpha-tocopherol acetate (vitamin E) $100 \mathrm{mg}$, folic acid $4 \mathrm{mg}$, d-biotin $2 \mathrm{mg}$ and nicotinamide $180 \mathrm{mg}$. The authors stated that "[t]he dosing was calculated to provide the equivalent of one US RDA (National Research Council, 1980) of vitamin A and ten US RDAs of the remaining vitamins." The study was planned to last for 48 weeks, but due to very high dropout after week 24, no data were reported after 24 weeks.
* In Grodstein 2013, the experimental intervention was Centrum Silver ${ }^{\circledR}$ (Pfizer). Its composition is shown in Appendix 4.

* In Wolters 2005, the experimental intervention was Nobilin Q10 ${ }^{\circledR}$ (Medicom Pharma) providing daily doses of 150 $\mathrm{mg}$ vitamin C (calcium ascorbate), $50 \mathrm{mg}$ magnesium (magnesium carbonate), $36 \mathrm{mg}$ vitamin $\mathrm{E}$ (D-alfa-tocopherol acetate), $34 \mathrm{mg}$ niacin (nicotinamide), $16 \mathrm{mg}$ pantothenic acid, $9 \mathrm{mg}$ ß-carotene, $3.4 \mathrm{mg}$ pyridoxine (pyridoxine hydrochloride), $3.2 \mathrm{mg}$ riboflavin, $2.4 \mathrm{mg}$ thiamine (thiamine mononitrate), $400 \mu \mathrm{g}$ folic acid (pteroyl glutamic acid), $200 \mu \mathrm{g}$ biotin, $60 \mu \mathrm{g}$ selenium (selenium-enriched yeast), and $9 \mu \mathrm{g}$ cobalamin (cyanocobalamin).

- Population.

* Cockle 2000 randomised 139 participants, Grodstein 2013 randomised 5947, and Wolters 2005 reported results for 220 (not clear how many were randomised).

* Wolters 2005 included women only and Grodstein 2013 included men only.

* The participants in Cockle 2000 had a mean MMSE at baseline of $28.8 \pm 1.5$ years. There was no baseline cognitive assessment in Grodstein 2013. In Wolters 2005, baseline cognitive assessment supported the authors' assertion that subjects were cognitively healthy.

* The age of participants at baseline was median 63 years in Wolters 2005, median 70 years in Cockle 2000 and mean 72 years in Grodstein 2013.

\section{Excluded studies}

Forty-five studies were excluded (See Characteristics of excluded studies). Studies were excluded if they did not meet the inclusion criteria relating to: population (ACTRN12607000321448, Alavi 2014, Anonymous 2003, Benton 1995, Corless 1987, De Jager 2012, Flicker 2011, Hvas 2004, Imaoka 2016, Krikorian 2010, Kwok 2017, Li 2015, Macpherson 2012, Murray-Kolb 2011, NCT00903695, NCT02185222, Petersen 2005, Smith 1999, Van Uffelen 2007), outcomes (Abbasi 2013, Ford 2008, Miller 2016, NCT02467153), intervention (Arwert 2003, Bryan 2002, Chan 2010, Chew 2015; Dhesi 2004, Harris 2015, NCT01095211, NCT01708005, Ng 2017, Ong 2016, Pase 2015, Pathansali 2006, Pettersen 2017, Schietzel 2016, Summers 2010, Wouters-Wesseling 2005), or study design (Cheng 2016, Quick 2013, Rietsema 2014). One study was withdrawn prior to enrolment (Liu 2015). Maniam 2004 was a potentially eligible RCT described in an abstract published in 2004, but we were unable to identify any related full report. Some of the studies were excluded in this review, but were included in the Cochrane review on vitamin and mineral supplementation in people with mild cognitive impairment (McCleery 2018).

\section{Risk of bias in included studies}

Our judgments about the risks of bias in the included studies are detailed in the Characteristics of included studies tables and shown graphically in Figure 2. 
Figure 2. Risk of bias summary: review authors' judgements about each risk of bias item for each included study.

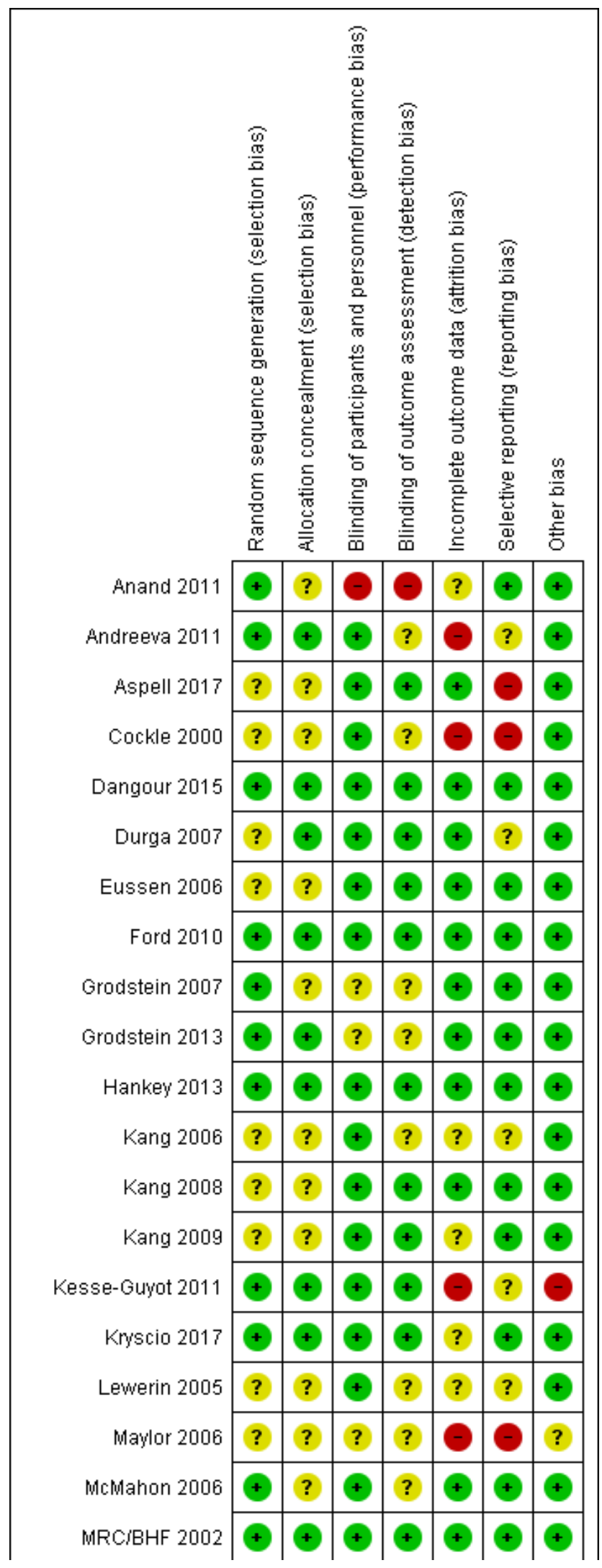


Figure 2. (Continued)

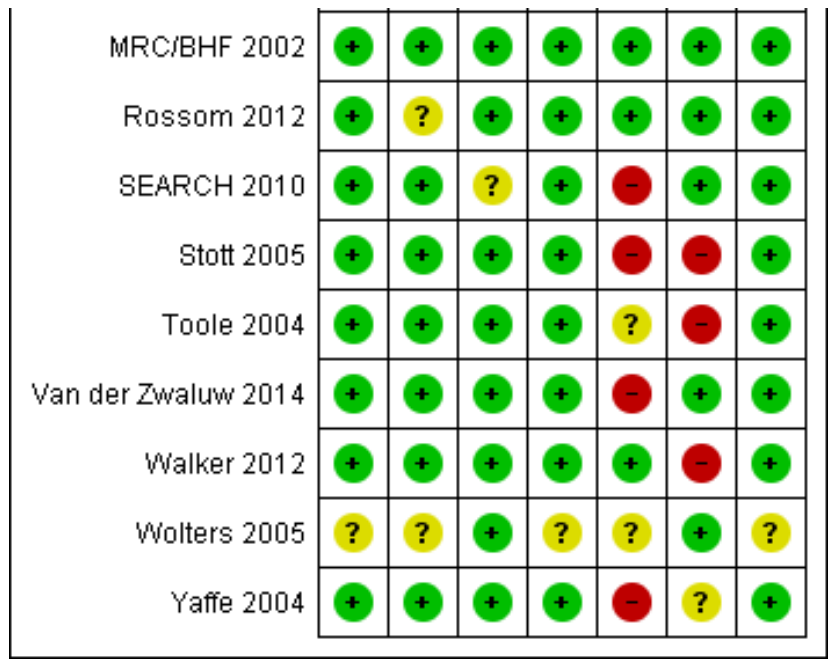

\section{Allocation}

Overall, selection bias was not a major concern. We judged all studies to be at low or unclear risk of bias in this domain. In a number of papers, our judgment was 'unclear' because there was a lack of detail given about the allocation methods used, but in some cases these were large, multicentre studies in which the methods of random sequence generation and allocation concealment were likely to have been adequate.

\section{Blinding}

One study (Anand 2011) was explicitly an open-label study and we therefore considered it to be at high risk of performance and detection bias. All other studies were described by their authors as being double-blind, although again there was, in some cases, a lack of reporting of the methods used to ensure blinding, especially of outcome assessment. In most cases, the experimental intervention and placebo were described as being identical. We judged all studies other than Anand 2011 to be at either low or unclear risk of bias in these domains.

\section{Incomplete outcome data}

Incomplete outcome data posed a significant risk of bias to the longer-term results. For some studies (Ford 2010, Grodstein 2013, Kang 2008), we judged the risk to be low or unclear for shorter-term outcomes, but high for longer-term outcomes when there had been greater loss of participants to follow-up.

\section{Selective reporting}

The included studies had a variety of primary outcomes, In a number of large studies, cognitive outcomes were not specified in protocols, but were added at a later stage. However, in these cases, simple cognitive measures were generally used and were reported. We judged five studies to be at high risk of selective reporting bias. Cockle 2000 did not report all the relevant outcomes described in the Methods section of the paper. Maylor 2006 did not report results in sufficient detail for inclusion in analyses. Stott 2005 mentioned functional outcomes in the trial registry entry which were not reported in the paper. Toole 2004 reported MMSE scores at 12 months but without the number of participants in each group, so we could not include the data in meta-analysis, and did not report the MMSE data at 24 months. Walker 2012 did not report all outcomes in sufficient detail for inclusion.

\section{Other potential sources of bias}

We identified no high risks of bias due to other factors.

\section{Effects of interventions}

See: Summary of findings for the main comparison B vitamins compared to placebo for maintaining cognitive function in cognitively healthy people in mid and late life; Summary of findings 2 Antioxidants compared to placebo for maintaining cognitive function in cognitively healthy people in mid and late life; Summary of findings $\mathbf{3}$ Vitamin D3 compared to placebo for maintaining cognitive function in cognitively healthy people in mid and late life; Summary of findings $\mathbf{4}$ Zinc + copper compared to placebo for maintaining cognitive function in cognitively healthy people in mid and late life; Summary of findings 5 Complex multivitamin compared to control for maintaining cognitive function in cognitively healthy people in mid and late life

The minimum clinically important difference on cognitive tests for healthy participants in prevention trials is unknown and is likely to vary with the age of participants and the duration of followup. We are therefore unable to judge the likely clinical importance of differences detected on any cognitive test. When describing the results, we refer to a difference between groups when $P<0.05$.

\section{B vitamins}

We compared B vitamins to placebo at four time points: 3-12 months of treatment, $>1-2$ years, $>2-5$ years and $>5-10$ years.

Some studies did not assess cognitive function at baseline and reported final measurement data. Some studies reported only change from baseline data. Because we were pooling outcomes measured with a variety of instruments, we used standardised mean differences and therefore pooled final measurement and change from baseline data separately.

Negative SMDs favoured B vitamins; positive SMDs favoured placebo. 


\section{Overall cognitive function}

See Figure 3; Analysis 1.1

Figure 3. Forest plot of comparison: 1 B vitamins versus control, outcome: 1.1 Overall cognitive functioning.

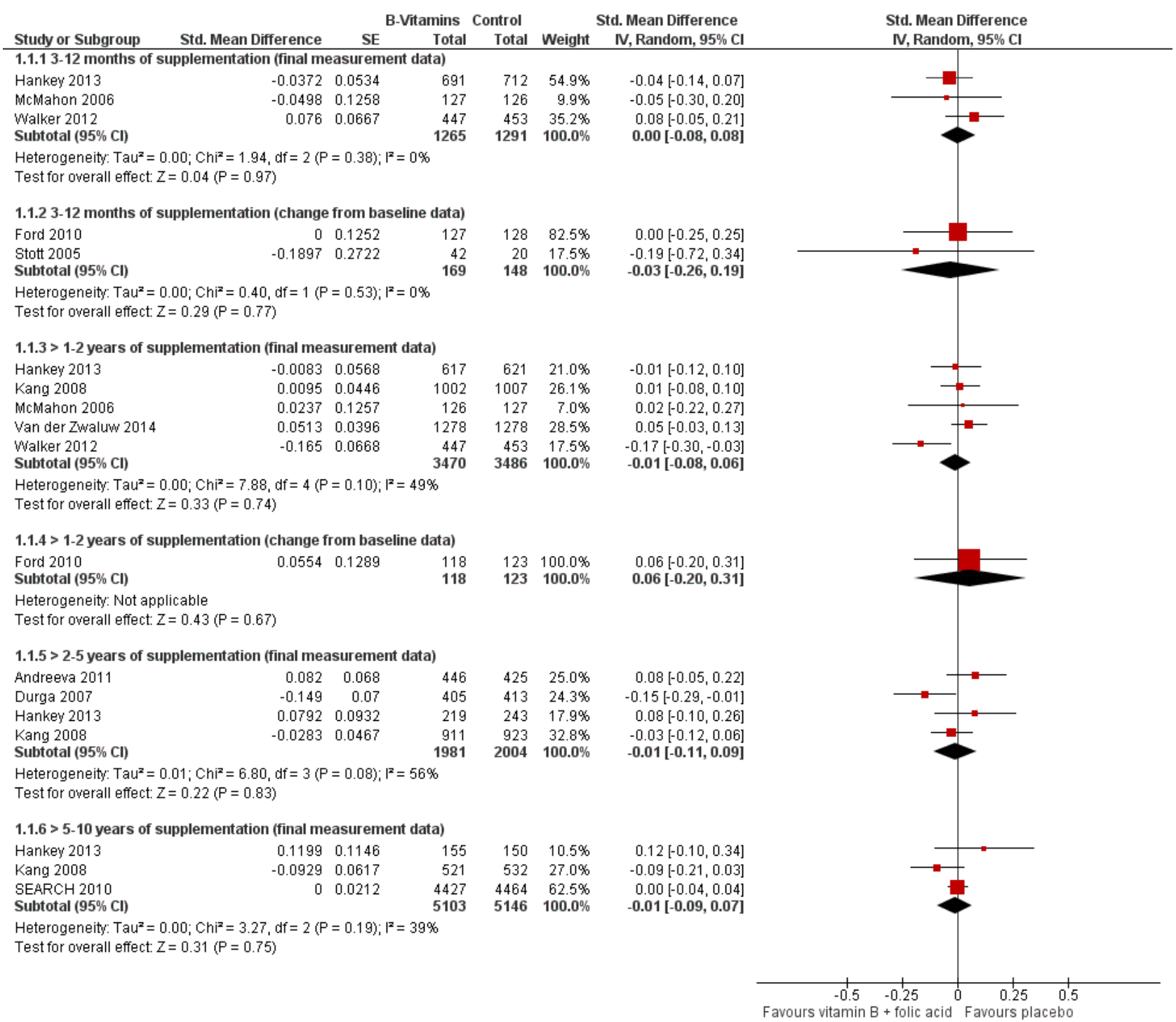

\section{3-12 months of supplementation:}

Three studies providing final measurement data showed that there is probably no effect of $\mathrm{B}$ vitamins on overall cognitive function (SMD $0.00,95 \% \mathrm{Cl}-0.08$ to $0.08, \mathrm{n}=2556$; moderatecertainty evidence). A fourth study (Toole 2004) also provided final measurement MMSE data on 3097 participants, but did not report the number of participants in each intervention group; it reported no significant difference between groups $(P=0.19)$. Two smaller studies providing change from baseline data confirmed that there may be no effect of $B$ vitamins (SMD $-0.03,95 \% \mathrm{Cl}-0.26$ to $0.19, \mathrm{n}=$ 317; low-certainty evidence).

\section{> 1-2 years of supplementation:}

Five studies providing final measurement data showed that there is probably no effect of $\mathrm{B}$ vitamins (SMD $-0.01,95 \% \mathrm{Cl}-0.08$ to 0.06 , $\mathrm{n}=6956$; moderate-certainty evidence). One study reporting only

change from baseline data similarly showed that there may be no effect of B vitamins (SMD $0.06,95 \% \mathrm{Cl}-0.20$ to $0.31, \mathrm{n}=241$; lowcertainty evidence).

\section{> 2-5 years of supplementation:}

Four studies provided final measurement data and suggested that there is probably no effect of $\mathrm{B}$ vitamins (SMD $-0.01,95 \% \mathrm{Cl}-0.11$ to $0.09, \mathrm{n}=3985$; moderate-certainty evidence).

\section{> 5-10 years of supplementation:}

Three studies contributed data to this comparison; low-certainty evidence indicated that there may be no effect of $B$ vitamins (SMD $-0.01,95 \% \mathrm{Cl}-0.09$ to $0.07, \mathrm{n}=10249$ ).

\section{Episodic memory}

See Analysis 1.2 


\section{3-12 months of supplementation:}

Four studies providing final measurement data showed that $B$ vitamins probably have no effect on episodic memory (SMD 0.02, -0.08 to $0.12, n=1442$; moderate-certainty evidence). Two studies providing change from baseline data confirmed that there may be no effect (SMD 0.04, 95\% Cl -0.15 to 0.23 , n = 430; low-certainty evidence).

\section{> 1-2 years of supplementation:}

Four studies providing final measurement data suggested there may be no effect of treatment (SMD $0.05,95 \% \mathrm{Cl}-0.03$ to $0.13, \mathrm{n}=$ 5626; low-certainty evidence). The one study providing only change from baseline data on this outcome confirmed an absence of effect (SMD $0.06,95 \% \mathrm{Cl}-0.19$ to $0.32, \mathrm{n}=241$; low-certainty evidence).

\section{> 2-5 years of supplementation:}

Three studies providing final measurement data suggested there may be no effect of treatment (SMD $-0.05,95 \% \mathrm{Cl}-0.15$ to $0.05, \mathrm{n}=$ 3523; low-certainty evidence).

\section{> 5-10 years of supplementation:}

From one study, there was low-certainty evidence that there may be little or no effect of treatment (SMD $-0.10,95 \% \mathrm{Cl}-0.22$ to 0.02 , $n=1053)$.

\section{Executive function}

\section{See Analysis 1.3}

\section{3-12 months of supplementation:}

From three studies providing final measurement data, the effect estimate slightly favoured placebo, but there was uncertainty about the size and direction of the effect (SMD $0.14,95 \% \mathrm{Cl}-0.18$ to $0.46, n=536$ ). A single study providing change from baseline data also favoured placebo, but the certainty of this evidence was very low (SMD $0.39,95 \% \mathrm{Cl} 0.07$ to $0.71, \mathrm{n}=171$ ).

\section{> 1-2 years of supplementation:}

Very low-certainty evidence from three studies providing final measurement data suggested no effect of treatment (SMD -0.01, $95 \% \mathrm{Cl}-0.15$ to $0.13, \mathrm{n}=2976)$. There was inconsistency in this analysis in which one study (McMahon 2006) tended to favour placebo.

\section{> 2-5 years of supplementation:}

Two studies providing final measurement data showed that there may be no effect of treatment (SMD $-0.06,95 \% \mathrm{Cl}-0.13$ to $0.02, \mathrm{n}=$ 2648; low-certainty evidence).

\section{> 5-10 years of supplementation:}

From one study, there was low-certainty evidence that there may be no effect of treatment (SMD 0.02, 95\% -0.10 to $0.15, \mathrm{n}=1049$ ).

\section{Speed of processing}

See Analysis 1.4

\section{3-12 months of supplementation:}

Two studies provided final measurement data on this outcome and showed that there may be no effect of treatment (SMD - $0.04,95 \%$ $\mathrm{Cl}-0.28$ to $0.19, \mathrm{n}=289$; low-certainty evidence). Pooled data from three studies providing change from baseline data gave a similar result, but with very low-certainty evidence (SMD 0.12, 95\% Cl-0.34 to $0.58, \mathrm{n}=487$ ).

\section{> 1-2 years of supplementation:}

Two studies provided final measurement data and showed that there is probably no effect of treatment (SMD 0.03, 95\% Cl -0.09 to $0.15, \mathrm{n}=1030$; moderate-certainty evidence). A further study providing change from baseline data confirmed this (SMD -0.04, -0.29 to $0.21, \mathrm{n}=241$; low-certainty evidence).

\section{> 2-5 years of supplementation:}

One study provided final measurement data and showed no effect of treatment (SMD $-0.08,95 \% \mathrm{Cl}-0.22$ to $0.06, \mathrm{n}=818$; high-certainty evidence).

\section{Quality of life}

> 1-2 years of supplementation:

Ford 2010 reported that participants in the B vitamin and placebo groups did not differ significantly on any of the four mental summary scales of the SF-36 after 24 months.

No other included studies reported on quality of life.

\section{Clinical global impression}

No included studies reported on clinical global impression.

\section{Functional performance}

No included studies reported on functional performance.

\section{Incidence of $\mathrm{MCl}$ or dementia}

See Analysis 1.5.

Hankey 2013 (VITATOPS study) reported on the incidence of cognitive impairment (defined as MMSE score $<24$ during followup on two or more occasions) after a median of 2.8 years of supplementation. Of those who had at least two MMSE measurements during follow-up, 50/908 (5.51\%) in the B vitamin group and $49 / 895(5.47 \%)$ in the placebo group met this criterion for cognitive impairment ( $R R 1.01,95 \% \mathrm{Cl} 0.69$ to $1.48, \mathrm{n}=1803$; moderate-certainty evidence).

Ford 2010 treated participants for two years, but also followed up the participants who were still alive approximately eight years after the baseline study assessment, assessing 73 of the 299 randomised participants with the Telephone Interview for Cognitive Status scale (TICS) and ascertaining dementia diagnoses from a population register for all 172 survivors. Defining cognitive impairment as TICS $\leq 27$, they found an OR $0.72(95 \% \mathrm{Cl} 0.25$ to 2.09$)$ favouring the $\mathrm{B}$ vitamin group. For either a dementia diagnosis or TICS $\leq 27$, the OR was 0.76 ( $95 \% \mathrm{Cl} 0.37$ to 1.56 ) also favouring B vitamins. Due to serious imprecision and risk of attrition bias, this was very lowcertainty evidence.

SEARCH 2010 investigators recorded diagnoses of dementia at final follow-up (after a mean of 6.7 person-years) "based on reports from a participant/relative or doctor, there was no further confirmation or adjudication" (communication from author). The paper stated that "similar numbers of participants in each treatment group were 
reported to have developed dementia during follow-up (vitamins, $43(0.7 \%)$, vs placebo, $38(0.6 \%)) "$.

\section{Serious adverse events}

Most papers made only general statements about an absence of serious adverse events in both treatment groups.

\section{All-cause mortality}

See Analysis 1.6

\section{3-12 months of supplementation:}

In one study (Dangour 2015), one participant died in the placebo group and no participants in the B vitamin group.

\section{> 1-2 years of supplementation:}

In Toole 2004, in which all participants had a history of recent ischaemic stroke, 99/1821 participants (5.4\%) died in the B vitamin group compared to $117 / 1847$ participants $(6.3 \%)$ in the comparator group over 2 years of follow-up (RR $0.9,95 \% \mathrm{Cl} 0.7$ to $1.1, \mathrm{n}=3668$ ).

\section{$>2-5$ years of supplementation}

In one study (Andreeva 2011), 24/585 participants (4.1\%) died in the placebo group and $44 / 586$ participants $(7.5 \%)$ in the $B$ vitamin group (RR 1.8 favouring placebo, $95 \% \mathrm{Cl} 1.17$ to $3.08, \mathrm{n}=1171$; very low-certainty evidence).

\section{> 5-10 years of supplementation:}

In SEARCH 2010, in which all participants had a history of myocardial infarction, $983 / 6033$ participants $(16.3 \%)$ died in the B vitamin group compared to $951 / 6031$ participants $(15.8 \%)$ in the placebo group over a mean of 6.7 years of follow-up (RR 1.03, 95\% $\mathrm{Cl} 0.95$ to $1.12, \mathrm{n}=12064$; moderate-certainty evidence).

Mortality data was not clearly reported in any other study.

\section{Antioxidant vitamins}

We compared antioxidants to placebo at four time points: 3-12 months of treatment, $>2-5$ years, $>5-10$ years and $>10$ years. (We had no data for the $>1-2$ year time point).

\section{Overall cognitive function}

See Analysis 2.1; Figure 4 
Figure 4. Forest plot of comparison: 2 Antioxidants versus control, outcome: 2.1 Overall cognitive functioning.

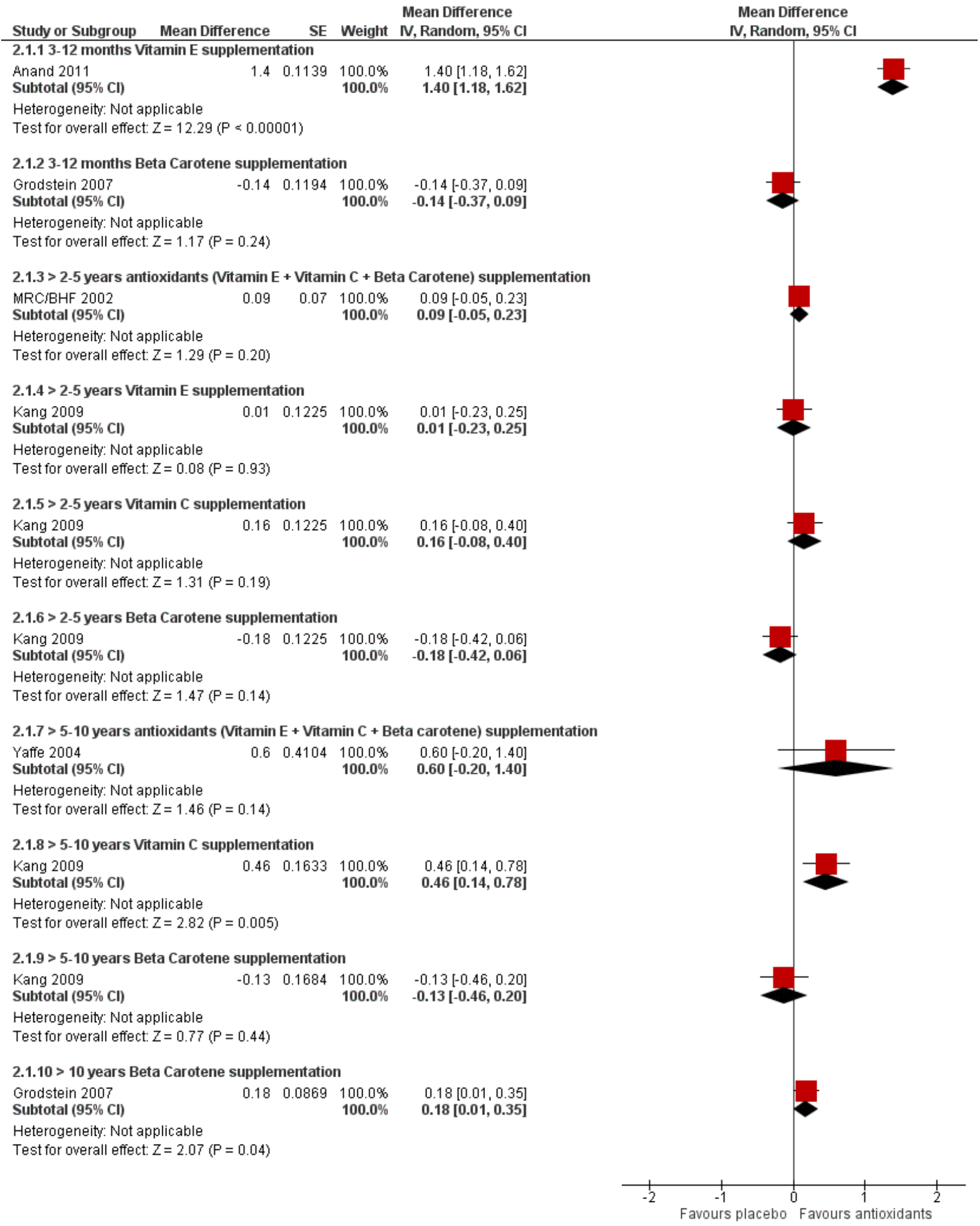

Positive values favoured antioxidants; negative values favoured placebo. 


\section{3-12 months of supplementation:}

One study of vitamin $\mathrm{E}$ in middle-aged adults with type 2 diabetes (Anand 2011) found a higher MMSE in the intervention group, but this was the only open-label study and the certainty of this evidence was very low due to risk of bias, imprecision and indirectness (MD $1.4,95 \% \mathrm{Cl} 1.18$ to $1.62, \mathrm{n}=74)$.

One study of beta-carotene (Grodstein 2007) included an older population (mean age 73 years) who were treated for a mean of 12 months, but a range of two months to three years. Among these participants, there was probably no effect of beta-carotene on overall cognitive function measured with the TICS (MD -0.14, 95\% $\mathrm{Cl}-0.37$ to $0.09, \mathrm{n}=1904$; moderate-certainty evidence).

\section{> 2-5 years of supplementation:}

One study using a combination of vitamin C, E, and beta-carotene (MRC/BHF 2002) found that there was probably no effect of the antioxidant treatment on the TICS after a mean five years of followup (MD 0.09, 95\% Cl -0.05 to $0.23, \mathrm{n}=20536$; moderate-certainty evidence).

Kang 2009 was a factorial study which reported TICS results separately for vitamin C, E, and beta-carotene after a mean of 3.5 years of treatment. It reported the mean difference (with 95\% Cl) between each vitamin group and placebo, but reported only the total number of participants (2824) and not the number in each treatment group. This study showed that there may be no effect of vitamin C (MD $0.16,95 \% \mathrm{Cl}-0.08$ to 0.40 , $\mathrm{n}$ not reported; lowcertainty evidence), vitamin $\mathrm{E}$ (MD $0.01,95 \% \mathrm{Cl}-0.23$ to 0.25 , $\mathrm{n}$ not reported; low-certainty evidence) or beta-carotene (MD -0.18, 95\% $\mathrm{Cl}-0.42$ to 0.06 ; n not reported; low-certainty evidence).

\section{> 5-10 years of supplementation:}

One study using a combination of vitamins $C$ and $E$ and betacarotene for a median of 6.9 years (Yaffe 2004) found that there may be no effect on the modified MMSE (3MS) (MD 0.6, $95 \% \mathrm{Cl}-0.2$ to $1.40, \mathrm{n}=1100$; moderate-certainty evidence).

Kang 2009 also reported outcome data from a final assessment after a mean of 8.9 years. However, again it reported only the total number of participants $(n=1586)$ at this time point and not the number in each group. A second study (Kang 2006) reported TICS data after approximately 10 years of treatment with vitamin $\mathrm{E}$. We were unable to pool data vitamin $E$ data from these two studies because of the unknown number of relevant participants in Kang 2009. In Kang 2006, the first cognitive assessment was conducted 5.6 years (range 4.4 to 6.8 ) after randomisation and the last 4.0 (range 2.6 to 5.7) years later. The mean difference in TICS scores between groups at final cognitive assessment was 0.04 points $(95 \%$ $\mathrm{Cl}-0.12$ to $0.21, \mathrm{n}=5226$ ). The mean difference in cognitive decline on the TICS between the vitamin $E$ and placebo groups from first to last cognitive assessment was 0.02 points $(95 \% \mathrm{Cl}-0.02$ to 0.06 ; $P=0.31$ ). In the vitamin $E$ arm from Kang 2009, there was also no evidence of an effect on final TICS score (MD $-0.16,95 \% \mathrm{Cl}-0.49$ to $0.16 ; n$ not reported, $P=0.33$ ). We considered the overall certainty of this evidence on vitamin $E$ to be low. In the vitamin C arm from Kang 2009 , there may have been a small beneficial effect of vitamin $\mathrm{C}$ on final TICS score (MD $0.46,95 \% \mathrm{Cl} 0.14$ to $0.78, \mathrm{n}$ not reported, $\mathrm{P}=$ 0.006 ; low-certainty evidence). In the beta-carotene arm from Kang 2009 , there was no evidence of an effect of treatment (MD - $0.13,95 \%$ $\mathrm{Cl}-0.46$ to $0.19, \mathrm{n}$ not reported, $\mathrm{P}=0.42$; low-certainty evidence).

\section{$>10$ years of supplementation:}

Grodstein 2007 included 4052 participants who had been treated with beta-carotene for a mean of 18 years (range 15 to 20 years), starting at a mean age of 56 years. There was moderatecertainty evidence of a very small beneficial effect of beta-carotene treatment on the TICS (MD 0.18, 95\% CI 0.01 to 0.35, $\mathrm{n}=4052$ ).

\section{Episodic memory}

See Analysis 2.2; Figure 5 
Figure 5. Forest plot of comparison: 2 Antioxidants versus control, outcome: 2.2 Episodic memory.

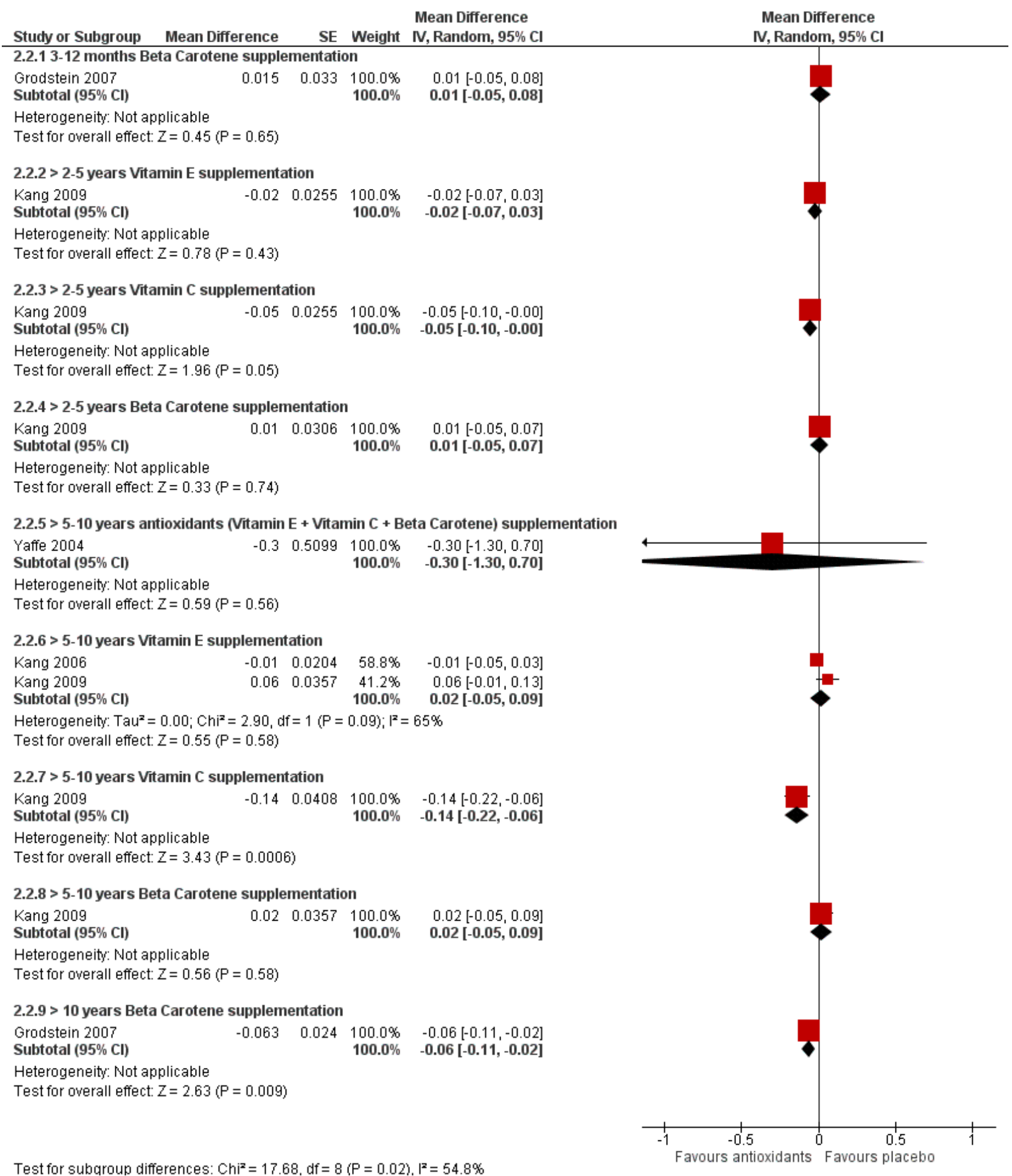

\section{3-12 months of supplementation:}

Grodstein 2007 found that there was probably no effect of betacarotene (MD $0.01,95 \% \mathrm{Cl}-0.05$ to $0.08, \mathrm{n}=1904$; moderatecertainty evidence) on a composite verbal memory measure after a mean of 12 months (range two months to three years).

\section{$>2-5$ years of supplementation:}

From Kang 2009, there was probably a very small beneficial effect of vitamin C on the TICS 10 -word recall test (MD $-0.05,95 \% \mathrm{Cl}-0.10$ to 0 ; $\mathrm{n}=2824$; low-certainty evidence), but probably no effect of vitamin $\mathrm{E}$ (MD-0.02, $95 \% \mathrm{Cl}-0.07$ to $0.03, \mathrm{n}=2824$; low-certainty evidence) or beta-carotene (MD 0.01, $95 \% \mathrm{Cl}-0.05$ to $0.07, \mathrm{n}=2824$; low-certainty evidence). 


\section{> 5-10 years of supplementation:}

Yaffe 2004, using combined vitamin C and E and beta-carotene, found no evidence of an effect on the delayed recall logical memory test (MD $-0.30,95 \% \mathrm{Cl}-1.30$ to $0.70, \mathrm{n}=1100$; low-certainty evidence).

A pooled analysis of two studies using vitamin E provided very lowcertainty evidence of no effect (MD $0.02,95 \% \mathrm{Cl}-0.05$ to $0.09, \mathrm{n}=$ 6812, 2 studies). There was low-certainty evidence from a single study (Kang 2009) that there may be a small beneficial effect of vitamin C (MD $-0.14,95 \% \mathrm{Cl}-0.22$ to $-0.06, \mathrm{n}=1583$ ) and no effect of beta-carotene (MD 0.02, $95 \% \mathrm{Cl}-0.05$ to $0.09, \mathrm{n}=1583$ ).

Kesse-Guyot 2011 treated participants for eight years with a combination of vitamin C, vitamin E, beta-carotene, zinc, and selenium and assessed cognition six years after the end of treatment. On a delayed cued-recall test (the RI-48), there was a small benefit for the vitamin group (MD 0.61, 95\% Cl 0.02-1.20, $\mathrm{n}=$ 4447 , moderate-certainty evidence).

\section{$>10$ years of supplementation:}

Grodstein 2007 found evidence of a small beneficial effect of betacarotene on a composite verbal memory measure after treatment for a mean of 18 years (range 15 to 20 years), starting at a mean age of 56 years (MD $-0.06,95 \% \mathrm{Cl}-0.11$ to $-0.02 ; \mathrm{n}=4052$; moderatecertainty evidence).

\section{Executive function}

See Analysis 2.3

\section{3-12 months of supplementation:}

There was moderate-certainty evidence from Grodstein 2007 that beta-carotene probably has no effect on executive function measured with a category fluency test after a mean of 12 months (range two months to three years) (MD $0.07,95 \% \mathrm{Cl}-0.48$ to $0.62, \mathrm{n}$ $=$ 1904).

\section{> 2-5 years of supplementation:}

There was low-certainty evidence from Kang 2009 of a small detrimental effect of vitamin E on category fluency (MD 0.42, 95\% $\mathrm{Cl} 0.06$ to $0.78, \mathrm{n}=2819)$ and of no effect of vitamin C (MD - $0.03,95 \%$ $\mathrm{Cl}-0.39$ to $0.33, \mathrm{n}=2819$ ) or beta-carotene (MD $0.22,95 \% \mathrm{Cl}-0.14$ to $0.58, \mathrm{n}=2819$ ).

\section{> 5-10 years of supplementation:}

Yaffe 2004 found no evidence of an effect of combined vitamin C and $\mathrm{E}$ and beta-carotene on category fluency (MD - $0.4,95 \% \mathrm{Cl}-0.99$ to $0.19, n=1100$; low-certainty evidence)

Pooled data on vitamin E from Kang 2006 and Kang 2009 showed no evidence of an effect on category fluency (MD $0.11,95 \% \mathrm{Cl}-0.26$ to $0.48, n=6808$; low-certainty evidence). Kang 2009 also found no evidence of an effect of vitamin C (MD $-0.25,95 \% \mathrm{Cl}-0.7$ to $0.2, n$ $=1583$; low-certainty evidence) or beta-carotene (MD 0.01, $95 \% \mathrm{Cl}$ -0.44 to $0.46, n=1583$; low-certainty evidence).

Kesse-Guyot 2011 treated participants for eight years with a combination of vitamin C, vitamin E, beta-carotene, zinc, and selenium and assessed cognition six years after the end of treatment. There was no clear evidence of a difference between groups on category fluency (MD $0.50,95 \% \mathrm{Cl}-0.09$ to $1.09, \mathrm{n}=4447$, moderate-certainty evidence).

\section{$>10$ years of supplementation:}

Grodstein 2007 found that beta-carotene probably has no effect on executive function measured with a category fluency test after treatment for a mean of 18 years (range 15 to 20 years) (MD 0.01, $95 \% \mathrm{Cl}-0.36$ to $0.38, \mathrm{n}=4052$; moderate-certainty evidence).

\section{Speed of processing}

\section{> 5-10 years of supplementation:}

Kesse-Guyot 2011 treated participants for eight years with a combination of vitamin C, vitamin E, beta-carotene, zinc, and selenium and assessed cognition six years after the end of treatment. There was no difference between groups on time taken to complete a trial-making task (TMT) (MD $0.00,95 \% \mathrm{Cl}-0.59$ to 0.59 , $n=4447$, moderate-certainty evidence).

\section{Incidence of dementia}

See Analysis 2.4

\section{> 2-5 years of supplementation:}

One study (MRC/BHF 2002) reported the number of participants who developed dementia during follow-up. All participants were at high vascular risk. There were 62 events, 31 in each group (RR 1, 95\% $\mathrm{Cl} 0.61$ to $1.64, \mathrm{n}=20536$; (ow-certainty evidence).

\section{> 5-10 years of supplementation:}

The mean duration of supplement use in Kryscio 2017 was $5.4 \pm$ 1.2 years although follow-up continued for up to six years after supplement discontinuation. The unadjusted cumulative incidence of dementia was 3.95\% in the vitamin E arm, 4.96\% in the (vitamin $\mathrm{E}+$ selenium) arm and $4.62 \%$ in the placebo arm. A modified ITT analysis including all participants who had at least one follow-up visit and adjusted for a variety of covariates showed that neither arm had an incidence significantly different from the placebo arm: vitamin E HR $0.88(95 \% \mathrm{Cl} 0.64$ to $1.20, \mathrm{P}=0.41)$; (vitamin $\mathrm{E}+$ selenium) HR 1.00 ( $95 \% \mathrm{Cl} 0.74$ to $1.35, \mathrm{P}=0.98)$. We considered this to be low-certainty evidence due to imprecision and indirectness.

\section{All-cause mortality}

See Analysis 2.5

\section{> 2-5 years of supplementation:}

In one study (MRC/BHF 2002), 1389/10267 participants died in the placebo group and 1446/10269 participants in the antioxidant group (RR $1.04,95 \% \mathrm{Cl} 0.97$ to $1.11, \mathrm{n}=20536$; moderate-certainty evidence).

\section{Serious adverse events}

Kryscio 2017 was an ancillary study to SELECT, in which the primary study was the incidence of prostate cancer. SELECT began recruitment in 2002. By 2011, there was a statistically significant $17 \%$ increase in the risk of prostate cancer in the men taking vitamin E only compared to those taking placebo only. After a mean of seven years of follow-up (mean 5.5 years taking supplements) there were 65 prostate cancer cases per 1000 men taking placebo only and 76 prostate cancer cases per 1000 men taking vitamin E only. 


\section{Other outcomes}

Not reported.

\section{Vitamin D}

We considered data unsuitable for pooling because of the five-fold difference in the daily dose of vitamin D3.

\section{Overall cognitive function}

\section{See Analysis 3.1}

There was moderate-certainty evidence from the small pilot study (Aspell 2017) that the change in Montreal Cognitive Assessment (MoCA) score over six months did not differ between the vitamin D3 group (4000 IU on alternate days) and the placebo group (MD 0.76 points, SD not reported, $n=60, P=0.186$ ).

There was moderate-certainty evidence from one study (Rossom 2012) that there was probably no effect of treatment with a daily dose of 400 IU vitamin D3 + calcium carbonate on the modified MMSE (3MS) at any time point up to a mean follow-up of 7.8 years.

\section{3-12 months of supplementation:}

MD $0,95 \% \mathrm{Cl}-0.24$ to $0.24, \mathrm{n}=4122$.

\section{$>1-2$ years of supplementation:}

$\mathrm{MD} 0,95 \% \mathrm{Cl}-0.25$ to $0.25, \mathrm{n}=3910$.

\section{> 2-5 years of supplementation:}

MD $-0.2,95 \% \mathrm{Cl}-0.53$ to $0.13, \mathrm{n}=3515$.

\section{> 5-10 years of supplementation:}

MD $-0.1,95 \% \mathrm{Cl}-0.81$ to $0.61, \mathrm{n}=918$ (low-certainty evidence, additional downgrade due to incomplete outcome data).

\section{Episodic memory/executive function/speed of processing}

Aspell 2017 reported results for executive function using the Trail Making Task but no results for episodic memory, although the trial registry entry indicated that it was to be measured with the Wechsler Memory Scale. For change in TMT scores over six months, there was probably little or no difference between the groups (TMTB-A: MD 5.1, SD not reported, $n=60, P=0.467$ ).

In annual domain-specific cognitive assessments over approximately three to eight years, the authors of Rossom 2012 reported that there were "no significant differences in any domain-specific cognitive scores between treatment groups either in unadjusted analyses or after adjustment for age, smoking, baseline 3MS, and treatment assignment in the hormone or diet modification trials." Results were not fully reported. They included the California Verbal Learning Test (episodic memory), letter and category fluency (executive function) and finger tapping (speed of processing).

\section{Incidence of $\mathrm{MCl}$ or dementia}

In Rossom 2012, "[t]he incidence of $\mathrm{MCl}$ or all-cause dementia did not differ significantly between placebo and treatment groups, with $4.8 \%$ of calcium plus vitamin D subjects (62.2 per 10,000 person years) and $5.1 \%$ of placebo subjects ( 65.9 per 10,000 person years) developing cognitive impairment during a mean follow-up time of 7.8 years ( $\mathrm{HR} 0.94,95 \% \mathrm{Cl} 0.72$ to $1.24 ; \mathrm{P}=0.68$ )". The survival curve showed that the incidence did not differ over the course of followup. We considered this to be low-certainty evidence, downgraded due to imprecision and indirectness (women only).

\section{Other outcomes}

Not reported.

\section{Zinc and copper}

For this comparison, the only data we were able to extract came from Yaffe 2004 which treated participants with $80 \mathrm{mg}$ zinc and $2 \mathrm{mg}$ copper daily for a median of 6.9 years. No usable data were available from Maylor 2006, but the authors reported finding no cognitive effects of six months of supplementation with zinc gluconate.

\section{Overall cognitive function}

See Analysis 4.1

\section{> 5-10 years of supplementation:}

One study (Yaffe 2004) found no evidence of an effect of treatment on the modified MMSE (MD $0.6,95 \% \mathrm{Cl}-0.19$ to $1.39, \mathrm{n}=1072$; moderate-certainty evidence).

\section{Episodic memory}

See Analysis 4.2

\section{> 5-10 years of supplementation:}

One study (Yaffe 2004) found no evidence of an effect of treatment on a delayed recall test (MD $-0.795 \% \mathrm{Cl}-1.74$ to $0.34, \mathrm{n}=1072$; moderate-certainty evidence).

\section{Executive function}

See Analysis 4.3

\section{> 5-10 years of supplementation:}

One study (Yaffe 2004) found no evidence of an effect of treatment on category fluency (MD $-0.3,95 \% \mathrm{Cl}-0.89$ to $0.29, \mathrm{n}=1072$; moderate-certainty evidence).

\section{Incidence of dementia or MCI}

Yaffe 2004 reported that at the time of administration of the cognitive test battery, $4.5 \%$ of participants had a $3 \mathrm{MS}$ score $<80$, which was the authors' definition of cognitive impairment, and that "there was no significant effect of treatment group on likelihood of having cognitive impairment." We considered this to be lowcertainty evidence.

\section{Other outcomes}

Not reported.

\section{Selenium}

For this comparison, the only data came from the selenium arm of Kryscio 2017. The only outcome reported was incidence of dementia. Supplements - in this case, selenium $200 \mathrm{mcg}$ per day - were taken for a mean of $5.4 \pm 1.2$ years although follow-up continued for up to six years after supplement discontinuation. The unadjusted cumulative incidence of dementia was $4.15 \%$ in the selenium arm and $4.62 \%$ in the placebo arm. A modified ITT analysis including all participants who had at least one follow-up

Vitamin and mineral supplementation for maintaining cognitive function in cognitively healthy people in mid and late life (Review) $\mathbf{3 0}$ Copyright (c) 2019 The Cochrane Collaboration. Published by John Wiley \& Sons, Ltd. 
visit and adjusted for a variety of covariates showed no significant difference in incidence between the selenium and placebo arms ( $\mathrm{HR} 0.83,95 \% \mathrm{Cl} 0.61$ to $1.13, \mathrm{P}=0.23, \mathrm{n}=7388$ ). We considered this to be low-certainty evidence due to imprecision and indirectness.

\section{Complex multivitamins (containing $B$ vitamins and} antioxidants $+/$ - minerals)

\section{Overall cognitive function}

See Analysis 5.1

\section{$>2-5$ years of supplementation:}

One study (Grodstein 2013) found no effect of a complex multivitamin on the TICS over a mean of 2.5 years of treatment (range 0.18 to 5.3 years) (MD $0.04,95 \% \mathrm{Cl}-0.09$ to 0.18 ; $\mathrm{n}=5947$; lowcertainty evidence).

\section{> 5-10 years of supplementation:}

The same study found no effect of the complex multivitamin on the TICS over a mean of 8.5 years (range 0.3 to 14.2 years) (MD 0.12 , $95 \%$ $\mathrm{Cl}-0.14$ to $0.38 ; n=2324$; low-certainty evidence).

\section{Episodic memory}

See Analysis 5.2

\section{3-12 months of supplementation:}

One study (Cockle 2000) found no evidence of an effect of treatment on a word scan (recognition) test (MD 33.17, 95\% Cl-28.12 to 94.46; $n=124$; low-certainty evidence). Another study (Wolters 2005) used a pattern recognition subtest of the Berliner Amnesie test (BAT) and reported the results as medians with 5th to 95th percentiles; the difference between groups was 'not significant' (no P value given).

\section{> 2-5 years of supplementation:}

One study (Grodstein 2013) found no evidence of an effect of treatment on a composite verbal memory score after a mean of 2.5 years (range 0.18 to 5.3 years) ( $\mathrm{MD}-0.01,95 \% \mathrm{Cl}-0.05$ to $0.03 ; \mathrm{n}=$ 5942; low-certainty evidence).

\section{> 5-10 years of supplementation:}

One study (Grodstein 2013) found no evidence of an effect of treatment on a composite verbal memory score after a mean of 8.5 years (range 0.3 to 14.2 years) ( $\mathrm{MD}-0.01,95 \% \mathrm{Cl}-0.07$ to $0.05 ; \mathrm{n}=$ 2324; low-certainty evidence).

\section{Executive function}

\section{See Analysis 5.3}

\section{> 2-5 years of supplementation:}

One study (Grodstein 2013) found no evidence of an effect of treatment on verbal fluency after a mean of 2.5 years (range 0.18 to 5.3 years) ( $\mathrm{MD}-0.02,95 \% \mathrm{Cl}-0.33$ to $0.29 ; \mathrm{n}=5942$; low-certainty evidence).

\section{> 5-10 years of supplementation:}

One study (Grodstein 2013) found no evidence of an effect of treatment on verbal fluency after a mean of 8.5 years (range 0.3 to 14.2 years) ( $\mathrm{MD}-0.22,95 \% \mathrm{Cl}-0.65$ to $0.21 ; \mathrm{n}=2324$; low-certainty evidence).

\section{Speed of processing}

See Analysis 5.4

\section{3-12 months of supplementation:}

One study (Cockle 2000) found no evidence of an effect of treatment on a total reaction time (TRT) (MD -14.71, 95\% Cl-57.22 to $27.80 ; n=$ 127; low-certainty evidence). Another study (Wolters 2005) used the symbol search subtest from the WAIS-III and reported the results as medians with 5 th to 95 th percentiles. The vitamin group was significantly faster than the placebo group $(P=0.015)$ at baseline and this difference persisted at the end of the intervention $(P=$ 0.01).

\section{Other outcomes}

Not reported.

\section{DISCUSSION}

\section{Summary of main results}

\section{B vitamins}

Fourteen studies with 27,882 participants contributed data. Only two studies lasted for longer than five years, although between them these included more than 10,000 participants. We found no evidence that giving $B$ vitamin supplements to cognitively healthy adults, mainly in their 60 s and 70 s, had any effect on global cognitive function or on episodic memory, executive function, or speed of processing. There were very sparse data on adverse effects or on incidence of cognitive impairment or dementia, quality of life, functional performance, or clinical global impression.

\section{Antioxidant vitamins (vitamins $\mathrm{C}$ and $\mathrm{E}$, and beta-carotene)}

Eight studies with 47,840 participants contributed data. Six studies had a mean treatment duration longer than five years. Two studies followed participants up for more than 10 years. The results of these trials were more mixed than for B vitamins. There was low-certainty evidence that vitamin $C$ supplements may have a small beneficial effect on episodic memory after 2 to 5 years of treatment and on overall cognitive function after 5 to 10 years, although effects were not seen at other time points. There were no longer-term data on vitamin C. For vitamin E, there was low-certainty evidence of a small detrimental effect on executive function after 2 to 5 years and no data beyond 10 years. For beta-carotene, there was no evidence of any effects up to 10 years, but moderate-certainty evidence from one large study with a duration of 15 to 20 years of small benefits on overall cognitive function and episodic memory after a mean of 18 years of treatment. There were very few cognitive data from trials using combinations of antioxidant vitamins. There was no evidence of an effect of 5 to 10 years of antioxidant combination treatment in two trials, but one trial which assessed participants six years after the end of an 8-year treatment period (using vitamins C, $\mathrm{E}$, beta-carotene plus zinc and selenium) reported a small benefit on episodic memory. Two studies found no effect of antioxidant vitamins on the incidence of dementia. Other review outcomes were not reported in these trials.

\section{Vitamin D}

One large trial in this comparison provided low to moderatecertainty evidence of no effect on cognitive outcomes or the incidence of $\mathrm{MCl}$ or dementia of a relatively low dose of vitamin 
D3 with calcium carbonate in any time period up to 10 years. It provided no evidence on other review outcomes. There was also a small pilot trial which used a much higher dose of vitamin D3 and found no evidence of cognitive effects over six months.

\section{Zinc and copper}

One study contributed usable data, providing low-certainty evidence of no effect on cognitive outcomes or the incidence of cognitive impairment after 5 to 10 years, but no evidence on other outcomes.

\section{Selenium}

One study found no evidence of an effect of approximately five years of selenium supplementation on the incidence of dementia, but there was no information on other outcomes.

\section{Complex multivitamins (B vitamins and antioxidants $+/-$ minerals)}

Two small, short-term studies and one large study with a mean duration of treatment of 8.5 years at final follow-up found no effects of complex multivitamins on cognitive outcomes. There was no evidence on other review outcomes.

\section{Overall completeness and applicability of evidence}

Our principal interest was in whether or not vitamin supplementation could be of benefit to the general middle-aged or older population in terms of maintaining cognitive function or preventing dementia in late life. Some general points can be made about the evidence across all the interventions.

Many of the included studies, especially the larger and longer ones, were not designed primarily with cognitive outcomes in mind and did not assess cognition at baseline. It is therefore possible that some participants may not have been cognitively healthy at baseline, although we considered it unlikely that people with known dementia would have been recruited. In some cases, limited cognitive assessments, using measures which lack sensitivity to detect change in cognitively healthy people, were added to existing studies some years after onset. Participation in these studies was often restricted in ways which reflected the original aims, e.g. recruitment limited to one gender, or to people with particular comorbidities or risk factors, so the evidence was often not directly applicable to the older population in general. Only three studies specifically assessed the incidence of dementia. Studies which were designed to assess cognition tended to be shorter (less than two years), which may not be long enough to detect effects. If cognitive effects are detected on this timescale, it is not clear what implications this has for the incidence of dementia. There are problems inherent in combining short-term studies, in which separation of groups may only be seen if the intervention leads to cognitive improvement (or harm), and studies which are long enough to detect a change in the trajectory of age- or pathologyrelated decline. We considered it important to separate studies into groups of different durations, but our time divisions were inevitably somewhat arbitrary and this decision greatly limited the numbers of studies which could be combined.

There is no well developed understanding of the mechanisms by which any of these interventions might affect cognition, which may be the reason that studies used a wide variety of doses and treatment combinations. This makes it difficult to compare studies and leaves open the possibility that different doses or combinations could have different effects.

\section{B vitamins}

The body of evidence on vitamin B supplements addresses our review question only indirectly. Many studies restricted participation to those with particular comorbidities or who had some evidence of low vitamin B levels or exposure at baseline. Four of the 13 studies allowed inclusion of participants younger than 60 years, but in all cases, the mean age of participants was $>60$ years so the data do not adequately address the effects of supplementation in midlife. We excluded very short-term studies (< 3 months), but the majority of included studies treated participants for 2 years or less, which may not be long enough to detect any effect. The particular vitamin B subtypes and their doses differed between studies and in several studies, particularly those with factorial designs, some participants receiving B vitamins also received other potentially active interventions. The studies were too heterogeneous to allow these various characteristics to be explored in subgroup analyses.

\section{Antioxidant vitamins}

We considered vitamin $\mathrm{C}$, vitamin $\mathrm{E}$, and beta-carotene in this group. The evidence on cognitive effects of antioxidant vitamins is very largely from studies which had other primary aims and to which very limited cognitive assessment was added after the studies were underway. In two of the large trials, all participants were at high vascular risk. However, the age of participants at recruitment was generally lower and the duration of the trials was generally longer than the B vitamin trials, so this body of evidence may be more informative about the potential of prolonged treatment to protect cognitive function against decline. Only two of these studies assessed incidence of dementia so most of the results have no more than indirect implications for dementia prevention.There was substantial variation in the doses of vitamins used. Again, the use of factorial designs in some studies meant the comparator groups included participants exposed to a variety of treatments.

\section{Vitamin D}

One study used a combination of vitamin D and calcium carbonate. Mean follow-up was 7.8 years. All participants were postmenopausal women, but inclusion criteria were otherwise broad. The dose of vitamin D was relatively low (400 IU/day). This was one of very few studies that used a rigorous method to assess for incident $\mathrm{MCl}$ or dementia. The other study used a higher dose of vitamin D3 (4000 IU on alternate days), but was small and provided only preliminary evidence on supplementation with this dose.

\section{Minerals (zinc and copper, selenium)}

We found limited data from two studies of mineral supplements. One used a combination of zinc and copper oxides. It was designed to look for an effect on age-related macular degeneration, but there is no reason to think that this limits generalisibility of the cognitive results. Cognitive assessment was after a median of 6.9 years. Dementia incidence was not an outcome. The other was a selenium-only arm of a factorial study in which dementia incidence was the only relevant outcome reported. It found no evidence of an effect of selenium. 


\section{Complex multivitamins with or without minerals}

There were three included studies in this category. One used a combination of B vitamins and antioxidant vitamins. Two used commercially available multivitamin and mineral combinations. Two studies were very small and lasted less than a year. In the large study, all participants were men, treated for a mean of 8.5 years. Dementia incidence was not an outcome.

\section{Quality of the evidence}

The large studies were generally well-conducted and we did not consider that risk of bias was a major threat to the results, although there were some gaps in reporting in all domains. Uncertainty about the risk of selection bias and concerns about attrition bias led us to downgrade the certainty of some results due to possible study limitations. We considered much of the evidence to be indirect with respect to our review question because participation in many studies was restricted, e.g. by comorbidities, baseline biochemistry, or gender. Overall, we considered the certainty of the evidence behind almost all effect estimates to be moderate or low with respect to our review question.

\section{Potential biases in the review process}

Particularly for B vitamins, bias may arise from pooling studies which differed in participants (e.g. with or without elevated homocysteine at baseline) and interventions (various constituents and doses). This 'broad brush' approach may disguise effects.

\section{Agreements and disagreements with other studies or reviews}

A comprehensive systematic review and meta-analysis of the cognitive effects of several years of treatment with $B$ vitamins was published by the B-Vitamin Treatment Trialists' Collaboration in 2014 (Clarke 2014). It included 11 trials for which data were available by September 2010. All the included trials were also included in this review. The authors investigated the effect of the interventions on homocysteine levels as well as on cognition. Although they found that the treatments effectively lowered homocysteine levels (by slightly more than $25 \%$ ), they also found no evidence of significant effects on global ('MMSE-type') cognitive function, domain-specific cognitive function, or cognitive aging. We are not aware of similar systematic reviews of the effects of treatment with non-B vitamins or minerals.

\section{AUTHORS' CONCLUSIONS}

\section{Implications for practice}

We found no evidence to support recommending any vitamin or mineral supplement to middle-aged or older adults who wish to maintain their cognitive function or prevent dementia.

\section{Implications for research}

All of the studies in this review differed in their population, interventions, and outcomes. Therefore, many questions about possible effects of different doses or treatment combinations on different participants remain unanswered. In particular, there are very few data on the long-term effects of supplementation started in midlife. Identifying the most important questions is likely to depend on a better understanding of the pathophysiology of cognitive decline and dementia and of the mechanisms by which vitamins and minerals might modify these processes. Moving forward, there is a place both for investigating possible mechanisms in smaller trials, which can incorporate highly sensitive cognitive assessments and possibly biomarker outcomes, and for larger, longer, pragmatic trials in which it may be necessary to rely on simpler and less sensitive outcome measures. Considering the data in this review, the only real signals of effect were from long-term studies of antioxidant vitamins (vitamin C and beta-carotene) so these might be considered the most promising candidates for further research.

\section{ACKNOWLEDGEMENTS}

The protocol for this review was largely based on a general template constructed for the development of a larger series of protocols and reviews covered by a National Institute for Health Research (NIHR) Systematic Reviews Programme Grant. The common protocol covered four types of intervention, for which some evidence exists that these may modify the risk of developing cognitive impairments or dementia. These include vitamin or mineral supplementation (or vitamin and mineral supplementation), exercise, cognition, and dietary interventions. The general protocol was inspired by a generic protocol approved by the Cochrane Musculoskeletal Group for another series of reviews (Da Costa 2012; Da Costa 2014; Nüesch 2009a; Reichenbach 2010; Rutjes 2009a; Rutjes 2009b; Rutjes 2010).

The authors are grateful to Professors Lisette de Groot, Simone Eussen, and Jane Armitage for responding to enquiries about their work and providing additional data. 


\section{RE F E R E N C E S}

\section{References to studies included in this review}

Anand 2011 \{published data only\}

Anand VPR, Kumar BJ, Varghese JM, Das SK. Supplementation of vitamin $\mathrm{E}$ improves cognitive status and oxidative stress in type 2 diabetes mellitus. International Research Journal of Pharmacy 2011;2:169-72.

\section{Andreeva 2011 \{published data only\}}

Andreeva VA, Kesse-Guyot E, Barberger-Gateau P, Fezeu L, Hercberg S, Galan P. Cognitive function after supplementation with $B$ vitamins and long-chain omega- 3 fatty acids: ancillary findings from the SU.FOL.OM3 randomized trial. American Journal of Clinical Nutrition 2011;94:278-86.

\section{Aspell 2017 \{published data only\}}

Aspell N, Healy M, McPartlin J, Lawlor BA, O'Sullivan M. Effects of vitamin D supplementation on cognitive function in healthy community dwelling older adults: results from a randomised double-blind placebo-controlled trial. Proceedings of the Nutrition Society 2017;76 (OCE3):E59.

\section{Cockle 2000 \{published data only\}}

Cockle SM, Haller J, Kimber S, Dawe RA, Hindmarch I. The influence of multivitamins on cognitive function and mood in the elderly. Aging \& Mental Health 2000;4:339-53.

\section{Dangour 2015 \{published data only\}}

Dangour AD, Allen E, Clarke R, Elbourne D, Fasey N, Fletcher AE, et al. A randomised controlled trial investigating the effect of vitamin B12 supplementation on neurological function in healthy older people: the Older People and Enhanced Neurological function (OPEN) study protocol. Nutrition Journal 2011;10(22):1-8.

* Dangour AD, Allen E, Clarke R, Elbourne D, Fletcher AE, Letley $L$, et al. Effects of vitamin B-12 supplementation on neurologic and cognitive function in older people: a randomized controlled trial. American Journal of Clinical Nutrition 2015;102(3):639-47.

\section{Durga 2007 \{published data only\}}

* Durga J, Van Boxtel MP, Schouten EG, Kok FJ, Jolles J, Katan MB, et al. Effect of 3-year folic acid supplementation on cognitive function in older adults in the FACIT trial: a randomised, double blind, controlled trial. Lancet 2007;369:208-16.

Murff HJ. Folic acid supplementation improved cognitive function in older adults. Journal of Clinical Outcomes Management 2007;14:134-5.

Schiepers OJ, Van Boxtel MP, De Groot RH, Jolles J, de Kort WL, Swinkels DW, et al. Serum iron parameters, HFE C282Y genotype, and cognitive performance in older adults: results from the FACIT study. Journals of Gerontology. Series A, Biological Sciences and Medical Sciences 2010;65A:1312-21.

\section{Eussen 2006 \{published data only\}}

Eussen S, Ueland P, Clarke R, Blom H, Hoefnagels W, Van Staveren W, et al. The association of betaine, homocysteine and related metabolites with cognitive function in Dutch elderly people. British Journal of Nutrition 2007;98:960-8.

* Eussen SJ, De Groot LC, Joosten LW, Bloo RJ, Clarke R, Ueland PM, et al. Effect of oral vitamin B-12 with or without folic acid on cognitive function in older people with mild vitamin B-12 deficiency: a randomized, placebo-controlled trial. American Journal of Clinical Nutrition 2006;84:361-70.

\section{Ford 2010 \{published data only\}}

* Ford AH, Flicker L, Alfonso H, Thomas J, Clarnette R, Martins R, et al. Vitamins $\mathrm{B}(12), \mathrm{B}(6)$, and folic acid for cognition in older men. Neurology 2010;75:1540-7.

Ford AH, Flicker L, Alfonso H, Thomas J, Clarnette R, Martins R, et al. Vitamins B12, B6, and folic acid for cognition in older men: correction. Neurology 2011;77:804.

\section{Grodstein 2007 \{published data only\}}

Christen WG, Gaziano JM, Hennekens CH. Design of Physicians' Health Study II - a randomized trial of beta-carotene, vitamins $\mathrm{E}$ and $\mathrm{C}$, and multivitamins, in prevention of cancer, cardiovascular disease, and eye disease, and review of results of completed trials. Annals of Epidemiology 2000;10:125-34.

* Grodstein F, Kang JH, Glynn RJ, Cook NR, Gaziano JM. A randomized trial of beta carotene supplementation and cognitive function in men: the Physicians' Health Study II. Archives of Internal Medicine 2007;167:2184-90.

\section{Grodstein 2013 \{published data only\}}

Christen WG, Gaziano JM, Hennekens CH. Design of Physicians' Health Study II - a randomized trial of beta-carotene, vitamins $E$ and $C$, and multivitamins, in prevention of cancer, cardiovascular disease, and eye disease, and review of results of completed trials. Annals of Epidemiology 2000;10:125-34.

* Grodstein F, O'Brien J, Kang JH, Dushkes R, Cook NR, Okereke $\mathrm{O}$, et al. Long-term multivitamin supplementation and cognitive function in men: a randomized trial. Annals of Internal Medicine 2013;159:806-14.

Hankey 2013 \{published data only\}

* Hankey GJ, Ford AH, Qilong Yi, Eikelboom JW, Lees KR, Chen $C$, et al. Effect of B vitamins and lowering homocysteine on cognitive impairment in patients with previous stroke or transient ischemic attack. Stroke 2013;44:2232-9. [DOI: 10.1161/ STROKEAHA.113.001886]

VITATOPS Trial Study Group. The VITATOPS (Vitamins to Prevent Stroke) trial: rationale and design of an international, large, simple, randomized trial of homocysteine-lowering multivitamin therapy in patients with recent transient ischaemic attack or stroke. Cerebrovascular Diseases 2002;13:120-6. 
Kang 2006 \{published data only\}

* Kang JH, Cook N, Manson J, Buring JE, Grodstein F. A randomized trial of vitamin $\mathrm{E}$ supplementation and cognitive function in women. Archives of Internal Medicine 2006;166:2462-8.

Ridker PM, Cook NR, Lee IM, Gordon D, Gaziano JM, Manson JE, et al. A randomized trial of low-dose aspirin in the primary prevention of cardiovascular disease in women. New England Journal of Medicine 2005;352(13):1293-304.

Kang 2008 \{published data only\}

Albert CM, Cook NR, Gaziano JM, Zaharris E, MacFadyen J, Danielson $\mathrm{E}$, et al. Effect of folic acid and $\mathrm{B}$ vitamins on risk of cardiovascular events and total mortality among women at high risk for cardiovascular disease: a randomized trial. JAMA 2008;299(17):2027-36.

Bassuk SS, Albert CM, Cook NR, Zaharris E, MacFadyen JG, Danielson E, et al. The Women's Antioxidant Cardiovascular Study: design and baseline characteristics of participants. Journal of Women's Health 2004;13:99-117.

* Kang JH, Cook N, Manson J, Buring JE, Albert CM, Grodstein F. A trial of $B$ vitamins and cognitive function among women at high risk of cardiovascular disease. American Journal of Clinical Nutrition 2008;88:1602-10.

Manson JE, Gaziano JM, Spelsberg A, Ridker PM, Cook NR, Buring JE, et al. WACS Research Group. A secondary prevention trial of antioxidant vitamins and cardiovascular disease in women. Rationale, design, and methods. Annals of Epidemiology 1995;5(4):261-9.

\section{Kang 2009 \{published data only\}}

Albert CM, Cook NR, Gaziano JM, Zaharris E, MacFadyen J, Danielson E, et al. Effect of folic acid and B vitamins on risk of cardiovascular events and total mortality among women at high risk for cardiovascular disease: a randomized trial. JAMA 2008;299(17):2027-36.

Bassuk SS, Albert CM, Cook NR, Zaharris E, MacFadyen JG, Danielson E, et al. The Women's Antioxidant Cardiovascular Study: design and baseline characteristics of participants. Journal of Women's Health 2004;13:99-117.

* Kang JH, Cook NR, Manson JE, Buring JE, Albert CM, Grodstein F. Vitamin E, vitamin C, beta carotene, and cognitive function among women with or at risk of cardiovascular disease: the Women's Antioxidant and Cardiovascular Study. Circulation 2009;119(21):2772-80. [PUBMED: 19451353]

Manson JE, Gaziano JM, Spelsberg A, Ridker PM, Cook NR, Buring JE, et al: WACS Research Group. A secondary prevention trial of antioxidant vitamins and cardiovascular disease in women. Rationale, design, and methods. Annals of Epidemiology 1995;5(4):261-9.

\section{Kesse-Guyot 2011 \{published data only\}}

Hercberg S, Galan P, Preziosi P, Bertrais S, Mennen L, Malvy D, et al. The SU.VI.MAX Study: a randomized, placebo-controlled trial of the health effects of antioxidant vitamins and minerals. Archives of Internal Medicine 2004;164(21):2335-42.
Hercberg S, Preziosi P, Briançon S, Galan P, Triol I, Malvy D, et al. A primary prevention trial using nutritional doses of antioxidant vitamins and minerals in cardiovascular diseases and cancers in a general population: the SU.VI.MAX study design, methods, and participant characteristics. Controlled Clinical Trials 1998;19(4):336-51.

* Kesse-Guyot E, Fezeu L, Jeandel C, Ferry M, Andreeva V, Amieva $\mathrm{H}$, et al. French adults' cognitive performance after daily supplementation with antioxidant vitamins and minerals at nutritional doses: a post hoc analysis of the Supplementation in Vitamins and Mineral Antioxidants (SU.VI.MAX) trial. American Journal of Clinical Nutrition 2011;94:892-9.

\section{Kryscio 2017 \{published data only\}}

Abner E, Schmitt F, Caban AH, Dennis B, Mathews M, Cooper G, et al. Dual cognitive screening for dementia: preliminary case ascertainment in the antioxidant Alzheimer's prevention (PREADVISE) trial. Alzheimer's \& Dementia 2012;8(4 suppl):P144. [DOI: 10.1016/j.jalz.2012.05.385]

* Kryscio RJ, Abner EL, Caban-Holt A, Lovell M, Goodman P, Darke AK, et al. Association of antioxidant supplement use and dementia in the prevention of Alzheimer's disease by vitamin E and selenium trial (PREADVISE). JAMA Neurology 2017;74(5):567-73.

Kryscio RJ, Abner EL, Schmitt FA, Goodman PJ, Mendiondo M, Caban-Holt A, et al. A randomized controlled Alzheimer's disease prevention trial's evolution into an exposure trial: the PREADViSE trial. Journal of Nutrition, Health \& Aging 2013;17(1):72-5. [PUBMED: 23299383]

\section{Lewerin 2005 \{published data only\}}

* Lewerin C, Matousek M, Steen G, Johansson B, Steen B, Nilsson-Ehle H. Significant correlations of plasma homocysteine and serum methylmalonic acid with movement and cognitive performance in elderly subjects but no improvement from short-term vitamin therapy: a placebo-controlled randomized study. American Journal of Clinical Nutrition 2005;81:1155-62.

Lewerin C, Nilsson-Ehle H, Matousek M, Lindstedt G, Steen B. Reduction of plasma homocysteine and serum methylmalonate concentrations in apparently healthy elderly subjects after treatment with folic acid, vitamin B12 and vitamin B6: a randomised trial. European Journal of Clinical Nutrition 2003;57(11):1426-36.

\section{Maylor 2006 \{published data only\}}

Andriollo-Sanchez M, Hininger-Favier I, Meunier N, Toti E, Zaccaria M, Brandolini-Bunlon M, et al. Zinc intake and status in middle-aged and older European subjects: the ZENITH study. European Journal of Clinical Nutrition 2005;59(Suppl 2):S37-41. [DOI: 10.1038/sj.ejcn.1602296]

Coudray C, O'Connor JM, Maiani G, Cashman KD, Simpson EE, Secker DL, et al. Introduction to the ZENITH study and summary of baseline results. European Journal of Clinical Nutrition 2005;59(Suppl 2):S5-7.

* Maylor EA, Simpson EEA, Secker DL, Meunier N, AndriolloSanchez M, Polito A, et al. Effects of zinc supplementation on 
cognitive function in healthy middle-aged and older adults: the ZENITH study. British Journal of Nutrition 2006;96:752-60.

Simpson EE, Maylor EA, McConville C, Stewart-Knox B, Meunier N, Andriollo-Sanchez M, et al. Mood and cognition in healthy older European adults: the Zenith study. BMC Psychology 2014;2(1):11.

Simpson EE, Maylor EA, Rae G, Meunier N, Andriollo-Sanchez M, Catasta G, et al. Cognitive function in healthy older European adults: the ZENITH study. European Journal of Clinical Nutrition 2005;59(2 Suppl 2):S26-S30.

\section{McMahon 2006 \{published data only\}}

Anonymous. Homocysteine and cognitive function in healthy elderly people. Brown University Geriatric Psychopharmacology Update 2006;10(11):4-5.

Cacabelos R. Homocysteine and cognition: from Galenic dogmatism to genetic relativism. Aging Health 2006;2:783-6.

Clarke R. Vitamin B12, folic acid, and the prevention of dementia. New England Journal of Medicine 2006;354(26):2817-9.

* McMahon JA, Green TJ, Skeaff CM, Knight RG, Mann JI, Williams SM. A controlled trial of homocysteine lowering and cognitive performance. New England Journal of Medicine 2006;354:2764-72.

\section{MRC/BHF 2002 \{published data only\}}

* Heart Protection Study Collaborative Group. MRC/BHF Heart Protection Study of antioxidant vitamin supplementation in 20,536 high-risk individuals: a randomised placebo-controlled trial. Lancet 2002;360(9326):23-33.

Heart Protection Study Collaborative Group. MRC/BHF Heart Protection Study of cholesterol-lowering therapy and of antioxidant vitamin supplementation in a wide range of patients at increased risk of coronary heart disease death: early safety and efficacy experience. European Heart Journal 1999;20:725-41.

\section{Rossom 2012 \{published data only\}}

Jackson RD, LaCroix AZ, Gass M, Wallace RB, Robbins J, Lewis $C E$, et al. Calcium plus vitamin $D$ supplementation and the risk of fractures. New England journal of medicine 2006;354(7):669-83.

* Rossom RC, Espeland MA, Manson JE, Dysken MW, Johnson KC, Lane DS, et al. Calcium and vitamin D supplementation and cognitive impairment in the Women's Health Initiative. Journal of the American Geriatrics Society 2012;60:2197-205

\section{SEARCH 2010 \{published data only\}}

Armitage J, Browman L, Bulbulia R, Collins R, Haynes R, Parish S. SEARCH data analysis plan [SEARCH: Study of the Effectiveness of Additional Reductions in Cholesterol and Homocysteine]. ctsu.ox.ac.uk/research/search (accessed 31 December 2017).
Armitage J, Browman L, Bulbulia R, Collins R, Haynes R, Parish S. SEARCH study protocol [SEARCH: study of the effectiveness of additional reductions in cholesterol and homocysteine]. ctsu.ox.ac.uk/research/search (accessed 31 December 2017)

* SEARCH Collaborative Group. Effects of homocysteinelowering with folic acid plus vitamin B12 vs placebo on mortality and major morbidity in myocardial infarction survivors. JAMA 2010;303(24):2486-94.

SEARCH Study Collaborative Group. Study of the effectiveness of additional reductions in cholesterol and homocysteine (SEARCH): characteristics of a randomized trial among 12,064 myocardial infarction survivors. American Heart Journal 2007; 154:815-23.

\section{Stott 2005 \{published data only\}}

Stott DJ, MacIntosh G, Lowe GD, Rumley A, McMahon AD, Langhorne $P$, et al. Randomized controlled trial of homocysteine-lowering vitamin treatment in elderly patients with vascular disease. American Journal of Clinical Nutrition 2005;82(6):1320-6. [PUBMED: 16332666]

\section{Toole 2004 \{published data only\}}

Spence JD, Howard VJ, Chambless LE, Malinow MR, Pettigrew LC, Stampfer M, et al. Vitamin Intervention for stroke prevention (VISP) trial: rationale and design. Neuroepidemiology 2001;20(1):16-25.

* Toole JF, Malinow MR, Chambless LE, Spence JD, Pettigrew LC, Howard VJ, et al. Lowering homocysteine in patients with ischemic stroke to prevent recurrent stroke, myocardial infarction, and death. JAMA 2004;291:565-75.

\section{Van der Zwaluw 2014 \{published data only\}}

Van Wijngaarden J, Dhonukshe-Rutten R, Vaes A, Brouwer E, Enneman A, Swart K, et al. Vitamin B12 and folate intake, homocysteine levels and their association with cognitive functioning in Dutch elderly people. European Geriatric Medicine 2011;2(Suppl 1):S5-6.

Van der Zwaluw N, Van Wijngaarden J, Dhonukshe-Rutten R, Brouwer-Brolsma E, In 't Veld P, Kessels R, et al. The impact of $2 y$ b-vitamin supplementation on cognitive performance: the b-proof study. Alzheimer's \& Dementia 2013;9(4 Suppl):P880-1. [DOI: doi.org/10.1016/j.jalz.2013.08.228]

* Van der Zwaluw NL, Dhonukshe-Rutten RA, Van Wijngaarden JP, Brouwer-Brolsma EM, Van de Rest O, in 't veld $\mathrm{PH}$, et al. Results of 2-year vitamin B treatment on cognitive performance: secondary data from an RCT. Neurology 2014;83:2158-66.

\section{Walker 2012 \{published data only\}}

NCT00214682. Beyond Ageing Project: a study for the prevention of depression [Beyond Ageing Project: a RCT to assess the benefit of improving mental health literacy as well as the effect of folate and B12, and physical activity, in preventing major depression and cognitive decline among older Australians]. clinicaltrials.gov/show/NCT00214682 (first received 22 September 2005). 
* Walker JG, Batterham PJ, Mackinnon AJ, Jorm AF, Hickie I, Fenech M, et al. Oral folic acid and vitamin B-12 supplementation to prevent cognitive decline in communitydwelling older adults with depressive symptoms - the Beyond Ageing Project: a randomized controlled trial. American Journal of Clinical Nutrition 2012;95(1):194-203. [PUBMED: 22170358]

Walker JG, Mackinnon AJ, Batterham P, Jorm AF, Hickie I, McCarthy $A$, et al. Mental health literacy, folic acid and vitamin $B 12$, and physical activity for the prevention of depression in older adults: randomised controlled trial. British Journal of Psychiatry 2010;197(1):45-54.

\section{Wolters 2005 \{published data only\}}

Wolters M, Hickstein M, Flintermann A, Tewes U, Hahn A. Cognitive performance in relation to vitamin status in healthy elderly German women - the effect of 6-month multivitamin supplementation. Preventive Medicine 2005;41:253-9.

\section{Yaffe 2004 \{published data only\}}

Clemons TE, Rankin MW, McBee WL. Cognitive impairment in the Age-Related Eye Disease Study: AREDS report no. 16. Archives of Ophthalmology 2006;124(4):537-43.

Yaffe K, Clemons TE, McBee WL, Lindblad AS, Bressler SB. $A$ randomized, controlled trial of antioxidants and zinc and the impact on cognition in the elderly: the AREDS ancillary trial. Annals of Neurology 2003;54(Suppl 7):S28-9. [DOI: doi.org/10.1002/ana.5051]

* Yaffe K, Clemons TE, McBee WL, Lindblad AS, Age-Related Eye Disease Study Research Group. Impact of antioxidants, zinc, and copper on cognition in the elderly - a randomized, controlled trial. Neurology 2004;63:1705-7.

\section{References to studies excluded from this review}

\section{Abbasi 2013 \{published data only\}}

Abbasi B, Kimiagar M, Shahidi S, Shirazi MM, Sadeghniiat K, Payab M, et al. Effect of magnesium supplementation on mental health in elderly subjects with insomnia: a doubleblind randomized clinical trial. Iranian Journal of Psychiatry and Clinical Psychology 2013;19:9-19.

\section{ACTRN12607000321448 \{published data only\}}

ACTRN12607000321448. Vitamin D and Cognition Trial [Vitamin D and Cognition Trial (VITA-D). A randomised, placebo controlled trial of vitamin $D$ in older adults with mild cognitive impairment and low vitamin D concentration to prevent cognitive decline and delay progression of cognitive decline]. anzctr.org.au/Trial/Registration/TrialReview.aspx?id=82086 (first received 13 June 2007).

\section{Alavi 2014 \{published data only\}}

Alavi N, Elmadfa I, Djazayery A, Barekatain M, Aghaye G, Djalali $M$, et al. The effect of antioxidant vitamins $E$ and $C$ on cognitive performance of the elderly with mild cognitive impairment in Isfahan, Iran: a double-blind, randomized, placebo-controlled trial. European Journal of Nutrition 2014;53:1255-62.

\section{Almeida 2010 \{published data only\}}

Almeida OP, Marsh K, Alfonso H, Flicker L, Davis TM, Hankey GJ. B-vitamins reduce the long-term risk of depression after stroke: the VITATOPS-DEP trial. Annals of Neurology 2010;68:503-10.

\section{Anonymous 2003 \{published and unpublished data\}}

Anonymous. Effect of vitamins and aspirin on markers of platelet activation, oxidative stress and homocysteine in people at high risk of dementia. Journal of Internal Medicine 2003;354:67-75.

\section{Arwert 2003 \{published data only\}}

Arwert LI, Deijen JB, Drent ML. Effects of an oral mixture containing glycine, glutamine and niacin on memory, $\mathrm{GH}$ and IGF-I secretion in middle-aged and elderly subjects. Nutritional Neuroscience 2003;6:269-75.

\section{Benton 1995 \{published data only\}}

Benton D, Fordy J, Haller J. The impact of long-term vitamin supplementation on cognitive functioning. Psychopharmacology 1995;117:298-305.

\section{Bryan 2002 \{published data only\}}

Bryan J, Calvaresi E, Hughes D. Short-term folate, vitamin B-12 or vitamin B-6 supplementation slightly affects memory performance but not mood in women of various ages. Journal of Nutrition 2002;132:1345-56.

\section{Chan 2010 \{published data only\}}

Chan A, Remington R, Kotyla E, Lepore A, Zemianek J, Shea TB. $A$ vitamin/nutriceutical formulation improves memory and cognitive performance in community-dwelling adults without dementia. Journal of Nutrition, Health \& Aging 2010;14:224-30.

\section{Cheng 2016 \{published data only\}}

Cheng D, Kong H, Pang W, Yang H, Lu H, Huang C, et al. B vitamin supplementation improves cognitive function in the middle aged and elderly with hyperhomocysteinaemia. Nutritional Neuroscience 2016;19(10):461-6.

\section{Chew 2015 \{published data only\}}

Chew EY, Clemons TE, Agrón E, Launer LJ, Grodstein F, Bernstein PS, et al. Effect of Omega-3 fatty acids, Lutein/ Zeaxanthin, or other nutrient supplementation on cognitive function: the AREDS2 randomized clinical trial. JAMA 2015;314(8):791-801. [DOI: 10.1001/jama.2015.9677]

\section{Corless 1987 \{published data only\}}

Corless D, Ellis M, Dawson E, Fraser F, Evans S, Perry JD, et al. Using activities of daily living assessments to measure the effectiveness of vitamin D supplements in elderly long-stay patients. British Journal of Occupational Therapy 1987;50:60-2.

\section{De Jager 2012 \{published data only\}}

De Jager CA, Oulhaj A, Jacoby R, Refsum H, Smith AD. Cognitive and clinical outcomes of homocysteine-lowering B-vitamin treatment in mild cognitive impairment: a randomized controlled trial. International Journal of Geriatric Psychiatry 2012;27:592-600. 
Douaud G, Refsum H, De Jager CA, Jacoby R, Nichols TE, Smith SM, et al. Preventing Alzheimer's disease-related gray matter atrophy by B-vitamin treatment. PNAS Proceedings of the National Academy of Sciences of the United States of America 2013;110:9523-8.

Smith AD, Smith SM, De Jager CA, Whitbread P, Johnston C, Agacinski $G$, et al. Homocysteine-lowering by $B$ vitamins slows the rate of accelerated brain atrophy in mild cognitive impairment: a randomized controlled trial. PLOS One 2010;5:e12244.

\section{Dhesi 2004 \{published data only\}}

Dhesi J, Jackson S, Bearne L, Moniz C, Hurley M, Swift CG, et al. Vitamin D supplementation improves neuromuscular function in older people who fall. Age and Ageing 2004;33(6):589-95.

\section{Flicker 2011 \{published data only\}}

Flicker L, Greenop K, Almeida O, Beer C, Hill K, Nowson C, et al. Effect of vitamin d supplementation on cognitive function in older adults with mild cognitive impairment - a randomized trial. Journal of bone and mineral research 2011;26(1 suppl):S244. [DOI: 10.1111/j.1741-6612.2010.00523a.x]

\section{Ford 2008 \{published data only\}}

Ford AH, Flicker L, Thomas J, Norman P, Jamrozik K, Almeida OP. Vitamins B12, B6, and folic acid for onset of depressive symptoms in older men: results from a 2-year placebo-controlled randomized trial. Journal of Clinical Psychiatry 2008;69:1203-9.

\section{Harris 2015 \{published data only\}}

Harris E, Macpherson H, Pipingas A. Improved blood biomarkers but no cognitive effects from 16 weeks of multivitamin supplementation in healthy older adults. Nutrients 2015;7:3796-812.

\section{Hvas 2004 \{published data only\}}

Hvas AM, Juul S, Lauritzen L, Nexo E, Ellegaard J. No effect of vitamin B-12 treatment on cognitive function and depression: a randomized placebo controlled study. Journal of Affective Disorders 2004;81:269-73.

\section{Imaoka 2016 \{published data only\}}

Imaoka M, Higuchi Y, Todo E, Kitagwa T, Ueda T. Low-frequency exercise and vitamin D supplementation reduce falls among institutionalized frail elderly. International Journal of Gerontology 2016;10:202-6.

\section{Krikorian 2010 \{published data only\}}

Krikorian R, Eliassen JC, Boespflug EL, Nash TA, Shidler MD. Improved cognitive-cerebral function in older adults with chromium supplementation. Nutritional Neuroscience 2010;13:116-22.

\section{Kwok 2017 \{published data only\}}

Kwok T, Lee J, Ma R, Wong S, Kung K, Lam A, et al. A randomized placebo controlled trial of vitamin B12 supplementation to prevent cognitive decline in older diabetic people with borderline low serum vitamin B12. Clinical Nutrition 2017;36(6):1509-15. [DOI: 10.1016/j.clnu.2016.10.018]

\section{Li 2015 \{published data only\}}

* Li Y, Liu S, Man Y, Li N, Zhou Y. Effects of vitamins E and $\mathrm{C}$ combined with beta-carotene on cognitive function in the elderly. Experimental and Therapeutic Medicine 2015;9(4):1489-93.

Ma A, Li Y, Han X, Sun Y. Effect of beta-carotene, vitamin E and ascorbic acid supplementation on improving cognitive function in the old people. FASEB Journal 2007;21(6):A1072.

\section{Liu 2015 \{published data only\}}

Liu X, Shi M, Xia F, Han J, Liu Z, Wang B, et al. The China Stroke Secondary Prevention Trial (CSSPT) protocol: a double-blinded, randomized, controlled trial of combined folic acid and $B$ vitamins for secondary prevention of stroke. International Journal of Stroke 2015;10:264-8.

\section{Loriaux 1985 \{published data only\}}

Loriaux SM, Deijen JB, Orlebeke JF, De Swart JH. The effects of nicotinic acid and xanthinol nicotinate on human memory. Psychopharmacology 1985;87:390-5.

\section{Macpherson 2012 \{published data only\}}

* Macpherson H, Ellis KA, Sali A, Pipingas A. Memory improvements in elderly women following 16 weeks treatment with a combined multivitamin, mineral and herbal supplement: a randomized controlled trial. Psychopharmacology 2012;220:351-65.

Macpherson H, Pipingas A, Ellis K. Can taking a daily multivitamin improve cognitive performance in the elderly? Evidence from a steady state visually evoked potential investigation of memory in elderly women. International Journal of Psychophysiology 2010;77:239-87.

\section{Maniam 2004 \{published data only\}}

Maniam J, Krishnaswamy S, Mohame J. Randomized double blind placebo controlled human clinical trial investigating effect of 1200iu a-tocopherol on lipid peroxidation, antioxidant status and cognitive function of elderly. Free Radical Biology \& Medicine 2004;36:S146.

\section{McNeill 2007 \{published data only\}}

McNeill G, Avenell A, Campbell MK, Cook JA, Hannaford PC, Kilonzo MM, et al. Effect of multivitamin and multimineral supplementation on cognitive function in men and women aged 65 years and over: a randomised controlled trial. Nutrition Journal 2007;6:10.

\section{Miller 2016 \{published data only\}}

Miller B, Whisner C, Johnston C. Vitamin D supplementation appears to increase plasma $A \beta 40$ in vitamin $D$ insufficient older adults: a pilot randomized controlled trial. Journal of Alzheimer's Disease 2016;52:843-7.

\section{Murray-Kolb 2011 \{published data only\}}

Murray-Kolb LE, Wenger MJ, Venkatramanan S, Marquis GS, Wesley AS, Haas JD. Effects of double-fortified salt on perceptual and cognitive performance in women. FASEB Journal 2011;25(1 suppl):238.6. 


\section{NCT00903695 \{published data only\}}

NCT00903695. MemoryXL effects on mild cognitive impairment patients [Nutriceutical effects on cognitive status in mild cognitive impairment patients]. clinicaltrials.gov/show/ NCT00903695 (first received 18 May 2009).

NCT01095211 \{published data only\}

NCT01095211. B-vitamins treatment for improvement of cognitive function [Effect of B-vitamins on cognitive function in elderly people]. clinicaltrials.gov/show/NCT01095211 (first received 30 March 2010).

\section{NCT01708005 \{published data only\}}

NCT01708005. Dietary supplements, executive functions and vitamin D (DIET-D) [Dietary supplements, executive functions and vitamin D (DIET-D): a double-blind randomized controlled trial]. clinicaltrials.gov/show/NCT01708005 (first received 16 October 2012).

\section{NCT02185222 \{published data only\}}

NCT02185222. Effect of vitamin D on cognitive decline of patients with memory complaint (D-COG) [Effect of vitamin $D$ on cognitive decline of patients with memory complaint]. clinicaltrials.gov/show/NCT02185222 (first received 9 July 2014).

\section{NCT02467153 \{published data only\}}

NCT02467153. Vitamin D and resistance exercise training; effects on musculoskeletal health in frail older men and women (EXVITD) [Influence of combined vitamin D supplementation and resistance exercise training on musculoskeletal health in frail older men and women (EXVITD)]. clinicaltrials.gov/show/ NCT02467153 (first received 9 June 2015).

\section{Ng 2017 \{published data only\}}

$\mathrm{Ng}$ T, Nyunt M, Feng L, Feng L, Niti M, Tan BY, et al. Multi-domain lifestyle interventions reduces depressive symptoms among frail and pre-frail older persons: randomized controlled trial. Journal of Nutrition, Health \& Aging 2017;21(8):918-26. [DOI: $10.1007 / \mathrm{s} 12603-016-0867-y]$

\section{Ong 2016 \{published data only\}}

Ong A, Weiler H, Wall M, Haddad R, Gorgui J, Daskalopoulou SS, et al. Feasibility of a clinical trial to assess the effect of dietary calcium v. supplemental calcium on vascular and bone markers in healthy postmenopausal women. British Journal of Nutrition 2016;116:104-14.

\section{Pase 2015 \{published data only\}}

Pase MP, Grima N, Cockerell R, Stough C, Scholey A, Sali A, et al. The effects of long-chain Omega- 3 fish oils and multivitamins on cognitive and cardiovascular function: a randomized, controlled clinical trial. Journal of the American College of Nutrition 2015;34:21-31.

Pathansali 2006 \{published data only\}

Pathansali R, Mangoni AA, Creagh-Brown B, Lan ZC, Ngow GL, Yuan XF, et al. Effects of folic acid supplementation on psychomotor performance and hemorheology in healthy elderly subjects. Archives of Gerontology and Geriatrics 2006;43:127-37.

\section{Petersen 2005 \{published data only\}}

Petersen RC, Thomas RG, Grundman M, Bennett D, Doody R, Ferris S, et al. Vitamin E and donepezil for the treatment of mild cognitive impairment. New England Journal of Medicine 2005;352:2379-88, 2465

\section{Pettersen 2017 \{published data only\}}

Pettersen J. Does high dose vitamin D supplementation enhance cognition?: a randomized trial in healthy adults. Experimental Gerontology 2017;90:90-7.

\section{Quick 2013 \{published data only\}}

Quick M, Kiefer D. Calcium plus vitamin D supplementation and cognitive decline in women. Integrative Medicine Alert 2013;16:30-4.

\section{Rietsema 2014 \{published data only\}}

Rietsema WJ. Unexpected recovery of moderate cognitive impairment on treatment with oral methylcobalamin. Journal of the American Geriatrics Society 2014;62:1611-2.

Schietzel 2016 \{published data only\}

Schietzel S, Brugger P, Fischer K, Meyer O, Freystaetter G, Meyer S, et al. Effect of high dose vitamin D on cognitive performance in healthy seniors - a randomized controlled trial. European Geriatric Medicine 2016;7(Suppl 1):71.

Smith 1999 \{published data only\}

Smith A, Clark R, Nutt D, Haller J, Hayward S, Perry K. Antioxidant vitamins and mental performance of the elderly. Human Psychopharmacology 1999;14:459-71.

\section{Summers 2010 \{published data only\}}

Summers WK, Martin RL, Cunningham M, Deboynton VL, Marsh GM. Complex antioxidant blend improves memory in community-dwelling seniors. Journal of Alzheimer's Disease 2010;19:429-39.

\section{Van Uffelen 2007 \{published data only\}}

Van Uffelen JG, Chinapaw MJ, Hopman-Rock M, Van Mechelen W. The effect of walking and vitamin B supplementation on quality of life in community-dwelling adults with mild cognitive impairment: a randomized, controlled trial. Quality of Life Research 2007;16:1137-46.

Van Uffelen JG, Chinapaw MJ, Van Mechelen W, HopmanRock M. Walking or vitamin B for cognition in older adults with mild cognitive impairment? A randomised controlled trial. British Journal of Sports Medicine 2008;42(5):344-51.

\section{Wouters-Wesseling 2005 \{published data only\}}

Wouters-Wesseling W, Wagenaar LW, Rozendaal M, Deijen JB, De Groot LC, Bindels JG, et al. Effect of an enriched drink on cognitive function in frail elderly persons. Journals of Gerontology 2005;60A:265-70. 


\section{References to studies awaiting assessment}

Sanchez 2011 \{published data only\}

* Sanchez H, Albala C, Lera L, Castillo JL, Verdugo R, Lavados M, et al. Comparison of two modes of vitamin B12 supplementation on neuroconduction and cognitive function among older people living in Santiago, Chile: a cluster randomized controlled trial. A study protocol. Nutrition Journal 2011;10:100. [PUBMED: 21952034]

\section{Additional references}

\section{Amanullah 2010}

Amanullah S, Seeber C. Niacin deficiency resulting in neuropsychiatric symptoms: a case study and review of literature. Clinical Neuropsychiatry 2010;7(1):10-4.

\section{Anderson 1997}

Anderson RA, Cheng N, Bryden NA, Polansky MM, Cheng N, $\mathrm{Chi} \mathrm{J}$, et al. Elevated intakes of supplemental chromium improve glucose and insulin variables in individuals with type 2 diabetes. Diabetes 1997;46(11):1786-91.

\section{Bath 2013a}

Bath SC, Rayman MP. Iodine deficiency in the U.K.: an overlooked cause of impaired neurodevelopment?. Proceedings of the Nutrition Society 2013; Vol. 72, issue 2:226-35.

\section{Bath 2013b}

Bath SC, Steer CD, Golding J, Emmett P, Rayman MP. Effect of inadequate iodine status in UK pregnant women on cognitive outcomes in their children: results from the Avon Longitudinal Study of Parents and Children (ALSPAC). Lancet 2013;382(9889):331-7.

\section{Behl 1992}

Behl C, Davis J, Cole GM, Schubert D. Vitamin E protects nerve cells from amyloid beta protein toxicity. Biochemical and Biophysical Research Communications 1992;186(2):944-50.

\section{Bennett 2009}

Bennett S, Grant MM, Aldred S. Oxidative stress in vascular dementia and Alzheimer's disease: a common pathology. Journal of Alzheimer's Disease 2009;17(2):245-57.

\section{Berr 2012}

Berr C, Arnaud J, Akbaraly TN. Selenium and cognitive impairment: a brief-review based on results from the EVA study. BioFactors 2012;38(2):139-44.

\section{Bjelakovic 2012}

Bjelakovic G, Nikolova D, Gluud LL, Simonetti RG, Gluud C. Antioxidant supplements for prevention of mortality in healthy participants and patients with various diseases. Cochrane Database of Systematic Reviews 2012, Issue 3. [DOI: 10.1002/14651858.CD007176.pub2]

\section{Borchardt 1999}

Borchardt T, Camakaris J, Cappai R, Masters CL, Beyreuther K, Multhaup G. Copper inhibits beta-amyloid production and stimulates the non-amyloidogenic pathway of amyloid- precursor-protein secretion. Biochemical Journal 1999;344 Pt 2:461-7. [PUBMED: 10567229]

\section{Brigelius-Flohe 2007}

Brigelius-Flohe, R. Adverse effects of vitamin E by induction of drug metabolism. Genes \& Nutrition 2007;2(3):249-56.

\section{Bruner 1996}

Bruner AB, Joffe A, Duggan AK, Casella J F, Brandt J. Randomised study of cognitive effects of iron supplementation in non-anaemic iron-deficient adolescent girls. Lancet 1996;348(9033):992-6.

\section{Centers for Disease Control and Prevention 2014}

Centers for Disease Control and Prevention. Vitamins and minerals. cdc.gov/nutrition/everyone/basics/vitamins/ index.html (accessed before 15 June 2015).

\section{Christensen 2013}

Christensen K, Thinggaard M, Oksuzyan A, Steenstrup T, Andersen-Ranberg K, Jeune $B$, et al. Physical and cognitive functioning of people older than 90 years: a comparison of two Danish cohorts born 10 years apart. Lancet 2013;382(9903):1507-13.

\section{Clarke 2007a}

Clarke R. Homocysteine, B vitamins, and the risk of dementia American Journal of Clinical Nutrition 2007;85(2):329-30.

\section{Clarke 2007b}

Clarke R, Birks J, Nexo E, Ueland PM, Schneede J, Scott J, et al. Low vitamin B-12 status and risk of cognitive decline in older adults. American Journal of Clinical Nutrition 2007;86(5):1384-91.

\section{Clarke 2014}

Clarke R, Bennett D, Parish S, Lewington S, Skeaff M, Eussen SJ, et al. Effects of homocysteine lowering with $B$ vitamins on cognitive aging: meta-analysis of 11 trials with cognitive data on 22,000 individuals. American Journal of Clinical Nutrition 2014;100:657-66.

\section{Da Costa 2012}

Da Costa BR, Nüesch E, Reichenbach S, Juni P, Rutjes AW. Doxycycline for osteoarthritis of the knee or hip. Cochrane Database of Systematic Reviews 2012, Issue 11. [DOI: 10.1002/14651858.CD007323.pub3]

\section{Da Costa 2014}

Da Costa BR, Nüesch E, Kasteler R, Husni E, Welch V, Rutjes AW, et al. Oral or transdermal opioids for osteoarthritis of the knee or hip. Cochrane Database of Systematic Reviews 2014, Issue 9. [DOI: 10.1002/14651858.CD003115.pub4]

\section{Delage 2014}

Delage B. Minerals: calcium. Ipi.oregonstate.edu/mic/minerals/ calcium (accessed 21 September 2015).

\section{DeLuca 1975}

DeLuca HF. Function of the fat-soluble vitamins. American Journal of Clinical Nutrition 1975;28(4):339-45. 


\section{Denton 2015}

Denton DA, Abraham RP, Al-Assaf AS, Rutjes AW, Chong LY, Al-Assaf AS, et al. Vitamin and mineral supplementation for maintaining cognitive function in cognitively healthy people in mid life. Cochrane Database of Systematic Reviews 2015, Issue 10. [DOI: 10.1002/14651858.CD011904]

\section{Depp 2012}

Depp CA, Harmell A, Vahia IV. Successful cognitive aging. Current Topics in Behavioral Neurosciences 2012;10:35-50. [PUBMED: 22275006]

\section{DerSimonian 1986}

DerSimonian R, Laird N. Meta-analysis in clinical trials. Controlled Clinical Trials 1986;7(3):177-88. [PUBMED: 3802833]

\section{Dolphin 2012}

Dolphin AC. Calcium channel auxiliary $\alpha 2 \delta$ and $\beta$ subunits: trafficking and one step beyond. Nature Reviews Neuroscience 2012;13(8):542-5.

\section{Duara 2011}

Duara R, Loewenstein DA, Greig MT, Potter E, Barker W, Raj A, et al. Pre- $\mathrm{MCl}$ and $\mathrm{MCl}$ : neuropsychological, clinical, and imaging features and progression rates. American Journal of Geriatric Psychiatry 2011;19(11):951-60. [PUBMED: 21422909]

\section{Ferland 2012}

Ferland G. Vitamin K, an emerging nutrient in brain function. BioFactors 2012;38(2):151-7.

\section{Ferland 2013}

Ferland G, Presse N, Belleville S, Gaudreau P, Greenwood CE, Kergoat MJ, et al. Vitamin $\mathrm{K}$ and cognitive function in healthy older adults. The NuAge study. FASEB Journal 2013;27(Suppl):840.13.

\section{Guyatt 2008}

Guyatt GH, Oxman AD, Vist GE, Kunz R, Falck-Ytter Y, AlonsoCoello $P$, et al. GRADE: an emerging consensus on rating quality of evidence and strength of recommendations. $B M J$ 2008;336(7650):924-6. [PUBMED: 18436948]

\section{Hendrie 2006}

Hendrie HC, Albert MS, Butters MA, Gao S, Knopman DS, Launer LJ, et al. The NIH Cognitive and Emotional Health Project. Report of the critical evaluation study committee. Alzheimer's \& Dementia 2006;2(1):12-32. [PUBMED: 19595852]

\section{Higgins 2003}

Higgins JP, Thompson SG, Deeks JJ, Altman DG. Measuring inconsistency in meta-analyses. BMJ 2003;327(7414):557-60.

\section{Higgins 2011}

Higgins JPT, Green S, editor(s). Cochrane Handbook for Systematic Reviews of Interventions Version 5.1.0 (updated March 2011). The Cochrane Collaboration, 2011. Available from handbook.cochrane.org.

\section{Institute of Medicine 2011}

Pillsbury L (ed), Institute of Medicine (US) Committee on Nutrition Trauma and the Brain. Nutrition and Traumatic Brain Injury: Improving Acute and Subacute Health Outcomes in Military Personnel. Washington DC (USA): National Academies Press (US), 2011.

\section{Jeandel 1989}

Jeandel C, Nicolas MB, Dubois F, Nabet-Belleville F, Penin F, Cuny $G$. Lipid peroxidation and free radical scavengers in Alzheimer's disease. Gerontology 1989;35(5-):275-82.

\section{Jellinger 2006}

Jellinger KA. Clinicopathological analysis of dementia disorders in the elderly - an update. Journal of Alzheimer's Disease 2006;9(3 Suppl):61-70. [PUBMED: 16914845]

\section{Kaden 2011}

Kaden D, Bush Al, Danzeisen R, Bayer TA, Multhaup G. Disturbed copper bioavailability in Alzheimer's disease. International Journal of Alzheimer's Disease 2011:345614. [DOI: $10.4061 / 2011 / 345614]$

\section{Kelly 2011}

Kelly GS. Pantothenic acid. Alternative Medicine Review 2011;16(3):263-74.

\section{Kennedy 2011}

Kennedy DO, Haskell CF. Vitamins and cognition: what is the evidence?. Drugs 2011;71(15):1957-71.

\section{Kühnast 2013}

Kuhnast S, Louwe MC, Heemskerk MM, Pieterman EJ, Van Klinken J B, Van den Berg SA, et al. Niacin reduces atherosclerosis development in APOE*3Leiden.CETP mice mainly by reducing nonHDL-cholesterol. PLOS One 2013;8(6):e66467.

\section{Langlais 1995}

Langlais PJ, Savage LM. Thiamine deficiency in rats produces cognitive and memory deficits on spatial tasks that correlate with tissue loss in diencephalon, cortex and white matter. Behavioural Brain Research 1995;68(1):75-89.

\section{Launer 1999}

Launer LJ, Andersen K, Dewey ME, Letenneur L, Ott A, Amaducci LA, et al. EURODEM Incidence Research Group and Work Groups. Rates and risk factors for dementia and Alzheimer's disease: results from EURODEM pooled analyses. Neurology 1999;52(1):78-84.

\section{Lindsay 2002}

Lindsay J, Laurin D, Verreault R, Hebert R, Helliwell B, Hill GB, et al. Risk factors for Alzheimer's disease: a prospective analysis from the Canadian Study of Health and Aging. American Journal of Epidemiology 2002;156(5):445-53. [PUBMED: 12196314]

\section{Lourida 2013}

Lourida I, Soni M, Thompson-Coon J, Purandare N, Lang IA, Ukoumunne OC, et al. Mediterranean diet, cognitive 
function, and dementia: a systematic review. Epidemiology 2013;24(4):479-89. [PUBMED: 23680940]

\section{Matthews 2007}

Matthews FE, Stephan BC, Bond J, McKeith I, Brayne C. Operationalization of mild cognitive impairment: a graphical approach. PLOS Medicine 2007;4(10):1615-9. [PUBMED: 17973571]

\section{Matthews 2008}

Matthews FE, Stephan BC, McKeith IG, Bond J, Brayne C. Twoyear progression from mild cognitive impairment to dementia: to what extent do different definitions agree?. Journal of the American Geriatrics Society 2008;56(8):1424-33.

\section{Matthews 2013}

Matthews FE, Arthur A, Barnes LE, Bond J, Jagger C, Robinson L, et al. A two-decade comparison of prevalence of dementia in individuals aged 65 years and older from three geographical areas of England: results of the Cognitive Function and Ageing Study I and II. Lancet 2013;382(9902):1405-12. [PUBMED: 23871492]

\section{Mattson 2003}

Mattson MP, Shea TB. Folate and homocysteine metabolism in neural plasticity and neurodegenerative disorders. Trends in Neurosciences 2003;26(3):137-46.

\section{McCann 2008}

McCann JC, Ames BN. Is there convincing biological or behavioral evidence linking vitamin $D$ deficiency to brain dysfunction?. FASEB Journal 2008;22(4):982-1001.

\section{McCleery 2018}

McCleery J, Abraham RP, Denton DA, Rutjes AW, Chong LY, Al-Assaf AS, et al. Vitamin and mineral supplementation for preventing dementia or delaying cognitive decline in people with mild cognitive impairment. Cochrane Database of Systematic Reviews 2018, Issue 11. [DOI: 10.1002/14651858.CD011905.pub2]

\section{McCullagh 2001}

McCullagh CD, Craig D, Mcllroy SP, Passmore AP. Risk factors for dementia. Advances in Psychiatric Treatment 2001;7(1):24-31.

\section{Mehdi 2013}

Mehdi Y, Hornick JL, Istasse L, Dufrasne I. Selenium in the environment, metabolism and involvement in body functions. Molecules 2013;18(3):3292-311.

\section{Miller 2005}

Miller ER 3rd, Pastor-Barriuso R, Dalal D, Riemersma RA, Appel LJ, Guallar E. Meta-analysis: high-dosage vitamin E supplementation may increase all-cause mortality. Annals of Internal Medicine 2005;142(1):37-46.

\section{Mitchell 2009}

Mitchell AJ, Shiri-Feshki M. Rate of progression of mild cognitive impairment to dementia - meta-analysis of 41 robust inception cohort studies. Acta Psychiatrica Scandinavica 2009;119(4):252-65. [PUBMED: 19236314]

\section{Norton 2014}

Norton S, Matthews FE, Barnes DE, Yaffe K, Brayne C. Potential for primary prevention of Alzheimer's disease: an analysis of population-based data. Lancet Neurology 2014;13(8):788-94. [PUBMED: 25030513]

\section{Nüesch 2009a}

Nüesch E, Rutjes AW, Trelle S, Reichenbach S, Juni P. Doxycycline for osteoarthritis of the knee or hip. Cochrane Database of Systematic Reviews 2009, Issue 4. [DOI: 10.1002/14651858.CD007323.pub2; PUBMED: 19821404]

\section{O'Leary 2012}

O'Leary F, Allman-Farinelli M, Samman S. Vitamin $B_{12}$ status, cognitive decline and dementia: a systematic review of prospective cohort studies. British Journal of Nutrition 2012;108(11):1948-61.

\section{ODS 2014}

Office of Dietary Supplements (ODS). Dietary supplement fact sheet: vitamin B6. ods.od.nih.gov/factsheets/VitaminB6HealthProfessional (accessed prior to 25 November 2014).

\section{Ono 2012}

Ono K, Yamada M. Vitamin A and Alzheimer's disease. Geriatrics \& Gerontology International 2012;12(2):180-8.

\section{Osiezagha 2013}

Osiezagha K, Ali S, Freeman C, Barker NC, Jabeen S, Maitra S, et al. Thiamine deficiency and delirium. Innovations in Clinical Neuroscience 2013;10(4):26-32.

\section{Ozawa 2012}

Ozawa M, Ninomiya T, Ohara T, Hirakawa Y, Doi Y, Hata J, et al. Self-reported dietary intake of potassium, calcium, and magnesium and risk of dementia in the Japanese: the Hisayama Study. Journal of the American Geriatrics Society 2012;60(8):1515-20.

\section{Pawlak 2014}

Pawlak R, Lester SE, Babatunde T. The prevalence of cobalamin deficiency among vegetarians assessed by serum vitamin B12: a review of literature. European Journal of Clinical Nutrition 2014;68(5):541-8.

\section{Perrig 1997}

Perrig WJ, Perrig P, Stahelin HB. The relation between antioxidants and memory performance in the old and very old. Journal of the American Geriatrics Society 1997;45(6):718-24.

\section{Petersen 1999}

Petersen RC, Smith GE, Waring SC, Ivnik RJ, Tangalos EG, Kokmen E. Mild cognitive impairment: clinical characterization and outcome. Archives of Neurology 1999;56(3):303-8. [PUBMED: 10190820]

\section{Powell 2000}

Powell SR. The antioxidant properties of zinc. Journal of Nutrition 2000;130(5S Suppl):1447S-54S. 


\section{Powers 2003}

Powers HJ. Riboflavin (vitamin B-2) and health. American Journal of Clinical Nutrition 2003;77(6):1352-60.

\section{Preuss 1997}

Preuss HG, Grojec PL, Lieberman S, Anderson RA. Effects of different chromium compounds on blood pressure and lipid peroxidation in spontaneously hypertensive rats. Clinical Nephrology 1997;47(5):325-30.

\section{Prince 2014}

Prince M, Albanese E, Guerchet M, Prina M. The World Alzheimer Report 2014. Dementia and Risk Reduction: An Analysis of Protective and Modifiable Factors. London, UK: Alzheimer's Disease International (ADI), 2014.

\section{Przybelski 2007}

Przybelski RJ, Binkley NC. Is vitamin D important for preserving cognition? A positive correlation of serum 25 -hydroxyvitamin $D$ concentration with cognitive function. Archives of Biochemistry and Biophysics 2007;460(2):202-5.

\section{Rahman 2007}

Rahman K. Studies on free radicals, antioxidants, and cofactors. Clinical Interventions in Aging 2007;2(2):219-36.

\section{Reichenbach 2010}

Reichenbach S, Rutjes AW, Nüesch E, Trelle S, Jüni P. Joint lavage for osteoarthritis of the knee. Cochrane Database of Systematic Reviews 2010, Issue 5. [DOI: 10.1002/14651858.CD007320.pub2; PUBMED: 20464751]

\section{Review Manager 2014 [Computer program]}

Nordic Cochrane Centre, The Cochrane Collaboration. Review Manager 5 (RevMan 5). Version 5.3. Copenhagen: Nordic Cochrane Centre, The Cochrane Collaboration, 2014.

\section{Rutjes 2009a}

Rutjes AW, Nüesch E, Sterchi R, Kalichman L, Hendriks E, Osiri M, et al. Transcutaneous electrostimulation for osteoarthritis of the knee. Cochrane Database of Systematic Reviews 2009, Issue 4. [DOI: 10.1002/14651858.CD002823.pub2; PUBMED: 19821296]

\section{Rutjes 2009b}

Rutjes AW, Nuesch E, Reichenbach S, Juni P. S-

Adenosylmethionine for osteoarthritis of the knee or hip. Cochrane Database of Systematic Reviews 2009, Issue 4. [DOI: 10.1002/14651858.CD007321.pub2; PUBMED: 19821403]

\section{Rutjes 2010}

Rutjes AW, Nuesch E, Sterchi R, Juni P. Therapeutic ultrasound for osteoarthritis of the knee or hip. Cochrane Database of Systematic Reviews 2010, Issue 1. [DOI: 10.1002/14651858.CD003132.pub2; PUBMED: 20091539]

\section{Rutjes 2012}

Rutjes AW, Juni P, Da Costa BR, Trelle S, Nuesch E, Reichenbach S. Viscosupplementation for osteoarthritis of the knee: a systematic review and meta-analysis. Annals of Internal Medicine 2012;157(3):180-91. [PUBMED: 22868835]

\section{Rücker 2008}

Rücker G, Schwarzer G, Carpenter JR, Schumacher M. Undue reliance on $\mathrm{I}^{2}$ in assessing heterogeneity may mislead. $B M C$ Medical Research Methodology 2008;8(1):79.

\section{Savva 2009}

Savva GM, Wharton SB, Ince PG, Forster G, Matthews FE, Brayne C. Age, neuropathology, and dementia. New England Journal of Medicine 2009;360(22):2302-9. [PUBMED: 1947442]

\section{Scott 2013}

Scott TM, Tucker KL. Low plasma vitamin B6 predicts cognitive decline and depression in at-risk individuals. FASEB Journal 2013;27:346.6.

\section{Smorgon 2004}

Smorgon C, Mari E, Atti AR, Dalla Nora E, Zamboni PF, Calzoni F, et al. Trace elements and cognitive impairment: an elderly cohort study. Archives of Gerontology and Geriatrics 2004; Vol. Suppl 9:393-402.

\section{Sodhi 2013}

Sodhi RK, Singh N. All-trans retinoic acid rescues memory deficits and neuropathological changes in mouse model of streptozotocin-induced dementia of Alzheimer's type. Progress in Neuro-Psychopharmacology \& Biological Psychiatry 2013;40:38-46.

\section{Sperling 2011}

Sperling RA, Aisen PS, Beckett LA, Bennett DA, Craft S, Fagan AM, et al. Toward defining the preclinical stages of Alzheimer's disease: recommendations from the National Institute on Aging and the Alzheimer's Association workgroup. Alzheimer's \& Dementia 2011;7(3):280-92.

\section{Spiegelhalter 2004}

Spiegelhalter DJ, Abrams KJ, Myles JP. Bayesian Approaches to Clinical Trials and Health-Care Evaluation. Chichester, UK: J Wiley, 2004.

\section{Stephan 2007}

Stephan BC, Matthews FE, McKeith IG, Bond J, Brayne C. Early cognitive change in the general population: how do different definitions work?. Journal of the American Geriatrics Society 2007;55(10):1534-40. [PUBMED: 17908056]

\section{Stephan 2013}

Stephan BCM, Minett T, Pagett E, Siervo M, Brayne C, McKeith IG. Diagnosing mild cognitive impairment $(\mathrm{MCl})$ in clinical trials: a systematic review. BMJ Open 2013;3(2):e001909. [PUBMED: 23386579]

\section{Van den Berg 2012}

Van den Berg S, Splaine M. Policy brief risk factors for dementia. alz.co.uk/sites/default/files/policy-brief-risk-factors-fordementia.pdf (accessed 19 September 2014).

\section{Van der Flier 2005}

Van der Flier WM, Scheltens P. Epidemiology and risk factors of dementia. Journal of Neurology, Neurosurgery, and Psychiatry 2005;76(Suppl 5):v2-v7. 


\section{Wang 2000}

Wang X, Quinn PJ. The location and function of vitamin $\mathrm{E}$ in membranes (review). Molecular Membrane Biology 2000;17(3):143-56.

\section{WHO 2012}

World Health Organization (WHO). Dementia: a Public Health Priority. Geneva, Switzerland: WHO, 2012. [ISBN 9789241564458]

CHARACTERISTICS OF STUDIES

Characteristics of included studies [ordered by study ID]

Anand 2011

\begin{tabular}{|c|c|}
\hline Methods & 2-arm, open-label RCT, with 3 months duration of treatment and follow-up. \\
\hline Participants & $\begin{array}{l}\text { Location: Ootacamund, Tamil Nadu India. Single centre } \\
\text { Recruitment: outpatient department, Government headquarters hospital, Ootacamund } \\
\text { Sample size: } \\
\text { - Number randomised: } 38 \text { in intervention, } 36 \text { in comparison } \\
\text { - Number completed: } 38 \text { in intervention, } 36 \text { in comparison } \\
\text { Participant baseline characteristics: } \\
\text { - Age: mean } 54.65 \pm 8.44 \text { intervention and } 56.61 \pm 8.17 \text { in comparison } \\
\text { - Total MMSE: } 25.16 \pm 0.66 \text { in intervention, } 25.3 \pm 0.37 \text { in comparison } \\
\text { - Gender: male/female } 15 / 23 \text { intervention and } 14 / 22 \text { in comparison } \\
\text { - Others: Most of the participants were from an economically deprived background, non-vegetarians. } \\
\text { Inclusion criteria: } \\
\text { - Type } 2 \text { diabetes with no comorbidities } \\
\text { - Age between } 35 \text { and } 65 \text { of either sex } \\
\text { - On oral hypoglycaemic agents (metformin, glibenclamide and combination) } \\
\text { - Duration of disease less than or equal to } 10 \text { years } \\
\text { - HbA1c > } 9 \% \\
\text { Exclusion criteria: } \\
\text { - Dementia } \\
\text { - Antidepressant therapy } \\
\text { - Type } 1 \text { diabetes } \\
\text { - Suvenile diabetes } \\
\text { Pregnancy/lactation } \\
\text { - }\end{array}$ \\
\hline
\end{tabular}

Interventions Intervention group ( $\mathbf{n}=\mathbf{3 8}$ ): vitamin E $600 \mathrm{mg}$ once daily for three months

Comparator group $(\mathbf{n}=\mathbf{3 6})$ : treatment-as-usual for three months

Treatment received by both groups: oral hypoglycaemic agents (glibenclamide $5 \mathrm{mg}$, metformin 500 $\mathrm{mg}$ ) for three months

Outcomes

Outcomes of interest in the review:

Vitamin and mineral supplementation for maintaining cognitive function in cognitively healthy people in mid and late life (Review) 44 Copyright @ 2019 The Cochrane Collaboration. Published by John Wiley \& Sons, Ltd. 


Funding Sources: "Nil".
Declarations of interest: none declared.
$\begin{aligned} & \text { Other: population was from a government hospital clinic in India and "most of the enrolled patients } \\ & \text { were coming under economically deprived background." }\end{aligned}$

\section{Risk of bias}

\begin{tabular}{|c|c|c|}
\hline Bias & Authors' judgement & Support for judgement \\
\hline $\begin{array}{l}\text { Random sequence genera- } \\
\text { tion (selection bias) }\end{array}$ & Low risk & $\begin{array}{l}\text { Quote: "Enrolled patients were randomized by using computer assisted ran- } \\
\text { domization procedure and assigned to control group and intervention group" } \\
\text { Comment: adequate generation of a randomised sequence }\end{array}$ \\
\hline $\begin{array}{l}\text { Allocation concealment } \\
\text { (selection bias) }\end{array}$ & Unclear risk & $\begin{array}{l}\text { Comment: no description of allocation concealment. The study was open-la- } \\
\text { bel. Unknown whether allocation for the next patient to be enrolled could be } \\
\text { known in advance. }\end{array}$ \\
\hline $\begin{array}{l}\text { Blinding of participants } \\
\text { and personnel (perfor- } \\
\text { mance bias) } \\
\text { All outcomes }\end{array}$ & High risk & $\begin{array}{l}\text { Quote: "open-label trial" } \\
\text { Comment: did not describe control group receiving placebo of Vitamin E. No } \\
\text { description of blinding and described as an 'open-label' study. }\end{array}$ \\
\hline $\begin{array}{l}\text { Blinding of outcome as- } \\
\text { sessment (detection bias) } \\
\text { All outcomes }\end{array}$ & High risk & $\begin{array}{l}\text { Comment: no description of measures used, if any, to blind personnel involved } \\
\text { in measuring outcomes. Since outcome measures depended on patient per- } \\
\text { formance, risk of bias was judged to be high. }\end{array}$ \\
\hline $\begin{array}{l}\text { Incomplete outcome data } \\
\text { (attrition bias) } \\
\text { All outcomes }\end{array}$ & Unclear risk & $\begin{array}{l}\text { Comment: There was no description of the completeness of outcome data for } \\
\text { each main outcome, nor of exclusions from the analysis. }\end{array}$ \\
\hline $\begin{array}{l}\text { Selective reporting (re- } \\
\text { porting bias) }\end{array}$ & Low risk & Comment: no evidence of selective reporting bias \\
\hline Other bias & Low risk & No other risk of bias detected. \\
\hline
\end{tabular}

Andreeva 2011

\begin{tabular}{ll} 
Methods & Multicentre, randomised, placebo-controlled, 2 x 2 factorial trial \\
& An ancillary study of SU.FOL.OM3 \\
\hline Participants & Main study took place from 2003-2009. Quote: "As part of the SU.FOL.OM3 assessment battery, the F- \\
TICS-m was administered during 2007-2009 only to participants who had completed 4 years of fol- \\
low-up." \\
Location: 257 participating centres in France \\
Recruitment: recruitment of subjects done through a network of 417 cardiologists and neurologists \\
from all over France, working either in general hospitals, independently or in rehabilitation centres. \\
Treatment with tablets at home. \\
Sample size: $\mathbf{1 8 8 1}$ participants were eligible for the cognitive study (had completed 4 years of fol- \\
low-up in main study); $\mathbf{1 7 4 8}$ completed the cognitive assessment.
\end{tabular}




\section{- Number randomised in SU.FOL.OM3:}

- 620 in group A (B vitamins and Omega-3 PUFA)

- 633 in group B (Omega-3 PUFA)

- 622 in group C (B vitamins)

- 626 in group D (placebo)

- Number completing cognitive study:

- 438 in group $A$ ( $B$ vitamins and Omega-3 PUFA)

- 439 in group B (Omega-3 PUFA)

- 446 in group C (B vitamins)

- 425 in group $D$ (placebo)

Group A (B Vitamins and Omega -3 PUFA) baseline characteristics:

- age $(\mathrm{y}): 61.6 \pm 8.8$

- gender, $\mathrm{n}(\%)$ female: 80 (18.3)

\section{Group B (Omega-3 PUFA) baseline characteristics:}

- age: $60.1 \pm 8.7$

- gender, $\mathrm{n}(\%)$ female: 88 (20.0)

\section{Group C (B vitamins) baseline characteristics:}

- age $(y): 61.4 \pm 8.7$

- gender, $n(\%)$ female: 93 (20.9)

\section{Group D (Placebo) baseline characteristics:}

- age $(y): 60.9 \pm 8.9$

- gender, $\mathrm{n}(\%)$ female: $96(22.6)$

\section{Inclusion criteria:}

Men and women aged 45-80 y with a recent (1-12 months prior to inclusion) myocardial infarction (MI), unstable angina, or ischaemic stroke were eligible for participation.

There was no diagnostic criterion used to detect dementia/cognitive impairment. Instead, participants were given the Issac's Set Test at baseline and results were stated as a Mean \pm SD.

\section{Exclusion criteria:}

Patients incapable of understanding the study protocol or who refused to sign the informed consent, patients with a pathology that might interfere with homocysteine or omega-3 fatty acid metabolism, in particular, those that use methotrexate for the treatment of a cancer or rheumatoid arthritis, chronic renal failure (plasma level of creatinine $>200 \mu \mathrm{mol} / \mathrm{L}$ or creatinine clearance $<40 \mathrm{~mL} / \mathrm{min}$ ), patients with a non-cardiovascular pathology with a suspected survival time less than the 5 years period of the study (solid cancer, evolved dementia, leukaemia) and patients taking B vitamins or omega-3 fatty acids. day. The supplements were provided in a package containing 53 blisters of $7 \times 2$ capsules, each corresponding to one week of both treatments. A year's supply was given at baseline and given again at each annual follow-up appointment for 5 years in total.

Group A (B vitamins and Omega-3 PUFA): 5-methyltetrahydrofolate (folate, $0.56 \mathrm{mg}$ ) and vitamins B6 (3 $\mathrm{mg})$ and $B 12(0.02 \mathrm{mg})$ and eicosapentaenoic and docosahexaenoic acids $(600 \mathrm{mg})$ in a 2:1 ratio

Group B (Omega-3 PUFA): eicosapentaenoic and docosahexaenoic acids (600 mg) in a 2:1 ratio 
Andreeva 2011 (Continued)

Group C (B Vitamins): 5-methyltetrahydrofolate (folate, $0.56 \mathrm{mg}$ ) and vitamins B6 (3 mg) and B12 (0.02 $\mathrm{mg})$

Group D (placebo): 2 placebo Capsules

Comparator group ( $\mathbf{n}=\mathbf{4 2 5}$ ): 2 placebo tablets given once daily. The placebo capsules looked and tasted identical to the active supplements (taken from SU.FOL.OM3 trial paper).

Use of additional interventions (common to all treatment arms): no

Outcomes
Global cognitive functioning: French version of the modified Telephone Interview for Cognitive Status
(F-TICS-m)
Episodic memory: delayed recall subdomain from F-TICSm
Funding sources: The SU.FOL.OM3 trial was supported by the French Ministry of Research
(grant R02010JJ), the Ministry of Health, Sodexo, Candia, Unilever, Danone, Roche Laboratories, Merck
EPROVA AG, and Pierre Fabre Laboratories.
Declarations of interest: none declared
Treatment adherence: Compliance with treatment was self-reported in the biannual questionnaires
(or by telephone interview). Compliance was defined as taking at least $80 \%$ of the allocated treatment.
(taken from SU.FOL.OM3 trial paper).

Risk of bias

\begin{tabular}{lll}
\hline Bias & Authors' judgement & Support for judgement \\
\hline $\begin{array}{ll}\text { Random sequence genera- } \\
\text { tion (selection bias) }\end{array}$ & Low risk & $\begin{array}{l}\text { Quote: "We used computerized block randomisation (block size }=8) \text { with strat- } \\
\text { ification by sex, age }(45-54,55-64, \text { and } 65-80 \text { y), prior CVD, and city of resi- } \\
\text { dence." } \\
\end{array}$ \\
& Comment: adequate method of random sequence generation. \\
\hline
\end{tabular}

\begin{tabular}{lll}
$\begin{array}{l}\text { Allocation concealment } \\
\text { (selection bias) }\end{array}$ & Low risk & $\begin{array}{l}\text { Comment: no information. Centralised, computerised system, likely to be ade- } \\
\text { quately concealed }\end{array}$ \\
\hline $\begin{array}{l}\text { Blinding of participants } \\
\begin{array}{l}\text { and personnel (perfor- } \\
\text { mance bias) }\end{array}\end{array}$ & Low risk & $\begin{array}{l}\text { Quote: "The placebo capsules looked and tasted identical to the active supple- } \\
\text { ments" }\end{array}$ \\
All outcomes & Comment: probably blinded
\end{tabular}

Blinding of outcome as- Unclear risk sessment (detection bias) All outcomes Comment: did not mention blinding of study personnel including outcome assessors

Incomplete outcome data High risk (attrition bias) Comment: $24.8 \%$ of participants in SU.FOL.OM3 were lost to follow-up over the

All outcomes first 4 years and before the onset of the cognitive study. These participants appeared to be well balanced between groups.

133/1881 (7\%) participants eligible for the cognitive study were excluded: 72 (3.8\%) were unable to complete the cognitive assessment and 61 refused to participate. Treatment allocations of these participants were not reported.

Cognitive data were reported for $69.9 \%$ of the randomised participants.

\begin{tabular}{ll}
\hline $\begin{array}{l}\text { Selective reporting (re- } \\
\text { porting bias) }\end{array}$ & $\begin{array}{l}\text { Quote: "No changes to the outcomes of interest were made after launching the } \\
\text { trial" }\end{array}$ \\
\hline
\end{tabular}


Comment: The authors have stated no changes to the outcomes were made, however, these were not previously published in a protocol as this is an ancillary study and the main study protocol did not mention any cognitive outcomes.

\begin{tabular}{ll}
\hline Other bias $\quad$ Low risk $\quad$ No other risks identified \\
\hline
\end{tabular}

\section{Aspell 2017}

\begin{tabular}{|c|c|}
\hline Methods & 2-arm, parallel group RCT \\
\hline \multirow[t]{8}{*}{ Participants } & Location: one site in Ireland \\
\hline & Recruitment: no details provided \\
\hline & Number randomised: 60 \\
\hline & Participant characteristics: \\
\hline & - age: mean 68.5 years (SD 4.9 years) \\
\hline & - gender: $53.3 \%$ female \\
\hline & Inclusion criteria: community dwelling \\
\hline & $\begin{array}{l}\text { Exclusion criteria: low or high serum vit } D \text { (defined as }<15 \mathrm{nmol} / \mathrm{L} \text { or }>125 \mathrm{nmol} / \mathrm{L} \text { ), current use of sup- } \\
\text { plemental vit } \mathrm{D} \geq 800 \mathrm{IU} / \text { day, screen positive for cognitive impairment using the Telephone Cognitive } \\
\text { Screen (TCogS), hypercalcaemia, hyperparathyroidism, epilepsy, stroke, renal disease, schizophrenia, } \\
\text { bipolar affective disorder, recurrent psychotic depression, alcohol and drug abuse within the past } 5 \\
\text { years, anti-convulsants, anti-psychotic medications, significant hearing difficulties even when wearing } \\
\text { hearing aids, illness that caused permanent decrease in memory or other mental function }\end{array}$ \\
\hline Interventions & $50 \mathrm{mcg} /$ day of vitamin D3 administered as $4000 \mathrm{IU}$ on alternate days or placebo \\
\hline \multirow[t]{4}{*}{ Outcomes } & Overall cognitive function: Montreal Cognitive Assessment (MoCA) \\
\hline & Executive function: (Trails Making Task A \& B, B-A) \\
\hline & Episodic memory: Wechsler Memory Scale - in trial registry entry, not reported \\
\hline & Attention and visual reasoning: 2 validated measures (not included in review) \\
\hline \multirow[t]{2}{*}{ Notes } & Described as a pilot study. Only conference abstract available. \\
\hline & $\begin{array}{l}\text { 18.3\% of participants were deemed vitamin D deficient at baseline according to Institute of Medicine } \\
\text { guidelines. }\end{array}$ \\
\hline
\end{tabular}

\section{Risk of bias}

\begin{tabular}{lll}
\hline Bias & Authors' judgement & Support for judgement \\
\hline $\begin{array}{l}\text { Random sequence genera- } \\
\text { tion (selection bias) }\end{array}$ & Unclear risk & "Randomised", no additional details \\
\hline $\begin{array}{l}\text { Allocation concealment } \\
\text { (selection bias) }\end{array}$ & Unclear risk & No details \\
\hline $\begin{array}{l}\text { Blinding of participants } \\
\begin{array}{l}\text { and personnel (perfor- } \\
\text { mance bias) }\end{array}\end{array}$ & Low risk & From trial registry entry: masking: double (participant, investigator) \\
\hline
\end{tabular}


Aspell 2017 (Continued)

All outcomes

Blinding of outcome as-
sessment (detection bias) $\quad$ Low risk From trial registry entry: masking: double (participant, investigator)

sessment (detection bias)

All outcomes

$\begin{array}{ll}\begin{array}{l}\text { Incomplete outcome data } \\ \text { (attrition bias) }\end{array} & \text { Low risk } \\ \begin{array}{l}\text { All outcomes } \\ \text { ment of missing participants }\end{array}\end{array}$

All outcomes

Selective reporting (re- High risk
porting bias)

Trial registry entry included a measure of episodic memory which was not reporting bias) ported with other results in the conference abstract

\begin{tabular}{ll}
\hline Other bias $\quad$ Low risk $\quad$ No other risks identified \\
\hline
\end{tabular}

\title{
Cockle 2000
}

Methods
2-arm, parallel group, double-blind, placebo-controlled RCT
(Intended duration was 48 weeks, but due to very high dropout after 24 weeks, no data were reported
beyond 24 weeks).

Participants

\author{
Location: One site in UK
}

Recruitment: subjects recruited by newspaper advertisement

Number randomised: 69 in intervention, 70 in comparison

\section{Participant baseline characteristics:}

- Age:

* overall: median 70 years

* placebo: mean 70.2 (5.4) and median 70 (60-81)

* intervention: mean 70.7 (5.6 and median 70 (60-81)

- Gender:

* overall: 51 males and 88 females

* placebo (24 males and 46 females)

* intervention (27 males and 42 females)

- Main diagnosis: All subjects were in good physical and mental health and had no history of significant disease or mental illness, as determined by a medical examination and health questionnaire.

- MMSE:

* intervention: 28.9 (SD:1.4)

* placebo: 28.6 (SD:1.5)

Inclusion criteria: not reported

Exclusion criteria: not reported contained vitamin A palmitate $3334 \mathrm{IU}$, thiamine mononitrate $14 \mathrm{mg}$, riboflavin $16 \mathrm{mg}$, pyridoxine 22 $\mathrm{mg}$, vitamin B12 $0.03 \mathrm{mg}$, vitamin C $600 \mathrm{mg}$, dl-alpha-tocopherol acetate $100 \mathrm{mg}$, folic acid $4 \mathrm{mg}$, d-biotin $2 \mathrm{mg}$ and nicotinamide $180 \mathrm{mg}$.

Quote: "The dosing was calculated to provide the equivalent of one US RDA (National Research Council, 1980) of vitamin A and ten US RDAs of the remaining vitamins."

Capsules supply were provided at baseline and, in patients who were compliant, a second supply was given at week 12 for an intended treatment duration of 24 weeks. 
Cockle 2000 (Continued)

Comparator group $(\mathbf{n}=\mathbf{7 0})$ : matching placebo (rape seed oil)

Use of additional interventions (common to both treatment arms): not reported

Outcomes $\quad$ Primary Outcomes: Relationship between vitamin status and cognitive function.

"At each visit, treatment compliance, blood vitamin levels and Critical Flicker Fusion, Choice ReactionTimeTask, Sternberg Memory ScanningTask, Word ScanTask, and the Profile Of Mood States questionnaire were carried out".

"MMSE, Sundrom Kurtz Test, National Adult Reading Test, Alice Heim's 4, Alice Heim's 5 and the Geriatric Depression Scale were assessed at baseline and at week 48."

\section{Eligible cognitive outcomes:}

- episodic memory measured with Sternberg Memory Scanning Task (msec), lower values indicated benefit

- episodic memory measured with Word scan task ( $\mathrm{msec})$, lower values indicated benefit*

- speed of processing measured with Total reaction time $(\mathrm{msec})$, lower values indicated benefit*

- speed of processing measured with Recognition reaction time (msec), lower values indicated benefit

- speed of processing measured with Motor reaction time ( $\mathrm{msec}$ ), lower values indicated benefit

* outcome data used in statistical analyses

Notes

Quote: "the objectives of the study were to examine the relationship between vitamin status and cognitive functioning and mood in healthy, elderly volunteers and to assess the subsequent impact of multivitamin supplementation on these measures".

Funding sources: none stated

Declarations of interest: none stated, but second author from Roche Pharmaceutical

\section{Risk of bias}

Bias Authors' judgement Support for judgement

Random sequence genera- Unclear risk tion (selection bias)

Quote: "Subjects were allocated to each treatment group according to a predetermined randomization schedule."

Comment: insufficient information about the sequence generation method

\begin{tabular}{|c|c|c|}
\hline $\begin{array}{l}\text { Allocation concealment } \\
\text { (selection bias) }\end{array}$ & Unclear risk & $\begin{array}{l}\text { Quote: "Subjects were allocated to each treatment group according to a pre- } \\
\text { determined randomization schedule." }\end{array}$ \\
\hline
\end{tabular}

Comment: insufficient information about allocation concealment

Blinding of participants Low risk and personnel (perfor-

mance bias)

All outcomes

Quote: "The study was a double-blind, placebo-controlled, parallel group study with each subject receiving a multivitamin supplement or placebo daily for up to 24 weeks."

Quote: "Treatments were given orally as two soft gelatine capsules containing either multivitamins or matching placebo (rape seed oil)".

Comment: The study was reported as double-blinded with the use of matching placebo.
Blinding of outcome as-
Unclear risk
Quote: "at each visit, treatment compliance, blood vitamin levels and Critical Flicker Fusion, Choice Reaction Time Task, ...were carried out".
All outcomes
Comment: It was not reported whether outcome assessment was blinded. 
Cockle 2000 (Continued)

Incomplete outcome data High risk (attrition bias)

All outcomes
Quote: 'Due to circumstances not related to the study treatment, there was a significant dropout of subjects after the first six months of this study, with no participants continuing through to visit 4. Data from 139 subjects was available at baseline, from 127 subjects at visit 1 and from 90 subjects at visit 2 . Due to the high dropout of subjects between visit 2 and visit 3, data from the latter visit was not included."

Comment: There were 12 dropouts (8.6\%) at visit 1 ( 12 weeks) and 49 dropouts $(35.8 \%)$ at visit 2 (24 weeks). Outcome data were completely missing from planned visits 3 and 4 ( 36 and 48 weeks).

\begin{tabular}{|c|c|c|}
\hline $\begin{array}{l}\text { Selective reporting (re- } \\
\text { porting bias) }\end{array}$ & High risk & $\begin{array}{l}\text { Comment: A number of tests of cognition and functioning reported in the } \\
\text { Methods to have been measured at baseline and } 48 \text { weeks were not reported } \\
\text { (including MMSE). }\end{array}$ \\
\hline
\end{tabular}

Other bias Low risk No other risks identified

\section{Dangour 2015}

\section{Methods}

Participants 2-arm, double-blinded, multicentre, parallel group RCT, with 12 months of treatment and follow-up

Location: 7 general practices in South East England

Recruitment: recruited at GP by mail, baseline appointment and 12-month follow-up at King's College Hospital, London, treatment one tablet daily at home

\section{Sample size:}

- Number randomised: 99 in intervention, 102 in comparison

- Number completed: 91 in intervention, 92 in comparison

\section{Group A (B vitamins) baseline characteristics:}

- age (mean \pm SD): $79.9 \pm 3.5$

- gender (n) : 46 males, 54 females

- main diagnosis: no diagnosis

\section{Group B (placebo) baseline characteristics:}

- age: $80.1 \pm 3.7$

- gender: 48 males, 54 females

- main diagnosis: no diagnosis

\section{(Inclusion criteria:)}

Age: $\geq 75$ years, Participants with a Mini-Mental State Examination score $>24$ (maximum score 30) were asked to provide a blood sample to assess serum vitamin B12 and haemoglobin concentration. Those with moderate vitamin B12 deficiency who did not have anaemia (serum vitamin B12 concentrations $\geq$ 107 and $<210 \mathrm{pmol} / \mathrm{L}$ were eligible to join the trial.

The diagnostic criterion used for dementia/cognitive impairment screening was the MMSE. Only those with a score $>24$ were eligible to join the trial.

(Exclusion criteria:) Diabetes, dementia, epilepsy, alcohol addiction, pacemakers (and other implanted metallic devices where central neurophysiologic testing was contraindicated), residents of nursing homes, diagnosis of pernicious anaemia, current consumption of vitamin B12 supplements and those who had received a vitamin B12 injection within the previous 6 months. Individuals with very low vitamin B12 concentrations ( $<107 \mathrm{pmol} / \mathrm{L}$, which is a cutoff typically used for deficiency) or who were 
shown to have anaemia (haemoglobin concentration, $110 \mathrm{~g} / \mathrm{L}$ for women and $120 \mathrm{~g} / \mathrm{L}$ for men) were excluded.

Interventions

Intervention ( $\mathbf{n}=\mathbf{9 7}$ ): vitamin B12 (cyanocobalamin), oral administration, $1 \mathrm{mg}$ tablet/day, 12 months

Comparator group ( $\mathbf{n}=\mathbf{9 7}$ ): placebo tablet administered once daily identical to intervention in shape, size, colour, smell, taste, and identically packaged

Use of additional interventions (common to both treatment arms): not reported

Outcomes of interest in the review:
- Episodic memory measured with California Verbal Learning Test at delayed recall, with higher values
indicating benefit
- Executive function measured with verbal fluency, with higher values indicating benefit
- Speed of processing measured with Choice Reaction time, with lower values indicating benefit

Notes

Funding sources: Supported by the Food Standards Agency (N05072) and the Department of Health. National Health Service.

Research and Development and King's College Hospital Trust Research and Development provided service support costs.

Declarations of interest: none declared

Treatment adherence: Adherence was measured by counting the number of tablets returned at the end of the study.

\section{Risk of bias}

\begin{tabular}{lll}
\hline Bias & Authors' judgement & Support for judgement \\
\hline $\begin{array}{l}\text { Random sequence genera- } \\
\text { tion (selection bias) }\end{array}$ & Low risk & $\begin{array}{l}\text { Quote: "Allocation codes were obtained from a central computerized random- } \\
\text { ization service." } \\
\text { Comment: adequate method of random sequence generation }\end{array}$ \\
\hline $\begin{array}{l}\text { Allocation concealment } \\
\text { (selection bias) }\end{array}$ & Low risk & $\begin{array}{l}\text { Quote: "Allocation codes were obtained from a central computerized random- } \\
\text { ization service." }\end{array}$ \\
& Comment: adequate method of allocation concealment \\
\hline
\end{tabular}

Blinding of participants Low risk and personnel (perfor-

mance bias)

All outcomes
Quote: "All study personnel were blinded to the treatment allocation."

"Allocated treatment consisted of a single tablet administered daily that was identical in size, shape, color, smell, and taste for both the intervention and placebo and packaged into identical pots."

Comment: As all participants were given identical tablets this ensured blinding was maintained.

Blinding of outcome as- Low risk sessment (detection bias)

All outcomes
Quote: "All study personnel were blinded to the treatment allocation."

"Allocated treatment consisted of a single tablet administered daily that was identical in size, shape, color, smell, and taste for both the intervention and placebo and packaged into identical pots."

Comment: Study mentions personnel were blinded to treatment allocation and due to identical tablets this would have maintained appropriate blinding.

Comment: Cognitive outcome data were available for 184/201 participants (92\%). Dropout rates and reasons were similar in both groups.

$\begin{aligned} & \text { Incomplete outcome data Low risk } \\ & \text { (attrition bias) }\end{aligned}$
(92\%). Dropout rates and reasons were similar in both groups.


Dangour 2015 (Continued)

All outcomes

Selective reporting (re- Low risk $\quad$ Comment: followed study protocol, no reporting bias found
porting bias)

Other bias Low risk Comment: none found

Durga 2007

Methods 2-arm, placebo-controlled, randomised clinical trial, with 3-year duration of treatment

Participants Location: Gelderland region in the Netherlands, single centre

Recruitment: Division of Human Nutrition, Wageningen University, Wageningen, Netherlands

Number randomised: 406 in intervention, 413 in comparison

Participant baseline characteristics:

- Age at baseline (years), mean (SD):

* placebo: 60 (6)

* folic acid: 60 (5)

- Male, n (\%):

* placebo: $292(70 \%)$

* folic acid: $294(72 \%)$

- MMSE (points):

* placebo: 29 (28-30)

* folic acid: $29(28-30)$

\section{Inclusion criteria:}

- Participants were men and post-menopausal women aged 50-70 years.

- More than $80 \%$ self-reported compliance during a 6-week placebo run-in period was required.

\section{Exclusion criteria:}

- homocysteine concentration less than 13 micromol/L and greater than 26 micromol/L

- self-reported medical diagnosis of renal or thyroid disease

- self-reported use of medications that influence folate metabolism

- participants reportedly used B vitamin supplements or drugs that could affect atherosclerotic progression

Interventions

Intervention ( $\mathbf{n}$ 405): $800 \mu \mathrm{g}$ per day folic acid.

Comparator group $(n=413)$ : placebo

\section{Outcomes}

\section{Cognitive outcomes:}

5 cognitive tests were used: word learning test, concept shifting test, Stroop colour-word test, verbal fluency test, letter digit substitution test

These 5 tests were used to construct 5 a priori defined cognitive domains using z-scores: memory, sensorimotor speed, complex speed, information processing speed, and word fluency

Outcomes used in this review were:

1. Global cognitive function (average of 5 domains); 
2. Episodic memory: Memory $\left(Z_{15}\right.$-Word Learning test 'total immediate recall' $+Z_{15}$-Word Learning Test 'maximum immediate recall ${ }^{+} Z_{15}$-Word Learning Test 'delayed recall' $) / 3$ )

3. Executive function: Word fluency ( $\left.Z_{\text {Verbal Fluency test }}\right)$

4. Speed of processing: Information processing speed ( $\left.Z_{\text {Letter Digit Substitution test }}\right)$

Notes

Funding sources: The research was funded by a grant from the Netherlands Organisation for Health Research and Development (ZonMw, grant number 20010002), Wageningen University, and Wageningen Centre for Food Sciences. Wageningen Centre for Food Sciences is an alliance of major Dutch food industries, research institutes and the Dutch government. Wageningen Centre for Food Sciences does long-term strategic research for the development of new and innovated food with attention to health aspects.

Declarations of interest: Jane Durga currently works at Nestle Research Center in Lausanne, Switzerland and Petra Verhoef currently works at the Unilever Food and Health Research Institute in Vlaardingen, the Netherlands. The work at both food companies entails examining the health benefits of a variety of food ingredients, including folic acid. However, the study reported in the current manuscript was completed and submitted to The Lancet before the authors joined the companies, when they were still employed by Wageningen University and Wageningen Centre for Food Sciences. All authors declare that they have no conflict of interest.

\section{Risk of bias}

Bias Authors' judgement Support for judgement

Random sequence genera- Unclear risk tion (selection bias)
Quote: "Patients were allocated treatment or placebo with permuted blocks of sizes four and six, which varied randomly. Specialised staff who were not involved in the study allocated and labelled the capsule boxes with participants' unique sequence number. Participants in the same household received the same treatment."

Comment: Method of sequence generation was not reported.

\begin{tabular}{ll}
\hline $\begin{array}{l}\text { Allocation concealment } \\
\text { (selection bias) }\end{array}$ & Low risk \\
& $\begin{array}{l}\text { Quote: "Specialized staff who were not involved in the study allocated and la- } \\
\text { belled the capsule boxes with participants' unique sequence number". }\end{array}$ \\
Comment: appropriate allocation concealment
\end{tabular}

Comment: appropriate allocation concealment

$\begin{array}{ll}\begin{array}{l}\text { Blinding of participants } \\ \text { and personnel (perfor- }\end{array} & \text { Low risk } \\ \begin{array}{l}\text { mance bias) } \\ \text { All outcomes }\end{array} & \begin{array}{l}\text { pearance". } 70 \% \text { of participants in the folic acid group and } 71 \% \text { in the placebo } \\ \text { group thought they had been allocated to folic acid. }\end{array}\end{array}$

Comment: well blinded

\begin{tabular}{|c|c|c|}
\hline $\begin{array}{l}\text { Blinding of outcome as- } \\
\text { sessment (detection bias) }\end{array}$ & Low risk & $\begin{array}{l}\text { Comment: All staff, including all authors, were unaware of group assignment } \\
\text { until completion of the trial and after data analyses. }\end{array}$ \\
\hline
\end{tabular}

All outcomes

Quote: outcome assessment well blinded

$\begin{array}{ll}\begin{array}{l}\text { Incomplete outcome data Low risk } \\ \text { (attrition bias) }\end{array} & \begin{array}{l}\text { Quote: } 17 \text { participants lost to follow-up were assigned the median test score of } \\ \text { the total population at the end of the study. }\end{array} \\ \text { All outcomes } & \begin{array}{l}\text { Comment: Although there were imputations, the small proportion of loss to } \\ \text { follow-up unlikely to affect results. }\end{array}\end{array}$
Selective reporting (re- Unclear risk
porting bias) 


\begin{tabular}{ll}
\hline Other bias $\quad$ Low risk $\quad$ No other risks detected \\
\hline
\end{tabular}

\section{Eussen 2006}

Methods 3-arm, parallel-group, randomised, placebo-controlled trial, 24 weeks duration

Participants

Location: the Netherlands

Recruitment: free-living older persons and older persons living in care-facility homes, recruited via mailed health questionnaires

Number randomised: 195 randomised, of whom 119 had CDR 0 at baseline and were included in this review

"Randomization was stratified according to MMA concentration at the screening visit $(<$ and $>0.45$ $\mu \mathrm{mol} / \mathrm{L})$, age (< and $>80$ ), sex and MMSE score (< and $>24$ points)."

Vitamin B12: 38

Vitamin B12 + folic acid: 38

Placebo: 43

\section{Participant baseline characteristics:}

- Age, mean (SD):

* vitamin B12: 80.42 (5.52)

* vitamin B12 + folic acid: 80.82 (4.18)

* placebo: 79.86 (4.74)

- .Gender

* vitamin B12: female 29/38 (76\%)

* vitamin B12 + folic acid: female 29/38 (76\%)

* placebo: female 34/43 (79\%)

- Baseline cognitive function - MMSE score (mean (SD))

* vitamin B12: 28.18 (1.43)

* vitamin B12 + folic acid: 28.34 (1.40)

* placebo: 27.93 (1.80)

Inclusion criteria: aged $\geq 70 \mathrm{y}$. Mild vitamin B12 deficiency defined as (1) a serum vitamin B12 concentration between 100 and $200 \mathrm{pmol} / \mathrm{L}$, or (2) a serum vitamin B12 concentration between 200 and 300 $\mathrm{pmol} / \mathrm{L}$, a plasma MMA concentration $\geq 0.32 \mu \mathrm{mol} / \mathrm{L}$, and a serum creatinine concentration $\leq 120 \mu \mathrm{mol} /$ L. Ingested $90 \%$ or more of capsules during a 2 -week placebo run-in period prior to randomisation.

Exclusion criteria: history of cobalamin deficiency, use of cobalamin ( $>50 \mu \mathrm{g} /$ day) or folic acid (> 200 $\mu \mathrm{g} /$ day) supplementation or injections, surgery or diseases of the stomach or small intestine, anaemia, dementia, life-threatening diseases, or severe hearing or visual problems

\section{Intervention:}

1. vitamin B12: $1000 \mu \mathrm{g}$ vitamin B12 (cyanocobalamin) per day orally for 24 weeks

2. vitamin B12 and folic acid: $1000 \mu \mathrm{g}$ vitamin B12 (cyanocobalamin) plus $400 \mu \mathrm{g}$ folic acid per day orally for 24 weeks

\section{Comparator group:}

- Placebo capsule 
Eussen 2006 (Continued)

The placebo capsules contained AVICEL PH102 (Medipulp GmbH, Aschaffenburg, Germany) as a filler.

Use of additional interventions (common to all treatment arms): not reported

\section{Outcomes}

Notes

\section{Cognitive function}

Cognitive function was assessed before and after 24 wk of treatment with the use of an extensive neuropsychologic test battery that included the domains of attention, construction, sensorimotor speed, memory, and executive function.

Cognitive function was assessed by 6 trained and registered neuropsychologists during the run-in period (baseline) and at week 24 of the intervention during a 1.5-2-h session.

Neuropsychological test battery included:

- finger tapping, computerised

- motor planning 2 and 3, computerised

- Figure of Rey copy, immediate recall and delayed recall

- 15-word learning immediate recall, delayed recall and recognition

- Trail-making test, part A and part B

- Digit span forward and backward

- Raven

- Stroop test

- Similarities, WAIS

- Word fluency, letter

- Word fluency, animals

Depression measured with GDS

Biochemical measures: vitamin B12, MMA, holoTC, homocystine, RBC folate

Compliance was checked by counting the number of unused capsules remaining in capsule dispensers and by verifying pill counts in the participants' diaries. Mean compliance was $99 \%$.

Professor Simone Eussen and Professor Lisette de Groot kindly provided data separately on participants with CDR 0 at baseline for inclusion in this review.

Study supported by grants from ZON-MW, The Hague, Netherlands; Kellogg's Benelux, Zaventem, Belgium; Foundation to Promote Research into Functional Vitamin B12 Deficiency and the European Union BIOMED Demonstration Project; Nutricia Health Foundation, Wageningen, Netherlands.

\section{Risk of bias}

\begin{tabular}{lll}
\hline Bias & Authors' judgement & Support for judgement \\
\hline $\begin{array}{l}\text { Random sequence genera- } \\
\text { tion (selection bias) }\end{array}$ & Unclear risk & "Randomized", no further information \\
\hline $\begin{array}{l}\text { Allocation concealment } \\
\text { (selection bias) }\end{array}$ & Unclear risk & No information \\
\hline
\end{tabular}

\section{Blinding of participants Low risk} and personnel (performance bias)

All outcomes
Quotes: "The capsules given to the separate treatment groups were identical
in appearance, smell and taste." "The study had a double-blind design."
Blinding of outcome as- Low risk sessment (detection bias) All outcomes
Comment: participants and personnel blind to allocation

Quote: "The study had a double-blind design." No specific mention of outcome assessors". 
Incomplete outcome data Low risk (attrition bias)

All outcomes
Incomplete outcome data varied between cognitive tests. For included outcomes, data available for minimum of $82 \%$ of participants.

In study as a whole, "16\% ... were unable to complete the trial, mostly because of illness, and the dropout rate was slightly higher in the vitamin B12 + folic acid group than in the other groups." Dropout in whole study: 10/64 B12, 15/66 B12 + folic acid, 8/65 placebo.

Comment: major effect of differential dropout unlikely

Selective reporting (re- Low risk All outcomes mentioned in methods fully reported
porting bias)

Other bias Low risk No other biases identified

Ford 2010

Methods 2-arm, double-blinded, parallel group RCT, with 2 years duration of treatment and 8-year follow-up

The average follow-up time (time to event) was 8.3 years in both groups.

Participants Location: Australia, number of sites not reported

Recruitment: community-representative hypertensive men 75 years and older randomly selected from a large population-based study of abdominal aortic aneurysm screening (Health in Men Study)

Participants were recruited from July 18, 2000, to February 6, 2002.

Number randomised: 150 in intervention, 149 in comparator

Participant (baseline) characteristics:

- Age, mean (SD):

* placebo: $78.7(2.7)$

* vitamin: $79.3(2.8)$

- Baseline cognitive function

* ADAS-cog, mean (SD)

$\square$ placebo: $11.8(6.0)$

$\square$ vitamin: 11.0 (5.1)

- MMSE score, mean (SD)

* placebo: $27.6(1.9)$

* vitamin: $27.5(1.8)$

Inclusion criteria: community-representative hypertensive men 75 years and older

Exclusion criteria: Beck Depression Inventory (BDI) score $\geq 18$ or a Mini-Mental State Examination (MMSE) score $\leq 24$, illness likely to cause severe disability or death within 12 months (for example, metastatic cancer, Parkinson disease, or a history of stroke), non-English speaking, living in residential care facilities, or patients who were already taking vitamin B supplements

Interventions

\section{Intervention ( $\mathbf{n}=150)$ :}

Vitamins: one capsule containing $400 \mu \mathrm{g} \mathrm{B12,25} \mathrm{mg} \mathrm{B6,} 2 \mathrm{mg}$ folic acid, every morning for 2 years

\section{Comparator group $(n=149)$ :}

Placebo, one identical oral capsule every morning for 2 years 

would improve cognitive performance (change in the cognitive subscale of the Alzheimer's Disease Assessment Scale) compared with placebo in older men

\section{Secondary Outcomes:}

Longer-term impact of B vitamin supplementation by comparing performance on the TICS as well as a diagnosis of dementia registered in the Western Australian Data Linkage System (WADLS) until September 30, 2009

A diagnosis of dementia was recorded if the death certificate contained one of the following ICD-10 codes: F00 (dementia in AD), F01 (vascular dementia), F03 (unspecified dementia), and G30 (AD). Additionally, a dementia diagnosis was sought from records of inpatient admissions and outpatient contacts.

Secondary measures of interest included also the California Verbal Learning Test, Mini-Mental State Examination, Digit Cancellation Test, Clock Drawing Test* ${ }^{\star}$, TICS, changes in biochemical parameters (total plasma homocysteine, vitamin B12 and quality of life (Short Form (SF)-36).

\section{Eligible cognitive outcomes:}

- global cognitive function measured with ADAS-cog at 1 and 2 years, with higher values indicating benefit

- global cognitive function measured with MMSE at 1 and 2 years, with higher values indicating benefit*

- episodic memory measured with California Verbal Learning Test 1 (CVLT 1 ) at 1 and 2 years, with higher values indicating benefit

- episodic memory measured with California Verbal Learning Test 2 (CVLT 2) at 1 and 2 years, with higher values indicating benefit*

- semantic memory measured with Clock Drawing Test at 1 and 2 years, with higher values indicating benefit*

- speed of processing measured with Digit Cancellation Test (DCT) at 1 and 2 years, with higher values indicating benefit*

Function outcome extracted: none reported

Quality of life outcome: SF-36

Safety outcome: none reported

* outcome data used in statistical analyses

Declarations of interest, quote: "Dr. Ford reports no disclosures. Dr. Flicker serves as Internal Medicine Editor for Geriatric Medicine, Associate Editor for BMC Geriatrics, on the editorial board of the Australasian Journal on Ageing, and as Editor of the Cochrane Dementia and Cognitive Improvement Group; and receives/has received research support from Pfizer Inc. and NHMRC. Dr. Alfonso and J. Thomas report no disclosures. Dr. Clarnette serves on scientific advisory boards for Lundbeck Inc., Pfizer Inc., and Novartis; serves as an editorial advisor to Geriatric Medicine in General Practice; and estimates that $10 \%$ of his practice at Fremantle Hospital consists of cognitive testing. Dr. Martins serves as Senior Editor for the Journal of Alzheimer's Disease; serves as a consultant for and holds stock in Alzhyme Ltd.; and receives research support from Commonwealth Scientific and Industrial Research Organisation (Australia). Dr. Almeida has received funding for travel from Blackmores Ltd."

\section{Treatment adherence}

Men who consumed at least $75 \%$ of the study tablets during this 2 -year trial were considered compliant. Compliance was determined by pill count and medication diaries. 
Ford 2010 (Continued)

Risk of bias

\begin{tabular}{lll}
\hline Bias & Authors' judgement & Support for judgement \\
\hline $\begin{array}{ll}\text { Random sequence genera- } \\
\text { tion (selection bias) }\end{array}$ & Low risk & $\begin{array}{l}\text { Quote: "Participants were given consecutive numbers and allocated to ac- } \\
\text { tive vs placebo arms based on computer-generated random permuted blocks. } \\
\text { Blocks consisted of } 8 \text { subjects (4 subjects allocated to each group) so as to } \\
\text { minimize the risk of having unbalanced entry into each arm of the study during } \\
\text { the period of recruitment." } \\
\text { Comment: adequate method of sequence generation }\end{array}$ \\
&
\end{tabular}

\begin{tabular}{|c|c|c|}
\hline $\begin{array}{l}\text { Allocation concealment } \\
\text { (selection bias) }\end{array}$ & Low risk & $\begin{array}{l}\text { Quote: "An external and independent academic controlled the randomization } \\
\text { procedures of the trial." }\end{array}$ \\
\hline
\end{tabular}

Comment: adequate method of allocation concealment

\begin{tabular}{|c|c|c|}
\hline $\begin{array}{l}\text { Blinding of participants } \\
\text { and personnel (perfor- } \\
\text { mance bias) } \\
\text { All outcomes }\end{array}$ & Low risk & $\begin{array}{l}\text { Quote: "Vitamins and placebo were administered in the form of identical oral } \\
\text { capsules." } \\
\text { "Participants and investigators were blinded to the group membership of men } \\
\text { in the trial until the last follow-up assessment was completed. There were no } \\
\text { breaches of protocol". }\end{array}$ \\
\hline & & Comment: participants and personnel blinded \\
\hline
\end{tabular}

$\begin{array}{lll}\begin{array}{l}\text { Blinding of outcome as- } \\ \text { sessment (detection bias) }\end{array} \quad \text { Low risk } & \begin{array}{l}\text { Quote: "Participants and investigators were blinded to the group membership } \\ \text { of men in the trial until the last follow-up assessment was completed." }\end{array}\end{array}$

Comment: outcome assessment blinded

$\begin{array}{ll}\begin{array}{l}\text { Incomplete outcome data } \\ \text { (attrition bias) }\end{array} & \text { Low risk } \\ \text { withdrew consent or were lost during the trial." }\end{array}$

Comment: For the primary outcome, an ITT analysis was presented and attrition bias was considered as low.

For the secondary outcome of cognitive impairment or dementia at long-term follow-up : "Seventy-three of these men took part in a later telephone survey in 2008 and completed the Telephone Interview for Cognitive Status (TICS) questionnaire", "41 (27\%) in the intervention group and $32(21 \%)$ in the placebo group". Data on dementia diagnosis were available on all 172/299 (57.5\%) participants who were alive in 2008.

Comment: high risk of attrition bias for this long-term secondary outcome

\begin{tabular}{lll}
\hline $\begin{array}{l}\text { Selective reporting (re- } \\
\text { porting bias) }\end{array}$ & Low risk & $\begin{array}{l}\text { Comment: All outcomes specified in the Methods were reported in the Results. } \\
\text { Protocol not available }\end{array}$ \\
\hline Other bias & Low risk & No other risks identified \\
\hline
\end{tabular}

\section{Grodstein 2007}

Methods

$$
\begin{aligned}
& \text { Substudy of the Physicians' Health Study II, a randomised, double-blind, placebo-controlled, } 2 \times 2 \times 2 \times \\
& 2 \text { factorial trial testing ß-carotene, vitamin E, ascorbic acid, and a multivitamin for their role in prevent- } \\
& \text { ing chronic diseases including total and prostate cancer, cardiovascular disease, and age-related eye } \\
& \text { disease among } 14,641 \text { male physicians aged } 50 \text { years or older }
\end{aligned}
$$


The trial was done from 1997 to 1 June 2011. The cognitive function substudy began in 1998. Those eligible for the cognitive substudy were PHS II participants older than 65 years in November 1998.

The Physicians' Health Study II was a continuation of the Physicians' Health Study, which began in 1982 and had randomised male participants to low-dose aspirin and ß-carotene. Participants included those continuing their original ß-carotene assignment from the Physicians' Health Study and newer recruits randomised from 1998 onwards.

\section{Participants}

\section{Location: not reported}

Recruitment: The Physicians' Health Study II. Quote: "In July 1997, invitations to enrol in PHS II were mailed to eligible participants from PHS I who had been part of an earlier trial of aspirin and ß-carotene among 22071 physicians aged 40 to 84 years in 1982. Second, in July 1999, invitation letters were mailed to a new group of male physicians identified from a list provided by the American Medical Association."

Quote: "PHS I participants who are willing and eligible for participation in PHS II will retain their randomized ß-carotene assignment from PHS I and will be also randomized to vitamin E..."

"new physician participants will be randomly assigned to the same interventions"

\section{Number randomised:}

- 2967 ß-carotene (2031 continuing from PHS and 936 newer recruiters)

- 2989 placebo (2021 continuing from PHS and 968 newer recruiters)

\section{Participant (baseline) characteristics (at entry PHS III):}

All participants were men.

Age, mean:

- Patients from PHS at entry in PHS II

- ß-carotene: 70.9

- placebo: 71.0

- Newly recruited

- B-carotene: 72.9

- placebo: 72.8

\section{Inclusion criteria: not reported}

Exclusion criteria: history of cirrhosis or active liver disease, patients receiving anticoagulants, or reported a serious illness that may interfere with study participation

Men were also required to forgo current use of multivitamins or individual supplements containing more than $100 \%$ of the recommended daily allowance of vitamin E, vitamin C, B-carotene, or vitamin A during PHS II follow-up

For those newly recruited: no history of cancer, active liver disease, current renal disease, peptic ulcer, or gout

Quote: "Only physicians who comply with the pill-taking regimen at least two-thirds of the time and remain willing and eligible to participate will be subsequently randomized".

\section{Intervention:}

1. B-carotene (Lurotin, $50 \mathrm{mg}$ on alternate days, or its placebo; BASF, Florham Park, New Jersey);

2. vitamin $E$ (synthetic alfa-tocopherol, $400 \mathrm{IU}$ on alternate days, or its placebo; BASF);

3. ascorbic acid (synthetic ascorbic acid, $500 \mathrm{mg}$ daily, or its placebo; BASF);

4. multivitamin (Centrum Silver or its placebo daily; Pfizer, New York, New York)

NB: Grodstein 2007 reported on the ß-carotene and Grodstein 2013 on multivitamin supplementation. 
Comparator group: placebo ß-carotene.

\section{Exposure to study intervention:}

2031 patients in ß-carotene and 2021 placebo continued from the PHS study (started in 1982) in which they were receiving $ß$-carotene versus placebo $ß$-carotene. As most of the cognitive assessments were done in 2001, some of the patients continuing from PHS had been exposed to ß-carotene (or placebo ßcarotene) for about 19 years, whereas the "new recruiters" had been exposed from 1997 to 2001, thus for about 4 years.

The mean time from randomisation to cognitive assessment was 18 years (range, 15-20 years) in 4052 continuing participants from the PHS, and was 1 year in 2021 new recruits (range, 2 months- 3 years).

Quote: "PHS participants, who remained blinded to beta carotene assignment."

Quote: "Treatment assignment to beta carotene or beta carotene placebo was retained from the PHS (although participants may have stopped taking beta carotene during the 18-month interval between studies), and the men were newly randomized to receive vitamin E, ascorbic acid, multivitamin, or placebo."

Use of additional interventions (common to both treatment arms): not reported

\section{Outcomes}

\section{Primary Outcomes:}

A global composite score averaging 5 tests of global cognition, verbal memory, and category fluency.

The cognitive battery included the Telephone Interview for Cognitive Status (TICS); immediate and delayed recall on the East Boston Memory Test (EBMT); delayed recall of a 10-word list; and a category fluency task.

The cognitive function substudy began in 1998.

The beta carotene arm of the PHS II continued until May 2003, its planned stopping date, but most of the assessments were done in 2001.

Quote: "Second cognitive assessments were begun in 2002. The beta carotene arm was terminated prior to completion of second assessments (second and third assessments were planned to allow further data collection in the continuing trial of other vitamins). Nonetheless, some data from the second interview were available $(n=4074$, with $88.3 \%$ participation of those who were contacted before termination of the beta carotene study)."

\section{Eligible cognitive outcomes:}

- global cognitive function measured with TICS*

- episodic memory (verbal memory) measured using an average of z-scores ${ }^{\star}$ for immediate and delayed recall on the EBMT and delayed recall of a 10-word list

- executive functioning measured with category fluency: animals named during 1 minute*

Function outcome extracted: none reported

Quality of life outcome extracted: none reported

Safety outcome extracted: none reported

* outcome data used in statistical analyses CA40360, CA97193, HL26490, HL34595, and AG15933), and from BASF Corporation (Florham Park, New Jersey), Wyeth (New Jersey), and DMS (New Jersey). Dr Grodstein was partially supported by a New Scholars in Aging award from the Ellison Medical Foundation. Role of the Sponsor: No supporting organization had any role in the study design; conduct of the study; collection, management, analysis, and interpretation of the data; or preparation, review, or approval of the manuscript."

Declaration of interest: "None reported". 
Grodstein 2007 (Continued)

\section{Treatment adherence:}

ß-carotene study:

"Overall, $79.3 \%$ reported taking at least 2 of 3 of their study pills; this was similar in those assigned to active treatment $(79.1 \%)$ or placebo $(79.5 \%)$, and in the continuing participants from the PHS (79.2\%) vs new recruits $(79.4 \%) "$.

\section{Risk of bias}

\begin{tabular}{|c|c|c|}
\hline Bias & Authors' judgement & Support for judgement \\
\hline \multirow[t]{3}{*}{$\begin{array}{l}\text { Random sequence genera- } \\
\text { tion (selection bias) }\end{array}$} & Low risk & $\begin{array}{l}\text { Quote: "The PHS II is a randomized, double-blind, placebo-controlled, } 2 \times 2 \times 2 \times 2 \\
\text { factorial trial". }\end{array}$ \\
\hline & & "Randomization..using a computer-generated list of random numbers". \\
\hline & & Comment: adequate method of random generation \\
\hline \multirow[t]{2}{*}{$\begin{array}{l}\text { Allocation concealment } \\
\text { (selection bias) }\end{array}$} & Unclear risk & $\begin{array}{l}\text { Quote: "The PHS II is a randomized, double-blind, placebo-controlled, } 2 \times 2 \times 2 \times 2 \\
\text { factorial trial". }\end{array}$ \\
\hline & & Comment: method of allocation concealment not reported \\
\hline
\end{tabular}

\begin{tabular}{|c|c|c|}
\hline $\begin{array}{l}\text { Blinding of participants } \\
\text { and personnel (perfor- }\end{array}$ & Unclear risk & $\begin{array}{l}\text { Quote: "The PHS II is a randomized, double-blind, placebo-controlled, } 2 \times 2 \times 2 \times 2 \\
\text { factorial trial". }\end{array}$ \\
\hline All outcomes & & Comment: method of blinding not reported \\
\hline
\end{tabular}

Blinding of outcome as- Unclear risk sessment (detection bias)

All outcomes
Quote: "The PHS II is a randomized, double-blind, placebo-controlled, $2 \times 2 \times 2 \times 2$ factorial trial".

"An Endpoint Committee of physicians blinded to the participants' treatment assignment, will review the medical records for final confirmation of a reported diagnosis".

Comment: The method of blinding of outcome assessment for the cognitive substudy was not reported. The statement about the Endpoint Committee is contained in the design paper which, however, does not mention any cognitive outcome.

Incomplete outcome data Low risk
(attrition bias)

Quote: "of the 7045 age-eligible patients, 271 were no longer active PHSII participants (3.8\%) and 4 were deceased $(0.06 \%)$. Of the remaining 6770 , we were unable to reach 315 (4.7\%). Of the 6455 participants contacted, 5956 (92.3\%) completed a cognitive assessment: 4052 from the original PHS and 1904 new recruits.." "Participation (in the cognitive substudy) was virtually identical in those assigned to beta-carotene (92.0\%) vs placebo $(92.6 \%)$ and in continuing participants (from the PHS) (92.1\%) vs new recruits (to PHS II) (92.7\%)."

Selective reporting (re- Low risk porting bias)

Comment: no differences found between the protocol (clinicaltrials.gov Identifier: NCT00270647) and article. In addition, all outcomes specified in the Methods were reported in the Results.

Other bias Low risk No other source of bias identified

$\begin{array}{ll}\text { Methods } & \text { Substudy of the Physicians' Health Study II, a randomised, double-blind, placebo-controlled, } 2 \times 2 \times 2 \times \\ 2 \text { factorial trial testing ß-carotene, vitamin E, ascorbic acid, and a multivitamin for their role in prevent- }\end{array}$


Grodstein 2013 (Continued)

ing chronic diseases including total and prostate cancer, cardiovascular disease, and age-related eye disease among 14641 male physicians aged 50 years or older.

The trial was done from 1997 to 1 June 2011. The cognitive function substudy began in 1998.

Participants

\section{Location: not reported}

Recruitment: The Physicians' Health Study II. Quote: "In July 1997, invitations to enrol in PHS II were mailed to eligible participants from PHS I who had been part of an earlier trial of aspirin and beta-carotene among 22,071 physicians aged 40 to 84 years in 1982. Second, in July 1999, invitation letters were mailed to a new group of male physicians identified from a list provided by the American Medical Association."

The substudy of cognitive function was conducted among PHS II participants aged 65 years or older.

Number randomised: 2980 in multivitamin, 2967 in placebo

Participant (baseline) characteristics:

All participants were men.

- Age, mean (SD):

* multivitamin: $71.6(6.0)$

* placebo: $71.6(5.9)$

Inclusion criteria: not reported

Exclusion criteria: history of cirrhosis or active liver disease, patients receiving anticoagulants, or reported a serious illness that may interfere with study participation

Men were also required to forgo current use of multivitamins or individual supplements containing more than $100 \%$ of the recommended daily allowance of vitamin E, vitamin C, B-carotene, or vitamin A during PHS II follow-up.

For those newly recruited: no history of cancer, active liver disease, current renal disease, peptic ulcer, or gout.

Quote: "Only physicians who comply with the pill-taking regimen at least two-thirds of the time and remain willing and eligible to participate will be subsequently randomized".

\section{Intervention:}

1. B-carotene (Lurotin, $50 \mathrm{mg}$ on alternate days, or its placebo; BASF, Florham Park, New Jersey);

2. vitamin $E$ (synthetic alfa-tocopherol, $400 \mathrm{IU}$ on alternate days, or its placebo; BASF);

3. ascorbic acid (synthetic ascorbic acid, $500 \mathrm{mg}$ daily, or its placebo; BASF);

4. multivitamin (Centrum Silver or its placebo daily; Pfizer, New York, New York)

NB: Grodstein 2007 reported on the ß-carotene and Grodstein 2013 on multivitamin supplementation.

Comparator group: placebo multivitamin

Use of additional interventions (common to both treatment arms): Because of the factorial design, some participants were also taking vitamin $\mathrm{E}$ and/or vitamin C.

Exposure to study intervention: Mean time from randomisation to initial cognitive assessment was 2.5 years (range, 0.18 to 5.3 years) and mean time from randomisation to the final cognitive assessment was 8.5 years (range, 0.3 to 14.2 years).

\section{Outcomes}

\section{Primary Outcomes:}

A global composite score averaging 5 tests of global cognition, verbal memory, and category fluency. 
The cognitive battery included the Telephone Interview for Cognitive Status (TICS); immediate and delayed recall on the East Boston Memory Test (EBMT) (verbal memory); the delayed recall of a 10-word list (verbal memory); and a category fluency task.

The cognitive function substudy began in 1998. Up to 4 repeated cognitive assessments by telephone interview were completed over 12 years.

Quote: "The beta-carotene group of the PHS II continued as planned through May 2003... Treatment and follow-up of the vitamin E and C components continued through August 2007...The multivitamin intervention continued through 1 June 2011.."

\section{Eligible cognitive outcomes:}

- global cognitive function measured with TICS

- episodic memory (verbal memory) measured using an average of $z$-scores ${ }^{\star}$ for immediate and delayed recall on the EBMT and delayed recall of a 10 -word list

- executive functioning measured with category fluency: animals named during 1 minute

Function outcome extracted: none reported

Quality of life outcome extracted: none reported

Safety outcome extracted: none reported

Funding sources, Quote: "National Institutes of Health, BASF, Pfizer, and DSM Nutritional Products." "By grants CA 097193, CA 34944, CA 40360, HL 26490, HL 34595, AG 15933, and T32-AG000158 from the National Institutes of Health, and an investigator-initiated grant from BASF. Study agents and packaging were provided by BASF and Pfizer, and study packaging was provided by DSM Nutritional Products."

Declarations of interest, quote: "Disclosures can be viewed at www.acponline.org/authors/icmje/ConflictOfInterestForms.do?msNum_M13-1340." Several authors reported some conflicts of interest.

\section{Treatment adherence:}

"83.5\% of the multivitamin group and $84.2 \%$ of the placebo group reported taking at least two thirds of their study pills".

\section{Risk of bias}

\begin{tabular}{|c|c|c|}
\hline Bias & Authors' judgement & Support for judgement \\
\hline \multirow[t]{3}{*}{$\begin{array}{l}\text { Random sequence genera- } \\
\text { tion (selection bias) }\end{array}$} & Low risk & $\begin{array}{l}\text { Quote: "The PHS II is a randomized, double-blind, placebo-controlled, } 2 \times 2 \times 2 \times 2 \\
\text { factorial trial". }\end{array}$ \\
\hline & & "Randomization..using a computer-generated list of random numbers". \\
\hline & & Comment: adequate method of random generation \\
\hline
\end{tabular}

Allocation concealment Low risk
(selection bias)

Quote: "The PHS II is a randomized, double-blind, placebo-controlled, $2 \times 2 \times 2 \times 2$ factorial trial".

Comment: method of allocation concealment not reported, but likely to be adequate

\begin{tabular}{|c|c|c|}
\hline $\begin{array}{l}\text { Blinding of participants } \\
\text { and personnel (perfor- } \\
\text { mance bias) } \\
\text { All outcomes }\end{array}$ & Unclear risk & $\begin{array}{l}\text { Quote: "The PHS II is a randomized, double-blind, placebo-controlled, } 2 \times 2 \times 2 \times 2 \\
\text { factorial trial". } \\
\text { Comment: method of blinding not reported }\end{array}$ \\
\hline All outcomes & & Comment: method of blinding not reported \\
\hline $\begin{array}{l}\text { Blinding of outcome as- } \\
\text { sessment (detection bias) }\end{array}$ & Unclear risk & $\begin{array}{l}\text { Quote: "The PHS II is a randomized, double-blind, placebo-controlled, } 2 \times 2 \times 2 \times 2 \\
\text { factorial trial". }\end{array}$ \\
\hline
\end{tabular}


Grodstein 2013 (Continued)

All outcomes
"An Endpoint Committee of physicians blinded to the participants' treatment assignment, will review the medical records for final confirmation of a reported diagnosis".

Comment: The method of blinding of outcome assessment for the cognitive substudy was not reported. The statement about the Endpoint Committee is contained in the design paper which, however, does not mention any cognitive outcome.
Incomplete outcome data Low risk (attrition bias)

All outcomes
There was good retention of participants from the first to the second (96\%) and the third (90\%) assessments.

Quote: "the fourth assessment was not attempted in many participants because of trial completion (that is, 2700 (45\%) of the initial 5947 who completed the initial interview were invited to participate at the fourth assessment before the trial closed on 1 June 2011)".

Comment: 3623 (61\%) patients had none of the assessments at last visit so we considered there was a high risk of attrition bias for the final assessment only (time point $>5$ to 10 years).

Comment: No differences identified between the protocol ClinicalTrials.gov: NCT00270647) and the article. All outcomes specified in the Methods were reported in the Results.
Selective reporting (re- Low risk porting bias)
No other risks identified

Hankey 2013

Methods Prespecified substudy of the VITATOPS trial, a randomized, 2-arm, parallel group, placebo-controlled trial

Participants Location: international, multicentre (20 countries from 4 continents)

Number randomised: 8164 participants with recent stroke or TIA randomised in VITATOPS. This substudy was of the 2214 participants who were cognitively unimpaired - defined as MMSE $\geq 24$ six months after the qualifying cerebrovascular event - and who had 1 or more further MMSEs during follow-up.

$1110 / 2214$ allocated to B vitamins

$1104 / 2214$ allocated to placebo

\section{Participant (baseline) characteristics:}

- gender: $67.3 \%$ male

- age, mean (SD): 63.6 (11.8)

- baseline cognitive function:

- B vitamins group MMSE 28.05 (SD 1.76)

- placebo group MMSE 28.09 (SD 1.77)

Inclusion criteria: "patients presenting within 7 months of stroke (ischaemic or haemorrhagic) or TIA (eye or brain), as defined by standard criteria, are eligible" (for VITATOPS). For cognitive substudy, MMSE $\geq 24$ six months after the qualifying cerebrovascular event and $\geq 1$ further MMSE measured during follow-up.

Exclusion criteria: patients taking folic acid or vitamin B6 on medical advice; taking methotrexate for any reason; pregnant or at risk of pregnancy; limited life expectancy 
Comparator $(n=1104)$ :

Placebo

\begin{tabular}{ll}
\hline Outcomes & $\begin{array}{l}\text { Primary outcome for this prespecified substudy was a new diagnosis of cognitive impairment (MMSE } \\
\text { score }<24 \text { on } \geq 2 \text { follow-up visits } \geq 6 \text { months after the qualifying stroke. }\end{array}$ \\
Secondary outcomes were tHcy, the mean MMSE, cognitive decline (i.e. a decline from baseline, $\geq 6$ \\
months after the qualifying stroke, of $\geq 3$ points in the MMSE score on $\geq 2$ follow-up visits), composite of \\
cognitive impairment and decline.
\end{tabular}

\section{Risk of bias}

\begin{tabular}{lll}
\hline Bias & Authors' judgement & Support for judgement \\
\hline $\begin{array}{l}\text { Random sequence genera- } \\
\text { tion (selection bias) }\end{array}$ & Low risk & $\begin{array}{l}\text { Quote: "After baseline data have been provided by the investigator and it is } \\
\text { confirmed that the patient meets the study eligibility criteria, a central 24-hour } \\
\text { telephone service or an interactive website ... uses random permuted blocks } \\
\text { stratified by hospital to allocate a treatment pack number." }\end{array}$
\end{tabular}

Allocation concealment Low risk

(selection bias)
Quote: "After baseline data have been provided by the investigator and it is confirmed that the patient meets the study eligibility criteria, a central 24-hour telephone service or an interactive website ... uses random permuted blocks stratified by hospital to allocate a treatment pack number."

Blinding of participants Low risk
and personnel (perfor-
mance bias)
All outcomes

Quote: "the tablets being either vitamin supplements or matching placebo"

All outcomes

Blinding of outcome as-
sessment (detection bias) $\quad$ Low risk $\quad$ No specific information about site investigators. Likely blinded.

All outcomes

$\begin{array}{ll}\begin{array}{l}\text { Incomplete outcome data } \\ \text { (attrition bias) }\end{array} & \begin{array}{l}\text { Quote: "The } 2214 \text { cognitively unimpaired participants who underwent subse- } \\ \text { quent cognitive testing were more likely to be white, have a qualifying TIA and } \\ \text { lacunar syndrome at baseline, and less likely to have experienced an early re- } \\ \text { current stroke within } 1 \text { year of randomization ... compared with the } 394 \text { cogni- } \\ \text { tively unimpaired participants who did not proceed to further cognitive test- } \\ \text { ing." } \\ \text { ".there was no significant difference in the prevalence of baseline characteris- } \\ \text { tics among the } 2214 \text { cognitively unimpaired participants allocated B vitamins } \\ \text { (n }=1110) \text { compared with placebo }(n=1104), \text { with the exception of atrial fibril- } \\ \text { lation }(9.1 \% \text { B vitamins versus } 6.5 \% \text { placebo; } P=0.022) . "\end{array}\end{array}$

\begin{tabular}{lll}
\hline $\begin{array}{l}\text { Selective reporting (re- } \\
\text { porting bias) }\end{array}$ & Low risk & Prespecifed cognitive outcomes fully reported \\
\hline Other bias & Low risk & No other risks identified \\
\hline
\end{tabular}




\section{Participants}

Location: USA, number of sites not reported

Recruitment: female health professionals

Number randomised: 3184 in intervention, 3193 in comparator

Participant (baseline) characteristics:

- Age at randomisation:

* vitamin E group: $66.2( \pm 4)$ (range 60.4-89.9)

* placebo: $66.3( \pm 4.1)$ (range 60.4-87.1)

- Age at initial cognitive assessment:

* vitamin E group : $71.8( \pm 4)$ (range 66.1-95.5)

* placebo: $71.9( \pm 4.1)$ (range 66.0-92.8)

- Gender: women $100 \%$

- Baseline cognitive function: not assessed

Inclusion criteria: Women 65 years or older participating in the Women's Health Study. Inclusion criteria for the main study: "Women were eligible if they were 45 years of age or older; had no history of coronary heart disease, cerebrovascular disease, cancer (except non-melanoma skin cancer), or other major chronic illness; had no history of side effects to any of the study medications; were not taking aspirin or nonsteroidal antiinflammatory medications (NSAIDs) more than once a week (or were willing to forego their use during the trial); were not taking anticoagulants or corticosteroids; and were not taking individual supplements of vitamin A, vitamin E, or beta carotene more than once a week."

Exclusion criteria: not reported for the cognitive substudy

\section{Intervention ( $\mathbf{n}$ 3184):}

Vitamin E supplementation (600 IU a-tocopherol acetate; Natural Source Vitamin E Association, La Grange III) on alternate days

\section{Comparator group $(n=3193)$ :}

Placebo

Participants also randomised to aspirin $100 \mathrm{mg}$ on alternate days in $2 \times 2$ factorial design

Use of additional interventions (common to both treatment arms): not reported

\section{Outcomes}

The first cognitive assessment was a mean of 5.6 years (range 4.4 to 6.8 years) after randomisation and the final assessment was a mean of 4 years (range 2.6 to 5.7 years) later. We considered that all assessments fell into our duration category of > 5-10 years of treatment and, following the protocol, used the latest, i.e. the final, assessment only.

Primary Outcomes: global composite score averaging performance on general cognition, verbal memory and category fluency

Tests used:

- Telephone Interview of cognitive status (TICS)

- East Boston Memory test immediate and delayed recall

- Delayed recall of the TICS 10-word list

Secondary Outcomes: composite score of verbal memory, averaging performance across 4 measures of verbal memory

Cognitive assessments of general cognition, verbal memory, and category fluency were administered by telephone at 2-year intervals by trained nurses. 
Kang 2006 (Continued)

Time from randomisation to final cognitive assessment: approximately 10 years

\section{Eligible cognitive outcomes:}

- global cognitive function measured at approximately 10 years, with higher values indicating benefit

- executive functioning measured at approximately 10 years, with higher values indicating benefit

- episodic memory measured with TICS 10-word test delayed recall at approximately 10 years, with higher values indicating benefit

Function outcome extracted: none reported

Quality of life outcome extracted: none reported

Safety outcome extracted: none reported vascular disease and cancer. At the time of initiation of the cognitive substudy, participants had been treated for a mean of 5.6 years since randomisation.

Funding sources, quote: "This work was supported by grants CA47988 and AG15933 from the National Institute of Health", "The funding agency did not play any role in the design and conduct of the study; collection, management, analysis, and interpretation of the data; and preparation, review, or approval of the manuscript".

Declarations of interest, For the sub-study: none reported. For the main study, quote: "Dr. Ridker reports having received grant support from Bayer. Dr. Cook reports having served as a consultant to Bayer. Dr. Gaziano reports having served as a consultant to, and receiving grant support from, Bayer and McNeil. Dr. Hennekens reports having served as a consultant to Bayer and McNeil and receiving grant support from Bayer".

\section{Treatment adherence}

Quote: "compliance was comparable between the 2 groups: as of the final cognitive assessment, the percentage that reported taking at least two thirds of the assigned pill was $75.4 \%$ for the vitamin $\mathrm{E}$ group and $76.9 \%$ for the placebo group".

\section{Risk of bias}

\begin{tabular}{lll}
\hline Bias & Authors' judgement & Support for judgement \\
\hline $\begin{array}{l}\text { Random sequence genera- } \\
\text { tion (selection bias) }\end{array}$ & Unclear risk & $\begin{array}{l}\text { Comment: method of random sequence generation not reported. Probably ad- } \\
\text { equate }\end{array}$ \\
\hline $\begin{array}{l}\text { Allocation concealment } \\
\text { (selection bias) }\end{array}$ & Unclear risk & $\begin{array}{l}\text { Comment: method of allocation concealment not reported. Probably ade- } \\
\text { quate }\end{array}$ \\
\hline $\begin{array}{l}\text { Blinding of participants } \\
\text { and personnel (perfor- } \\
\text { mance bias) }\end{array}$ & Low risk & Quote: "The WHS is a double-blind, .... RCT." \\
All outcomes & \\
\hline
\end{tabular}

\begin{tabular}{lll}
\hline $\begin{array}{l}\text { Blinding of outcome as- } \\
\text { sessment (detection bias) } \\
\text { All outcomes }\end{array}$ & Unclear risk & $\begin{array}{l}\text { Comment: for the substudy on cognitive function, blinding of outcome assess- } \\
\text { ment was not reported }\end{array}$ \\
\hline $\begin{array}{l}\text { Incomplete outcome data } \\
\text { (attrition bias) }\end{array}$ & Unclear risk & $\begin{array}{l}\text { Comment: } 18 \% \text { of patients randomised and included in the substudy were not } \\
\text { included in the analysis at last assessment. }\end{array}$ \\
\hline
\end{tabular}


Kang 2006 (Continued)

Selective reporting (re- Unclear risk Comment: All outcomes in the Methods were reported in the results. Protocol porting bias) not available

Other bias

Low risk

No other risks identified

Kang 2008

Methods

WAFACS study. A $2 \times 2 \times 2 \times 2$ factorial, randomised, placebo-controlled trial of 3 antioxidants (vitamin $\mathrm{E}$, vitamin $C$, and $B$-carotene) and $B$ vitamins with 6.6 years of treatment and 5.4 years of follow-up of cognitive function.

The WAFACS study was started in 1998 and continued the WACS study (Kang 2009) with the introduction of a fourth arm treated with folic acid, vitamin B6, and vitamin B12.

Surviving participants of the WACS were invited to participate in the WAFACS.

When the folic acid, vitamin B6, and B12 arm was added, this combination or its placebo was combined in a retained factorial design with the vitamin $\mathrm{C}$ tablet or placebo.

Participants

Location, Country: United States of America, number of sites not reported. Inclusion from December 1998 to July 2000

Recruitment: female health professionals

Number randomised: 1071 in intervention, 1093 in comparison, but 1002 and 1007 considered at baseline because had available baseline cognitive assessment

\section{Participant (baseline) characteristics:}

- Mean age \pm SD (range) at randomisation:

* vitamin: $71.3 \pm 4.2(65.3-89.9)$

* placebo:71.3 $\pm 4.2(65.3-90.0)$

- Mean age \pm SD (range) at initial cognitive assessment:

* vitamin: $72.5 \pm 4.2$ (66.1-90.9)

* placebo: $72.5 \pm 4.2(66.1-91.2)$

- Gender: women $100 \%$

- Main diagnosis: female health professionals aged $\geq 40 y$ with cardiovascular disease or $\geq 3$ coronary risk factors

\section{Inclusion criteria:}

This was a substudy of cognitive function among 2009 participants aged $\geq 65$ years from the Women's Antioxidant and Folic Acid Cardiovascular Study, a randomised placebo-controlled trial designed to test the effect of a combination of $B$ vitamins on secondary prevention of cardiovascular disease in female health professionals aged $\geq 40$ years with cardiovascular disease or $\geq 3$ coronary risk factors.

The substudy was initiated a mean of 1.2 years after randomisation.

Exclusion criteria: not reported for the substudy

Exclusion criteria in the main study, quote: "Women were excluded if they had a history of cancer (excluding non-melanoma skin cancer) within the past ten years, any serious non-CVD illness, or were currently using warfarin or other anticoagulants. To be eligible for the folic acid/vitamin B6/B12 component, potential participants in the ongoing eight-arm trial had to be additionally willing to forgo individual supplements of folic acid, vitamin B6, and vitamin B12 at levels beyond the US recommended daily allowance". 
Kang 2008 (Continued)

\section{$2.5 \mathrm{mg}$ folic acid/day, $50 \mathrm{mg}$ vitamin B6/day, and $1 \mathrm{mg}$ vitamin B12/day}

Quote: "5442 women were assigned to 16 treatment assignments that were combinations of the 3 antioxidants" and $1 \mathrm{~B}$ vitamin supplement.

Quote: "Every $12 \mathrm{mo}$, the women were sent a year's supply of monthly calendar packs containing active agents or placebo."

Comparator group $(n=1007)$ : placebo.

Use of additional interventions (common to both treatment arms): not reported.

Primary Outcomes: global composite score averaging all 5 test results measuring general cognition, verbal memory, and category fluency using z scores

Quote: "We assessed cognitive function using a telephone cognitive battery with 5 tests measuring general cognition, verbal memory, and category fluency. "

The following tests were used:

- For general cognition, Telephone Interview of Cognitive Status (TICS);

- For verbal memory, delayed recall of the TICS 10-word list and the immediate and delayed recalls of the East Boston Memory Test;

- For category fluency, women were asked to name as many animals as possible in $1 \mathrm{~min}$.

Secondary Outcomes: verbal memory composite score, calculated by averaging 4 measures of verbal memory (the immediate and delayed recalls of both the East Boston Memory Test and the 10-word list).

Telephone cognitive function testing was administered up to 4 times over 5.4 years.

The average time from randomisation to the initial cognitive assessment was 1.2 years (range: $0.7-1.7$ years), and from randomisation to the last assessment was 6.6 years (range: 6.3- 6.9 years)."

\section{Eligible cognitive outcomes:}

- global cognitive function measured with TICS at the initial cognitive assessment (1.2 years); the second cognitive assessment (around 3 years of follow-up) and the fourth cognitive assessment (6.6 years follow-up), with higher values indicating benefit*

- episodic memory: composite(delayed East Boston memory, immediate East Boston memory, delayed TICS-10) at the initial cognitive assessment (1.2 years); the second cognitive assessment (around 3 years of follow-up) and the fourth cognitive assessment ( 6.6 years follow-up)

- executive functioning measured with Category fluency, animal naming test at the initial cognitive assessment (1.2 years); the second cognitive assessment (around 3 years of follow-up) and the fourth cognitive assessment ( 6.6 years follow-up), with higher values indicating benefit*

Function outcome extracted: none reported

Quality of life outcome extracted: none reported

Safety outcome extracted: none reported

* outcome data used in statistical analyses

Funding sources, quote: "Folic acid, vitamin B-6, vitamin B-12, and placebos were provided by the BASF Corporation (Mount Olive, NJ)".

"Supported by grants AG15933 and HL47959 from the National Institutes of Health".

Declarations of interest, quote: "None of the authors declared a conflict of interest."

"Other Financial Disclosures: Dr Gaziano has received investigator initiated study support in the form of vitamin pills and packaging from Wyeth. Dr Buring has received investigator initiated study support in

Vitamin and mineral supplementation for maintaining cognitive function in cognitively healthy people in mid and late life (Review) Copyright ( 2019 The Cochrane Collaboration. Published by John Wiley \& Sons, Ltd. 
Kang 2008 (Continued)

the form of vitamin pills and packaging from Natural Source Vitamin E Association. Dr. Manson has received investigator-initiated study support in the form of vitamin pills and packaging from Cognis and BASF."

\section{Treatment adherence}

Quote: "Compliance was comparable (83\%) in the 2 treatment groups". This statement, however, seems to have referred to the main study and not to this substudy on cognitive function,

\section{Risk of bias}

\begin{tabular}{lll}
\hline Bias & Authors' judgement & Support for judgement \\
\hline $\begin{array}{l}\text { Random sequence genera- } \\
\text { tion (selection bias) }\end{array}$ & Unclear risk & Quote: no information \\
& & Comment: method of random sequence generation not reported \\
\hline $\begin{array}{l}\text { Allocation concealment } \\
\text { (selection bias) }\end{array}$ & Unclear risk & Quote: no information \\
\hline $\begin{array}{l}\text { Blinding of participants } \\
\begin{array}{l}\text { and personnel (perfor- } \\
\text { mance bias) } \\
\text { All outcomes }\end{array}\end{array}$ & Low risk & Comment: method of allocation concealment not reported \\
\hline
\end{tabular}

Blinding of outcome as- Low risk Quote: "The telephone cognitive interviews were administered by trained insessment (detection bias) terviewers".

All outcomes

From the main study: "An endpoints committee of physicians who were blinded to randomized treatment assignment adjudicated all primary and secondary cardiovascular outcome events. Study medications and end point ascertainment were continued in a blinded fashion until the scheduled end of the trial, July 31, 2005."

Comment: It was not specifically reported whether cognitive assessors were blinded, but we considered this to be highly likely.

Incomplete outcome data Low risk (attrition bias)

All outcomes
Quote: "Participants received 3 follow-up cognitive assessments approximately every 2 y.... 94\% completed at least one follow-up assessment, and $83 \%$ completed $\geq 3$ of 4 assessments. In the fourth assessment, $24 \%$ of participants were not contacted for their assessment because only a short interval had passed between their third interview and the end of the trial in July 2005."

Comment: Although the authors provided some explanation for not seeing some patients at last visit (visit 4), the number of patients not undergoing cognitive evaluation was considerable: 956/2009 (47.5\%) at visit 4 and 314/2009 $(15.6 \%)$ at visit 3. RIsk of bias related to incomplete outcome data considered high for visit 4.

Selective reporting (re- Low risk
porting bias)

Comment: All outcomes reported in the Methods were presented in the Results. In addition, the outcomes reported in the protocol were reported as well in the article.

Other bias Low risk

\section{Quote: "155 women (7\%) were unreachable, had declined participation, or had died; thus, 2009 (93\%) women completed the initial telephone cognitive as- sessment." \\ Comment: inclusion was probably not consecutive, however, reasons for not including in the substudy were given and the number excluded appeared bal- anced between the 2 groups.}



carotene) with 8.9 years (range 7.8-9.6) of follow-up. 2000

Quote: "From November 1994 to October 1996 an introductory letter, informed consent form, and enrolment questionnaire were mailed to female health professionals who were originally identified through state licensing boards and professional organizations in the continental United States, Alaska and the Commonwealth of Puerto Rico".

"Potential candidates were also drawn from a cohort of women with prevalent CVD participating in the long-running Nurses' Health Study".

Recruitment: female health professionals

\section{Number randomised:}

2824 in cognitive substudy

- overall, vit E: 1428;

- overall, vit C: 1406 ;

- overall, betaCarot: 1406;

- placebo vit E, C, betaCarot: 353;

- placebo vit E: 1396;

- placebo vit C: 1418 ;

- placebo betaCarot: 1418.

\section{Participant (baseline) characteristics:}

Mean age ( \pm SD, range) at randomisation:

- overall, vit E: 69.1 (4.3; 62.6-87.4)

- placebo vit E: $69.0(4.2 ; 62.6-87.9)$

- overall, vit C: $69.0(4.2 ; 62.6-86.9)$

- placebo vit C: $69.1(4.3 ; 62.6-87.9)$

- overall, betaCarot: $69.1(4.3 ; 62.6-87.9)$

- placebo betaCarot: 69.0 (4.2; 62.6-87.6)

Mean age ( \pm SD, range) at initial cognitive assessment:

- overall, vit E: 72.6 (4.3; 66.1-90.9)

- placebo vit E: $72.5(4.2 ; 66.1-91.3)$

- overall, vit C: $72.5(4.2 ; 66.1-90.5)$

- placebo vit C: $72.6(4.3 ; 66.1-91.3)$

- overall, betaCarot: $72.6(4.3 ; 66.2-91.3)$

- placebo betaCarot: $72.5(4.2 ; 66.1-91.2)$

Gender: women $100 \%$

Main diagnosis: female health professionals aged $\geq 40 \mathrm{y}$ with cardiovascular disease or $\geq 3$ coronary risk factors

Inclusion criteria: This was a substudy of cognitive function among 2824 participants aged $\geq 65$ years from the Women's Antioxidant Cardiovascular Study, a randomised placebo-controlled trial designed to test the effect of a antioxidants on secondary prevention of cardiovascular disease in female health professionals aged $\geq 40$ years with cardiovascular disease or $\geq 3$ coronary risk factors. 
Exclusion criteria in the main study, quote: "Women were excluded if they had a history of cancer (excluding non-melanoma skin cancer) within the past ten years, any serious non-CVD illness, or were currently using warfarin or other anticoagulants. To be eligible for the folic acid/vitamin B6/B12 component, potential participants in the ongoing eight-arm trial had to be additionally willing to forgo individual supplements of folic acid, vitamin B6, and vitamin B12 at levels beyond the US recommended daily allowance".

Only women who were compliant (taking at least two-thirds of the pill) during the 12-week pre-randomisation run-in period were randomised.

Vitamin $\mathrm{E}$ at a dose of $402 \mathrm{mg}$ (600 IU) every other day, ß-carotene (50 mg every other day) and vitamin C (500 mg daily)

Every 12 months, the women were sent a year's supply of monthly calendar packs containing active agents or placebo.

Comparator group: placebo (placebo vitamin E, vitamin C, ß-carotene: 353; placebo vit E: 1396; placebo vitamin C: 1418; placebo ß-carotene: 1418)

Use of additional interventions (common to both treatment arms): not reported

Primary Outcomes: global composite score averaging all 5 test results measuring general cognition, verbal memory, and category fluency using z scores.

Quote: " We assessed cognitive function by telephone and administered 5 tests measuring general cognition, verbal memory and category fluency."

The following tests were used:

- Telephone Interview of Cognitive Status (TICS)

- delayed recall of the TICS 10-word list and the immediate and delayed recalls of the East Boston Memory Test (data not extractable per instrument)

- category (animal) fluency

Secondary Outcomes: 'verbal memory' composite score, calculated by averaging 4 measures of the immediate and delayed recalls of both the East Boston Memory Test and the TICS 10-word list.

Telephone cognitive function testing was administered up to 4 times over 5.4 years.

The substudy was initiated a mean of 3.5 years after randomisation. Quote: "The average time from randomization to the initial cognitive assessment was 3.5 years (range 3.1-4.7), and from randomization to the last assessment was 8.9 years (range $7.8-9.6$ )".

\section{Eligible cognitive outcomes:}

- global cognitive function measured with TICS

- executive function measured with category fluency

\section{Also known as the WACS study.}

Funding sources, quote: "Vitamin E and its placebo were provided by Cognis Corporation (LaGrange, IL); all other agents and their placebos were provided by BASF Corporation (Mount Olive, NJ)." "This work is supported by grants AG15933, HL046959 from the National Institutes of Health."

Declarations of interest, quote: "none." "Other Financial Disclosures: Dr Gaziano has received investigator initiated study support in the form of vitamin pills and packaging from Wyeth. Dr Buring has received investigator initiated study support in the form of vitamin pills and packaging from Natural Source Vitamin E Association. Dr. Manson has received investigator-initiated study support in the form of vitamin pills and packaging from Cognis and BASF." 
Kang 2009 (Continued)

\section{Treatment adherence}

"average compliance (defined as taking at least two-thirds of assigned study medications) during follow-up was $83 \%$ and did not differ significantly between the two groups". This statement, however, seemed to have referred to the main study and not to this substudy on cognitive function.

"At the end of the study, compliance (defined as taking at least two-thirds of study pills) was comparable across all groups (range 64-68\%)."

\section{Risk of bias}

\begin{tabular}{lll}
\hline Bias & Authors' judgement & Support for judgement \\
\hline $\begin{array}{ll}\text { Random sequence genera- } \\
\text { tion (selection bias) }\end{array}$ & Unclear risk & Quote: "randomized in a $2 \times 2 \times 2$ factorial design." \\
& & $\begin{array}{l}\text { Comment: method of random sequence generation not reported. Probably ad- } \\
\text { equate }\end{array}$
\end{tabular}

\begin{tabular}{ll}
\hline $\begin{array}{l}\text { Allocation concealment } \\
\text { (selection bias) }\end{array}$ & Unclear risk Comment: method of allocation concealment not reported \\
\hline
\end{tabular}

$\begin{array}{ll}\begin{array}{l}\text { Blinding of participants } \\ \text { and personnel (perfor- }\end{array} & \text { Quote: "matching placebo" } \\ \text { mance bias) } & \begin{array}{l}\text { Comment: same study as Kang } 2008 \text { (reported vitamin B arm) in which more } \\ \text { dell outcomes }\end{array} \\ & \begin{array}{l}\text { detailed description of the methods stated that "Participants and investiga- } \\ \text { tors will be blinded to treatment assignment." }\end{array}\end{array}$

\begin{tabular}{|c|c|c|}
\hline $\begin{array}{l}\text { Blinding of outcome as- } \\
\text { sessment (detection bias) } \\
\text { All outcomes }\end{array}$ & Low risk & $\begin{array}{l}\text { Quote: "The telephone cognitive interviews were administered by trained in- } \\
\text { terviewers, who were masked to the participants' randomized treatment as- } \\
\text { signment." }\end{array}$ \\
\hline
\end{tabular}

All outcomes signment."

From the main study: "An endpoints committee of physicians who were blinded to randomized treatment assignment adjudicated all primary and secondary cardiovascular outcome events. Study medications and end point ascertainment were continued in a blinded fashion until the scheduled end of the trial, July 31, 2005."

Comment: Physicians were blinded to treatment assignment in the main study. The nurses were the assessors in this cognitive substudy and were apparently not aware of treatment assignment.

\begin{tabular}{|c|c|c|}
\hline $\begin{array}{l}\text { Incomplete outcome data } \\
\text { (attrition bias) }\end{array}$ & Unclear risk & $\begin{array}{l}\text { In this review, we used outcome data from the first cognitive assessment (af- } \\
\text { ter a mean of } 3.5 \text { years) - this included } 2824 \text { of } 3170 \text { eligible participants ( } 89 \%)\end{array}$ \\
\hline All outcomes & & $\begin{array}{l}\text { - and the fourth cognitive assessment (after a mean of } 8.9 \text { years) - this includ- } \\
\text { ed } 1586 \text { participants }(50 \%) \text {. No information was given about the treatment as- } \\
\text { signments of missing participants. We considered there to be an unclear risk of } \\
\text { attrition bias for the first assessment and a high risk for the final assessment. }\end{array}$ \\
\hline
\end{tabular}

\begin{tabular}{ll}
\hline $\begin{array}{l}\text { Selective reporting (re- } \\
\text { porting bias) }\end{array}$ & Low risk \\
& $\begin{array}{l}\text { Comment: All outcomes reported in the Methods were presented in the Re- } \\
\text { sults. In addition, the outcomes specified in the protocol were reported in the } \\
\text { article. }\end{array}$
\end{tabular}

\begin{tabular}{ll}
\hline Other bias $\quad$ Low risk $\quad$ No other risks identified \\
\hline
\end{tabular}

Methods Substudy of the SU.VI.MAX, a randomised, double-blind, placebo-controlled, primary prevention trial


Kesse-Guyot 2011 (Continued)

Participants Location: France, number of sites not reported for the cognitive substudy

Recruitment: selected French participants aged 45-60 years who were enrolled in the SU.VI.MAX study (1994-2002). Quote: "A total of 12,741 individuals were included for a planned follow-up of $8 \mathrm{y}$. At the end of the supplementation (2002), a total of 6850 subjects who agreed to participate in a post-supplementation follow-up were included in the SU.VI.MAX 2 study, which sought to investigate the effect of nutrition on the quality of aging."

\section{Sample size:}

Number randomised: 6850 of the 12741 people randomised in the SU.VI.MAX study had agreed to participate in the follow-up study (SU.VI.MAX 2), which included a cognitive evaluation, but the authors reported only on the 5583 participants who were aged $45-60$ years at the onset of the treatment period.

Number completed: 4447 (see Inclusion criteria below ${ }^{\star}$ )

Participant (baseline) characteristics:

- Age at baseline: placebo $(n=2071): 52.1 \pm 4.6$, supplementation $(n=2376): 52.1 \pm 4.5$

- Age at cognitive evaluation: placebo $(n=2071): 65.5 \pm 4.6$, supplementation $(n=2376): 65.5 \pm 4.5$

- Male sex: placebo: $52.2 \%(n=1080)$, supplementation: $51.7 \%(n=1229)$

*Inclusion criteria: Quote: "Of the 6850 participants in the SU.VI.MAX 2 study, for the current analysis we selected participants who were 45-60 y old at baseline, had undergone a cognitive evaluation, and had available baseline data for serum antioxidants, smoking status, and alcohol consumption."

Exclusion criteria: not reported

Interventions Intervention ( $\mathrm{n}=2376)$ : daily vitamin C $(120 \mathrm{mg})$, beta-carotene $(6 \mathrm{mg})$, vitamin $\mathrm{E}(30 \mathrm{mg})$, selenium $(100 \mu \mathrm{g})$, and zinc $(20 \mathrm{mg})$ in combination

Comparison $(n=2071)$ : placebo

N.B. Intervention period was 8 years (1994-2002). Cognitive outcomes in SU.VI.MAX 2 were measured in 2007-9, a mean of $5.9( \pm 0.4)$ years after the end of the intervention in both groups.

Outcomes Outcomes of interest in the review:

1. Episodic memory: RI-48 test

2. Executive function: category fluency

3. Speed of processing: time taken to complete the Delis-Kaplan trail-making test (TMT)

Notes

Funding source: "Supported by the Agence Nationale de Recherche (no. ANR-05-PNRA- 010), Direction Générale de la Santé (Ministry of Health), Mederic, Sodexo, Ipsen, the Mutuelle Générale de l'Education Nationale (MGEN), and Pierre Fabre. Mederic and MGEN are French health insurance organizations that are complementary to the national health insurance system. Ipsen and Pierre Fabre are private pharmaceutical companies. They provided financial support for the overall implementation of the research project. Sodexo, a catering company, provided financial support for several teamwork events with researchers and study participants. Because French public research is independent, the sponsors were not involved in the analysis or interpretation of the findings."

Declarations of interest: "None of the authors had a conflict of interest".

Treatment adherence: "At the end of the trial phase (2002), 84\% of the participants reported having taken at least three-fourths of the capsules independent of the allocated supplementation group".

\section{Risk of bias}


Kesse-Guyot 2011 (Continued)

Random sequence genera- Low risk tion (selection bias)
Quote: "Random treatment allocation was performed by block-sequence generation stratified by sex and age group."

Comment: Should be adequate, since team included statisticians and computing staff who handled the data.

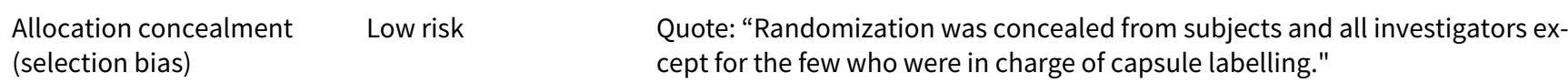

Comment: Should be adequate.

Blinding of participants Low risk and personnel (performance bias)

All outcomes
Quote: "Capsules were prepared in 52 weekly packages of 7 capsules and delivered each year in a box labelled with the participant's number and a 10-digit lot number"

"..a matching placebo".

"The absence of an easy way to distinguish antioxidant from placebo capsules was tested in a pilot study", "double-blind"

Comment: Blinding of participants and personnel seemed adequate.
Quote: "Once a possible event is suspected, all relevant records,... are collected from the hospitals, laboratories, or institutions or from the participants by the SU.VI.MAX medical investigators and are examined at the study coordinating centre".

Comment: It was not reported if outcome assessment was blinded for adverse events. However, the blinding should be adequate for cognitive function since the patients and investigators were well blinded.

$\begin{array}{ll}\begin{array}{l}\text { Incomplete outcome data } \\ \text { (attrition bias) }\end{array} & \text { High risk }\end{array}$

(attrition bias) analysis because of missing cognitive data.

All outcomes

\begin{tabular}{ll}
\hline $\begin{array}{l}\text { Selective reporting (re- } \\
\text { porting bias) }\end{array}$ & Unclear risk \\
& main study.
\end{tabular}

Other bias High risk

Participants in this study were those who responded to an invitation 6 years after the end of the parent study. The authors described this subsample of the original trial population as "more compliant and health conscious, as shown by the comparison between included and excluded subjects." This may work to reduce any difference between groups.

Kryscio 2017

\begin{tabular}{ll}
\hline Methods & PREADVISE (Prevention of Alzheimer's Disease by Vitamin E and Selenium Trial) \\
& Ancillary study to SELECT (primary aim prevention of prostate cancer) \\
& Began as a double-blind RCT in 2002, transformed into a cohort study from 2009-15 \\
Randomised, double-blind, $2 \times 2$ factorial design
\end{tabular}

Participants

Location: 130 SELECT clinical sites in the US, Canada and Puerto Rico

Recruitment: 7540 non-dementia men already enrolled in SELECT were recruited into PREADVISE between 2002 and 2008. 7338 had at least one follow-up visit. 4271 consented to continue annual tele- 
Kryscio 2017 (Continued)

phone follow-up after the RCT was closed and supplements stopped in 2009/10. Of these, 3786 were screened by telephone at least once.

Number randomised: 7540

\section{Participant characteristics:}

Age: Mean (SD) 67.5 (5.3) at PREADVISE baseline

Gender: all participants were male

Inclusion criteria: SELECT participants aged 62 years and over (age 60 years if black)

Exclusion criteria: dementia, active neurologic and/or neuropsychiatric conditions that affect cognition, as well as history of serious head injury (>30-minute loss of consciousness within the last five years prior to enrolment) and substance abuse

Interventions

Supplements were taken for $5.4 \pm 1.2$ years

$2 \times 2$ factorial design: vitamin E $400 \mathrm{IU} /$ day, selenium $200 \mathrm{mcg} /$ day, placebo

It was determined by one of two methods. First tier screening was the Memory Impairment Screen (MIS). A score $\leq 5 / 8$ triggered a second tier screen which was the expanded Consortium to Establish a Registry in Alzheimer's Disease (CERADe) battery during the RCT and the modified Telephone Interview for Cognitive Status (TICSm) during the cohort study.

Method 1: Participants with T score $\leq 35$ on CERADe or total score $\leq 35$ on TICSm were encouraged to obtain a memory work-up and share medical records with PREADVISE. Medical records were reviewed by a team of 2-3 expert neurologists and 2-3 expert neuropsychologists to determine a consensus diagnosis.

Method 2: Participants who did not obtain a memory work-up were assessed by additional measures collected during the study: AD8 Dementia Screening Interview, self-reported medical history, self-reported medication use, and cognitive test scores including the MIS, CERAD T Score, NYU Paragraph Delayed Recall, and TICSm. An AD8 $\geq 1$ (at any time during follow-up) plus a self-reported dementia diagnosis, use of a memory enhancing prescription drug (i.e. donepezil, rivastigmine, galantamine, memantine), or cognitive score $\geq 1.5$ standard deviations below expected performance yielded a dementia diagnosis. The diagnosis date was assigned to the earliest event.

Notes

"PREADVISE was ancillary to SELECT, a randomized controlled trial of the same antioxidant supplements for preventing prostate cancer. SELECT closed in 2009 due to a futility analysis." "The RCT was scheduled to continue supplements until 2012 but in September 2008, the SELECT Data and Safety Monitoring Committee recommended that supplements be discontinued due to lack of efficacy on prostate cancer incidence. Study sites closed over the next two years, during which time both PREADVISE and SELECT transitioned into cohort studies. RCT participants were asked to continue in the cohort study .."

PREADVISE had intended to recruit 10,400 men to achieve $80 \%$ power to detect a hazard ratio of 0.6 .

Power was reduced by under-recruitment, loss of sites and participants when RCT closed, and difficulties with case ascertainment.

\section{Risk of bias}

\begin{tabular}{lll}
\hline Bias & Authors' judgement & Support for judgement \\
\hline $\begin{array}{l}\text { Random sequence genera- } \\
\text { tion (selection bias) }\end{array}$ & Low risk & $\begin{array}{l}\text { "Randomized". No details. Large multisite cancer prevention trial. Likely ade- } \\
\text { quate }\end{array}$ \\
\hline
\end{tabular}


Kryscio 2017 (Continued)

$\begin{aligned} & \text { Allocation concealment } \\ & \text { (selection bias) }\end{aligned} \quad$ Low risk No details. Large multisite cancer prevention trial. Likely adequate

Blinding of participants Low risk "Double-blind". No details. Likely adequate
and personnel (perfor-
mance bias)
All outcomes

Blinding of outcome as- $\quad$ Low risk $\quad$ "Double-blind". No details. Likely adequate
sessment (detection bias)
All outcomes

\begin{tabular}{|c|c|c|}
\hline $\begin{array}{l}\text { Incomplete outcome data } \\
\text { (attrition bias) } \\
\text { All outcomes }\end{array}$ & Unclear risk & $\begin{array}{l}\text { The transition from RCT to cohort study was associated with loss of approxi- } \\
\text { mately half the participants to follow-up. "Fortunately ... the major cost was } \\
\text { sample size (reduction in person-years of follow-up) since no new large selec- } \\
\text { tion biases were introduced." }\end{array}$ \\
\hline & & $\begin{array}{l}\text { "All PREADVISE participants who completed at least one follow-up visit were } \\
\text { included in the current analyses (intent-to-treat analysis, ITT), whether they } \\
\text { participated in just the RCT or both the RCT and cohort studies." }\end{array}$ \\
\hline
\end{tabular}

\begin{tabular}{ll}
$\begin{array}{l}\text { Selective reporting (re- } \\
\text { porting bias) }\end{array}$ & Low risk \\
\hline Other bias & Low risk \\
& $\begin{array}{l}\text { "... despite randomization occurring at SELECT baseline rather than PREAD- } \\
\text { VISE enrolment, there were no perceivable differences between study arms in } \\
\text { terms of medical history, APOE \&4 genotype, or initial MIS." }\end{array}$ \\
\hline
\end{tabular}

\section{Lewerin 2005}

\begin{tabular}{ll}
\hline Methods & 2-arm, double-blinded, parallel group RCT, 4 months treatment and follow-up \\
\hline Participants & Location: one centre, Goteborg, Sweden \\
Recruitment: outpatient clinic \\
Number randomised: 126 in intervention, 69 in comparison. \\
Participant (baseline) characteristics in Vitamin ( $\mathbf{n}=\mathbf{1 2 6}$ ) and placebo ( $\mathbf{n}=\mathbf{6 9})$ \\
Age: \\
- vitamin $75.7( \pm 4.7) ;$ \\
- placebo $75.6( \pm 4.0)$ \\
- whole group ( $\mathbf{n}=209)$ mean age: 76 years and 5 months. Median 76 years (range $70-93)$ \\
Gender (males $\%):$ \\
- vitamin: $38 \%(48 / 126)$ \\
- placebo: $44 \%(30 / 69)$ \\
Inclusion criteria: community-dwelling subjects. Inclusion criteria not reported \\
Exclusion criteria: quote: "Those who had taken any vitamin supplements during the last 3 months or \\
pharmacological doses of vitamin B12, folic acid and/or vitamin B6 during the last 3 years were not al- \\
lowed to enter the study".
\end{tabular}


Daily tablet containing $500 \mu \mathrm{g}$ cyanocobalamin, $800 \mu \mathrm{g}$ folic acid, and $3 \mathrm{mg}$ vitamin B6 hydrochloride (manufactured and supplied by Recip AB, Årsta, Sweden)

Comparator group $(n=69)$ : daily oral placebo

The duration of treatment was 4 months.

\section{Use of additional interventions (common to both treatment arms):}

Use of cardiovascular medication:

- vitamin: $47 \%$

- placebo: $49 \%$

Use of antiepileptics, neuroleptics, or antidepressants (\%)

- vitamin: $22 \%$

- placebo: $23 \%$

Outcomes

Outcomes evaluated: postural-Locomotor-Manual test and cognitive tests

Postural-Locomotor-Manual test:

- Movement time

- Postural phase

- Locomotor phase

- Manual phase

- Simultaneity index

Cognitive tests:

- Digit span forward

- Digit span backward

- Identical forms

- Visual reproduction

- Synonyms

- Block design

- Digit symbol

- Thurstone's picture memory test

- Figure classification

No clear distinction between primary and secondary outcomes

In Lewerin 2003, cognitive and functional tests not reported in the Methods

Cognitive testing was conducted by the same psychologist at baseline and after 4 months.

Follow-up: 4 months (measurements before and after treatment). Mean or median follow-up not reported

Eligible cognitive outcomes:

- executive functioning measured with synonyms at 4 months, on a scale from not reported to 30 with higher values indicating benefit*

- episodic memory measured with Thurstone's picture memory test at 4 months, on a scale from not reported to 28 with higher values indicating benefit

- episodic memory measured with identical forms (Dureman 1959) at 4 months, on a scale from not reported to 60 with higher values indicating benefit

- episodic memory measured with Wechsler visual reproduction at 4 months, on a scale from not reported to 14 with higher values indicating benefit* 
- working memory measured with Wechsler digit span forward at 4 months, on a scale from not reported to 9 with higher values indicating benefit

- working memory measured with Wechsler digit span backward at 4 months, on a scale from not reported to 8 with higher values indicating benefit ${ }^{*}$

- speed of processing measured with Wechsler digit symbol at 4 months, on a scale from 0 to 90 with higher values indicating benefit*

- speed of processing measured with Thurstone's figure classification at 4 months, on a scale from not reported to 30 with higher values indicating benefit

Function outcome extracted: none reported

Quality of life outcome extracted: none reported

Safety outcome extracted: none reported

* outcome data used in statistical analyses

Funding sources, quote: "Supported by grants from the Hjalmar Svensson Foundation, the Göteborg Medical Society, the Medical Faculty at Göteborg University, the Wilhelm and Martina Lundgren Foundation, and the Magnus Strandqvist Foundation. Recip AB supported the study and provided the vitamin and placebo tablets".

Declarations of interest, quote: "None of the authors had a personal or financial conflict of interest with respect to this study".

Treatment adherence: quote "To ensure compliance, all subjects received a specified blinded number of tablets, and at the end of the study, the number of remaining tablets was compared with the initial number and planned intake during the study".

Data on treatment adherence were not clearly reported in the results.

\section{Risk of bias}

\begin{tabular}{lll}
\hline Bias & Authors' judgement & Support for judgement \\
\hline $\begin{array}{l}\text { Random sequence genera- } \\
\text { tion (selection bias) }\end{array}$ & Unclear risk & $\begin{array}{l}\text { Quote: "Of these } 195 \text { subjects, } 126 \text { were randomly assigned to receive vitamin } \\
\text { therapy and } 69 \text { to receive placebo." }\end{array}$ \\
& & Comment: method of random sequence generation not reported \\
\hline
\end{tabular}

$\begin{array}{ll}\begin{array}{l}\text { Allocation concealment } \\ \text { (selection bias) }\end{array} & \begin{array}{l}\text { Unclear risk } \\ \text { therapy and } 69 \text { to receive placebo." }\end{array} \\ & \text { Comment: method of allocation concealment not reported }\end{array}$

Blinding of participants Low risk and personnel (performance bias)

All outcomes
Quote: "and all subjects in the placebo group received an identical (other than the vitamin content) placebo tablet. " To ensure compliance, all subjects received a specified blinded number of tablets..."

"The tablet was identical in shape and composition to the placebo tablet apart from the vitamin content"; "double-blind" study.

Comment: Both participants and physicians were apparently blinded.

Blinding of outcome as-
sessment (detection bias)

All outcomes

\section{Quote: "Cognitive testing was conducted by the same psychologist (GS) at} baseline and after 4 mo."

Comment: Blinding of outcome assessors was not reported.

Incomplete outcome data Unclear risk
(attrition bias)
All outcomes

Quote: "From flow diagram, 30/209 (14\%) did not provide cognitive outcome data." 


Selective reporting (re- Unclear risk Comment: protocol not available

porting bias)

Other bias Low risk Comment: no other risks identified

Maylor 2006

Methods

3-arm, parallel group, randomised, placebo-controlled trial with 6 months duration of treatment and follow-up

Participants

Location: Two centres (Coleraine, UK and Clermont-Ferrand, France) recruited younger participants (55-70 years) and another two centres (Rome, Italy and Grenoble, France) recruited older participants (70-87 years).

Recruitment: Participants were recruited through posters, leaflets, local television and radio, and community groups and organizations serving older individuals living independently.

\section{Sample size:}

Number randomised: 201 younger participants (55-70 years), 232 older participants ( $70-87$ years)

Number completed study with compliance $>\mathbf{8 0} \%$ and included in analysis: 188 younger, 199 older

Participant baseline characteristics (baseline characteristics provided only for study completers):

Age in years, mean (SD):

- $15 \mathrm{mg} / \mathrm{d}$ : younger 61.4 (4.55), older 74.3 (3.91)

- $30 \mathrm{mg} / \mathrm{d}$ : younger 61.7 (4.57), older $74.6(3.89)$

- placebo: younger 62.3 (4.09), older 74.2 (3.58)

Gender, males/females:

- $15 \mathrm{mg} / \mathrm{d}$ : younger $30 / 30$, older $34 / 32$

- $30 \mathrm{mg} / \mathrm{d}$ : younger $31 / 34$, older $34 / 32$

- placebo: younger $32 / 31$, older $35 / 32$

Inclusion criteria:

1. men and women aged between 55 and 87 years;

2. BMI between 20 and $30 \mathrm{~kg} / \mathrm{m} 2$

3. good health;

4. MMSE score greater than 23;

5. geriatric depression scale score less than 6 .

\section{Exclusion criteria:}

"Participants were excluded from further involvement in the study according to the following criteria: (l) tobacco consumption of more than $10 \mathrm{~g} / \mathrm{day}$; (2) alcohol consumption of more than 30 (men) or 20 (women) g/day; \{3) unconventional dietary habits (for example, vegetarians, vegans); (4) use of a mineral supplement during the preceding 3 months; (5) use of more than three (55-70 years) or four (70-87 years) prescription drugs per day; (6) use of antidepressants, laxatives, or hormone replacement therapy; (7) pathological diseases, including cancer and diabetes. For participants satisfying the inclusion criteria, a biochemistry profile was performed, which included a full blood profile and tests of kidney and liver function. On the basis of these data, participants were excluded if there was insufficient renal and hepatic performance, malabsorption or inflammatory chronic pathologies, and were included if there was negative serology for the HIV and hepatitis C viruses." 
Maylor 2006 (Continued)

Quote: " $49 \%$ of the initial 842 volunteers being excluded from the study at screening on the basis of cognitive impairment, depression, pathological conditions, medications, and so on".

Interventions

\section{Intervention}

Intervention A: Zn supplementation as zinc gluconate $15 \mathrm{mg} /$ day, two tablets at the same time each day (usually after breakfast) for 6 months

Intervention B: Zn supplementation as zinc gluconate $30 \mathrm{mg} /$ day, two tablets at the same time each day (usually after breakfast) for 6 months

Comparator group: placebo/zinc gluconate $0 \mathrm{mg} /$ day, two tablets at the same time each day (usually after breakfast) for 6 months

Use of additional interventions (common to both treatment arms): not reported

Primary Outcomes: Cognitive measures (Cambridge Automated Neuropsychological Test Battery, CANTAB)

Visual memory was tested by pattern recognition memory; working memory was tested by spatial span and spatial working memory (SWM); and attention was tested by reaction time and matching to sample visual search (MTS).

Quote: "Cognitive Function was assessed in the laboratory at baseline (before supplementation) and after 3 and 6 months of supplementation, using different (parallel) versions of the CANTAB tests on each occasion."

Secondary Outcomes: serum and urinary zinc

Quote: "Participants fasted overnight for $12 \mathrm{~h}$ before blood and urine samples were taken on each of these occasions to determine Zn levels."

Funding sources, quote: “European Commission 'Quality of Life and Management of Living Resources' Fifth Framework Programme. contract no. QLKI-CT-2001-00168."

Declarations of interest: not reported

\section{Treatment adherence}

"Compliance was less than $80 \%$ for three older participants and so they were also excluded."

Outcome data were not reported separately for the Zinc and placebo groups

\section{Risk of bias}

\begin{tabular}{lll}
\hline Bias & Authors' judgement & Support for judgement \\
\hline $\begin{array}{l}\text { Random sequence genera- } \\
\text { tion (selection bias) }\end{array}$ & Unclear risk & $\begin{array}{l}\text { Quote: "Participants were assigned to one of three levels of Zn supplementa- } \\
\text { tion (placebo or } 0 \mathrm{mg} / \mathrm{d}, 15 \mathrm{mg} / \mathrm{d} \text { and } 30 \mathrm{mg} / \mathrm{d} \text { ) according to the same stan- } \\
\text { dardised random order in each centre." } \\
\text { Comment: not described how sequence generation was done. The possibility } \\
\text { that this was quasi-randomised could not be ruled out. }\end{array}$ \\
\hline $\begin{array}{l}\text { Allocation concealment } \\
\text { (selection bias) }\end{array}$ & Unclear risk & As above \\
\hline $\begin{array}{l}\text { Blinding of participants } \\
\text { and personnel (perfor- } \\
\text { mance bias) }\end{array}$ & Unclear risk & $\begin{array}{l}\text { Quote: “...Zn supplementation (0, } 15 \text { or } 30 \mathrm{mg} / \mathrm{d}) \text { was administered as zinc glu- } \\
\text { conate, participants taking two tablets at the same time each day (usually af- } \\
\text { ter breakfast) for } 6 \text { months. (Tablets were identified by a code so that neither } \\
\text { the experimenter nor the participants knew the dose. The code was not bro- } \\
\text { ken until the study had been completed and all the data had been entered into } \\
\text { computer files ready for analysis)". }\end{array}$
\end{tabular}


Comment: Although a placebo was mentioned, there was no description of its appearance or whether it could be distinguished from the zinc supplements.

\begin{tabular}{lll}
\hline $\begin{array}{l}\text { Blinding of outcome as- } \\
\text { sessment (detection bias) } \\
\text { All outcomes }\end{array}$ & Unclear risk & Comment: as above. Unclear whether blinding was adequate \\
\hline $\begin{array}{l}\text { Incomplete outcome data } \\
\text { (attrition bias) } \\
\text { All outcomes }\end{array}$ & High risk & $\begin{array}{l}\text { Comment: There was no description of the completeness of outcome data for } \\
\text { each main outcome, including attrition and exclusions from the analysis. }\end{array}$ \\
\hline $\begin{array}{l}\text { Selective reporting (re- } \\
\text { porting bias) }\end{array}$ & High risk & $\begin{array}{l}\text { Comment: CANTAB data for the different interventional groups was shown } \\
\text { graphically only. Number of participants for each outcome was not reported. }\end{array}$ \\
\hline $\begin{array}{l}\text { Other bias } \\
\text { Baseline characteristics were shown only for participants who completed the }\end{array}$
\end{tabular}

\section{McMahon 2006}

$\begin{array}{ll}\text { Methods } & \text { 2-arms, placebo-controlled, randomised clinical trial with intervention of } 2 \text { years and follow-up dura- } \\ \text { tion of } 2 \text { years. No mean or median (range) follow-up reported. }\end{array}$
tion of 2 years. No mean or median (range) follow-up reported.

Participants

Location: Dunedin, New Zealand, number of centres involved unclear

Recruitment: Department of Human Nutrition, University of Otago

Number randomised: 138 in intervention, 138 in comparison

Participant (baseline) characteristics:

Age, years, mean (SD)

- placebo $(n=126): 73.4 \pm 5.7$

- $\operatorname{vitamin}(n=127): 73.6 \pm 5.8$

Female sex, $\mathrm{n}(\%)$ :

- placebo $(n=126): 65(52)$

- $\operatorname{vitamin}(n=127): 47$ (37)

Inclusion criteria:- age of 65 years or older. Those with a fasting homocysteine concentration of at least $13 \mu \mathrm{mol} / \mathrm{L}$ and a normal plasma creatinine concentration $(133 \mu \mathrm{mol} / \mathrm{L}(1.5 \mathrm{mg} / \mathrm{dL})$ in men and 115 $\mu \mathrm{mol} / \mathrm{L}(1.3 \mathrm{mg} / \mathrm{dL})$ in women) were invited to participate in the trial.

\section{Exclusion criteria:}

- ineligible if they had suspected dementia;

- were taking medications known to interfere with folate metabolism (e.g. oral hypoglycaemic agents or antiepileptic agents);

- were taking vitamin supplements containing folic acid, vitamin B12, or vitamin B6;

- were being treated for depression;

- had diabetes or had a history of stroke or transient ischaemic attacks.

Quote: "Five participants (three in the placebo group and two in the vitamin group) had a baseline MMSE score of less than 26." 
Treatment capsules contained the filler plus $1000 \mu \mathrm{g}$ of folate (the calcium salt of l-5-methyltetrahydrofolate), $500 \mu \mathrm{g}$ of vitamin B12 (cobalamin), and $10 \mathrm{mg}$ of vitamin B6 (pyridoxine) (Merck Eprova).

Comparator group ( $n=133)$ : placebo.

The placebo capsules contained a blend of magnesium stearate and microcrystalline cellulose as a filler.

All capsules were gelatin-coated, identical in colour and shape, and packaged in blister packs.

Outcomes

Primary outcomes: scores on tests of cognition including Mini-Mental State Examination, Wechsler Paragraph Recall test, Category Word Fluency test, Rey Auditory Verbal Learning Test, trials I-V, Rey Auditory Verbal Learning Test, trial VII, Raven's Progressive Matrices, Controlled Oral Word Association Test, Part B of the Reitan Trail Making Test, the National Adult Reading Test (at baseline).

Secondary Outcomes: biochemical measurements, including plasma concentrations of homocysteine, folate, and vitamin B12

\section{Eligible cognitive outcomes:}

- global cognitive function measured with MMSE at 1 and 2 years, with higher values indicating benefit

- executive functioning measured with Raven's Progressive Matrices at 1 and 2 years, with higher values indicating benefit

- executive functioning measured with Part B of the Reitan Trail Making at 1 and 2 years, with lower values indicating benefit

- executive function measured with Category Word Fluency test (total no. of words generated in three 1 -min tests) at 1 and 2 years, with higher values indicating benefit

- episodic memory measured with Rey Auditory Verbal Learning, Trials I-V at 1 and 2 years, with higher values indicating benefit*

- episodic memory measured with Wechsler Paragraph Recall test at 1 and 2 years, with higher values indicating benefit

- episodic memory measured with Rey Auditory Verbal Learning, Trial VII at 1 and 2 years, with higher values indicating benefit

Notes

Funding sources: supported by an Otago Research Grant, Merck Eprova for providing the vitamin and placebo capsules

Declarations of interest: No potential conflict of interest relevant to this article was reported.

\section{Treatment adherence:}

Compliance was assessed by counting returned capsules. Data on compliance were not reported.

\section{Risk of bias}

Bias Authors' judgement Support for judgement

Random sequence genera- Low risk tion (selection bias)
Quote: "Before randomization, all eligible participants were stratified according to the median values for age and homocysteine concentration in the screening population. Random decimals between 0 and 1 were generated for each person in each of the four strata. Those below the median of the random numbers in each stratum were assigned to the vitamin group, and the remainder were assigned to the placebo group."

Comment: adequate method of sequence generation

Allocation concealment Unclear risk
(selection bias)

Quote: "Random decimals between 0 and 1 were generated for each person in each of the four strata. Those below the median of the random numbers in each stratum were assigned to the vitamin group, and the remainder were assigned to the placebo group." 
Comment: unclear method of allocation concealment

$\begin{array}{ll}\begin{array}{l}\text { Blinding of participants } \\ \text { and personnel (perfor- }\end{array} & \text { Low risk } \\ \begin{array}{l}\text { mance bias) } \\ \text { All outcomes }\end{array} & \begin{array}{l}\text { Quote: "We conducted a two-year, double-blind, placebo-controlled, random- } \\ \text { ized clinical trial". }\end{array} \\ & \begin{array}{l}\text { "All capsules were gelatin-coated, identical in color and shape, and packaged } \\ \text { in blister packs." }\end{array} \\ & \text { Comment: Participants and personnel were blinded. }\end{array}$

\begin{tabular}{lll}
\hline $\begin{array}{l}\text { Blinding of outcome as- } \\
\text { sessment (detection bias) } \\
\text { All outcomes }\end{array}$ & Unclear risk & $\begin{array}{l}\text { Quote: "One of the authors administered all the cognitive tests." } \\
\text { Comment: unclear whether outcome assessment was blinded }\end{array}$ \\
\hline $\begin{array}{l}\text { Incomplete outcome data } \\
\begin{array}{l}\text { attrition bias) } \\
\text { All outcomes }\end{array}\end{array}$ & Low risk & Comment: $<10 \%$ of randomised patients were not included in the analysis. \\
\hline $\begin{array}{l}\text { Selective reporting (re- } \\
\text { porting bias) }\end{array}$ & Low risk & $\begin{array}{l}\text { Comment: All the primary and secondary outcomes mentioned in the Methods } \\
\text { and protocol were reported. }\end{array}$ \\
\hline \begin{tabular}{l} 
Other bias \\
\hline
\end{tabular} & Low risk & Comment: none identified \\
\hline
\end{tabular}

MRC/BHF 2002

$\begin{array}{ll}\text { Methods } & 2 \times 2 \text { factorial randomised placebo-controlled study of antioxidant vitamins and simvastatin. Mean du- } \\ \text { ration of follow-up } 5 \text { years }\end{array}$

Participants Location: 69 Hospitals in the UK

Recruitment: Medical collaborators from 69 UK hospitals appointed senior nurses to run special clinics for the study. With the permission of their relevant consultant colleagues, records of patient discharges and of special wards or clinics were used to identify potentially eligible candidates for the study. The coordinating centre used this information to seek agreement, in the name of the local collaborator, from general practitioners to invite patients to the local study clinic.

\section{Sample size:}

- Number randomised: 10,269 in intervention, 10,267 in comparison

- Number completed: 10,241 in intervention, 10,228 in comparison

\section{Participant (baseline) characteristics:}

\section{Inclusion criteria:}

1. Male or female aged 40 to 80 years;

2. High risk of coronary heart disease death over the next 5 years:

- (i) coronary disease: definite or probable clinical diagnosis of myocardial infarction, unstable angina, stable angina, PTCA or CABG;

- (ii) occlusive disease of non-coronary arteries: clinical, angiographic, or ultrasound diagnosis of carotid artery stenosis (e.g. transient ischaemic attack or non-disabling stroke not thought to be haemorrhagic), carotid endarterectomy, leg artery stenosis (e.g. intermittent claudication) or surgery;

- (iii) diabetes mellitus: clinical diagnosis of insulin-dependent or non-insulin-dependent diabetes;

- or (iv) treated hypertension: use of antihypertensive drug therapy in male aged 65 years or over (in order to be at sufficiently high risk of vascular events); 
3. No clear indications for the study treatments: the patient is not already taking HMG CoA reductase inhibitors or high-dose vitamin E supplements, and neither the patient nor the patient's doctor considers there to be any definite need to do so;

4. No clear contraindications to the study treatments:

- (i) baseline plasma cholesterol: $<3.5 \mathrm{mmol} . \mathrm{L}^{-1}$;

- (ii) chronic liver disease (i.e. cirrhosis or hepatitis) or abnormal liver function (i.e. alanine transaminase $>1.5 \mathrm{x}$ upper limit of normal);

- (iii) severe renal disease or evidence of renal impairment (i.e. creatinine $>2 x$ upper limit of normal);

- (iv) inflammatory muscle disease (such as dermatomyositis or polymyositis) or creatine kinase > $3 \times$ upper limit of normal;

- (v) concurrent treatment with cyclosporin (or a condition likely to result in organ transplantation and the need for cyclosporin);

- (vi) concurrent treatment with fibrates or high-dose niacin. (N.B. patients on cholesterol-lowering diets or drugs - other than HMG CoA reductase inhibitors, fibrates or high-dose niacin - could still be entered in the study);

- or (vii) child-bearing potential (i.e. premenopausal woman who is not sterilised or using a reliable method of contraception);

5. No other predominant medical problem:

- (i) severe heart failure or some importantly life-threatening condition other than vascular disease (such as very severe chronic airways disease or any cancer other than non-melanoma skin cancer);

- (ii) psychiatric disorder, senility or physical disability (such as severely disabling stroke);

- Or (iii) recent history of alcohol or drug abuse;

6. Eligible patients who completed a pre-randomisation run-in phase on active treatment were randomly allocated to receive simvastatin ( $40 \mathrm{mg}$ daily) or matching placebo tablets and, in a ' $2 \times 2$ factorial' design, antioxidant vitamins ( $600 \mathrm{mg}$ vitamin E, $250 \mathrm{mg}$ vitamin C, and $20 \mathrm{mg}$ beta-carotene daily) or matching placebo capsule.

\section{Exclusion criteria:}

People were ineligible if they had life-threatening conditions, such as chronic liver disease, severe renal disease, severe heart failure, severe chronic airways disease, or diagnosed cancer (other than nonmelanoma skin cancer). Those taking high-dose vitamin E supplements were not randomised.

Interventions

Intervention ( $\mathbf{n = 1 0 , 2 4 1 ) : ~} 600 \mathrm{mg}$ synthetic vitamin $\mathrm{E}, 250 \mathrm{mg}$ vitamin $\mathrm{C}$ and $20 \mathrm{mg} \beta$-carotene administered orally once per day for an average of 5 years

Comparator group $(\mathbf{n = 1 0 , 2 2 8 ) : ~ " M a t c h i n g ~ p l a c e b o ~ i n ~ s p e c i a l l y ~ p r e p a r e d ~ c a l e n d a r ~ p a c k s " ~}$

Use of additional interventions (common to both treatment arms): factorial design also included simvastatin

Outcomes

Outcomes of interest in the review:

Global cognitive function measured with TICSm

(The main comparisons for antioxidant vitamin supplementation were analyses of total coronary heart disease events and of fatal coronary heart disease events during the scheduled treatment period. Cognitive function was a secondary outcome. Quote: "It had been suggested that antioxidant vitamins (in particular, vitamin E) might slow cognitive decline, so the modified Telephone Interview for Cognitive Status (TICS-m) questionnaire was administered to participants during their final follow-up").

Notes

Funding sources: "The study was funded by the UK Medical Research Council, the British Heart Foundation, Merck \& Co (manufacturers of simvastatin: J Tobert, R Tomiak, J Young, A Tate, E John, F Walker, G Warner) and Roche Vitamins Ltd (manufacturers of the vitamins: R Salkeld, E Stöcklin, M Wahl)."

Declarations of interest: "P Sleight has received honoraria and costs for participating in meetings." 
Treatment adherence: Compliance with study treatment was assessed at each follow-up by reviewing the calendar packed capsules remaining and for those who had stopped, the reasons for doing so were sought.

\section{Risk of bias}

\begin{tabular}{lll}
\hline Bias & Authors' judgement & Support for judgement \\
\hline $\begin{array}{ll}\text { Random sequence genera- } \\
\text { tion (selection bias) }\end{array}$ & Low risk & $\begin{array}{l}\text { Quote: "The central telephone randomisation system used a minimisation al- } \\
\text { gorithm to balance the treatment groups with respect to eligibility criteria and } \\
\text { other major prognostic factors." } \\
\text { Comment: adequate method of random sequence generation }\end{array}$ \\
\end{tabular}

\begin{tabular}{|c|c|c|}
\hline $\begin{array}{l}\text { Allocation concealment } \\
\text { (selection bias) }\end{array}$ & Low risk & Comment: "central telephone randomisation system" \\
\hline $\begin{array}{l}\text { Blinding of participants } \\
\text { and personnel (perfor- } \\
\text { mance bias) } \\
\text { All outcomes }\end{array}$ & Low risk & Comment: "identical tablets" \\
\hline $\begin{array}{l}\text { Blinding of outcome as- } \\
\text { sessment (detection bias) } \\
\text { All outcomes }\end{array}$ & Low risk & $\begin{array}{l}\text { Comment: Outcome assessors at study centres not aware of treatment alloca- } \\
\text { tion. }\end{array}$ \\
\hline
\end{tabular}

\begin{tabular}{|c|c|c|}
\hline $\begin{array}{l}\text { Incomplete outcome data } \\
\text { (attrition bias) } \\
\text { All outcomes }\end{array}$ & Low risk & $\begin{array}{l}\text { Comment: Relatively low dropout rate and high number of participants com- } \\
\text { pleted follow-up at } 5 \text { years. }\end{array}$ \\
\hline
\end{tabular}

\begin{tabular}{lll}
\hline $\begin{array}{l}\text { Selective reporting (re- } \\
\text { porting bias) }\end{array}$ & Low risk & Comment: single cognitive outcome measure reported \\
\hline Other bias & Low risk & Comment: no other risks identified \\
\hline
\end{tabular}

Rossom 2012

$\begin{array}{ll}\text { Methods } & \text { Women's Health Initiative Memory Study } \\ \text { Post hoc analysis of a 2-arm randomised double-blind placebo-controlled trial }\end{array}$

Participants

Location: US multicentre

Recruitment: Forty Women's Health Initiative (WHI) clinical centres across the United States. Participants were enrolled between 1994 and 1999.

Number randomised: 2034 in intervention, 2109 in comparison

\section{Participant (baseline) characteristics:}

- Age: mean 71 years (65-80)

* vitamin D/calcium: mean 70.7 years

* placebo: mean 70.9 years

- Gender: women $100 \%$

- Main diagnosis: postmenopausal women aged 65 and older without probable dementia or cognitive impairment at baseline 
Inclusion criteria: women aged 65 and older without probable dementia or cognitive impairment at baseline who participated in the WHI Calcium and Vitamin D Trial

Other inclusion criteria specified in the main study: Eligible women were 50 to 79 years of age at the initial screening and had no evidence of a medical condition associated with a predicted survival of less than three years and no safety, adherence, or retention risks.

Exclusion criteria: diseases associated with significant risk of mortality (invasive cancer in the previous 10 years; any history of breast cancer or a suspicion of breast cancer at the time of screening; acute myocardial infarction, stroke, or transient ischaemic attack in the previous 6 months; known chronic active hepatitis or severe cirrhosis), safety (blood cell count indicative of disease, severe hypertension, current use of oral corticosteroids), and adherence or retention (unwillingness or inability to complete baseline study requirements)

Interventions

Intervention ( $\mathbf{n}=\mathbf{2 0 3 4})$ :

$1000 \mathrm{mg}$ of calcium carbonate and $400 \mathrm{IU}$ of vitamin D3

Two tablets per day in divided doses and with meals

Comparator group (n=2109): placebo

Two tablets per day in divided doses and with meals

Supplements or placebo were provided by GlaxoSmithKline.

Active tablets, chewable or swallowable (after July 1997), contained $500 \mathrm{mg}$ of elemental calcium (as calcium carbonate) and $200 \mathrm{IU}$ of vitamin D.

\section{Use of additional interventions (common to both treatment arms):}

Use of personal supplemental calcium up to $1000 \mathrm{mg} /$ day and vitamin D up to $600 \mathrm{IU} /$ day in addition to the study tablets was allowed.

Calcium supplement use, $\mathrm{n}(\%)$ :

- vitamin D/calcium: 1061 (52.2)

- placebo 1196 (56.7)

Vitamin D supplement use, $\mathrm{n}(\%)$ :

- vitamin D/calcium: 929 (45.7)

- placebo 1047 (49.6)

See also Notes below

\section{Outcomes}

\section{Outcomes of interest to the review:}

Quote: "The Women's Health Initiative Calcium and Vitamin D trial (CaD) was designed to determine whether calcium plus vitamin D3 supplementation prevents hip fracture and colorectal cancer".

WHIMS (the Women's Health Initiative Memory Study) was an ancillary study.

Primary outcomes of WHIMS: classifications of probable dementia, mild cognitive impairment and cognitively normal

Quote: "A diagnosis of dementia was based on Diagnostic and Statistical Manual of Mental Disorders, Fourth Edition, criteria."

Quote: "A diagnosis of $\mathrm{MCl}$ was based on accepted criteria at the time of WHIMS initiation, operationally defined as performance in the 10th or lower percentile on at least one Consortium to Establish a Registry for Alzheimer's Disease (CERAD) test based on CERAD norms, a report from the designated informant of functional impairment on the part of the participant that was not severe enough to interfere 
with basic activities of daily living, no evidence of a psychiatric or medical condition that could account for the cognitive decline, and absence of adjudicated dementia."

Secondary outcomes: global cognitive function as assessed annually using the Modified Mini Mental State Examination (3MS) and domain-specific cognitive functions as assessed annually in a subset of $1420 \mathrm{CaD}$ participants using the WHISCA cognitive battery

The WHISCA cognitive battery included the Digit Span Forward and Backward Test, the Primary Mental Abilities Vocabulary test, the Card Rotations Test, letter and semantic fluency tests, the California Verbal Learning Test, the Benton Visual Retention Test, and the Finger Tapping Test.

Depressive symptoms were measured using the Burnham screening algorithm.

Probable dementia or $\mathrm{MCl}$ were assessed during a mean follow-up of 7.8 years.

Domain-specific measures of cognitive function were obtained in the 1420 women enrolled in the $\mathrm{CaD}$ trial and WHISCA seen for an average of 4.9 (treatment) and 5.0 (placebo) annual visits through 2007.

\section{Eligible cognitive outcomes:}

- global cognitive function measured with Modified MMSE (3MS)

- episodic memory measured with Benton Visual Retention Test

- episodic memory measured with California Verbal Learning Test

- speed of processing measured with finger tapping

- executive function measured with letter and category fluency at 5 years

Notes

"All WHIMS participants ... were also participants in the WHI Hormone Therapy trials. Some were also participants in a third trial of dietary modification to compare a low-fat eating pattern to a usual ad-libitum diet."

Funding sources, quote: "The WHI program is funded by the National Heart, Lung, and Blood Institute, National Institutes of Health, U.S. Department of Health and Human Services through Contracts N01WH22110, 24152, 32100-2, 32105-6, 32108-9, 32111-13, 32115, 32118-32119, 32122, 42107-26, 42129-32, and 44221."

"Sponsor's Role: The sponsors did not play any role in the design or conduct of the study; collection, management, analysis, or interpretation of the data; or preparation, review, or approval of the manuscript".

Declarations of interest, quote: "Dr. Rossom's work on this manuscript was supported in part by the Veterans Health Administration through Clinical and Health Services Research and Development Grants 04SCRCOE-001 and HFP-98-001. Dr. JoAnn Manson and colleagues at Brigham and Women's Hospital, Harvard Medical School, are recipients of funding from the National Institutes of Health to conduct the VITamin D and OmegA-3 TriaL, a large-scale randomized trial of vitamin D and omega-3s in the prevention of cancer and cardiovascular disease".

\section{Treatment adherence}

"Adherence was assessed annually in a structured interview and by weighing remaining pills."

Adherence (defined as $\geq 80 \%$ ):

- vitamin D/calcium: $1446(72.3 \%)$

- placebo: $1566(75.5 \%)$

\section{Risk of bias}

\begin{tabular}{lll}
\hline Bias & Authors' judgement & Support for judgement \\
\hline $\begin{array}{l}\text { Random sequence genera- } \\
\text { tion (selection bias) }\end{array}$ & Low risk & $\begin{array}{l}\text { Quote: “Eligible women were randomly assigned in a double-blind fashion to } \\
\text { receive supplements or placebo (provided by GlaxoSmithKline) in equal pro- }\end{array}$
\end{tabular}


portions with use of a permuted-block algorithm stratified according to clinical center and age".

Comment: method of random sequence generation not reported, probably adequate

\section{Allocation concealment Unclear risk} (selection bias)
Quote: "Eligible women were randomly assigned in a double-blind fashion to receive supplements or placebo (provided by GlaxoSmithKline) in equal proportions with use of a permuted-block algorithm stratified according to clinical center and age".

Comment: method of allocation concealment not reported

$\begin{array}{ll}\begin{array}{l}\text { Blinding of participants } \\ \text { and personnel (perfor- }\end{array} & \text { Low risk } \\ \begin{array}{l}\text { mance bias) } \\ \text { All outcomes }\end{array} & \begin{array}{l}\text { Quote: "1,000 mg of calcium carbonate and } 400 \text { IU of vitamin D or identical } \\ \text { placebos." , Eligible women were randomly assigned in a double-blind fash- } \\ \text { ion". }\end{array} \\ & \text { Comment: Participants and personnel were apparently blinded. }\end{array}$

\begin{tabular}{|c|c|c|}
\hline $\begin{array}{l}\text { Blinding of outcome as- } \\
\text { sessment (detection bias) } \\
\text { All outcomes }\end{array}$ & Low risk & $\begin{array}{l}\text { Quote: "A central adjudication panel of experts at the WHIMS Clinical Coor- } \\
\text { dinating Center (Wake Forest School of Medicine, Winston-Salem, NC) made } \\
\text { classifications." }\end{array}$ \\
\hline
\end{tabular}

Comment: not reported but assessors were probably blinded

\begin{tabular}{ll}
\hline $\begin{array}{l}\text { Incomplete outcome data } \\
\text { (attrition bias) }\end{array}$ & Low risk \\
All outcomes & $\begin{array}{l}\text { Quote: "All primary outcomes were analyzed on a time to-event basis accord- } \\
\text { ing to the intention-to-treat principle." }\end{array}$ \\
& $\begin{array}{l}\text { Comment: All patients included in the post hoc analysis were considered for } \\
\text { the main outcome whereas only a subset was analysed for cognitive tests. }\end{array}$
\end{tabular}

\begin{tabular}{lll}
\hline $\begin{array}{l}\text { Selective reporting (re- } \\
\text { porting bias) }\end{array}$ & Low risk & $\begin{array}{l}\text { Comment: All outcomes described in the methods or protocol (ClinicalTrial- } \\
\text { s.gov number, NCT00000611) were reported in the results. }\end{array}$ \\
\hline Other bias & Low risk & No other risks identified \\
\hline
\end{tabular}

\section{SEARCH 2010}

\begin{tabular}{|c|c|}
\hline Methods & $2 \times 2$ factorial placebo-controlled randomised trial \\
\hline Participants & $\begin{array}{l}\text { Location: UK multicentre } \\
\text { Recruitment: potentially eligible patients identified from hospital discharge records of } 88 \text { UK hospi- } \\
\text { tals. Randomisation took place between September } 1998 \text { and October } 2001 \text {. } \\
\text { Number randomised: } 6033 \text { B vitamins, } 6031 \text { placebo } \\
\text { Participant (baseline) characteristics: } \\
\text { - Age: mean age } 64.2(8.9) \text { years } \\
\text { * B vitamins: } 1885<60 y ; 2414 \geq 60 y \text { and }<70 y ; 1734 \geq 70 y \\
* \text { placebo: } 1880<60 y ; 2414 \geq 60 y \text { and }<70 y ; 1737 \geq 70 y \\
\text { - Gender: } \\
* \text { B vitamins: } 83 \% \text { male } \\
\text { * placebo: } 83 \% \text { male } \\
\text { - Main diagnosis: myocardial infarction } \\
\text { Inclusion criteria: aged } 18-80 \text { years, myocardial infarction }>3 \text { months before screening, taking a statin } \\
\text { or clear indication for statin therapy }\end{array}$ \\
\hline
\end{tabular}


Exclusion criteria: clear indication for folic acid, contraindications to study treatments, other predominant medical problem which might limit compliance with 5 years of study treatment

\begin{tabular}{ll}
\hline Interventions & $\begin{array}{l}\text { Participants randomised in } 2 \times 2 \text { factorial design to (folic acid 2mg + vitamin B12 1mg) or placebo and } \\
\text { to simvastatin } 20 \mathrm{mg} \text { or } 80 \mathrm{mg}\end{array}$ \\
\hline Outcomes & $\begin{array}{l}\text { Outcomes relevant to this review: TICSm, verbal fluency test, diagnosis of dementia. All cognitive out- } \\
\text { comes measured at final follow-up, after a mean of } 6.7 \text { (1.5) person-years. }\end{array}$ \\
\hline Notes & $\begin{array}{l}\text { "The study was funded by Merck (manufacturers of simvastatin and suppliers of the vitamins)." "The } \\
\text { funders had no role in the design and conduct of the study; collection, management, analysis and inter- } \\
\text { pretation of the data; and preparation, review and approval of the manuscript." }\end{array}$ \\
\hline
\end{tabular}

\section{Risk of bias}

\begin{tabular}{lll}
\hline Bias & Authors' judgement & Support for judgement \\
\hline $\begin{array}{ll}\text { Random sequence genera- } \\
\text { tion (selection bias) }\end{array}$ & Low risk & $\begin{array}{l}\text { Quote: "The central telephone randomization system used a minimization al- } \\
\text { gorithm to balance the treatment groups with respect to major prognostic fac- } \\
\text { tors". }\end{array}$ \\
& $\begin{array}{l}\text { Comment: adequate method of random sequence generation } \\
\end{array}$
\end{tabular}

\begin{tabular}{ll}
\hline $\begin{array}{l}\text { Allocation concealment } \\
\text { (selection bias) }\end{array}$ & Low risk \\
& Comment: adequate method of allocation concealment
\end{tabular}

\begin{tabular}{l}
\hline Blinding of participants Unclear risk Comment: no information regarding participants and personnel blinding \\
and personnel (perfor- \\
mance bias) \\
All outcomes
\end{tabular}

\begin{tabular}{|c|c|c|}
\hline \multirow[t]{2}{*}{$\begin{array}{l}\text { Blinding of outcome as- } \\
\text { sessment (detection bias) } \\
\text { All outcomes }\end{array}$} & Low risk & $\begin{array}{l}\text { Quote: "All such information is reviewed by coordinating center clinical staff, } \\
\text { blind to study treatment allocation, and events are coded according to pre- } \\
\text { specified criteria". }\end{array}$ \\
\hline & & Comment: outcome assessors were blinded \\
\hline
\end{tabular}

\begin{tabular}{ll}
\hline Incomplete outcome data & High risk \\
$\begin{array}{l}\text { (attrition bias) } \\
\text { All outcomes }\end{array}$ & $\begin{array}{l}\text { Comment: For 3173/12064 (26\%) of the eligible patients, TICSm was not avail- } \\
\text { able. }\end{array}$
\end{tabular}

All outcomes

\begin{tabular}{ll}
\hline $\begin{array}{l}\text { Selective reporting (re- } \\
\text { porting bias) }\end{array}$ & Low risk \\
& $\begin{array}{l}\text { Comment: no cognitive outcomes were included in the original protocol pub- } \\
\text { lished in 1998. Additional information was obtained from the authors: "The } \\
\text { cognitive assessment was added during the study (before any unblinding) and } \\
\text { included in the Data Anaysis Plan but had not been specified in the original } \\
\text { Protocol." We considered there to be a low risk of this introducing any bias. }\end{array}$ \\
\hline
\end{tabular}

\begin{tabular}{ll}
\hline Other bias $\quad$ Low risk $\quad$ Comment: no other risks identified \\
\hline
\end{tabular}

\section{Stott 2005}

\begin{tabular}{ll}
\hline Methods & Factorial $2 \times 2 \times 2$, randomised, placebo-controlled, double-blind study with 3 active treatments with \\
12 -week treatment and 1-year follow-up
\end{tabular}


Stott 2005 (Continued)

Recruitment: hospital-based

Number randomised: 185

Participant (baseline) characteristics:

- Age, mean \pm SD:

* placebo: $72.8 \pm 5.4$

* folic acid plus vitamin B12: $72.9 \pm 6.0$

* riboflavin (vitamin B2): $74.6 \pm 5.3$

* vitamin B6: $74.7 \pm 6.1$

* folic acid plus vitamin B12 plus vitamin B2: $76.5 \pm 8.0$

* folic acid plus vitamin B12 plus vitamin B6: $72.6 \pm 6.4$

* vitamin B6 plus vitamin B2: $74.2 \pm 6.8$

* folic acid plus vitamin B12 plus vitamin B2 plus vitamin B6: $74.0 \pm 6.5$

- Gender (male/female):

* placebo: $14 / 10$

* folic acid plus vitamin B12: 12/11

* riboflavin (vitamin $B 2$ ): 10/13

* vitamin B6: 11/12

* folic acid plus vitamin B12 plus vitamin B2: 10/13

* folic acid plus vitamin B12 plus vitamin B6: 12/11

* vitamin B6 plus vitamin B2: 10/13

* folic acid plus vitamin B12 plus vitamin B2 plus vitamin B6: 9/14

- Main diagnosis: patients aged "65 y with ischemic vascular disease"

Inclusion criteria: age $\geq 65 \mathrm{y}$ and Ischaemic vascular disease, defined as one or more of the following: history of angina pectoris, previous acute myocardial infarction, evidence of major ischaemia or previous acute myocardial infarction on the basis of a 12-lead electrocardiogram, ischaemic stroke, transient ischaemic attack, intermittent claudication, or surgery for peripheral arterial disease

Exclusion criteria: acute vascular event $<1$ wk previously; major surgery $<1$ mo previously; any other major acute illness $<1$ mo previously; severe renal impairment (serum creatinine $>400 \mu \mathrm{mol} / \mathrm{L}$ ); severe hepatic impairment; malignancy within the previous year (excluding local skin cancer); severe congestive heart failure (New York Heart Association class IV); total anterior cerebral infarct with major residual disability; malabsorption; inability to give informed consent (e.g. due to dementia or dysphasia); major cognitive impairment (Mini-Mental State Examination score < 19); existing treatment with riboflavin, vitamin B6, vitamin B12, or folic acid preparations; haemoglobin concentration $<10 \mathrm{~g} / \mathrm{dL}$; and mean cell volume $>100 \mathrm{fL}$ plus either a low red blood cell folate concentration $(<280 \mathrm{ng} / \mathrm{mL}$ ) or a low serum vitamin $\mathrm{B} 12$ concentration $(<250 \mathrm{pg} / \mathrm{mL}$ )

Folic acid $2.5 \mathrm{mg}$ plus vitamin B12 $400 \mathrm{mcg}$; vitamin B6 $25 \mathrm{mg}$; riboflavin (vitamin B2) $25 \mathrm{mg}$; placebo in a $2 \times 2 \times 2$ factorial design

1. folic acid plus vitamin B12: 23

2. vitamin B6: 23

3. riboflavin (vitamin $B 2$ ): 23

4. folic acid plus vitamin B12 plus vitamin B2: 23

5. folic acid plus vitamin B12 plus vitamin B6: 23

6. vitamin B6 plus vitamin B2: 23

7. folic acid plus vitamin B12 plus vitamin B2 plus vitamin B6: 23

Comparator: placebo: 24

Intervention or placebo were continued for 12 weeks. The daily dose was provided in a total of 2 capsules ( 1 red and 1 white), irrespective of patient group. 
Stott 2005 (Continued)

Quote: "The patients initially entered a single-blind, placebo, run-in phase lasting between 2 and 4 weeks. Patients who successfully completed the run-in phase were randomly allocated".

Use of additional interventions (common to both treatment arms): not reported

\begin{tabular}{ll}
\hline Outcomes & $\begin{array}{l}\text { Overall cognitive function was assessed by using the Telephone Interview for Cognitive status (TICSm) } \\
\text { at both baseline visits and at } 6 \text { and } 12 \text { months; attention and speed of information processing were as- } \\
\text { sessed by using the Letter Digit Coding Test (at both baseline visits and } 12 \text { months). }\end{array}$ \\
Serious adverse events, including incident vascular events, were recorded at each review.
\end{tabular}

\section{Risk of bias}

Bias Authors' judgement Support for judgement

Random sequence genera- Low risk tion (selection bias)

Quote: "Allocation was determined at a site remote from the clinical study (Robertson Centre for Biostatistics) in randomized permuted blocks of 8 , stratified by hospital center."

Comment: adequate method of random sequence generation

\begin{tabular}{ll}
\hline $\begin{array}{l}\text { Allocation concealment } \\
\text { (selection bias) }\end{array}$ & Low risk \\
& $\begin{array}{l}\text { Quote: "Allocation was determined at a site remote from the clinical study } \\
\text { (Robertson Centre for Biostatistics) in randomized permuted blocks of 8, strat- } \\
\text { ified by hospital center." } \\
\text { Comment: adequate method of allocation concealment }\end{array}$
\end{tabular}

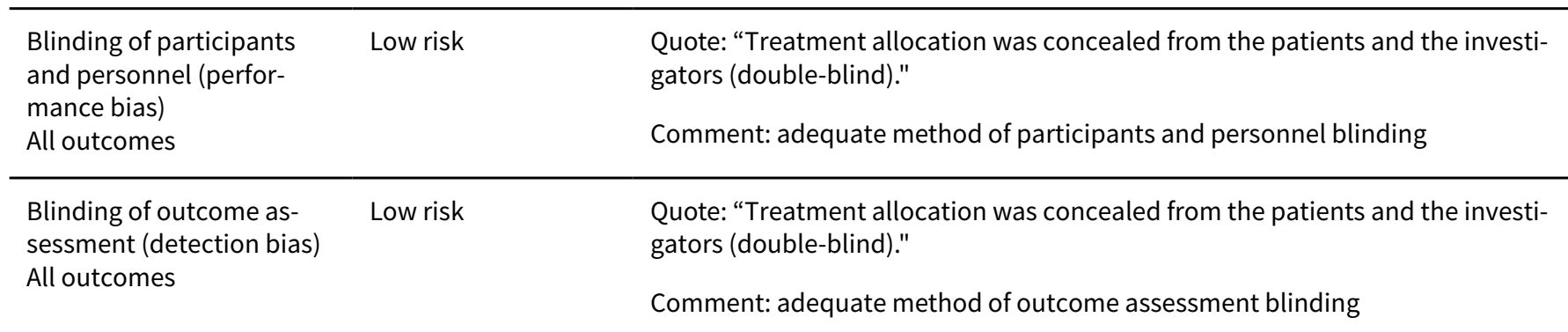

\begin{tabular}{|c|c|c|}
\hline $\begin{array}{l}\text { Incomplete outcome data } \\
\text { (attrition bias) } \\
\text { All outcomes }\end{array}$ & High risk & $\begin{array}{l}\text { Comment: Numbers of participants missing outcome data calculated from ta- } \\
\text { bles. } 18 / 185(10 \%) \text { missing data for TICSm at } 1 \text { year. } 39 / 185(21 \%) \text { missing da- } \\
\text { ta for LDCT at } 1 \text { year. Dropouts not mentioned in paper. No reasons for missing } \\
\text { data given. Presumed completers analysis. }\end{array}$ \\
\hline
\end{tabular}

$\begin{array}{ll}\begin{array}{l}\text { Selective reporting (re- } \\ \text { porting bias) }\end{array} & \text { High risk } \\ & \text { "Primary outcome measures: } \\ & \begin{array}{l}\text { 1. Serum HCY, plasma von Willebrand factor, vitamin levels (red cell folate, } \\ \text { serum vitamin B12, B2, and B6) }\end{array} \\ & \begin{array}{l}\text { 2. Piloting of telephone follow-up of cognition (Telephone Interview for Cogni- } \\ \text { tive Status (TICSm)) and of disability (Barthel Index and short Instrumental Ac- } \\ \text { tivities for Daily Living (ADL) scale). Secondary outcome measures: not provid- } \\ \text { ed at time of registration." }\end{array}\end{array}$

Comment: Disability and IADL (relevant to this review) not reported in paper. 
Stott 2005 (Continued)

Other bias Low risk Comment: no other risks identified

Toole 2004

$\begin{array}{ll}\text { Methods } & \text { 2-arm, parallel group, double-blind, randomised controlled trial (the Vitamin Intervention for Stroke } \\ \text { Prevention (VISP) Trial) }\end{array}$

Participants Location: 56 centres in USA, Canada and Scotland

Recruitment: university-affiliated hospitals, community hospitals, private neurology practices, and Veterans Affairs medical centres

Number randomised: 3680 (1853 in low-dose vitamin group, 1827 in high-dose vitamin group)

\section{Participant (baseline) characteristics:}

- Age, mean (SD):

* low-dose: $66.2(10.8)$

* high-dose: $66.4(10.8)$

- Gender:

* low-dose: $37.2 \%$ female

* high-dose: $37.7 \%$ female

- Baseline cognitive function, MMSE mean (SD):

* low-dose: 26.9 (3.3)

* high-dose: 26.9 (3.4)

Inclusion criteria: non-disabling ischaemic stroke (Modified Rankin Stroke Scale $\leq 3$ ) with onset $\leq 120$ days before randomisation; total homocysteine level $\geq 25$ th percentile for North American stroke population; age $\geq 35$ years, compliance $\geq 75 \%$ with low-dose vitamins for 1 month before randomisation

Exclusion criteria: potential sources of emboli, other major neurological illness, life expectancy $<2$ years, untreated anaemia or untreated B12 deficiency, systolic blood pressure $>185 \mathrm{mmHg}$ or diastolic blood pressure > $105 \mathrm{mmHg}$, refractor depression, severe cognitive impairment, alcoholism or other substance abuse, use within 30 days of medications that affect total homocysteine level, childbearing potential, participation in another trial with active intervention, general anaesthesia or hospital stay of $\geq 3$ days, invasive cardiac or carotid procedures within 30 days of randomisation

\section{Intervention $(\mathbf{n}=1827)$}

High-dose multivitamin formulation contained the reference daily intakes recommended by the US Food and Drug Administration for vitamins except for its content of folic acid, vitamin B6 and vitamin B12. Folic acid $2.5 \mathrm{mg}$, vitamin B6 $25 \mathrm{mg}$, vitamin B12 $0.4 \mathrm{mg}$.

\section{Comparator $(n=1853)$}

Low-dose multivitamin formulation contained the reference daily intakes recommended by the US Food and Drug Administration for vitamins (contained folic acid $20 \mu \mathrm{g}$, vitamin B6 $0.2 \mathrm{mg}$, vitamin B12 6 $\mu \mathrm{g})$

\begin{tabular}{ll}
\hline Outcomes & Outcomes relevant to review: \\
& mean MMSE at 1-year follow-up \\
\hline Notes & $\begin{array}{l}\text { "All eligible participants were given the low-dose vitamin formulation for } 1 \text { month to determine compli- } \\
\text { ance, assessed by pill counts. Only persons taking at least } 75 \% \text { of the vitamins during the run-in phase } \\
\text { were eligible to be randomized." }\end{array}$ \\
\hline
\end{tabular}

\section{Risk of bias}

Vitamin and mineral supplementation for maintaining cognitive function in cognitively healthy people in mid and late life (Review) 
Toole 2004 (Continued)

Bias Authors' judgement Support for judgement

Random sequence genera- Low risk tion (selection bias)

\section{Allocation concealment Low risk} (selection bias)
Quote: "Participants were randomized to the high-dose or low-dose vitamin groups within strata defined by clinic, sex and age ( $\geq 70$ years, $<70$ years). Permuted block randomization (with block size randomly selected as 4 or 6 ) was used."

Quote: "The allocation of participants was programmed by the statistical coordinating center, encrypted, and entered into a data entry program installed on a study computer at each site. After computer verification that all eligibility criteria had been met, participants were randomly assigned 1 of 20 medication codes. Allocation information was accessible only to the drug distribution center, which bottled and distributed the vitamins to clinics, and to selected coordinating center personnel who could assist with randomization in case of computer failure."

\begin{tabular}{lll}
\hline $\begin{array}{l}\text { Blinding of participants } \\
\text { and personnel (perfor- } \\
\text { mance bias) }\end{array}$ & Low risk & $\begin{array}{l}\text { Quote: "Both pill formulations were manufactured (Magno-Humphries Labora- } \\
\text { tories, Tigard, Ore) to be indistinguishable by external colour, weight or disso- } \\
\text { lution in water. No request was ever made to break the blind." }\end{array}$ \\
\hline $\begin{array}{l}\text { Blinding of outcome as- } \\
\text { sessment (detection bias) } \\
\text { All outcomes }\end{array}$ & Low risk & $\begin{array}{l}\text { Quote: "Both pill formulations were manufactured (Magno-Humphries Labora- } \\
\text { tories, Tigard, Ore) to be indistinguishable by external colour, weight or disso- } \\
\text { lution in water. No request was ever made to break the blind." No information } \\
\text { specifically on site investigators. Blind probably maintained. }\end{array}$ \\
\hline
\end{tabular}

Incomplete outcome data Unclear risk Mean MMSE score available for 3097/3680 (84.2\%) participants at 1-year fol-
(attrition bias) low-up. No information on missing participants, including group allocation.

All outcomes

\begin{tabular}{|c|c|c|}
\hline $\begin{array}{l}\text { Selective reporting (re- } \\
\text { porting bias) }\end{array}$ & High risk & $\begin{array}{l}\text { Protocol-specified MMSE at } 24 \text { months not reported. Number of participants } \\
\text { with MMSE score in each treatment group at } 12 \text { months not reported. }\end{array}$ \\
\hline
\end{tabular}

Other bias Low risk No other risks identified

Van der Zwaluw 2014

$\begin{array}{ll}\text { Methods } & \text { Multicentre, double-blind, randomised, placebo-controlled trial, with 2-year duration of treatment and } \\ \text { 2-year duration of follow-up }\end{array}$
2-year duration of follow-up

Participants Location: 3 research centres in the Netherlands: VU University Medical Center (Amsterdam), Erasmus Medical Center (Rotterdam), and Wageningen University (WU, Wageningen)

Recruitment: Dutch elderly men and women who participated in the B-PROOF (B-Vitamins for the Prevention of Osteoporotic Fractures) study which assessed the efficacy of oral supplementation with 400 $\mu \mathrm{g}$ folic acid and $500 \mu \mathrm{g}$ vitamin B in the prevention of fractures, with cognitive performance as secondary outcome.

Most participants were recruited via registries of municipalities in surroundings of the research centres.

The study was conducted between October 2008 and March 2013.

Number randomised: 1516 in intervention, 1511 in comparison

Participant (baseline) characteristics: 
Van der Zwaluw 2014 (Continued)

- Age (mean, SD):

* total population ( $n=2919): 74.1$ years (6.5)

* cognitive sub-sample $(n=856)$ :

$\square$ B vitamin ( $n=425): 72.6$ years $(5.7)$

$\square$ placebo $(n=431): 72.6$ years $(5.8)$

- Gender (males, $\mathrm{n} \%)$ :

* total population ( $n=2919): 1459$ (50)

* cognitive sub-sample $(n=856)$ :

$\square$ B vitamin ( $n=425): 244(57)$

$\square$ placebo ( $n=431): 255$ (59)

- Main diagnosis: not reported

Inclusion criteria: age 65 years or older, having an elevated plasma homocysteine level $(12-50 \mu \mathrm{mol} /$ $\mathrm{L})$, being competent to make own decisions, and having a compliant tablet intake $(\geq 85 \%)$ in the run-in period

Exclusion criteria: cancer diagnosis within the last 5 years except for basal cell carcinoma and squamous cell carcinoma, bedridden, serum creatinine level $>150 \mu \mathrm{mol} / \mathrm{L}$, current or recent ( $<4$ months) use of intramuscular injections of vitamin B12 or folic acid supplementations ( $>300 \mu \mathrm{mol})$, and participation in other intervention studies

$6 \%$ of the study population had a MMSE $<25$.

Interventions

Intervention $(\mathrm{n}=1516)$ :

B vitamin group: $400 \mu \mathrm{g}$ folic acid and $500 \mu \mathrm{g}$ vitamin B12 daily

Comparator group ( $n=1511)$ : placebo.

Treatment was continued for 2 years.

Use of additional interventions (common to both treatment arms): Both tablets contained $15 \mu \mathrm{g}$ (600 IU) vitamin D3.

Outcomes

\section{Outcomes of interest in review:}

Quote: "The primary goal of the B-PROOF study was [to] assess the efficacy of oral supplementation with folic acid and vitamin B12 in the prevention of fractures, with cognitive performance as a secondary outcome."

The 'primary' outcome of the cognitive study was "the difference between treatment groups in performance on episodic memory after 2 years of supplementation."

'Secondary' cognitive outcomes were "differences in performance at follow-up on attention and working memory, information processing speed, executive function, and single test scores."

Quote: "Cognitive performance was assessed at baseline and at the end of the intervention period by well-trained research assistants following a standard protocol. We used the MiniMental State Examination (MMSE) and an extensive, sensitive, and validated neuropsychological test battery" ..that "consisted of the Rey Auditory Verbal Learning Test (RAVLT), Digit Span forward and backward, Trail Making Test (TMT) parts A and B, Stroop Color-Word Test, Symbol Digit Modalities Test, and Letter Fluency (3 letters)".

Quote: "To compare results of the individual cognitive tests and to limit the number of dependent variables, crude test scores were clustered into compound scores for the 4 neuropsychological domains".

"For all 4 cognitive domains, predefined interaction terms of treatment with sex, baseline age $(<80, \geq$ 80 years), plasma HCY (<14.4, $\geq 14.4 \mu \mathrm{mol} / \mathrm{L})$, and APOE genotype (APOE e4 or not) were tested".

\section{Cognitive outcomes:}

- global cognitive function measured with MMSE at 2 years, with higher values indicating benefit 
- executive functioning measured with Trial making test (part B/partA) at 2 years, with lower values indicating benefit

- executive functioning measured with Stroop Interference (part 3 - (part $1+$ part 2/2/)) at 2 years, with lower values indicating benefit

- working memory measured with Digit span backward at 2 years, with higher values indicating benefit

- working memory measured with Digit span forward at 2 years, with higher values indicating benefit

- episodic memory measured with RAVLT-Decay (delayed recall trial 5) at 2 years, with higher values indicating benefit

- episodic memory measured with RAVLT- trials I-V, immediate Recall max 75 words at 2 years, with higher values indicating benefit

- episodic memory measured with RAVLT- trial 9 Recognition max 30 words at 2 years, with higher values indicating benefit

- speed of processing measured with Trail making part A at 2 years, with lower values indicating benefit

- speed of processing measured with Stroop 1 and 2 mean at 2 years, with lower values indicating benefit

- speed of processing measured with Symbol digit modalities test at 2 years, with higher values indicating benefit

- verbal fluency measured with Verbal Fluency - total no at 2 years, with higher values indicating benefit

Notes

Funding sources, quote: "B-PROOF was supported and funded by The Netherlands Organization for Health Research and Development (ZonMw, grant 6130.0031), the Hague; unrestricted grant from NZO (Dutch Dairy Association), Zoetermeer; MCO Health, Almere; NCHA (Netherlands Consortium Healthy Ageing) Leiden/Rotterdam; Ministry of Economic Affairs, Agriculture and Innovation (project KB-15-004-003), the Hague; Wageningen University, Wageningen; VU University Medical Center, Amsterdam; and Erasmus Medical Center, Rotterdam. All organizations are based in the Netherlands. The sponsors had no role in the design or implementation of the study, data collection, data management, data analysis, data interpretation, or in the preparation, review, or approval of the manuscript."

Declarations of interest, quote: "The authors report no disclosures relevant to the manuscript."

\section{Treatment adherence}

"Average compliance to treatment was $90 \%$, and $84 \%$ of all participants had an overall compliance $\geq$ $80 \%$. Compliance was equal for both treatment groups".

\section{Risk of bias}

\begin{tabular}{|c|c|c|}
\hline Bias & Authors' judgement & Support for judgement \\
\hline $\begin{array}{l}\text { Random sequence genera- } \\
\text { tion (selection bias) }\end{array}$ & Low risk & $\begin{array}{l}\text { Quote: "Randomization was done by an independent person by means of com- } \\
\text { puter-generated randomization numbers in stratified permuted blocks of size } \\
4 \text {, stratified by study center, sex, age (65-79 years, } \geq 80 \text { years), and HCY levels } \\
(12-17 \mathrm{mmol}, \geq 18 \mathrm{mmol}) \text { ". }\end{array}$ \\
\hline & & Comment: computer-generated sequence \\
\hline
\end{tabular}

$\begin{aligned} & \text { Allocation concealment } \\ & \text { (selection bias) }\end{aligned} \quad$ Low risk

(selection bias)

Comment: allocation probably concealed

\begin{tabular}{|c|c|c|}
\hline $\begin{array}{l}\text { Blinding of participants } \\
\text { and personnel (perfor- } \\
\text { mance bias) }\end{array}$ & Low risk & $\begin{array}{l}\text { Quote: "Participants and employees of the study were blinded until data } \\
\text { analyses were finished." }\end{array}$ \\
\hline
\end{tabular}

All outcomes

Low risk

Blinding of outcome assessment (detection bias)

All outcomes
Quote: "Participants and employees of the study were blinded until data analyses were finished."

Comment: outcome assessors blinded 
Van der Zwaluw 2014 (Continued)

\begin{tabular}{lll}
$\begin{array}{l}\text { Incomplete outcome data } \\
\text { (attrition bias) } \\
\text { All outcomes }\end{array}$ & High risk & $\begin{array}{l}\text { Quote: from CONSORT flow diagram, 22-24\% attrition from each group } \\
\text { Comment: significant loss of participants, but reasons given and appeared bal- } \\
\text { anced between groups }\end{array}$ \\
\hline $\begin{array}{l}\text { Selective reporting (re- } \\
\text { porting bias) }\end{array}$ & Low risk & $\begin{array}{l}\text { Comment: No differences identified in the outcomes reported in the protocol } \\
\text { (clinicaltrials.gov: NCT00696514) and the article. All outcomes specified in the } \\
\text { Methods were reported in the Results. }\end{array}$ \\
\hline Other bias & Low risk & Comment: no other apparent sources of bias
\end{tabular}

Walker 2012

Methods $2 \times 2 \times 2$ factorial design, parallel group, double-blinded, multicentre, duration of treatment 24 months, duration of follow-up 24 months

Participants Location: Australia. 3 sites: 2 urban and 1 rural

Recruitment: The population-based sample was recruited by a direct mailing of a screening survey and consent form to 105,000 randomly selected adults aged from 60 to 74 years.

Number randomised: 453 in intervention, 456 in comparison

Participant (baseline) characteristics:

- Age, mean $( \pm \mathrm{SD})$ :

* overall: $65.94 \pm 4.24$

* folic acid-vitamin B12: $65.92 \pm 4.30$

* placebo: $65.97 \pm 4.18$

- Gender, male, n (\%):

* overall: 358 (39.8)

* folic acid-vitamin B12: 181 (40.5)

* placebo: 177 (39.1)

- Main diagnosis: elevated psychological distress (Kessler Distress 10 Scale > 15)

Inclusion criteria: cohort of community-dwelling older 60-74 y adults with elevated psychological distress (Kessler Distress 10-Scale; scores > 15); did not engage in physical activity at public health-recommended levels as indicated by International Physical Activity Questionnaire scores; did not take folic acid, vitamin B12, or vitamin B complex supplements; had no history of dementia, bipolar disorder, or current suicide risk; had competent literacy skills; and did not have a medical condition that would contraindicate exercise or folic acid use

Exclusion criteria: High likelihood of a depressive disorder with $\mathrm{K} 10$ scores of $\geq 30$ were excluded. Those individuals with low concentrations of red blood cell folate $(<250 \mathrm{nmol} / \mathrm{L})$ and vitamin $\mathrm{B} 12(<130$ $\mathrm{nmol} / \mathrm{L})$, and abnormal thyroid stimulating hormone concentrations $(0.35-5.0 \mathrm{mU} / \mathrm{L})$ were excluded because participation may have led to potentially adverse outcomes.

\section{Intervention:}

1) Daily oral dose of one tablet consisting of $400 \mu \mathrm{g}$ folic acid $+100 \mu \mathrm{g}$ vitamin B12 supplementation (Matchland Pty Ltd, t/a New Products Development -ABN57052101176, Brisbane, Australia) for 24 months

The protocol changed to 2 daily oral doses ( $200 \mu \mathrm{g}$ folic acid + $50 \mu \mathrm{g}$ vitamin B12 each) from July 2007.

\section{Comparator group:}

Drug: placebo. 
Walker 2012 (Continued)

Placebo tablets were manufactured by the same producers of the folic acid + vitamin B12 tablets and were identical except for the omission of the active substances under investigation.

\section{Use of additional interventions (common to both treatment arms):}

Due to the factorial design, in both vitamin and placebo groups, approximately half the participants received an intervention to promote physical activity and approximately half info about nutrition for older adults; and approximately half received a mental health literacy intervention and approximately half received arthritis and pain management info.

\section{Outcomes of interest in the review:}

Primary outcomes:

- TICSm total score

Secondary outcomes:

- TICSm subscores: 1) orientation; 2) registration, recent memory, and delayed recall (immediate and delayed recall reported separately); 3) attention/calculation; and 4) semantic memory, comprehension, and repetition

- Processing speed measured with BTACT

- IQCODE

Funding sources, quote:"Supported by beyond blue: the national depression initiative and the Australian Government Department of Health and Ageing. HC was supported by a National Health and Medical Research Council (NHMRC) fellowship no. 525411. JGW was supported by NHMRC Capacity Building Grant 418020".

"The sponsors had no role in the design and conduct of the study; collection, management, analysis, and interpretation of the data; or preparation, review, or approval of the manuscript."

Declarations of interest, quote: "None of the authors had any conflicts of interest."

\section{Treatment adherence}

"Adherence was monitored by telephone assessment at 14 time points and by blood assay at baseline and at 12- and 24-mo assessments."

\section{Risk of bias}

\begin{tabular}{lll}
\hline Bias & Authors' judgement & Support for judgement \\
\hline $\begin{array}{ll}\text { Random sequence genera- } \\
\text { tion (selection bias) }\end{array}$ & Low risk & $\begin{array}{l}\text { Quote: "Randomisation followed the screening assessment with block size } \\
\text { fixed at eight and using strata comprising location, gender and high (19) and } \\
\text { low (16-18) K10 depression scores (conducted by A.J.M.) using an automated } \\
\text { computerised system." }\end{array}$ \\
& Comment: adequate method of random sequence generation
\end{tabular}

\begin{tabular}{|c|c|c|}
\hline $\begin{array}{l}\text { Allocation concealment } \\
\text { (selection bias) }\end{array}$ & Low risk & $\begin{array}{l}\text { Quote: "using an automated computerised system". } \\
\text { Comment: adequate method of allocation concealment }\end{array}$ \\
\hline $\begin{array}{l}\text { Blinding of participants } \\
\text { and personnel (perfor- } \\
\text { mance bias) } \\
\text { All outcomes }\end{array}$ & Low risk & $\begin{array}{l}\text { Quote: "Participants, interviewers, investigators and the survey administrators } \\
\text { were masked to active intervention and folic placebo (sic) allocation." } \\
\text { Comment: Participants and personnel were blinded. }\end{array}$ \\
\hline $\begin{array}{l}\text { Blinding of outcome as- } \\
\text { sessment (detection bias) } \\
\text { All outcomes }\end{array}$ & Low risk & $\begin{array}{l}\text { Quote: "Participants, interviewers, investigators and the survey administrators } \\
\text { were masked to active intervention and folic placebo (sic) allocation." }\end{array}$ \\
\hline
\end{tabular}


Walker 2012 (Continued)

Comment: Outcome evaluators were blinded.

Incomplete outcome data Low risk (attrition bias)

All outcomes
Quote: "Of those who were recruited into the trial, the dropout rate was low, with only $123(13.5 \%)$ participants withdrawing from the time of randomisation to the 24-mo assessment".

Comment: Reasons for withdrawal balanced across groups

\begin{tabular}{|c|c|c|}
\hline $\begin{array}{l}\text { Selective reporting (re- } \\
\text { porting bias) }\end{array}$ & High risk & $\begin{array}{l}\text { Comment: All cognitive results were reported, but not all were reported in suf- } \\
\text { ficient detail for inclusion. Results of this study were therefore missing from } \\
\text { some analyses. }\end{array}$ \\
\hline
\end{tabular}

Other bias Low risk Comment: no other important risks identified

Wolters 2005

\begin{tabular}{ll}
\hline Methods & $\begin{array}{l}\text { 2-arm, parallel group, placebo controlled, double-blind RCT. Duration of treatment } 6 \text { months, duration } \\
\text { of follow-up } 6 \text { months }\end{array}$
\end{tabular}

Participants

Location: Germany, single centre

Recruitment: recruited by newspaper advertisement in Hannover region. Institute of Food Science, University of Hanover

Number randomised: not reported. Baseline measures were taken from 241 women. Data are reported for 220 who completed the study.

Participant (baseline) characteristics (provided for those who completed):

- Age, median (5th-95th percentile)

* overall: 63 years $(60-74)$

* vitamin: 63 years $(60-74)$

* placebo: 64 years $(60-75)$

- Gender: female $100 \%$

- Main diagnosis: healthy volunteers

Inclusion criteria: healthy females 60 years or older; no vitamin supplementation for two months before intervention; no medications that affect vitamin absorption on status at the time of enrolment

Exclusion criteria: not reported

Interventions $\quad$ Intervention $(\mathbf{n = 1 1 1})$ :

Vitamin capsule (Nobilin Q10) contained $150 \mathrm{mg}$ vitamin C (calcium ascorbate), $50 \mathrm{mg}$ magnesium (magnesium carbonate), $36 \mathrm{mg}$ vitamin $\mathrm{E}$ ( $\mathrm{D}$ - alfa-tocopherol acetate), $34 \mathrm{mg}$ niacin (nicotinamide), 16 $\mathrm{mg}$ pantothenic acid, $9 \mathrm{mg}$ ß-carotene, $3.4 \mathrm{mg}$ pyridoxine (pyridoxine hydrochloride), $3.2 \mathrm{mg}$ riboflavin, $2.4 \mathrm{mg}$ thiamine (thiamine mononitrate), $400 \mu \mathrm{g}$ folic acid (pteroyl glutamic acid), $200 \mu \mathrm{g}$ biotin, $60 \mu \mathrm{g}$ selenium (selenium-enriched yeast), and $9 \mu \mathrm{g}$ cobalamin (cyanocobalamin).

One capsule/day at breakfast for 6 months

Comparator group ( $\mathbf{n = 1 0 9 ) : ~ p l a c e b o ~}$

One capsule/day at breakfast for 6 months

Use of additional interventions: $4.5 \%$ women received statin medication.

\section{Outcomes}


Wechsler Adult Intelligence Scale-Revised (WAIS III)

Intelligence assessed by the Kurztest fuer Allgemeine Intelligenz (KAI)

Mild up to severe memory disorders assessed by a subtest of the Berliner Amnesie Test (BAT)

Secondary outcomes: levels of homocysteine and methylmalonic acid at baseline and end of treatment

\section{Eligible cognitive outcomes:}

- episodic memory measured with Pattern recognition subtest of Berliner Amnesie Test (BAT) (higher values indicate benefit)

- speed of processing measured with WAIS-III revised symbol search test (higher values indicate benefit)

Function outcome extracted: none reported

Quality of life outcome extracted: none reported

Safety outcome extracted: none reported

*: outcome data included in statistical analyses

Notes

Funding sources: Medicom Pharma. Vitamin capsules (Nobilin Q10R) and placebo capsules were donated by Medicom Pharma AG, Springe (Germany).

Declarations of interest: no information provided

\section{Risk of bias}

Bias Authors' judgement Support for judgement

Random sequence genera- Unclear risk tion (selection bias)
Quote: "Of these, 109 women had been randomly assigned to the placebo group and 111 women to the vitamin group by a lottery."

Comment: unclear method of sequence generation

Allocation concealment $\quad$ Unclear risk
(selection bias)
(selection bias)

Quote: "Of these, 109 women had been randomly assigned to the placebo group and 111 women to the vitamin group by a lottery."

Comment: unclear method of allocation concealment

\begin{tabular}{ll}
\hline $\begin{array}{l}\text { Blinding of participants } \\
\begin{array}{l}\text { and personnel (perfor- } \\
\text { mance bias) }\end{array}\end{array}$ & $\begin{array}{l}\text { Quote: "Both capsules, the multivitamin and the placebo, were soft gelatine } \\
\text { capsules filled with soy oil. The oil in the placebo capsule was colored for iden- } \\
\text { All outcomes }\end{array}$ \\
tical appearance."
\end{tabular}

\begin{tabular}{lll}
\hline $\begin{array}{l}\text { Blinding of outcome as- } \\
\begin{array}{l}\text { sessment (detection bias) } \\
\text { All outcomes }\end{array}\end{array}$ & Unclear risk & $\begin{array}{l}\text { Quote: "The cognitive tests were performed on the day of blood sampling after } \\
\text { the women had had breakfast." } \\
\text { Comment: blinding of outcome assessment not reported }\end{array}$ \\
\hline $\begin{array}{l}\text { Incomplete outcome data } \\
\text { (attrition bias) } \\
\text { All outcomes }\end{array}$ & Unclear risk & $\begin{array}{l}8.7 \%(21 / 241 \text { assessed at baseline) dropped out, but it is unclear from which } \\
\text { group. Two participants were excluded by the experimenters for non-compli- } \\
\text { ance. The total number of patients randomised was unclear. Only completers' } \\
\text { data reported }\end{array}$ \\
\hline
\end{tabular}

Selective reporting (re- Low risk All primary and secondary outcomes specified in the Methods were reported.


Wolters 2005 (Continued)

$\begin{array}{ll}\text { Other bias } & \text { Unclear risk } \\ & \text { There were baseline imbalances in educational level (higher in vitamin group) }\end{array}$
and Symbol Search (better in vitamin group).

Yaffe 2004

Methods 4-arm, double-blinded, multicentre parallel group RCT, with up to 8 years of treatment

Participants

Location: 11 clinical centres in the US

Recruitment: recruited through 11 clinical centres in the US

Sample size: Quote "Of the 3640 AMD trial participants, 2166 (60\%) completed the AREDS cognitive battery near the end of the trial."

- Number randomised: 2737 in intervention, 903 in comparison (total 3640)

- Number completed cognitive battery: 1632 in intervention, 534 in comparison (total 2166)

Group A (Antioxidants) baseline characteristics:

- Age (y), \%:

* 55-59: 4

* 60-64: 16

* 65-69: 34

* 70-74: 29

* 75-80: 16

- Median age, y: 69

- Gender, \% female: 55

\section{Group B (Zinc) baseline characteristics:}

- Age (y), \%:

* 55-59: 2

* 60-64: 18

* 65-69: 29

* 70-74: 34

* 75-80: 18

- Median age, y: 70

- Gender, \% female: 57

Group C (Antioxidants and Zinc) Baseline characteristics:

- Age (y), \%:

* 55-59: 3

* 60-64: 17

* 65-69: 33

* 70-74: 30

* 75-80: 17

- Median age, y: 69

- Gender, \% female: 56

Group D (Placebo) Baseline characteristics: 
Yaffe 2004 (Continued)

- Age (y), \%:

* 55-59: 3

* 60-64: 16

* 65-69: 32

* 70-74: 31

* 75-80: 18

- Median age, y: 69

- Gender, \% female: 56

\section{Inclusion criteria:}

Aged 55 to 80 years old

Individuals who passed the screening evaluation and were interested in participating in AREDS were provided with a one-month "run-in" supply of placebo to assess potential for tolerance of the inactive ingredients and compliance with the treatment regimen. They were asked to take two tablets twice a day for 1 month. Participants taking fewer than $75 \%$ of the prescribed tablets were ineligible for enrolment. Participants who had good compliance with the run-in medication, who had adequate pupillary dilation and no disqualifying lesions noted on photographs sent to the Reading Center for grading, and who signed a second consent form were stratified into AMD categories at the time of randomisation.

\section{Exclusion criteria:}

Had to be free of any illness or condition that would make long-term follow-up or compliance with study medications unlikely or difficult.

Interventions

Intervention ( $\mathbf{n = 1 6 3 2 ) : ~ T w o ~ s t u d y ~ m e d i c a t i o n ~ t a b l e t s ~ w e r e ~ t o ~ b e ~ t a k e n ~ o r a l l y ~ e a c h ~ m o r n i n g ~ a n d ~} 2$ each evening to meet the total daily dose requirement.

Group A (Antioxidants): $500 \mathrm{mg}$ Vitamin C, 400 IU Vitamin E and $15 \mathrm{mg}$ beta carotene daily

Group B (Zinc and Copper): $80 \mathrm{mg}$ zinc oxide and $2 \mathrm{mg}$ cupric oxide daily

Group C (Antioxidants and Zinc and Copper): $500 \mathrm{mg}$ Vitamin C, 400 IU Vitamin E, $15 \mathrm{mg}$ beta carotene, $80 \mathrm{mg}$ zinc oxide, $2 \mathrm{mg}$ cupric oxide daily

Comparator group ( $\mathbf{n = 5 3 4 ) : ~ p l a c e b o ~ t a k e n ~ o r a l l y ~ t h a t ~ w a s ~ i d e n t i c a l ~ i n ~ e x t e r n a l ~ a p p e a r a n c e ~ a n d ~ s i m i l a r ~}$ in internal appearance and taste

N.B. Data from groups A and B and the placebo group were included in this review.

Use of additional interventions (common to both treatment arms): no

Outcomes

\section{Outcomes of interest in the review:}

The primary purpose of the study was to investigate the effects of the interventions on the progression of age-related macular degeneration.

The AREDS cognitive function battery included six validated cognitive tests with eight components: 1) The Modified Mini-Mental State Examination (3MS); 2) Animal Category; 3) Letter Fluency; 4) Logical Memory Part I and 5) Logical Memory Part II, Wechsler Memory Scale Revised; 6) Immediate Recall and 7) Word List Mean, Bushke Selective Reminding Test; and 8) Digits Backwards.

Notes

This was a cognitive substudy of AREDS, the Age-Related Eye Disease Study.

Funding sources: "Supported by contracts from the National Eye Institute and the National Institute on Aging, National Institutes of Health, Department of Health and Human Services, Bethesda, MD, with additional support from Bausch \& Lomb Inc, Rochester, NY".

Declarations of interest: none declared. "The Writing Team for this report and the AREDS investigators have no commercial or proprietary interest in the supplements used in this study". 
Treatment adherence: At each visit, participants returned their used study medication bottles and any unused tablets, and received new bottles of their study medication. "Estimated pill counts showed that most patients took $75 \%$ or more of the assigned medications and adherence was balanced by treatment”.

\section{Risk of bias}

Bias Authors' judgement Support for judgement

Random sequence genera- Low risk tion (selection bias)

Quote: "Eligibility verification and random treatment assignment were performed by the Coordinating Center using the on-site computers, with procedures to protect the integrity of randomization and to provide randomization backup in case of hardware malfunction. Multiple levels of data encryption ensure the integrity of the treatment assignment files." "Each treatment assignment database residing on the hard drives at each Clinical Center is encrypted and includes check numbers to insure tamper free operation and proper sequential treatment assignments. There were no cases of database corruption during randomization."

Comment: adequate method of random sequence generation

Allocation concealment Low risk (selection bias)

Quote: "Eligibility verification and random treatment assignment were performed by the Coordinating Center using the on-site computers, with procedures to protect the integrity of randomization and to provide randomization backup in case of hardware malfunction. Multiple levels of data encryption ensure the integrity of the treatment assignment files." "Each treatment assignment database residing on the hard drives at each Clinical Center is encrypted and includes check numbers to insure tamper free operation and proper sequential treatment assignments. There were no cases of database corruption during randomization."

Comment: adequate allocation concealment

Blinding of participants Low risk and personnel (perfor-

mance bias)

All outcomes
Quote: "Four participants (0.1\%) were reported to have been unmasked during the trial."

"AREDS is a double-masked study. The AREDS participants, investigators and Reading Center personnel are masked to study-wide outcome data and treatment assignments."

Comment: low risk for personnel and participants. Although 4 participants were "unmasked", this is likely to have been for safety reasons.
Blinding of outcome as- Low risk sessment (detection bias) All outcomes
Comment: "AREDS is a double-masked study. The AREDS participants, investigators and Reading Center personnel are masked to study-wide outcome data and treatment assignments."
Incomplete outcome data High risk (attrition bias)

All outcomes
Quote: "Another limitation is that not all participants in the trial had cognitive testing."

"Of the 3,640 AMD trial participants, 2,166 (60\%) completed the AREDS cognitive battery near the end of the trial. Of the 1,474 participants without cognitive testing, 330 died before the implementation of the cognitive study, and 1,144 refused or were otherwise unable to participate. Participants without cognitive testing were more likely to be older, have more ocular abnormalities, and be less educated compared with those participating in the ancillary study." No information was given about the treatment allocation of participants and non-participants in the cognitive sub-study.

Comment: high risk of differential non-participation 


\section{Yaffe 2004 (Continued)}

\begin{tabular}{|c|c|c|}
\hline $\begin{array}{l}\text { Selective reporting (re- } \\
\text { porting bias) }\end{array}$ & Unclear risk & $\begin{array}{l}\text { Comment: This was an ancillary study and did not have a protocol of its own. } \\
\text { The AREDS study design did not mention any cognitive outcomes. }\end{array}$ \\
\hline
\end{tabular}

Other bias Low risk Comment: no other risks identified

AD: Alzheimer's disease

AD8: Ascertain Dementia 8-Item Informant Questionnaire (AD8) Dementia Screening Interview

ADAS-cog: Alzheimer's Disease Assessment Scale - cognitive

ADL: Activities of Daily Living

AMD: Age-related Macular Degeneration

APOE $\epsilon 4$ : Apolipoprotein-E gene, $\epsilon 4$ allele

AREDS: The Age-Related Eye Disease Study

BASF: BASF is a registered chemical company, BASF originally stood for Badische Anilin- und Soda-Fabrik.

BAT: Berliner Amnesie Test

BDI: Beck Depression Inventory

betaCarot: $ß$-carotene

B-PROOF: B-Vitamins for the Prevention of Osteoporotic Fractures study

BTACT: Brief Test of Adult Cognition by Telephone

CaD: Calcium and Vitamin D

CANTAB: Cambridge Automated Neuropsychological Test Battery

CDR: Clinical Dementia Rating scale

CERAD: Consortium to Establish a Registry for Alzheimer's Disease

CERAD e: expanded Consortium to Establish a Registry in Alzheimer's Disease

CERAD T: CERAD battery total score

CoA: coenzyme A reductase

CONSORT: Consolidated Standards of Reporting Trials

CVD: CardioVascular Disease

CVLT: California Verbal Learning Test

DCT: Digit Cancellation Test

DSM-IV: Diagnostic and Statistical Manual of Mental Disorders, 4th Edition

EBMT: East Boston Memory Test

FA: Folic acid

F00: ICD-10 code for dementia in Alzheimer's disease

F01: ICD-10 code for vascular dementia

F03: ICD-10 code for unspecified dementia

F-TICSm: modified Telephone Interview for Cognitive Status

G30: ICD-10 code for Alzheimer's disease

GDS: Geriatric Depression Scale

HbAlc: Hemoglobin Alc

HCY: homocysteine

HMG-COA: 3-hydroxy-3-methyl-glutaryl-coenzyme A reductase

holoTC: Holotranscobalamin

IADL: Instrumental Activities of Daily Living

IQCODE: Informant Questionnaire on Cognitive Decline in the Elderly

IQR: Interquartile range

ISRCTN: International Standard Randomised Controlled Trial Number

KAI: Kurztest fuer Allgemeine Intelligenz

K10: Kessler Distress 10-Scale

LDCT: Letter Digit Coding Test.

$\mathrm{MCl}$ : Mild cognitive impairment

MI: Memory Impairment

MIS: Memory Impairment Screen

MMA: Methylmalonic acid

MMSE: Mini-Mental State Examination

MoCA: Montreal Cognitive Assessment 
MRI: Magnetic resonance imaging

msec: millisecond

MTS: Matching To Sample visual search test

$\mathrm{n}$ : number

NYU: New York University

PHS: Physicians' Health Study

RAVLT: Rey Auditory Verbal Learning Test

RBC: Red blood cell

RDA: recommended daily allowances

RI-48: rappel indicé-48 items (cued-recall test-48 items)

SD: standard deviation

SF-36: 36-item Short Form Survey

SU.FOL.OM3: SUpplementation with FOlate, vitamin B6 and B12 and/or OMega-3 fatty acids trial

$\mathrm{RCT}$ : randomised clinical trial

SWM: spatial working memory

TCogS: Telephone Cognitive Screen

TIA: Transient Ischaemic Attack

TICS: Telephone Interview for Cognitive Status

TICSm: Modified Telephone Interview for Cognitive Status

TMT: Trail Making Test

VISP: Vitamin Intervention for stroke prevention trial

vit: vitamin

Vit D: vitamin D supplementation

WACS: Women's Antioxidant and Cardiovascular Study

WADLS: Western Australian Data Linkage System

WAFACS: Women's Antioxidant and Folic Acid Cardiovascular Study

WAIS: Wechsler Adult Intelligence Scale

WHI: Women's Health Initiative

WHIMS: Women's Health Initiative Memory Study

WHISCA: Women's Health Initiative study of Cognitive Aging

wk: week

y: year

Zn: zinc

3MS: The Modified Mini-Mental State Examination

Characteristics of excluded studies [ordered by study ID]

\begin{tabular}{ll}
\hline Study & Reason for exclusion \\
\hline Abbasi 2013 & No cognitive outcomes \\
\hline ACTRN12607000321448 & Ineligible population: participants had MCl \\
\hline Alavi 2014 & $\begin{array}{l}\text { Ineligible population. Additional detail: included in related Cochrane review focussing on the MCl } \\
\text { study population }\end{array}$ \\
\hline Almeida 2010 & $\begin{array}{l}\text { Subpopulation of included study focussing on depression outcome. Participants also included in } \\
\text { Hankey } 2013\end{array}$ \\
\hline Anonymous 2003 & Ineligible population \\
\hline Arwert 2003 & Ineligible intervention \\
\hline Benton 1995 & Ineligible population \\
\hline Bryan 2002 & Ineligible intervention: duration of intervention 5 weeks \\
\hline \hline
\end{tabular}

Vitamin and mineral supplementation for maintaining cognitive function in cognitively healthy people in mid and late life (Review) 


\section{Study}

Chan 2010

Cheng 2016

Chew 2015

\section{Reason for exclusion}

Ineligible experimental intervention: combined experimental intervention

Wrong design: non-randomised

Wrong design: RCT with $2 \times 2$ factorial design (omega-3 fatty acids; lutein and zeaxanthin; the combination; double placebo) with a second randomisation to multivitamin supplements with or without beta carotene and with or without high dose of zinc. The analyses of effects of beta carotene and zinc were not eligible, as no tests for interaction were performed for omega-3, lutein and zeaxanthin.

\begin{tabular}{|c|c|}
\hline Corless 1987 & Wrong population \\
\hline De Jager 2012 & Ineligible population: participants had $\mathrm{MCl}$ \\
\hline Dhesi 2004 & Ineligible intervention: vitamin D delivered parenterally \\
\hline Flicker 2011 & Wrong population: all had vitamin D deficiency \\
\hline Ford 2008 & Ineligible outcomes \\
\hline Harris 2015 & Ineligible intervention: included plant extracts and probiotics as well as vitamins and minerals \\
\hline Hvas 2004 & Ineligible population: $56 \%$ cognitively impaired at baseline \\
\hline Imaoka 2016 & Ineligible population: participants cognitively impaired at baseline \\
\hline Krikorian 2010 & $\begin{array}{l}\text { Ineligible population: participants had CDR (Clinical Dementia Rating scale) classification consis- } \\
\text { tent with } \mathrm{MCl}\end{array}$ \\
\hline Kwok 2017 & $\begin{array}{l}\text { Ineligible population: We were unable to obtain separate data for participants with mild cognitive } \\
\text { impairment (CDR 0.5) and normal cognition (CDR 0) at baseline. }\end{array}$ \\
\hline Li 2015 & $\begin{array}{l}\text { Ineligible population. Baseline cognitive status unclear. Data presented pictorially only (bar } \\
\text { charts). Baseline mean MMSE }<23\end{array}$ \\
\hline Liu 2015 & Study withdrawn prior to participant enrolment (ClinicalTrials.gov Identifier: NCT01317849) \\
\hline Loriaux 1985 & Ineligible experimental intervention \\
\hline Macpherson 2012 & Ineligible population: participants had subjective cognitive decline \\
\hline Maniam 2004 & $\begin{array}{l}\text { Other reason. Additional details: potentially eligible RCT described only in an abstract published in } \\
\text { 2004. No related full report has been identified and the likelihood such report will be published in } \\
\text { future was judged to be minimal. }\end{array}$ \\
\hline McNeill 2007 & No eligible outcomes \\
\hline Miller 2016 & No eligible outcomes \\
\hline Murray-Kolb 2011 & Ineligible population: age range $19-55$ years \\
\hline NCT00903695 & Ineligible population: participants had $\mathrm{MCl}$ \\
\hline NCT01095211 & Ineligible population: duration of intervention 45 days \\
\hline
\end{tabular}




\begin{tabular}{|c|c|}
\hline Study & Reason for exclusion \\
\hline NCT01708005 & Ineligible intervention: combined vitamins, endophospholipids, and omega-3 fatty acids \\
\hline NCT02185222 & Ineligible population: participants had memory complaint \\
\hline NCT02467153 & No eligible outcomes \\
\hline Ng 2017 & Ineligible intervention: combined protein, calorie, and vitamin supplements \\
\hline Ong 2016 & Ineligible intervention: no placebo control \\
\hline Pase 2015 & Ineligible intervention: combined experimental intervention \\
\hline Pathansali 2006 & Ineligible intervention: duration of intervention 4 weeks \\
\hline Petersen 2005 & $\begin{array}{l}\text { Ineligible population. Additional detail: included in related Cochrane review focussing on popula- } \\
\text { tion with } \mathrm{MCl}\end{array}$ \\
\hline Pettersen 2017 & Ineligible intervention: no placebo control \\
\hline Quick 2013 & Ineligible design \\
\hline Rietsema 2014 & Ineligible design \\
\hline Schietzel 2016 & Ineligible intervention: no placebo control \\
\hline Smith 1999 & $\begin{array}{l}\text { Ineligible population: Excluded if } \mathrm{MMSE}<18 \text {, but no information on mean MMSE; likely to have in- } \\
\text { cluded participants with dementia or } \mathrm{MCl}\end{array}$ \\
\hline Summers 2010 & Ineligible experimental intervention: combined experimental intervention \\
\hline Van Uffelen 2007 & $\begin{array}{l}\text { Ineligible population. Additional detail: included in related Cochrane review focussing on popula- } \\
\text { tion with } \mathrm{MCl}\end{array}$ \\
\hline Wouters-Wesseling 2005 & Ineligible experimental intervention: combined experimental intervention \\
\hline
\end{tabular}

MCI: Mild cognitive impairment

CDR: Clinical Dementia Rating scale

MMSE: Mini Mental State Examination

Characteristics of studies awaiting assessment [ordered by study ID]

Sanchez 2011

\begin{tabular}{|c|c|}
\hline Methods & Cluster double-blind, placebo controlled trial with 18 month follow-up \\
\hline \multirow[t]{5}{*}{ Participants } & $\begin{array}{l}\text { Location: metropolitan Santiago, Chile, } 15 \text { health centres, } 20 \text { participants selected from each } \\
\text { health centre }\end{array}$ \\
\hline & Setting of recruitment and treatment: GP practices \\
\hline & Number randomised: not known \\
\hline & Participant (baseline) characteristics: not known \\
\hline & $\begin{array}{l}\text { Inclusion criteria: Potential study subjects will be identified from the registry of older people par- } \\
\text { ticipating in the PACAM in } 15 \text { health centres. }\end{array}$ \\
\hline
\end{tabular}


Sanchez 2011 (Continued)

1. men and women aged 70 to 79 years

2. participating in the National Health Service Nutrition Program for Older People (PACAM)

\section{Exclusion criteria:}

1. diabetes (fasting blood glucose greater than or equal to $126 \mathrm{mg} / \mathrm{dL}$ )

2. hypothyroidism (thyroid stimulating hormone (TSH) greater than $6 \mathrm{mlU} / \mathrm{L}$ )

3. serum creatinine greater than or equal to $30 \mathrm{mg} / \mathrm{mL}$

4. serum vitamin B12 level less than 120 or greater than $700 \mathrm{pmol} / \mathrm{L}$ or vitamin B12 supplemented

5. cerebrovascular disease

6. previous gastrointestinal surgery

7. unexplained weight lost greater than or equal to $3 \mathrm{~kg}$ in the previous 3 months

8. low cognitive development (Mini-mental test less than 20, and Pfeffer test greater than 5)

Interventions

\section{Intervention:}

1. $1 \mathrm{mg} \mathrm{B12}$ pill taken daily and a routine PACAM food

2. placebo pill and the PACAM food fortified to provide $1 \mathrm{mg}$ of $\mathrm{B} 12$ as consumed on a daily basis

\section{Comparator group:}

Routine PACAM food and a placebo pill

All subjects in the three study arms will receive both a pill and the food supplement in order to maintain the double blind nature of the study.

A routine fortified food program provided monthly is delivered by the Ministry of Health under the PACAM programme through the health centres. The nutritional products are $1 \mathrm{~kg}$ of Años Dorados (a cereal-legume and vegetable powdered food) which provides $400 \mathrm{kcal} / 100 \mathrm{~g}$ and multiple micronutrients (including B12 $1.4 \mathrm{\mu g} / 100 \mathrm{~g}$ ) and $1 \mathrm{~kg}$ of Bebida Láctea, a micronutrient fortified milkbased drink (including B12 $2.8 \mu \mathrm{g} / 100 \mathrm{~g}$ ). The recommended serving size of these supplements provides daily $1.4 \mathrm{\mu g}$ or $58.3 \%$ of the daily B12 recommended intake (World Health Organization (WHO) 2002) and $20 \%$ of daily energy needed by older people.

The pill will be identical in size, shape, colour, smell, and taste for both the intervention and the placebo arms of the trial. The intervention pill and the fortified milk base drink will each contain 1 $\mathrm{mg}$ of B12.

Use of additional interventions (common to both treatment arms): not reported

\section{Primary Outcomes:}

1. serum vitamin $B 12$ status, assessed at initial visit and 3, 9, and 18 months

2. haematological and biochemical parameters, assessed at initial visit and 3, 9, and 18 months

3. peripheral nerve conduction, assessed at initial visit, 3 , and 18 months

4. compound muscle action potential (CMAP) amplitude, distal motor latency, and F-wave latency (a measure of conduction time from the distal stimulation site to the spinal cord), assessed at initial visit, 3 , and 18 months

5. Mini-mental score: Mini Mental State Examination (MMSE), assessed at initial visit and 18 months

\section{Secondary Outcomes:}

1. serum folate, homocysteine, methyl malonic acid, holotranscobalamin, assessed at initial visit and 3,9 , and 18 months

2. neurological battery evaluation includes sensory pathways of conduction of afferent sensory pathways of small diameter, quantitative thermal and somatosensory responses, specific neurosensory pathways, and visual evoked potential. Assessed at initial visit, 3 , and 18 months.

3. cognitive function: Test Wechsler, Consortium to Establish a Registry for Alzheimer's Disease (CERAD), Test Hamilton and Trail Making Test, assessed at initial visit and 18 months 
Compliance with the nutrition intervention is defined for this study as collecting more than $1 \mathrm{~kg}$ per month of the fortified food as documented by the health centres. Compliance for the pill intervention will be monitored based on collection of the pills supplement from the health centre, 12 out of 18 months will be considered compliant.

A subsample of 120 subjects ( 8 per cluster, 40 per arm) will undergo neurophysiological tests.

Notes

Funding sources: Chilean National Science and Technology Research Fund (FONDECYT 1070592) (Fondo de Desarrollo Científico y Tecnológico (Chile) (ref: FONDECYT N ${ }^{\circ}$ 1070592)), Ministry of Health (Chile).

Declarations of interest, quote: "The authors declare that they have no competing interests."

\section{Reasons for classification as "study awaiting classification":}

This study is marked as "completed" in ISRCTN registry (last edited 11-10-2011), but no results are available. We made several attempts to contact authors of the protocol, but received no replies.

CERAD: Consortium to Establish a Registry for Alzheimer's Disease

CMAP: compound muscle action potential

PACAM: National Health Service Nutrition Program for Older People

DATA AND ANALYSES

\section{Comparison 1. B vitamins versus control}

\begin{tabular}{|c|c|c|c|c|}
\hline Outcome or subgroup title & No. of studies & $\begin{array}{l}\text { No. of partici- } \\
\text { pants }\end{array}$ & Statistical method & Effect size \\
\hline 1 Overall cognitive functioning & 10 & & $\begin{array}{l}\text { Std. Mean Difference (Ran- } \\
\text { dom, } 95 \% \mathrm{Cl} \text { ) }\end{array}$ & Subtotals only \\
\hline $\begin{array}{l}1.13-12 \text { months of supplementation (fi- } \\
\text { nal measurement data) }\end{array}$ & 3 & 2556 & $\begin{array}{l}\text { Std. Mean Difference (Ran- } \\
\text { dom, } 95 \% \mathrm{Cl} \text { ) }\end{array}$ & $0.00[-0.08,0.08]$ \\
\hline $\begin{array}{l}\text { 1.2 3-12 months of supplementation } \\
\text { (change from baseline data) }\end{array}$ & 2 & 317 & $\begin{array}{l}\text { Std. Mean Difference (Ran- } \\
\text { dom, } 95 \% \mathrm{Cl} \text { ) }\end{array}$ & $-0.03[-0.26,0.19]$ \\
\hline $\begin{array}{l}1.3>1-2 \text { years of supplementation (final } \\
\text { measurement data) }\end{array}$ & 5 & 6956 & $\begin{array}{l}\text { Std. Mean Difference (Ran- } \\
\text { dom, } 95 \% \mathrm{Cl} \text { ) }\end{array}$ & $-0.01[-0.08,0.06]$ \\
\hline $\begin{array}{l}1.4>1-2 \text { years of supplementation } \\
\text { (change from baseline data) }\end{array}$ & 1 & 241 & $\begin{array}{l}\text { Std. Mean Difference (Ran- } \\
\text { dom, } 95 \% \mathrm{Cl} \text { ) }\end{array}$ & $0.06[-0.20,0.31]$ \\
\hline $\begin{array}{l}1.5>2-5 \text { years of supplementation (final } \\
\text { measurement data) }\end{array}$ & 4 & 3985 & $\begin{array}{l}\text { Std. Mean Difference (Ran- } \\
\text { dom, } 95 \% \mathrm{Cl} \text { ) }\end{array}$ & $-0.01[-0.11,0.09]$ \\
\hline $\begin{array}{l}1.6>5-10 \text { years of supplementation (fi- } \\
\text { nal measurement data) }\end{array}$ & 3 & 10249 & $\begin{array}{l}\text { Std. Mean Difference (Ran- } \\
\text { dom, } 95 \% \mathrm{Cl} \text { ) }\end{array}$ & $-0.01[-0.09,0.07]$ \\
\hline 2 Episodic memory & 10 & & $\begin{array}{l}\text { Std. Mean Difference (Ran- } \\
\text { dom, } 95 \% \mathrm{Cl} \text { ) }\end{array}$ & Subtotals only \\
\hline $\begin{array}{l}2.13-12 \text { months of supplementation (fi- } \\
\text { nal measurement data) }\end{array}$ & 4 & 1442 & $\begin{array}{l}\text { Std. Mean Difference (Ran- } \\
\text { dom, } 95 \% \mathrm{Cl} \text { ) }\end{array}$ & $0.02[-0.08,0.12]$ \\
\hline
\end{tabular}




\begin{tabular}{|c|c|c|c|c|}
\hline Outcome or subgroup title & No. of studies & $\begin{array}{l}\text { No. of partici- } \\
\text { pants }\end{array}$ & Statistical method & Effect size \\
\hline $\begin{array}{l}\text { 2.2 3-12 months of supplementation } \\
\text { (change from baseline data) }\end{array}$ & 2 & 430 & $\begin{array}{l}\text { Std. Mean Difference (Ran- } \\
\text { dom, } 95 \% \mathrm{Cl} \text { ) }\end{array}$ & $0.04[-0.15,0.23]$ \\
\hline $\begin{array}{l}2.3>1-2 \text { years of supplementation (final } \\
\text { measurement data) }\end{array}$ & 4 & 5625 & $\begin{array}{l}\text { Std. Mean Difference (Ran- } \\
\text { dom, } 95 \% \mathrm{Cl} \text { ) }\end{array}$ & $0.05[-0.03,0.13]$ \\
\hline $\begin{array}{l}2.4>1-2 \text { years of supplementation } \\
\text { (change from baseline data) }\end{array}$ & 1 & 241 & $\begin{array}{l}\text { Std. Mean Difference (Ran- } \\
\text { dom, } 95 \% \mathrm{Cl} \text { ) }\end{array}$ & $0.06[-0.19,0.32]$ \\
\hline $\begin{array}{l}2.5>2-5 \text { years of supplementation (final } \\
\text { measurement data) }\end{array}$ & 3 & 3523 & $\begin{array}{l}\text { Std. Mean Difference (Ran- } \\
\text { dom, } 95 \% \mathrm{Cl} \text { ) }\end{array}$ & $-0.05[-0.15,0.05]$ \\
\hline $\begin{array}{l}2.6>5-10 \text { years of supplementation (fi- } \\
\text { nal measurement data) }\end{array}$ & 1 & 1053 & $\begin{array}{l}\text { Std. Mean Difference (Ran- } \\
\text { dom, } 95 \% \mathrm{Cl} \text { ) }\end{array}$ & $-0.10[-0.22,0.02]$ \\
\hline 3 Executive function & 7 & & $\begin{array}{l}\text { Std. Mean Difference (Ran- } \\
\text { dom, } 95 \% \mathrm{Cl} \text { ) }\end{array}$ & Subtotals only \\
\hline $\begin{array}{l}\text { 3.1 3-12 months of supplementation (fi- } \\
\text { nal measurement data) }\end{array}$ & 3 & 536 & $\begin{array}{l}\text { Std. Mean Difference (Ran- } \\
\text { dom, } 95 \% \mathrm{Cl} \text { ) }\end{array}$ & $0.14[-0.18,0.46]$ \\
\hline $\begin{array}{l}\text { 3.2 3-12 months of supplementation } \\
\text { (change from baseline data) }\end{array}$ & 1 & 171 & $\begin{array}{l}\text { Std. Mean Difference (Ran- } \\
\text { dom, } 95 \% \mathrm{Cl} \text { ) }\end{array}$ & $0.39[0.07,0.71]$ \\
\hline $\begin{array}{l}3.3>1-2 \text { years of supplementation (final } \\
\text { measurement data) }\end{array}$ & 3 & 2976 & $\begin{array}{l}\text { Std. Mean Difference (Ran- } \\
\text { dom, } 95 \% \mathrm{Cl} \text { ) }\end{array}$ & $-0.01[-0.15,0.13]$ \\
\hline $\begin{array}{l}3.4>2-5 \text { years of supplementation (final } \\
\text { measurement data) }\end{array}$ & 2 & 2648 & $\begin{array}{l}\text { Std. Mean Difference (Ran- } \\
\text { dom, } 95 \% \mathrm{Cl} \text { ) }\end{array}$ & $-0.06[-0.13,0.02]$ \\
\hline $\begin{array}{l}3.5>5-10 \text { years of supplementation (fi- } \\
\text { nal measurement data) }\end{array}$ & 1 & 1049 & $\begin{array}{l}\text { Std. Mean Difference (Ran- } \\
\text { dom, } 95 \% \mathrm{Cl} \text { ) }\end{array}$ & $0.02[-0.10,0.15]$ \\
\hline 4 Speed of processing & 7 & & $\begin{array}{l}\text { Std. Mean Difference (Ran- } \\
\text { dom, } 95 \% \mathrm{Cl} \text { ) }\end{array}$ & Subtotals only \\
\hline $\begin{array}{l}\text { 4.1 3-12 months of supplementation (fi- } \\
\text { nal measurement data) }\end{array}$ & 2 & 289 & $\begin{array}{l}\text { Std. Mean Difference (Ran- } \\
\text { dom, } 95 \% \mathrm{Cl} \text { ) }\end{array}$ & $-0.04[-0.28,0.19]$ \\
\hline $\begin{array}{l}\text { 4.2 3-12 months of supplementation } \\
\text { (change from baseline data) }\end{array}$ & 3 & 487 & $\begin{array}{l}\text { Std. Mean Difference (Ran- } \\
\text { dom, } 95 \% \mathrm{Cl} \text { ) }\end{array}$ & $0.12[-0.34,0.58]$ \\
\hline $\begin{array}{l}4.3>1-2 \text { years of supplementation (final } \\
\text { measurement data) }\end{array}$ & 2 & 1030 & $\begin{array}{l}\text { Std. Mean Difference (Ran- } \\
\text { dom, } 95 \% \mathrm{Cl} \text { ) }\end{array}$ & $0.03[-0.09,0.15]$ \\
\hline $\begin{array}{l}4.4>1-2 \text { years of supplementation } \\
\text { (change from baseline data) }\end{array}$ & 1 & 241 & $\begin{array}{l}\text { Std. Mean Difference (Ran- } \\
\text { dom, } 95 \% \mathrm{Cl} \text { ) }\end{array}$ & $-0.04[-0.29,0.21]$ \\
\hline $\begin{array}{l}4.5>2-5 \text { years of supplementation (final } \\
\text { measurement data) }\end{array}$ & 1 & 818 & $\begin{array}{l}\text { Std. Mean Difference (Ran- } \\
\text { dom, } 95 \% \mathrm{Cl} \text { ) }\end{array}$ & $-0.08[-0.22,0.06]$ \\
\hline 5 Incidence of $\mathrm{MCl}$ or dementia & 1 & & $\begin{array}{l}\text { Risk Ratio (M-H, Random, } \\
95 \% \mathrm{Cl})\end{array}$ & Subtotals only \\
\hline
\end{tabular}




\begin{tabular}{|c|c|c|c|c|}
\hline Outcome or subgroup title & No. of studies & $\begin{array}{l}\text { No. of partici- } \\
\text { pants }\end{array}$ & Statistical method & Effect size \\
\hline $5.1>2-5$ years of supplementation & 1 & 1803 & $\begin{array}{l}\text { Risk Ratio (M-H, Random, } \\
95 \% \mathrm{Cl} \text { ) }\end{array}$ & $1.01[0.69,1.48]$ \\
\hline 6 All-cause mortality & 4 & & $\begin{array}{l}\text { Risk Ratio (M-H, Random, } \\
95 \% \mathrm{Cl} \text { ) }\end{array}$ & Subtotals only \\
\hline 6.13-12 months of supplementation & 1 & 201 & $\begin{array}{l}\text { Risk Ratio (M-H, Random, } \\
95 \% \mathrm{Cl} \text { ) }\end{array}$ & $0.34[0.01,8.33]$ \\
\hline $6.2>1$ to 2 years of supplementation & 1 & 3680 & $\begin{array}{l}\text { Risk Ratio (M-H, Random, } \\
95 \% \mathrm{Cl} \text { ) }\end{array}$ & $0.86[0.66,1.11]$ \\
\hline $6.3>2-5$ years of supplementation & 1 & 1127 & $\begin{array}{l}\text { Risk Ratio (M-H, Random, } \\
95 \% \mathrm{Cl} \text { ) }\end{array}$ & $1.98[1.22,3.21]$ \\
\hline $6.4>5-10$ years of supplementation & 1 & 12064 & $\begin{array}{l}\text { Risk Ratio (M-H, Random, } \\
95 \% \mathrm{Cl} \text { ) }\end{array}$ & $1.03[0.95,1.12]$ \\
\hline
\end{tabular}

Analysis 1.1. Comparison $1 \mathrm{~B}$ vitamins versus control, Outcome 1 Overall cognitive functioning.

\begin{tabular}{|c|c|c|c|c|c|c|}
\hline \multirow[t]{2}{*}{ Study or subgroup } & B-Vitamins & Control & $\begin{array}{l}\text { Std. Mean } \\
\text { Difference }\end{array}$ & Std. Mean Difference & \multirow[t]{2}{*}{ Weight } & \multirow{2}{*}{$\begin{array}{l}\text { Std. Mean Difference } \\
\text { IV, Random, } 95 \% \mathrm{Cl}\end{array}$} \\
\hline & $\mathbf{N}$ & $\mathbf{N}$ & (SE) & IV, Random, $95 \% \mathrm{Cl}$ & & \\
\hline \multicolumn{7}{|c|}{ 1.1.1 3-12 months of supplementation (final measurement data) } \\
\hline Hankey 2013 & 691 & 712 & $-0(0.053)$ & & $54.91 \%$ & $-0.04[-0.14,0.07]$ \\
\hline McMahon 2006 & 127 & 126 & $-0(0.126)$ & $\cdots$ & $9.89 \%$ & $-0.05[-0.3,0.2]$ \\
\hline Walker 2012 & 447 & 453 & $0.1(0.067)$ & & $35.2 \%$ & $0.08[-0.05,0.21]$ \\
\hline Subtotal $(95 \% \mathrm{Cl})$ & & & & & $100 \%$ & $0[-0.08,0.08]$ \\
\hline \multicolumn{7}{|c|}{ Heterogeneity: $\operatorname{Tau}^{2}=0 ; \mathrm{Chi}^{2}=1.94, \mathrm{df}=2(\mathrm{P}=0.38) ; 1^{2}=0 \%$} \\
\hline \multicolumn{7}{|c|}{ Test for overall effect: $Z=0.04(P=0.97)$} \\
\hline \multicolumn{7}{|c|}{ 1.1.2 3-12 months of supplementation (change from baseline data) } \\
\hline Ford 2010 & 127 & 128 & $0(0.125)$ & & $82.54 \%$ & $0[-0.25,0.25]$ \\
\hline Stott 2005 & 42 & 20 & $-0.2(0.272)$ & & $17.46 \%$ & $-0.19[-0.72,0.34]$ \\
\hline Subtotal $(95 \% \mathrm{Cl})$ & & & & & $100 \%$ & $-0.03[-0.26,0.19]$ \\
\hline \multicolumn{7}{|c|}{ Heterogeneity: $\mathrm{Tau}^{2}=0 ; \mathrm{Chi}^{2}=0.4, \mathrm{df}=1(\mathrm{P}=0.53) ; \mathrm{I}^{2}=0 \%$} \\
\hline \multicolumn{7}{|c|}{ Test for overall effect: $Z=0.29(P=0.77)$} \\
\hline \multicolumn{7}{|c|}{ 1.1.3 $>1-2$ years of supplementation (final measurement data) } \\
\hline Hankey 2013 & 617 & 621 & $-0(0.057)$ & $\rightarrow$ & $20.95 \%$ & $-0.01[-0.12,0.1]$ \\
\hline Kang 2008 & 1002 & 1007 & $0(0.045)$ & & $26.09 \%$ & $0.01[-0.08,0.1]$ \\
\hline McMahon 2006 & 126 & 127 & $0(0.126)$ & & $6.98 \%$ & $0.02[-0.22,0.27]$ \\
\hline Van der Zwaluw 2014 & 1278 & 1278 & $0.1(0.04)$ & - & $28.47 \%$ & $0.05[-0.03,0.13]$ \\
\hline Walker 2012 & 447 & 453 & $-0.2(0.067)$ & $\because$ & $17.51 \%$ & $-0.16[-0.3,-0.03]$ \\
\hline Subtotal $(95 \% \mathrm{Cl})$ & & & & & $100 \%$ & $-0.01[-0.08,0.06]$ \\
\hline \multicolumn{7}{|c|}{ Heterogeneity: $\operatorname{Tau}^{2}=0 ; \mathrm{Chi}^{2}=7.88, \mathrm{df}=4(\mathrm{P}=0.1) ; 1^{2}=49.25 \%$} \\
\hline \multicolumn{7}{|c|}{ Test for overall effect: $Z=0.33(P=0.74)$} \\
\hline \multicolumn{7}{|c|}{ 1.1.4 > 1-2 years of supplementation (change from baseline data) } \\
\hline Ford 2010 & 118 & 123 & $0.1(0.129)$ & - & $100 \%$ & $0.06[-0.2,0.31]$ \\
\hline
\end{tabular}




\begin{tabular}{|c|c|c|c|c|c|c|}
\hline Study or subgroup & B-Vitamins & $\begin{array}{l}\text { Control } \\
\text { N }\end{array}$ & $\begin{array}{l}\text { Std. Mean } \\
\text { Difference } \\
\text { (SE) }\end{array}$ & $\begin{array}{l}\text { Std. Mean Difference } \\
\text { IV, Random, } 95 \% \mathrm{CI}\end{array}$ & Weight & $\begin{array}{l}\text { Std. Mean Difference } \\
\text { IV, Random, } 95 \% \mathrm{CI}\end{array}$ \\
\hline Subtotal $(95 \% \mathrm{Cl})$ & & & & & $100 \%$ & $0.06[-0.2,0.31]$ \\
\hline \multicolumn{7}{|c|}{ Heterogeneity: Not applicable } \\
\hline \multicolumn{7}{|c|}{ Test for overall effect: $Z=0.43(P=0.67)$} \\
\hline \multicolumn{7}{|c|}{ 1.1.5 $>2-5$ years of supplementation (final measurement data) } \\
\hline Andreeva 2011 & 446 & 425 & $0.1(0.068)$ & - & $24.98 \%$ & $0.08[-0.05,0.22]$ \\
\hline Durga 2007 & 405 & 413 & $-0.1(0.07)$ & 世 & $24.32 \%$ & $-0.15[-0.29,-0.01]$ \\
\hline Hankey 2013 & 219 & 243 & $0.1(0.093)$ & + & $17.87 \%$ & $0.08[-0.1,0.26]$ \\
\hline Kang 2008 & 911 & 923 & $-0(0.047)$ & & $32.83 \%$ & $-0.03[-0.12,0.06]$ \\
\hline Subtotal $(95 \% \mathrm{Cl})$ & & & & & $100 \%$ & $-0.01[-0.11,0.09]$ \\
\hline \multicolumn{7}{|c|}{ Heterogeneity: $\mathrm{Tau}^{2}=0.01 ; \mathrm{Chi}^{2}=6.8, \mathrm{df}=3(\mathrm{P}=0.08) ; \mathrm{I}^{2}=55.88 \%$} \\
\hline \multicolumn{7}{|c|}{ Test for overall effect: $Z=0.22(P=0.83)$} \\
\hline \multicolumn{7}{|c|}{ 1.1.6 > 5-10 years of supplementation (final measurement data) } \\
\hline Hankey 2013 & 155 & 150 & $0.1(0.115)$ & + & $10.48 \%$ & $0.12[-0.1,0.34]$ \\
\hline Kang 2008 & 521 & 532 & $-0.1(0.062)$ & 一 & $27.01 \%$ & $-0.09[-0.21,0.03]$ \\
\hline SEARCH 2010 & 4427 & 4464 & $0(0.021)$ & & $62.51 \%$ & $0[-0.04,0.04]$ \\
\hline Subtotal $(95 \% \mathrm{Cl})$ & & & & & $100 \%$ & $-0.01[-0.09,0.07]$ \\
\hline \multicolumn{7}{|c|}{ Heterogeneity: $\operatorname{Tau}^{2}=0 ; \mathrm{Chi}^{2}=3.27, \mathrm{df}=2(\mathrm{P}=0.19) ; \mathrm{I}^{2}=38.85 \%$} \\
\hline Test for overall effec & & & & & & \\
\hline
\end{tabular}

Analysis 1.2. Comparison 1 B vitamins versus control, Outcome 2 Episodic memory.

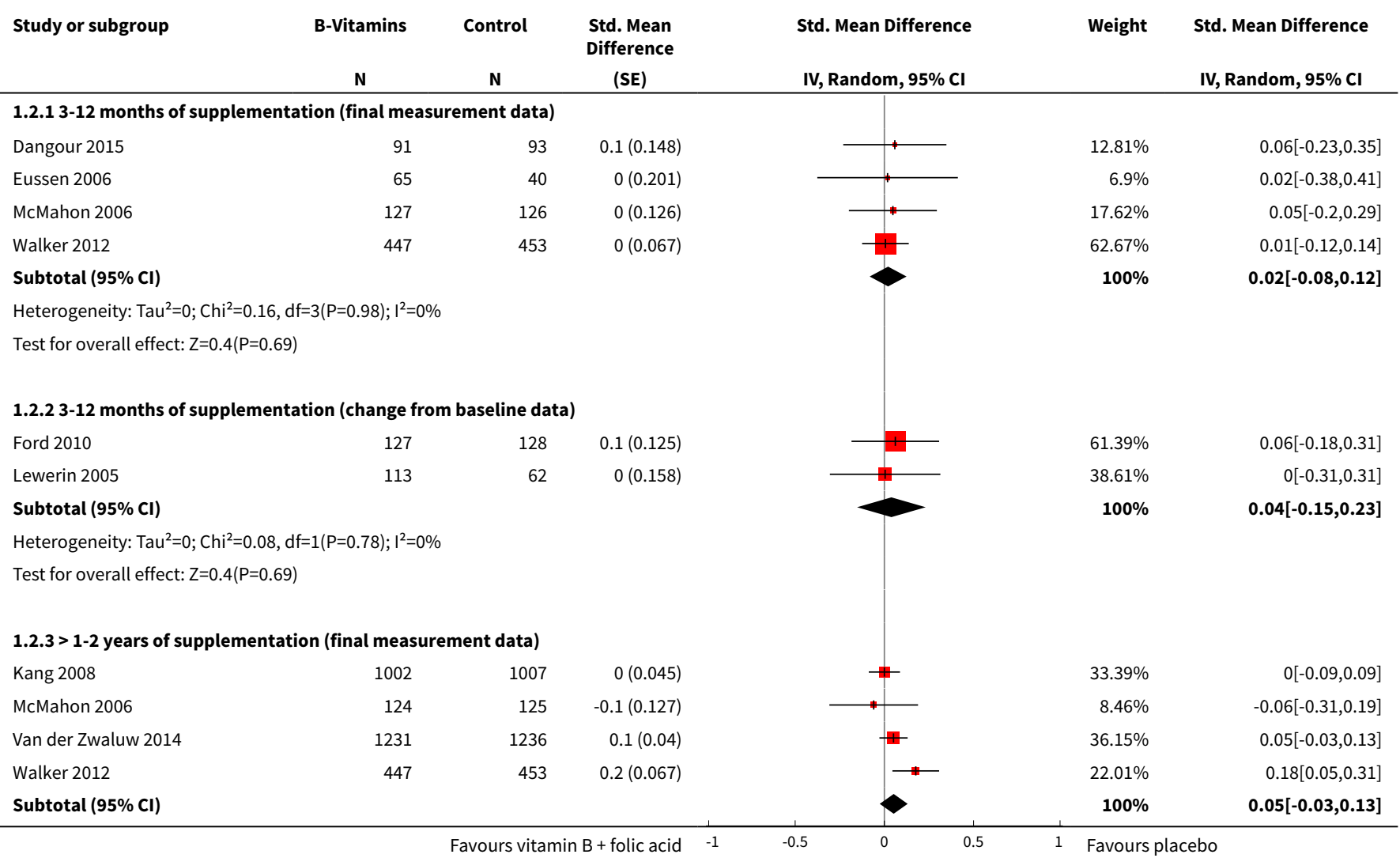




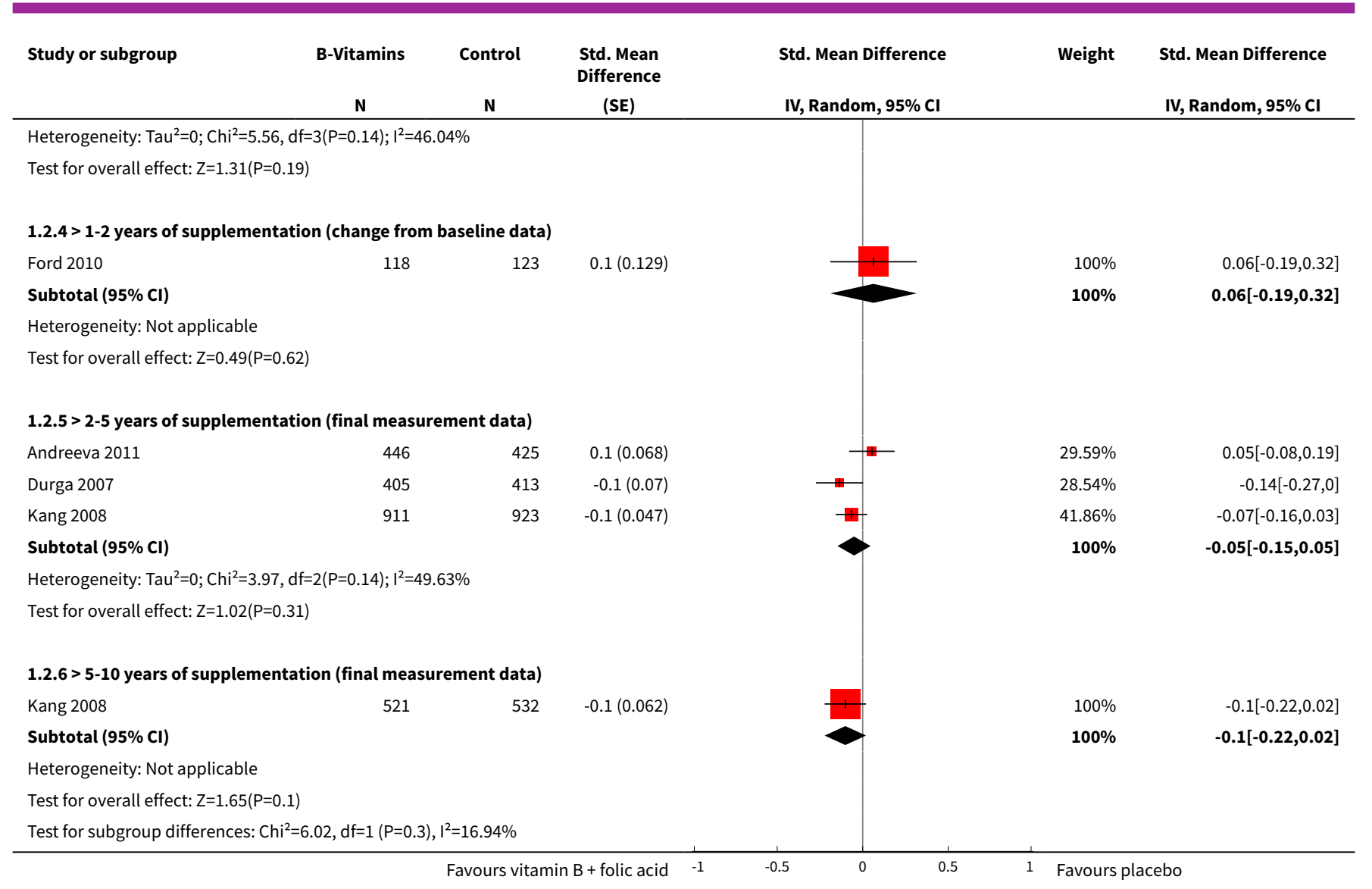

Analysis 1.3. Comparison 1 B vitamins versus control, Outcome 3 Executive function.

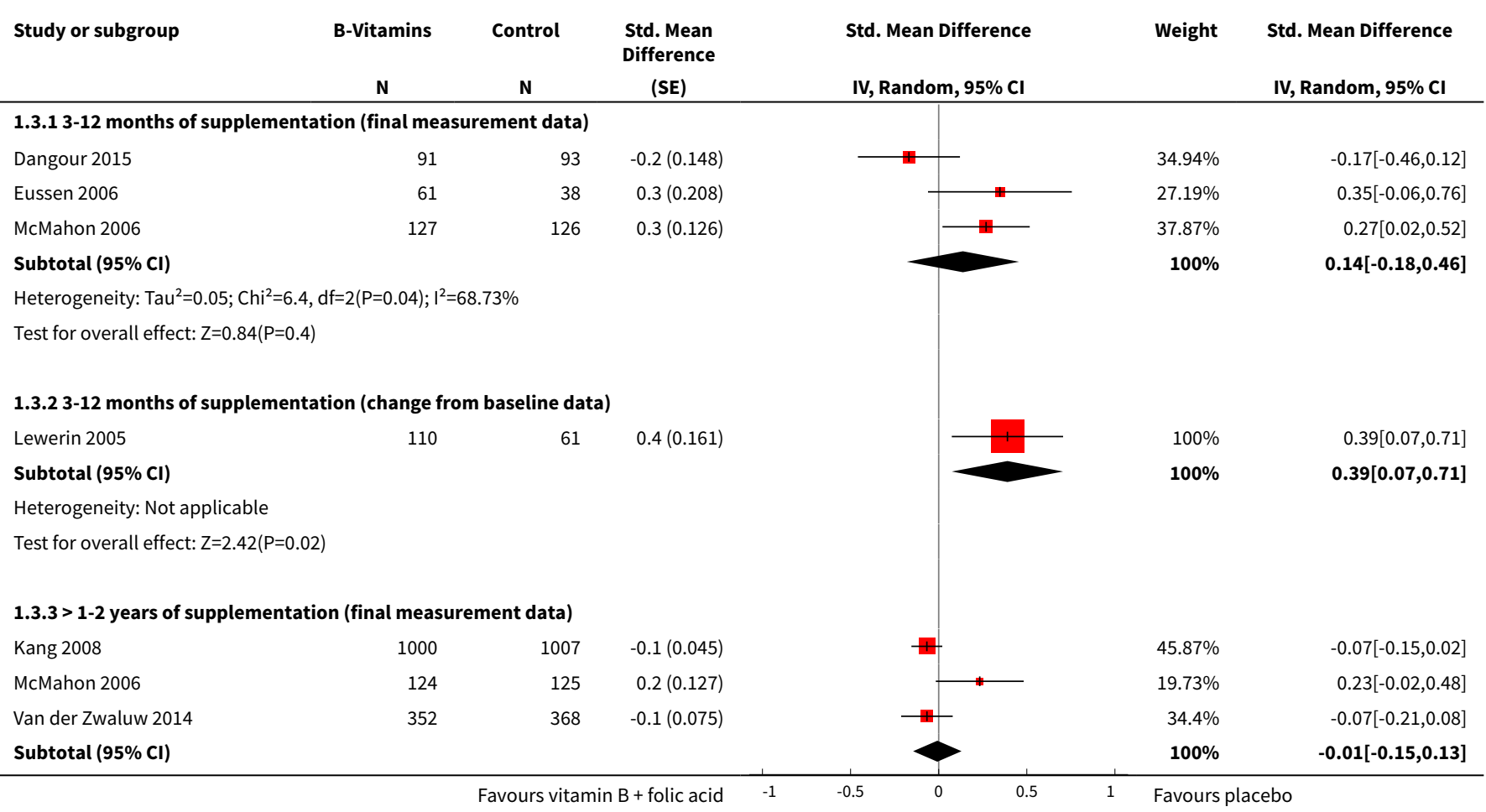




\begin{tabular}{|c|c|c|c|c|c|c|}
\hline Study or subgroup & B-Vitamins & Control & $\begin{array}{l}\text { Std. Mean } \\
\text { Difference } \\
\quad \text { (SE) }\end{array}$ & Std. Mean Difference & Weight & $\begin{array}{l}\text { Std. Mean Difference } \\
\text { IV, Random, } 95 \% \mathrm{CI}\end{array}$ \\
\hline \multicolumn{7}{|c|}{ Heterogeneity: $\mathrm{Tau}^{2}=0.01 ; \mathrm{Chi}^{2}=5.1, \mathrm{df}=2(\mathrm{P}=0.08) ; \mathrm{I}^{2}=60.77 \%$} \\
\hline \multicolumn{7}{|c|}{ Test for overall effect: $\mathrm{Z}=0.11(\mathrm{P}=0.91)$} \\
\hline \multicolumn{7}{|c|}{ 1.3.4 > 2-5 years of supplementation (final measurement data) } \\
\hline Durga 2007 & 405 & 413 & $-0(0.07)$ & $\rightarrow$ & $30.95 \%$ & $-0.04[-0.18,0.1]$ \\
\hline Kang 2008 & 909 & 921 & $-0.1(0.047)$ & & $69.05 \%$ & $-0.07[-0.16,0.03]$ \\
\hline Subtotal $(95 \% \mathrm{Cl})$ & & & & & $100 \%$ & $-0.06[-0.13,0.02]$ \\
\hline \multicolumn{7}{|c|}{ Heterogeneity: $\operatorname{Tau}^{2}=0 ; \mathrm{Chi}^{2}=0.11, \mathrm{df}=1(\mathrm{P}=0.74) ; \mathrm{I}^{2}=0 \%$} \\
\hline \multicolumn{7}{|c|}{ Test for overall effect: $Z=1.48(P=0.14)$} \\
\hline Kang 2008 & 519 & 530 & $0(0.062)$ & & $100 \%$ & $0.02[-0.1,0.15]$ \\
\hline Subtotal $(95 \% \mathrm{Cl})$ & & & & & $100 \%$ & $0.02[-0.1,0.15]$ \\
\hline \multicolumn{7}{|c|}{ Heterogeneity: Not applicable } \\
\hline \multicolumn{7}{|c|}{ Test for overall effect: $Z=0.4(P=0.69)$} \\
\hline Test for subgroup dif & $.8, \mathrm{df}=1(\mathrm{P}=0.0$ & $=54.52 \%$ & & & & \\
\hline
\end{tabular}

Analysis 1.4. Comparison $1 \mathrm{~B}$ vitamins versus control, Outcome 4 Speed of processing.

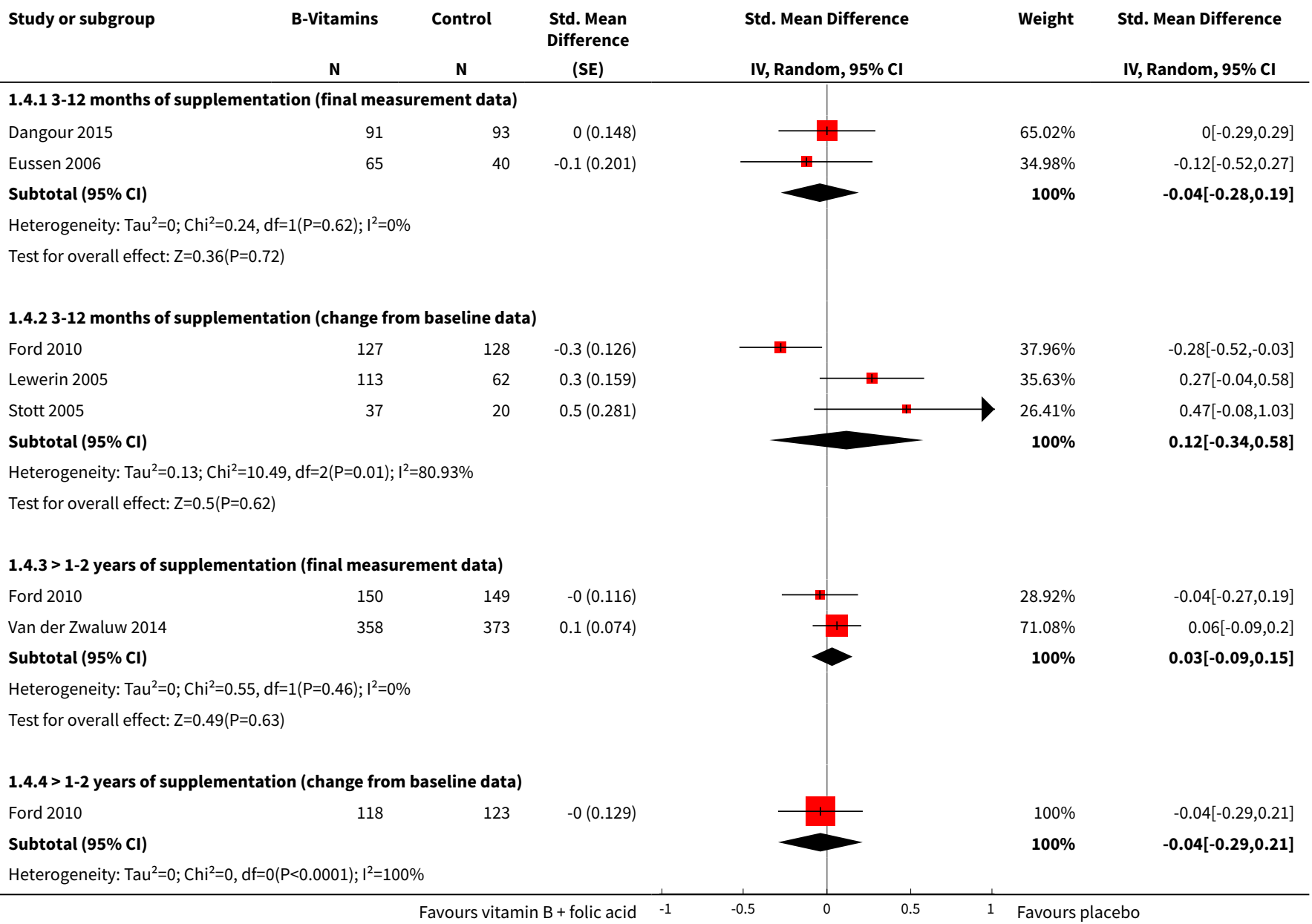




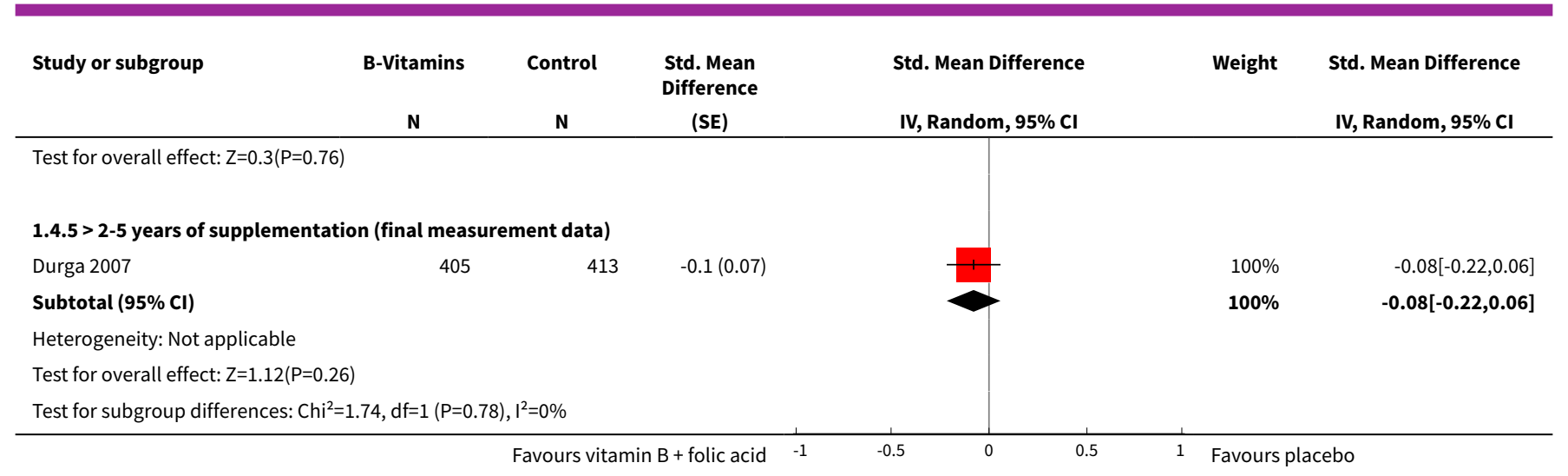

Analysis 1.5. Comparison $1 \mathrm{~B}$ vitamins versus control, Outcome 5 Incidence of $\mathrm{MCl}$ or dementia.

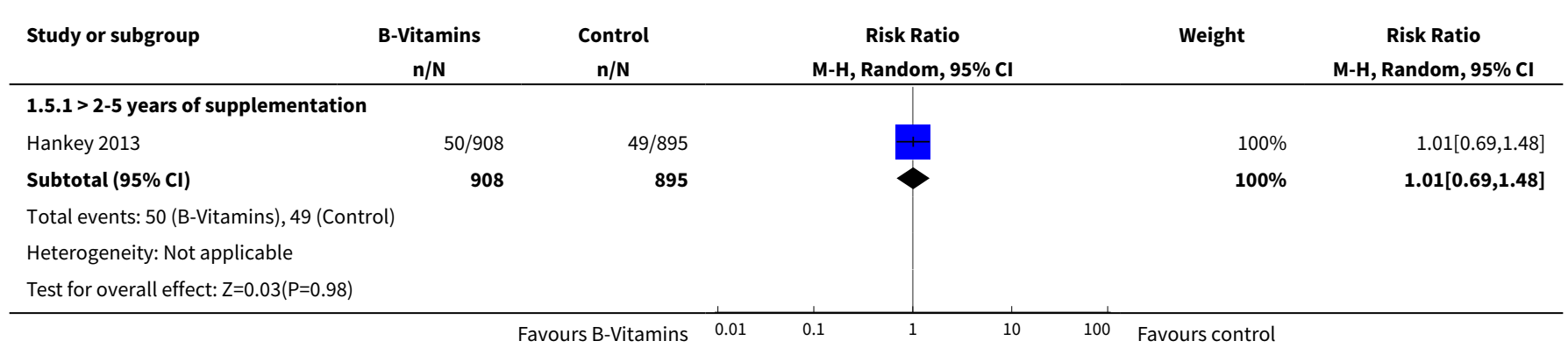

Analysis 1.6. Comparison $1 \mathrm{~B}$ vitamins versus control, Outcome 6 All-cause mortality.

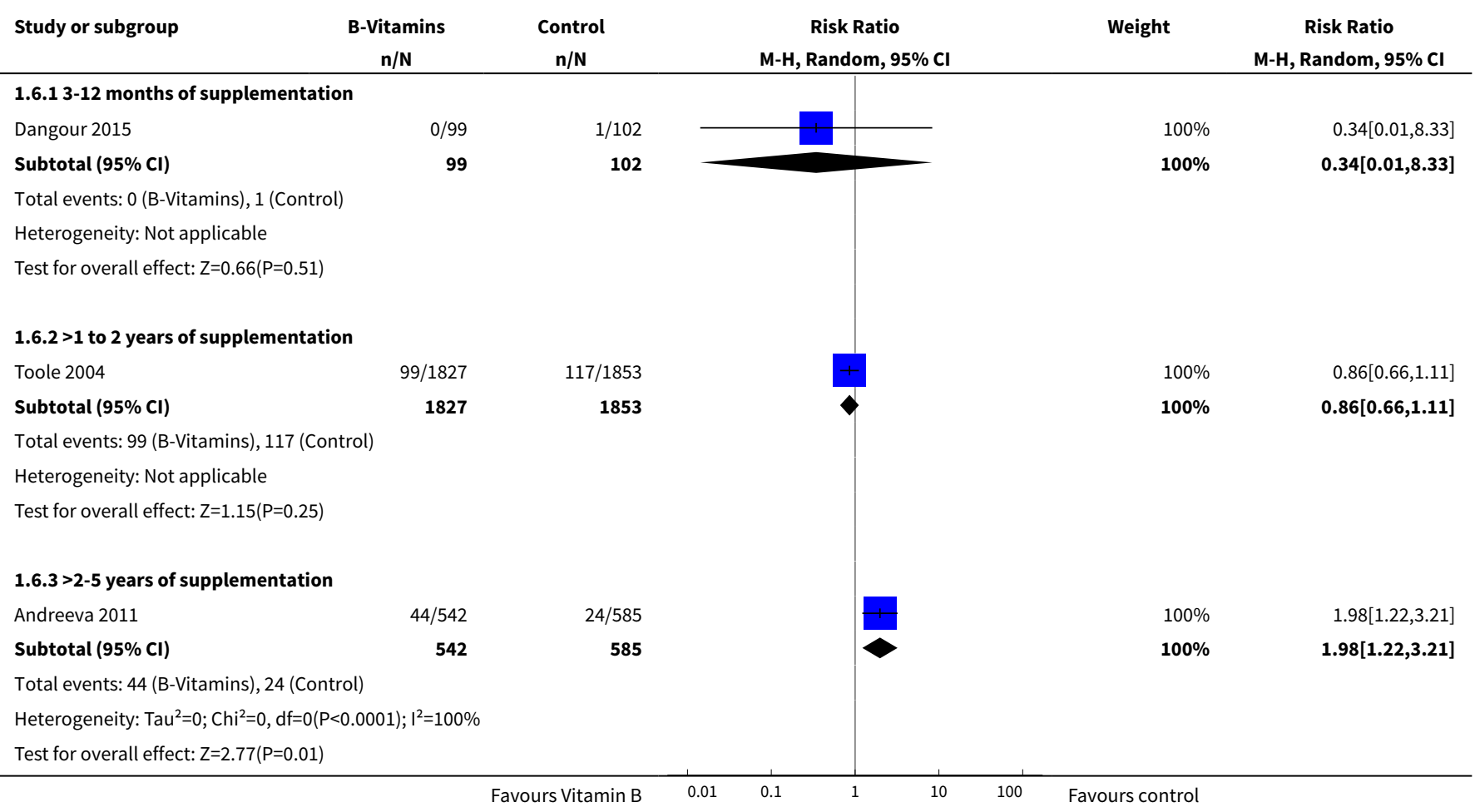




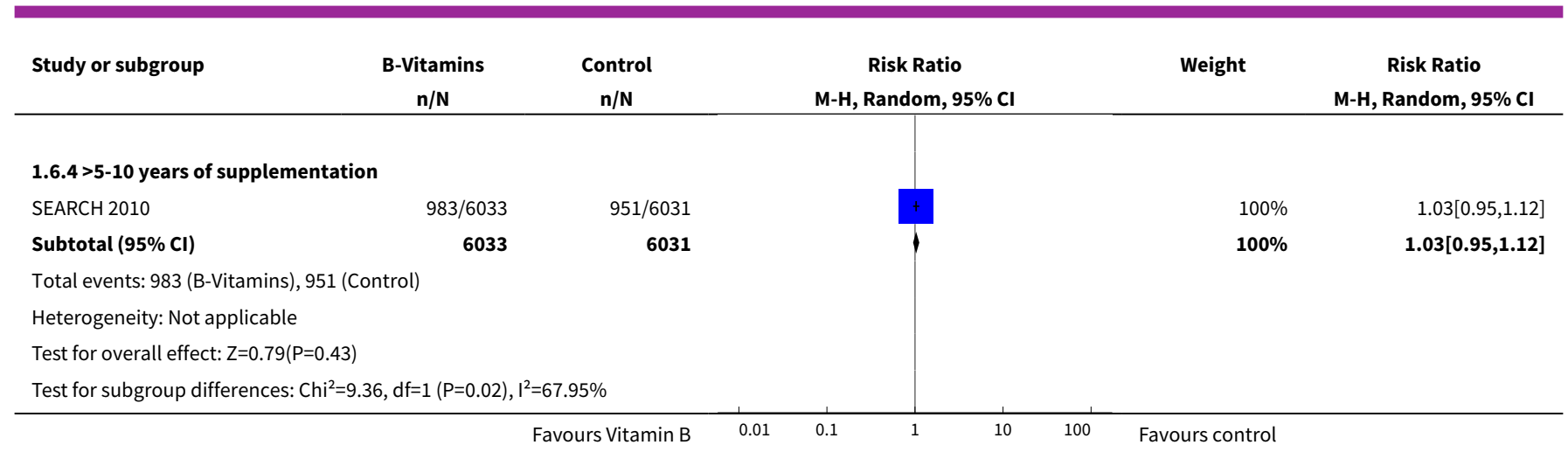

\section{Comparison 2. Antioxidants versus control}

\begin{tabular}{|c|c|c|c|c|}
\hline Outcome or subgroup title & No. of studies & $\begin{array}{l}\text { No. of partici- } \\
\text { pants }\end{array}$ & Statistical method & Effect size \\
\hline 1 Overall cognitive functioning & 5 & & $\begin{array}{l}\text { Mean Difference (Random, } \\
95 \% \mathrm{Cl} \text { ) }\end{array}$ & Subtotals only \\
\hline $\begin{array}{l}1.13-12 \text { months Vitamin E supplemen- } \\
\text { tation }\end{array}$ & 1 & & $\begin{array}{l}\text { Mean Difference (Random, } \\
95 \% \mathrm{Cl} \text { ) }\end{array}$ & $1.4[1.18,1.62]$ \\
\hline $\begin{array}{l}1.23-12 \text { months Beta Carotene supple- } \\
\text { mentation }\end{array}$ & 1 & & $\begin{array}{l}\text { Mean Difference (Random, } \\
95 \% \mathrm{Cl} \text { ) }\end{array}$ & $-0.14[-0.37,0.09]$ \\
\hline $\begin{array}{l}1.3>2-5 \text { years antioxidants (Vitamin E } \\
+ \text { Vitamin } C+\text { Beta Carotene) supple- } \\
\text { mentation }\end{array}$ & 1 & & $\begin{array}{l}\text { Mean Difference (Random, } \\
95 \% \mathrm{Cl} \text { ) }\end{array}$ & $0.09[-0.05,0.23]$ \\
\hline $\begin{array}{l}1.4>2-5 \text { years Vitamin E supplementa- } \\
\text { tion }\end{array}$ & 1 & & $\begin{array}{l}\text { Mean Difference (Random, } \\
95 \% \mathrm{Cl} \text { ) }\end{array}$ & $0.01[-0.23,0.25]$ \\
\hline $\begin{array}{l}1.5>2-5 \text { years Vitamin } C \text { supplementa- } \\
\text { tion }\end{array}$ & 1 & & $\begin{array}{l}\text { Mean Difference (Random, } \\
95 \% \mathrm{Cl} \text { ) }\end{array}$ & $0.16[-0.08,0.40]$ \\
\hline $\begin{array}{l}1.6>2-5 \text { years Beta Carotene supple- } \\
\text { mentation }\end{array}$ & 1 & & $\begin{array}{l}\text { Mean Difference (Random, } \\
95 \% \mathrm{Cl} \text { ) }\end{array}$ & $-0.18[-0.42,0.06]$ \\
\hline $\begin{array}{l}1.7>5-10 \text { years antioxidants (Vitamin } \\
E+\text { Vitamin } C+\text { Beta carotene) supple- } \\
\text { mentation }\end{array}$ & 1 & & $\begin{array}{l}\text { Mean Difference (Random, } \\
95 \% \mathrm{Cl} \text { ) }\end{array}$ & $0.6[-0.20,1.40]$ \\
\hline $\begin{array}{l}1.8>5-10 \text { years Vitamin C supplemen- } \\
\text { tation }\end{array}$ & 1 & & $\begin{array}{l}\text { Mean Difference (Random, } \\
95 \% \mathrm{Cl} \text { ) }\end{array}$ & $0.46[0.14,0.78]$ \\
\hline $\begin{array}{l}1.9>5-10 \text { years Beta Carotene supple- } \\
\text { mentation }\end{array}$ & 1 & & $\begin{array}{l}\text { Mean Difference (Random, } \\
95 \% \mathrm{Cl} \text { ) }\end{array}$ & $-0.13[-0.46,0.20]$ \\
\hline $\begin{array}{l}1.10>10 \text { years Beta Carotene supple- } \\
\text { mentation }\end{array}$ & 1 & & $\begin{array}{l}\text { Mean Difference (Random, } \\
95 \% \mathrm{Cl} \text { ) }\end{array}$ & $0.18[0.01,0.35]$ \\
\hline 2 Episodic memory & 4 & & $\begin{array}{l}\text { Mean Difference (Random, } \\
95 \% \mathrm{Cl} \text { ) }\end{array}$ & Subtotals only \\
\hline
\end{tabular}




\begin{tabular}{|c|c|c|c|c|}
\hline Outcome or subgroup title & No. of studies & $\begin{array}{l}\text { No. of partici- } \\
\text { pants }\end{array}$ & Statistical method & Effect size \\
\hline $\begin{array}{l}2.13-12 \text { months Beta Carotene supple- } \\
\text { mentation }\end{array}$ & 1 & & $\begin{array}{l}\text { Mean Difference (Random, } \\
95 \% \mathrm{Cl} \text { ) }\end{array}$ & $0.02[-0.05,0.08]$ \\
\hline $\begin{array}{l}2.2>2-5 \text { years Vitamin E supplementa- } \\
\text { tion }\end{array}$ & 1 & & $\begin{array}{l}\text { Mean Difference (Random, } \\
95 \% \mathrm{Cl} \text { ) }\end{array}$ & $-0.02[-0.07,0.03]$ \\
\hline $\begin{array}{l}2.3>2-5 \text { years Vitamin } C \text { supplementa- } \\
\text { tion }\end{array}$ & 1 & & $\begin{array}{l}\text { Mean Difference (Random, } \\
95 \% \mathrm{Cl} \text { ) }\end{array}$ & $-0.05[-0.10,-0.00]$ \\
\hline $\begin{array}{l}2.4>2-5 \text { years Beta Carotene supple- } \\
\text { mentation }\end{array}$ & 1 & & $\begin{array}{l}\text { Mean Difference (Random, } \\
95 \% \mathrm{Cl} \text { ) }\end{array}$ & $0.01[-0.05,0.07]$ \\
\hline $\begin{array}{l}2.5>5-10 \text { years antioxidants (Vitamin } \\
E+\text { Vitamin } C+\text { Beta Carotene) supple- } \\
\text { mentation }\end{array}$ & 1 & & $\begin{array}{l}\text { Mean Difference (Random, } \\
95 \% \mathrm{Cl} \text { ) }\end{array}$ & $-0.3[-1.30,0.70]$ \\
\hline $\begin{array}{l}2.6>5-10 \text { years Vitamin E supplemen- } \\
\text { tation }\end{array}$ & 2 & & $\begin{array}{l}\text { Mean Difference (Random, } \\
95 \% \mathrm{Cl} \text { ) }\end{array}$ & $0.02[-0.05,0.09]$ \\
\hline $\begin{array}{l}2.7>5-10 \text { years Vitamin C supplemen- } \\
\text { tation }\end{array}$ & 1 & & $\begin{array}{l}\text { Mean Difference (Random, } \\
95 \% \mathrm{Cl} \text { ) }\end{array}$ & $-0.14[-0.22,-0.06]$ \\
\hline $\begin{array}{l}2.8>5-10 \text { years Beta Carotene supple- } \\
\text { mentation }\end{array}$ & 1 & & $\begin{array}{l}\text { Mean Difference (Random, } \\
95 \% \mathrm{Cl} \text { ) }\end{array}$ & $0.02[-0.05,0.09]$ \\
\hline $\begin{array}{l}2.9>10 \text { years Beta Carotene supple- } \\
\text { mentation }\end{array}$ & 1 & & $\begin{array}{l}\text { Mean Difference (Random, } \\
95 \% \mathrm{Cl} \text { ) }\end{array}$ & $-0.06[-0.11,-0.02]$ \\
\hline 3 Executive function & 4 & & $\begin{array}{l}\text { Mean Difference (Random, } \\
95 \% \mathrm{Cl} \text { ) }\end{array}$ & Subtotals only \\
\hline $\begin{array}{l}\text { 3.1 3-12 months Beta Carotene supple- } \\
\text { mentation }\end{array}$ & 1 & & $\begin{array}{l}\text { Mean Difference (Random, } \\
95 \% \mathrm{Cl} \text { ) }\end{array}$ & $0.07[-0.48,0.62]$ \\
\hline $\begin{array}{l}3.2>2-5 \text { years Vitamin E supplementa- } \\
\text { tion }\end{array}$ & 1 & & $\begin{array}{l}\text { Mean Difference (Random, } \\
95 \% \mathrm{Cl} \text { ) }\end{array}$ & $0.42[0.06,0.78]$ \\
\hline $\begin{array}{l}3.3>2-5 \text { years Vitamin } C \text { supplementa- } \\
\text { tion }\end{array}$ & 1 & & $\begin{array}{l}\text { Mean Difference (Random, } \\
95 \% \mathrm{Cl} \text { ) }\end{array}$ & $-0.03[-0.39,0.33]$ \\
\hline $\begin{array}{l}3.4>2-5 \text { years Beta Carotene supple- } \\
\text { mentation }\end{array}$ & 1 & & $\begin{array}{l}\text { Mean Difference (Random, } \\
95 \% \mathrm{Cl} \text { ) }\end{array}$ & $0.22[-0.14,0.58]$ \\
\hline $\begin{array}{l}3.5>5-10 \text { years antioxidants (Vitamin } \\
\text { E + Vitamin C + Beta Carotene) supple- } \\
\text { mentation }\end{array}$ & 1 & & $\begin{array}{l}\text { Mean Difference (Random, } \\
95 \% \mathrm{Cl} \text { ) }\end{array}$ & $-0.4[-0.99,0.19]$ \\
\hline $\begin{array}{l}3.6>5-10 \text { years Vitamin E supplemen- } \\
\text { tation }\end{array}$ & 2 & & $\begin{array}{l}\text { Mean Difference (Random, } \\
95 \% \mathrm{Cl} \text { ) }\end{array}$ & $0.11[-0.26,0.48]$ \\
\hline $\begin{array}{l}3.7>5-10 \text { years Vitamin C supplemen- } \\
\text { tation }\end{array}$ & 1 & & $\begin{array}{l}\text { Mean Difference (Random, } \\
95 \% \mathrm{Cl} \text { ) }\end{array}$ & $-0.25[-0.70,0.20]$ \\
\hline $\begin{array}{l}3.8>5-10 \text { years Beta Carotene supple- } \\
\text { mentation }\end{array}$ & 1 & & $\begin{array}{l}\text { Mean Difference (Random, } \\
95 \% \mathrm{Cl} \text { ) }\end{array}$ & $0.01[-0.44,0.46]$ \\
\hline
\end{tabular}




\begin{tabular}{|c|c|c|c|c|}
\hline Outcome or subgroup title & No. of studies & $\begin{array}{l}\text { No. of partici- } \\
\text { pants }\end{array}$ & Statistical method & Effect size \\
\hline $\begin{array}{l}3.9>10 \text { years Beta Carotene supple- } \\
\text { mentation }\end{array}$ & 1 & & $\begin{array}{l}\text { Mean Difference (Random, } \\
95 \% \mathrm{Cl} \text { ) }\end{array}$ & $0.01[-0.36,0.38]$ \\
\hline 4 Incidence of dementia & 1 & & $\begin{array}{l}\text { Risk Ratio (M-H, Random, } \\
95 \% \mathrm{Cl} \text { ) }\end{array}$ & Subtotals only \\
\hline $4.1>2-5$ years of supplementation & 1 & 20536 & $\begin{array}{l}\text { Risk Ratio (M-H, Random, } \\
95 \% \mathrm{Cl} \text { ) }\end{array}$ & $1.00[0.61,1.64]$ \\
\hline 5 All-cause mortality & 1 & & $\begin{array}{l}\text { Risk Ratio (M-H, Random, } \\
95 \% \mathrm{Cl} \text { ) }\end{array}$ & Subtotals only \\
\hline $\begin{array}{l}5.1>2-5 \text { years antioxidants (Vitamin E } \\
+ \text { Vitamin } C++ \text { Beta Carotene) supple- } \\
\text { mentation }\end{array}$ & 1 & 20536 & $\begin{array}{l}\text { Risk Ratio (M-H, Random, } \\
95 \% \mathrm{Cl} \text { ) }\end{array}$ & $1.04[0.97,1.11]$ \\
\hline
\end{tabular}

Analysis 2.1. Comparison 2 Antioxidants versus control, Outcome 1 Overall cognitive functioning.

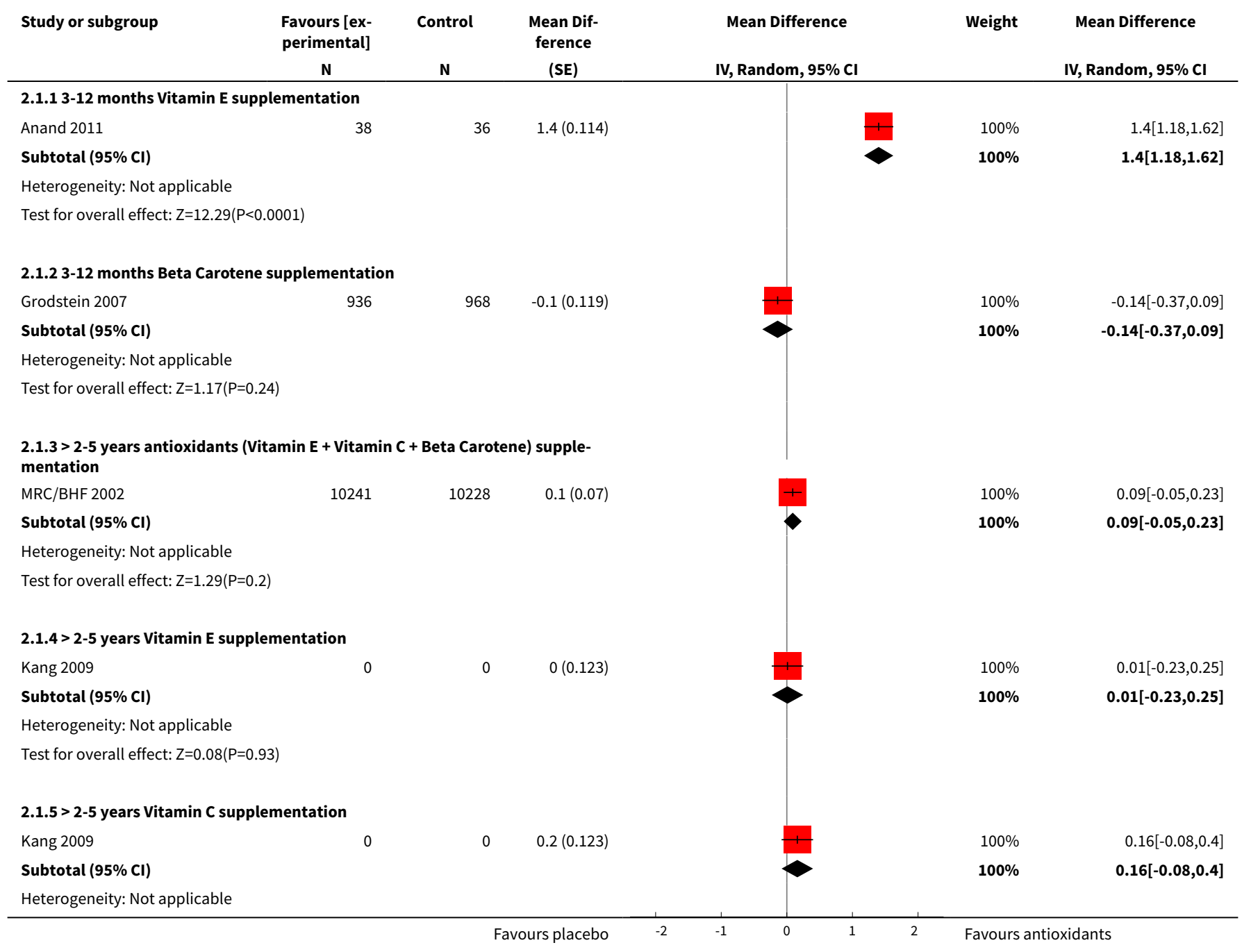




\begin{tabular}{|c|c|c|c|c|c|c|}
\hline \multirow[t]{2}{*}{ Study or subgroup } & $\begin{array}{l}\text { Favours [ex- } \\
\text { perimental] }\end{array}$ & Control & $\begin{array}{l}\text { Mean Dif- } \\
\text { ference }\end{array}$ & Mean Difference & Weight & Mean Difference \\
\hline & $\mathbf{N}$ & $\mathbf{N}$ & (SE) & IV, Random, 95\% Cl & & IV, Random, 95\% CI \\
\hline
\end{tabular}

Test for overall effect: $\mathrm{Z}=1.31(\mathrm{P}=0.19)$

2.1.6 > 2-5 years Beta Carotene supplementation

Kang 2009

Subtotal $(95 \% \mathrm{CI})$

$0 \quad 0 \quad-0.2(0.123)$

Heterogeneity: Not applicable

Test for overall effect: $Z=1.47(P=0.14)$

2.1.7 > 5-10 years antioxidants (Vitamin E + Vitamin C + Beta carotene) supplementation

$\begin{array}{llll}\text { Yaffe } 2004 & 566 & 534 & 0.6(0.41)\end{array}$

Subtotal $(95 \% \mathrm{Cl})$

$0.6(0.41)$

Heterogeneity: Not applicable

Test for overall effect: $\mathrm{Z}=1.46(\mathrm{P}=0.14)$

2.1.8 > 5-10 years Vitamin C supplementation

$\begin{array}{llll}\text { Kang } 2009 & 0 & 0 & 0.5(0.163)\end{array}$

Subtotal $(95 \% \mathrm{Cl})$

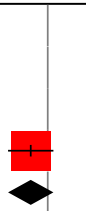

Heterogeneity: Not applicable

Test for overall effect: $Z=2.82(P=0)$

2.1.9 > 5-10 years Beta Carotene supplementation

Kang 2009

Subtotal $(95 \% \mathrm{Cl})$

Heterogeneity: Not applicable

Test for overall effect: $Z=0.77(P=0.44)$

2.1.10 > 10 years Beta Carotene supplementation

Grodstein 2007

2031

$2021 \quad 0.2(0.087)$

Analysis 2.2. Comparison 2 Antioxidants versus control, Outcome 2 Episodic memory.

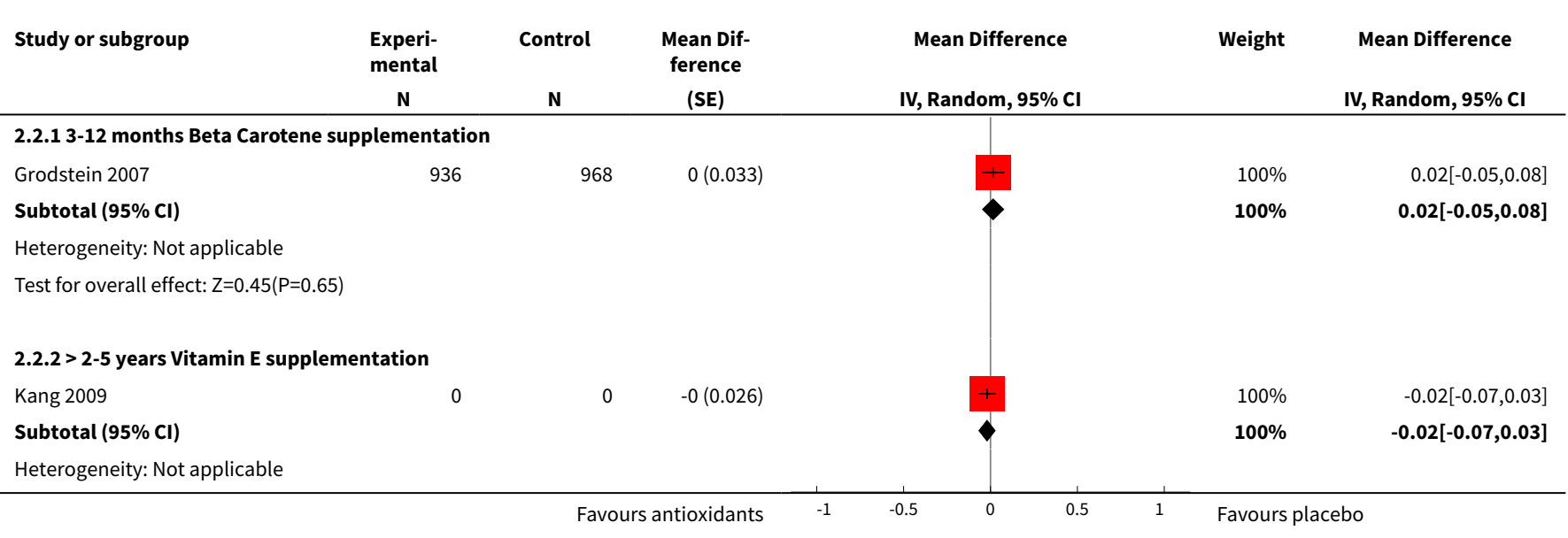




\begin{tabular}{lcccc} 
Study or subgroup & $\begin{array}{c}\text { Experi- } \\
\text { mental }\end{array}$ & Control & $\begin{array}{c}\text { Mean Dif- } \\
\text { ference }\end{array}$ & Mean Difference \\
\hline & N & N & (SE) & IV, Random, $95 \%$ Cl
\end{tabular}

Test for overall effect: $\mathrm{Z}=0.78(\mathrm{P}=0.43)$

2.2.3 > 2-5 years Vitamin C supplementation

Kang 2009

$0 \quad 0 \quad-0(0.026)$

Subtotal $(95 \% \mathrm{Cl})$

Heterogeneity: Not applicable

Test for overall effect: $\mathrm{Z}=1.96(\mathrm{P}=0.05)$

2.2.4 > 2-5 years Beta Carotene supplementation

Kang 2009

Subtotal $(95 \% \mathrm{Cl})$

$0(0.031)$

Heterogeneity: Not applicable

Test for overall effect: $Z=0.33(P=0.74)$

2.2.5 > 5-10 years antioxidants (Vitamin E + Vitamin C + Beta Carotene) supplementation

Yaffe 2004

566

534

$-0.3(0.51)$

Subtotal $(95 \% \mathrm{CI})$
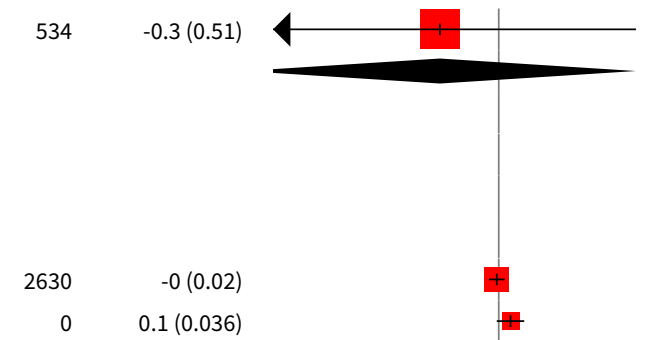

$100 \%$

$-0.3[-1.3,0.7]$

Heterogeneity: Not applicable

Test for overall effect: $\mathrm{Z}=0.59(\mathrm{P}=0.56)$

\subsection{6 > 5-10 years Vitamin E supplementation}

Kang 20062596

Kang 2009

0

$0.1(0.036)$

Subtotal $(95 \% \mathrm{CI})$

Heterogeneity: $\mathrm{Tau}^{2}=0 ; \mathrm{Chi}^{2}=2.9, \mathrm{df}=1(\mathrm{P}=0.09) ; \mathrm{I}^{2}=65.5 \%$

Test for overall effect: $Z=0.55(P=0.58)$

2.2.7 > 5-10 years Vitamin C supplementation

Kang 2009

0

Subtotal $(95 \% \mathrm{Cl})$

$0 \quad-0.1(0.041)$

Heterogeneity: Not applicable

Test for overall effect: $Z=3.43(P=0)$

2.2.8 > 5-10 years Beta Carotene supplementation

Kang 2009

0

$0 \quad 0(0.036)$

$100 \%$

$-0.3[-1.3,0.7]$

Subtotal $(95 \% \mathrm{CI})$

Heterogeneity: Not applicable

Test for overall effect: $\mathrm{Z}=0.56(\mathrm{P}=0.58)$

2.2.9 > 10 years Beta Carotene supplementation

Grodstein 2007

2031

$2021-0.1(0.024)$

Subtotal $(95 \% \mathrm{Cl})$

Heterogeneity: Not applicable

Test for overall effect: $Z=2.63(P=0.01)$

Test for subgroup differences: $\mathrm{Chi}^{2}=17.68, \mathrm{df}=1(\mathrm{P}=0.02), \mathrm{I}^{2}=54.76 \%$

Favours antioxidants 
Analysis 2.3. Comparison 2 Antioxidants versus control, Outcome 3 Executive function.

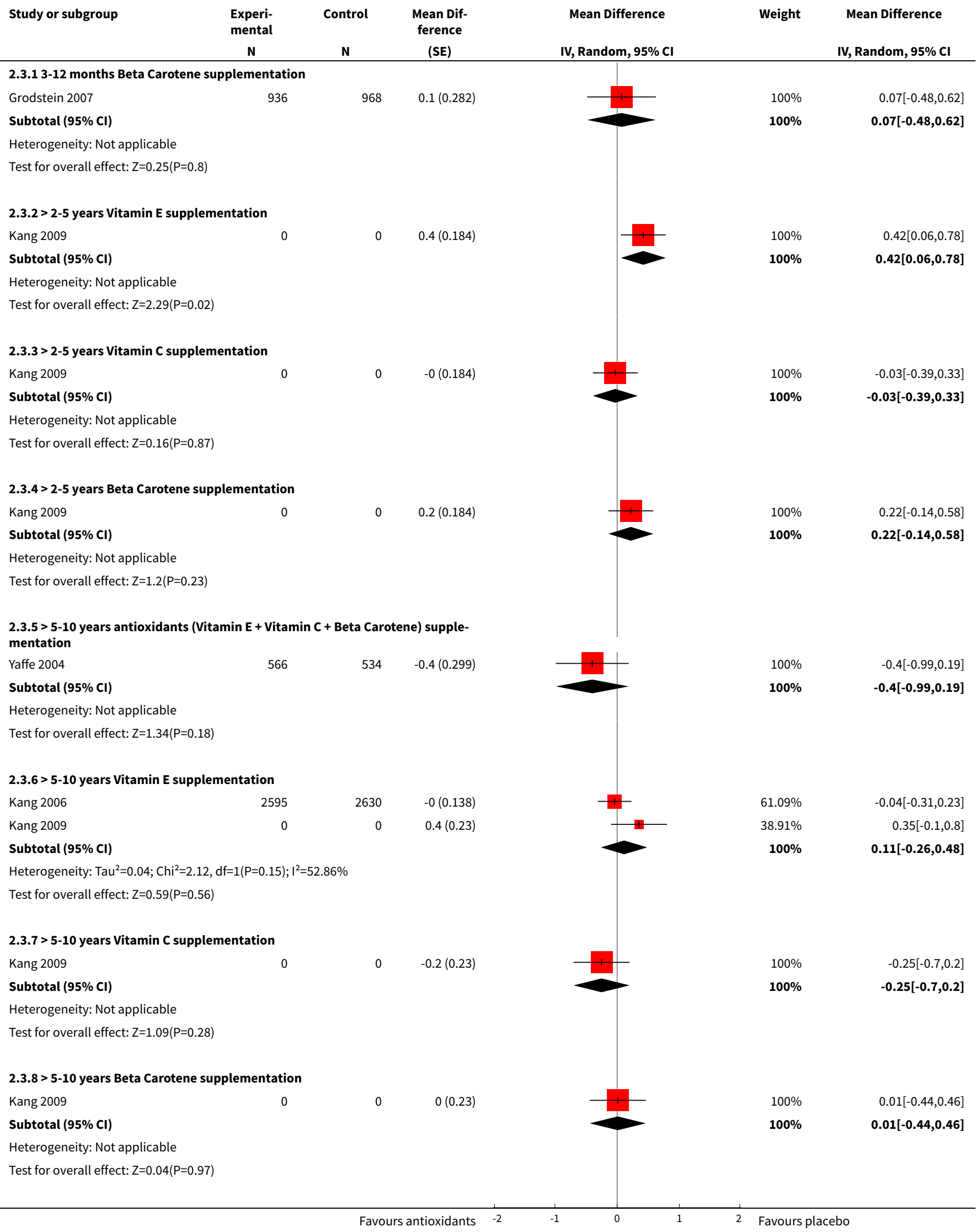

Vitamin and mineral supplementation for maintaining cognitive function in cognitively healthy people in mid and late life (Review) 


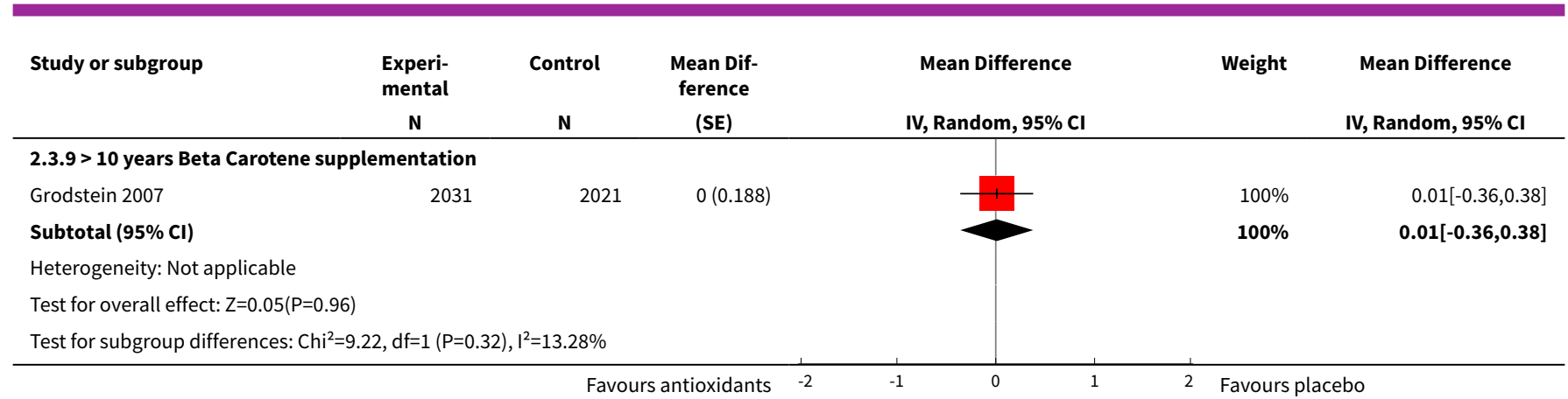

Analysis 2.4. Comparison 2 Antioxidants versus control, Outcome 4 Incidence of dementia.

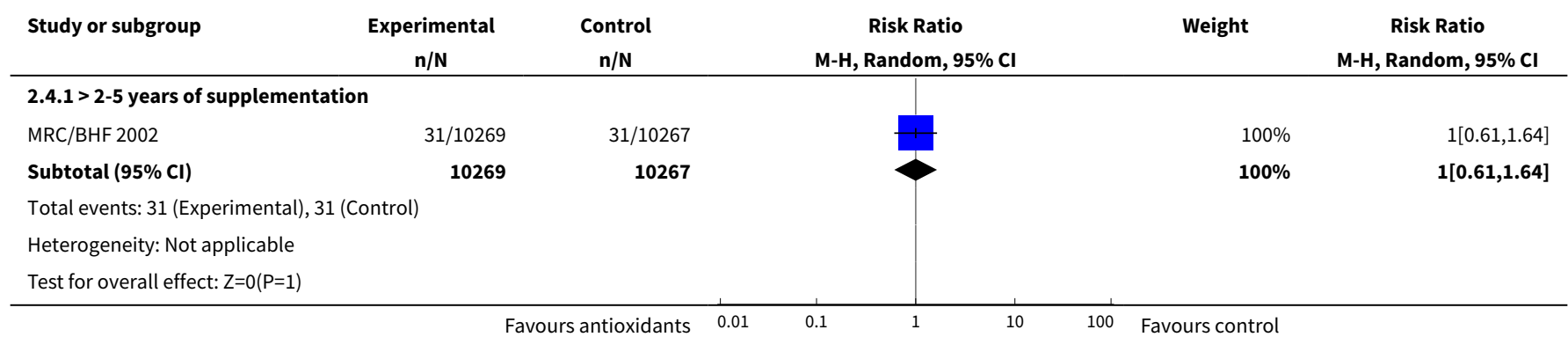

Analysis 2.5. Comparison 2 Antioxidants versus control, Outcome 5 All-cause mortality.

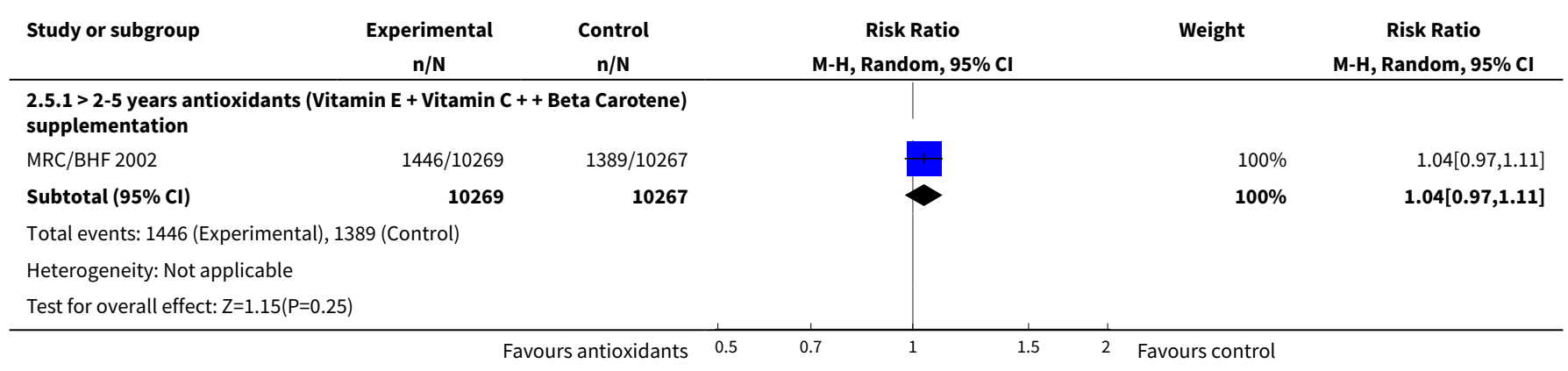

\section{Comparison 3. Vitamin D3 versus placebo}

\begin{tabular}{|c|c|c|c|c|}
\hline Outcome or subgroup title & No. of studies & $\begin{array}{l}\text { No. of partici- } \\
\text { pants }\end{array}$ & Statistical method & Effect size \\
\hline 1 Overall cognitive functioning & 1 & & Mean Difference (Random, 95\% Cl) & Subtotals only \\
\hline $\begin{array}{l}1.13-12 \text { months of supplemen- } \\
\text { tation }\end{array}$ & 1 & 4122 & Mean Difference (Random, 95\% Cl) & $0.0[-0.24,0.24]$ \\
\hline $\begin{array}{l}1.2>1-2 \text { years of supplemen- } \\
\text { tation }\end{array}$ & 1 & 3910 & Mean Difference (Random, 95\% Cl) & $0.0[-0.25,0.25]$ \\
\hline
\end{tabular}




\begin{tabular}{|c|c|c|c|c|}
\hline Outcome or subgroup title & No. of studies & $\begin{array}{l}\text { No. of partici- } \\
\text { pants }\end{array}$ & Statistical method & Effect size \\
\hline $\begin{array}{l}1.3>2-5 \text { years of supplemen- } \\
\text { tation }\end{array}$ & 1 & 3515 & Mean Difference (Random, 95\% Cl) & $-0.2[-0.53,0.13]$ \\
\hline $\begin{array}{l}1.4>5-10 \text { years of supplemen- } \\
\text { tation }\end{array}$ & 1 & 918 & Mean Difference (Random, 95\% Cl) & $-0.1[-0.81,0.61]$ \\
\hline 2 Episodic memory & 1 & & Mean Difference (Random, 95\% Cl) & Subtotals only \\
\hline $\begin{array}{l}2.1>5-10 \text { years of supplemen- } \\
\text { tation }\end{array}$ & 1 & 1420 & Mean Difference (Random, 95\% Cl) & $0.05[-0.03,0.13]$ \\
\hline 3 Executive function & 1 & & Mean Difference (Random, 95\% Cl) & Subtotals only \\
\hline $\begin{array}{l}3.1>5-10 \text { years of supplemen- } \\
\text { tation }\end{array}$ & 1 & 1420 & Mean Difference (Random, 95\% Cl) & $0.0[-0.08,0.08]$ \\
\hline 4 Speed of processing & 1 & & Mean Difference (Random, 95\% Cl) & Subtotals only \\
\hline $\begin{array}{l}4.1>5-10 \text { years of supplemen- } \\
\text { tation }\end{array}$ & 1 & 1420 & Mean Difference (Random, 95\% Cl) & $0.03[-0.05,0.11]$ \\
\hline 5 Incident $\mathrm{MCl}$ & 1 & & Risk Ratio (M-H, Random, 95\% Cl) & Subtotals only \\
\hline $\begin{array}{l}5.1>5-10 \text { years of supplemen- } \\
\text { tation }\end{array}$ & 1 & 4143 & Risk Ratio (M-H, Random, 95\% Cl) & $0.94[0.72,1.23]$ \\
\hline 6 Incident all-cause dementia & 1 & & Risk Ratio (M-H, Random, 95\% Cl) & Subtotals only \\
\hline $\begin{array}{l}6.1>5-10 \text { years supplementa- } \\
\text { tion }\end{array}$ & 1 & 4143 & Risk Ratio (M-H, Random, 95\% Cl) & $1.09[0.70,1.71]$ \\
\hline
\end{tabular}

Analysis 3.1. Comparison 3 Vitamin D3 versus placebo, Outcome 1 Overall cognitive functioning.

\begin{tabular}{|c|c|c|c|c|c|c|}
\hline Study or subgroup & $\begin{array}{c}\text { Experi- } \\
\text { mental } \\
\mathrm{N}\end{array}$ & Control & $\begin{array}{l}\text { Mean Dif- } \\
\text { ference } \\
\text { (SE) }\end{array}$ & $\begin{array}{c}\text { Mean Difference } \\
\text { IV, Random, 95\% CI }\end{array}$ & Weight & $\begin{array}{c}\text { Mean Difference } \\
\text { IV, Random, 95\% CI }\end{array}$ \\
\hline \multicolumn{7}{|c|}{ 3.1.1 3-12 months of supplementation } \\
\hline Rossom 2012 & 2028 & 2094 & $0(0.122)$ & & $100 \%$ & $0[-0.24,0.24]$ \\
\hline Subtotal $(95 \% \mathrm{CI})$ & & & & & $100 \%$ & $0[-0.24,0.24]$ \\
\hline \multicolumn{7}{|c|}{ Heterogeneity: Not applicable } \\
\hline \multicolumn{7}{|c|}{ 3.1.2 $>1-2$ years of supplementation } \\
\hline Rossom 2012 & 1918 & 1992 & $0(0.128)$ & & $100 \%$ & $0[-0.25,0.25]$ \\
\hline Subtotal $(95 \% \mathrm{Cl})$ & & & & & $100 \%$ & $0[-0.25,0.25]$ \\
\hline \multicolumn{7}{|c|}{ Heterogeneity: Not applicable } \\
\hline \multicolumn{7}{|c|}{ Test for overall effect: Not applicable } \\
\hline \multicolumn{7}{|c|}{ 3.1.3 $>2-5$ years of supplementation } \\
\hline Rossom 2012 & 1718 & 1797 & $-0.2(0.167)$ & & $100 \%$ & $-0.2[-0.53,0.13]$ \\
\hline
\end{tabular}




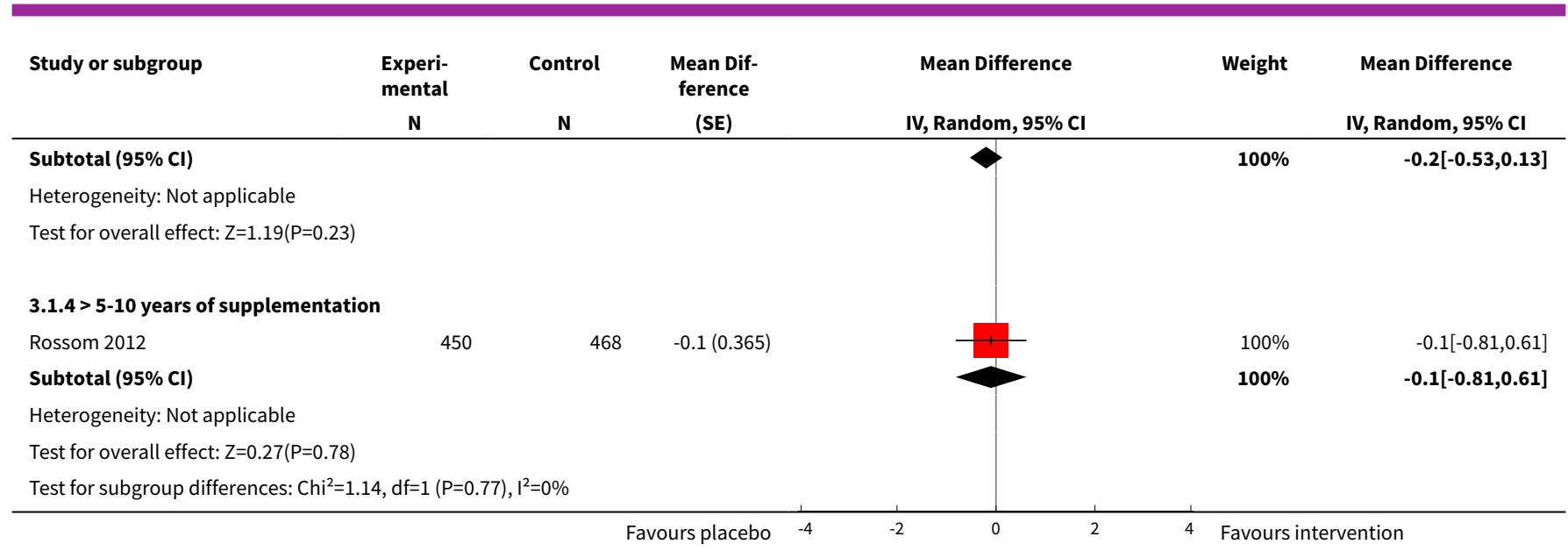

Analysis 3.2. Comparison 3 Vitamin D3 versus placebo, Outcome 2 Episodic memory.

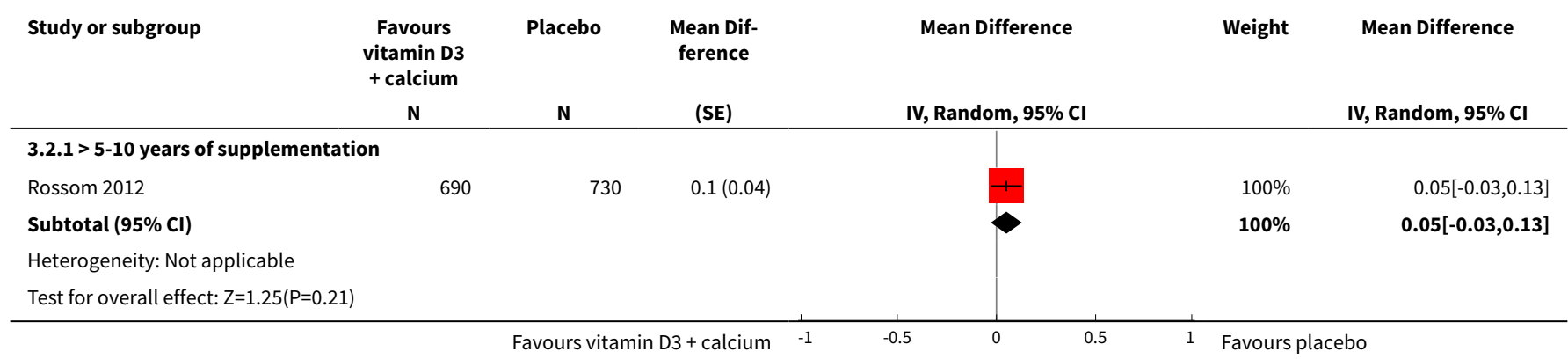

Analysis 3.3. Comparison 3 Vitamin $D 3$ versus placebo, Outcome 3 Executive function.

\begin{tabular}{|c|c|c|c|c|c|c|}
\hline Study or subgroup & $\begin{array}{c}\text { Experi- } \\
\text { mental } \\
\mathrm{N}\end{array}$ & Control & $\begin{array}{l}\text { Mean Dif- } \\
\text { ference } \\
\text { (SE) }\end{array}$ & $\begin{array}{l}\text { Mean Difference } \\
\text { IV, Random, 95\% CI }\end{array}$ & Weight & $\begin{array}{c}\text { Mean Difference } \\
\text { IV, Random, 95\% CI }\end{array}$ \\
\hline \multicolumn{7}{|c|}{ 3.3.1 $>5-10$ years of supplementation } \\
\hline Rossom 2012 & 690 & 730 & $0(0.04)$ & & $100 \%$ & $0[-0.08,0.08]$ \\
\hline Subtotal $(95 \% \mathrm{Cl})$ & & & & & $100 \%$ & $0[-0.08,0.08]$ \\
\hline \multicolumn{7}{|c|}{ Heterogeneity: Not applicable } \\
\hline Test for overall effect & & & & & & \\
\hline
\end{tabular}

Analysis 3.4. Comparison 3 Vitamin D3 versus placebo, Outcome 4 Speed of processing.

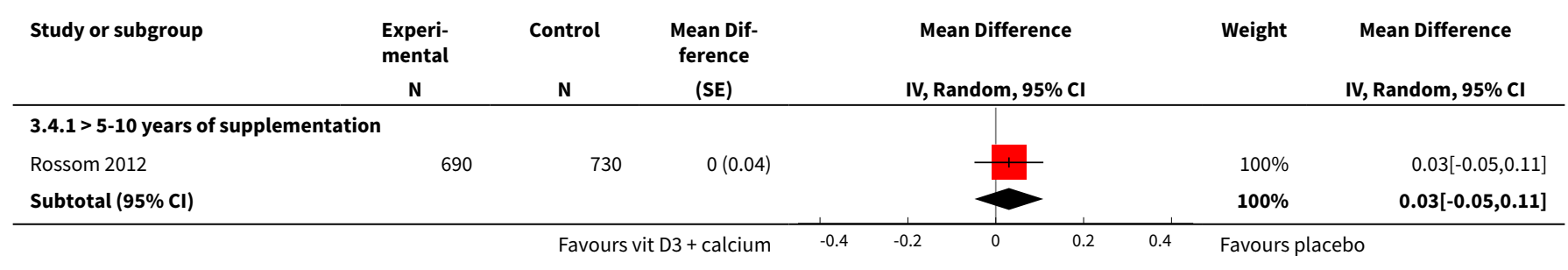




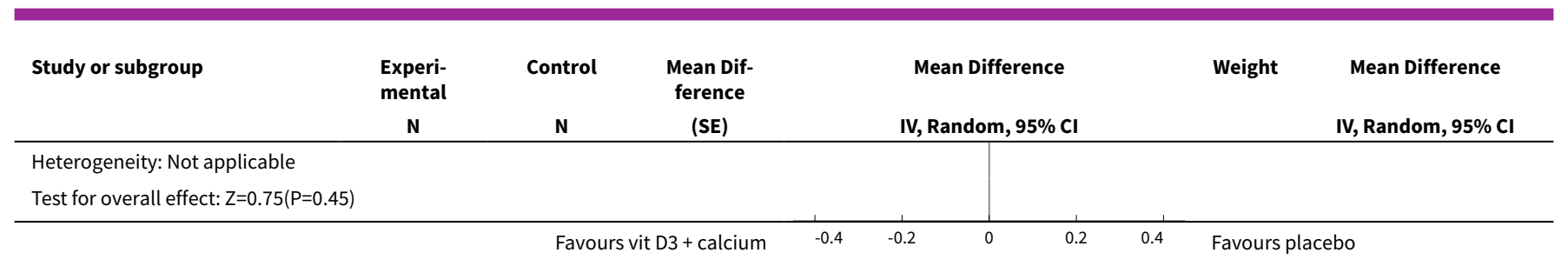

Analysis 3.5. Comparison 3 Vitamin D3 versus placebo, Outcome 5 Incident $\mathrm{MCl}$.

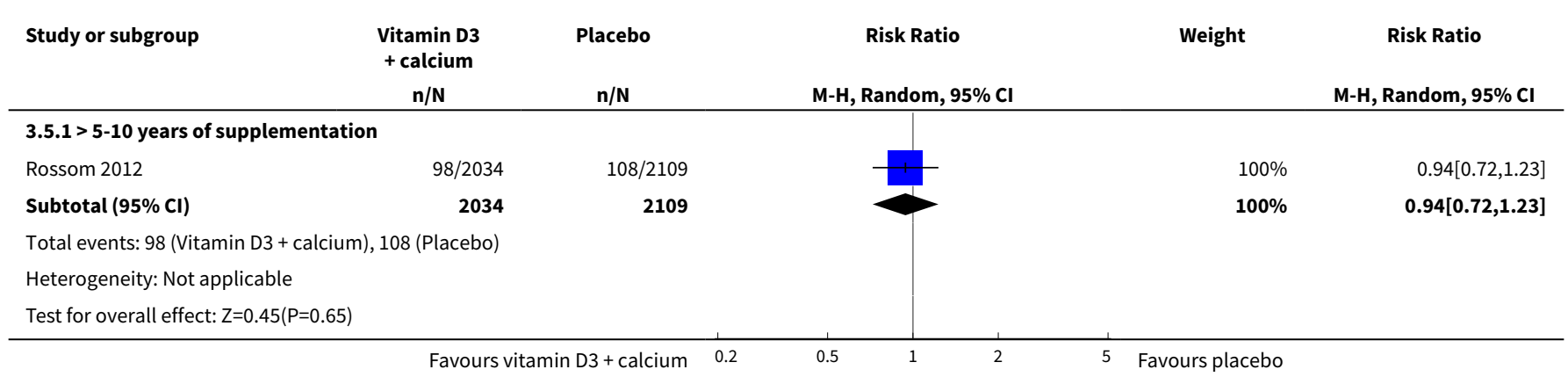

Analysis 3.6. Comparison 3 Vitamin D3 versus placebo, Outcome 6 Incident all-cause dementia.

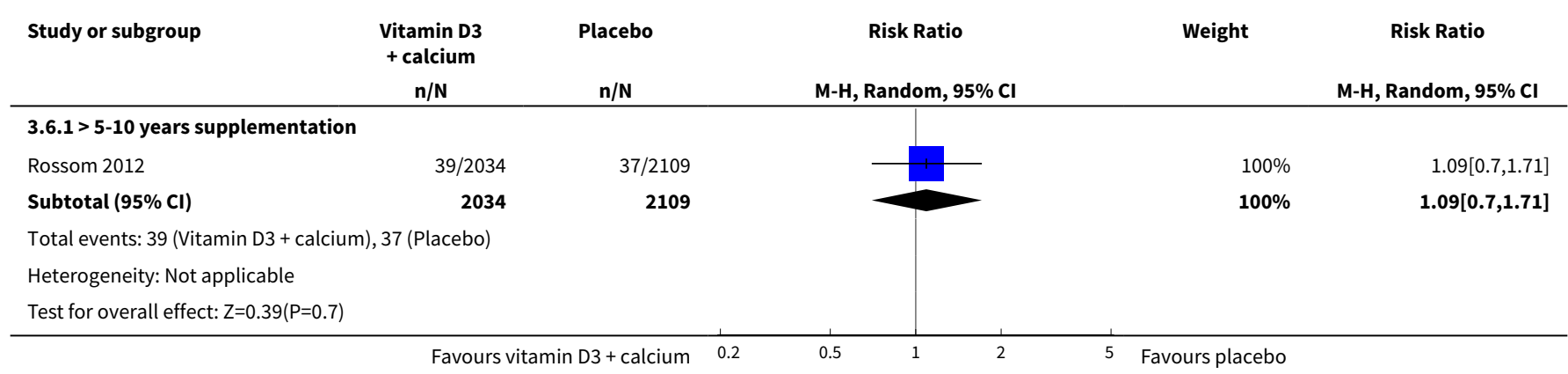

\section{Comparison 4. Zinc + copper versus placebo}

\begin{tabular}{|c|c|c|c|c|}
\hline Outcome or subgroup title & No. of studies & $\begin{array}{l}\text { No. of partici- } \\
\text { pants }\end{array}$ & Statistical method & Effect size \\
\hline 1 Overall cognitive functioning & 1 & & $\begin{array}{l}\text { Mean Difference (Random, 95\% } \\
\mathrm{Cl} \text { ) }\end{array}$ & Subtotals only \\
\hline $\begin{array}{l}1.1>5-10 \text { years of supplementa- } \\
\text { tion }\end{array}$ & 1 & 1072 & $\begin{array}{l}\text { Mean Difference (Random, 95\% } \\
\mathrm{Cl} \text { ) }\end{array}$ & $0.6[-0.19,1.39]$ \\
\hline 2 Episodic memory & 1 & & $\begin{array}{l}\text { Mean Difference (Random, 95\% } \\
\mathrm{Cl} \text { ) }\end{array}$ & Subtotals only \\
\hline $\begin{array}{l}2.1>5-10 \text { years of supplementa- } \\
\text { tion }\end{array}$ & 1 & 1072 & $\begin{array}{l}\text { Mean Difference (Random, 95\% } \\
\mathrm{Cl} \text { ) }\end{array}$ & $-0.7[-1.74,0.34]$ \\
\hline
\end{tabular}




\begin{tabular}{lllll}
\hline Outcome or subgroup title & No. of studies & $\begin{array}{l}\text { No. of partici- } \\
\text { pants }\end{array}$ & Statistical method & Effect size \\
\hline 3 Executive function & 1 & & $\begin{array}{l}\text { Mean Difference (Random, 95\% } \\
\mathrm{Cl})\end{array}$ & Subtotals only \\
\hline $\begin{array}{l}\text { 3.1>5-10 years of supplementa- } \\
\text { tion }\end{array}$ & 1 & 1072 & $\begin{array}{l}\text { Mean Difference (Random, 95\% } \\
\mathrm{Cl})\end{array}$ & $-0.3[-0.89,0.29]$ \\
\hline
\end{tabular}

Analysis 4.1. Comparison 4 Zinc + copper versus placebo, Outcome 1 Overall cognitive functioning.

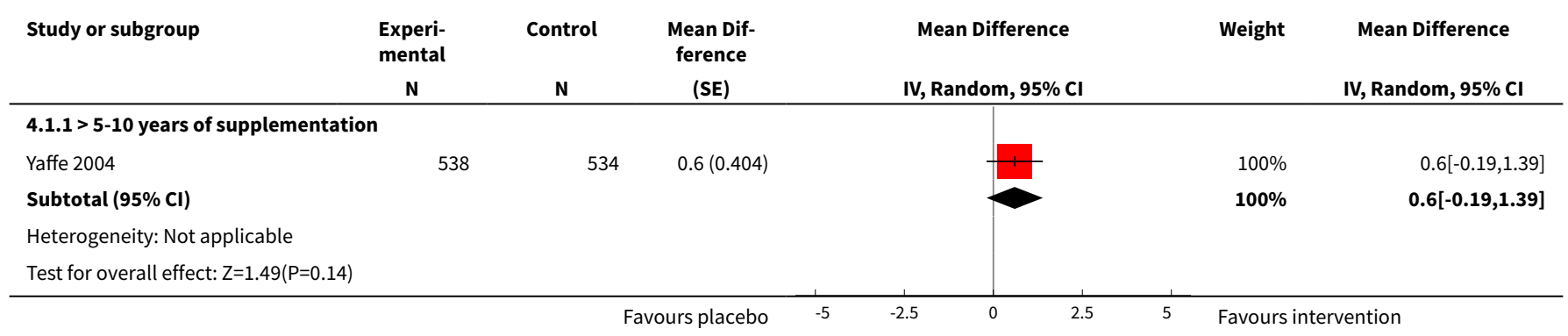

Analysis 4.2. Comparison 4 Zinc + copper versus placebo, Outcome 2 Episodic memory.

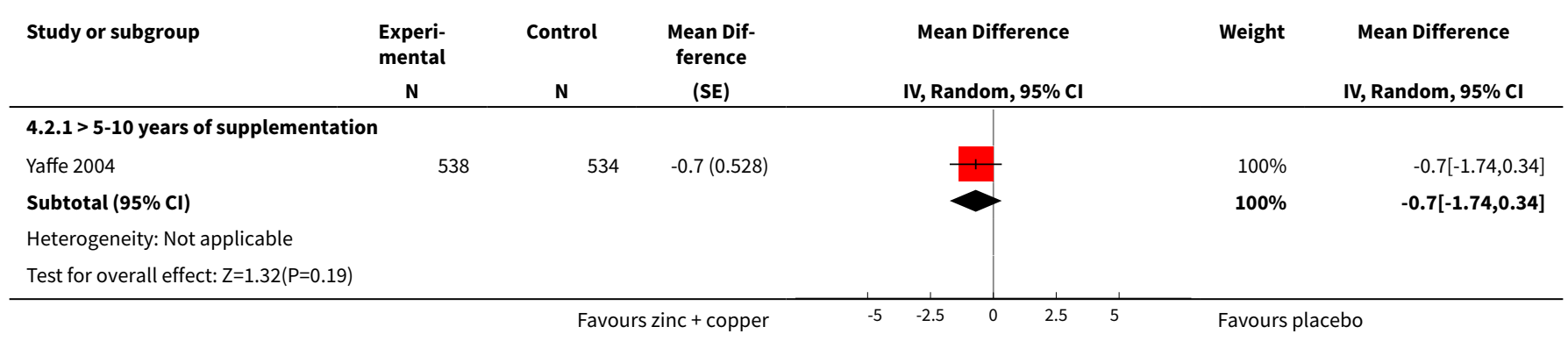

Analysis 4.3. Comparison 4 Zinc + copper versus placebo, Outcome 3 Executive function.

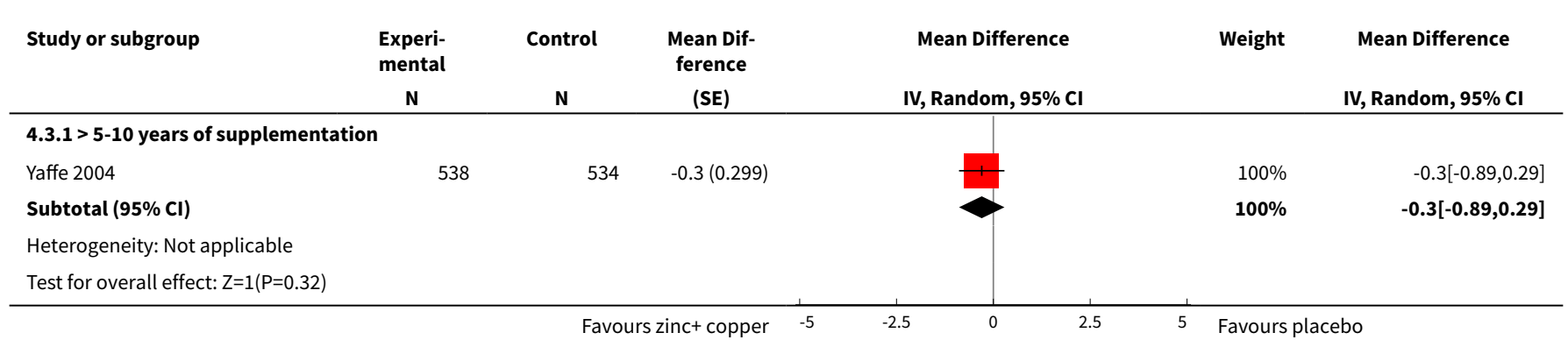


Comparison 5. Complex multivitamin versus control

\begin{tabular}{|c|c|c|c|c|}
\hline Outcome or subgroup title & No. of studies & $\begin{array}{l}\text { No. of partici- } \\
\text { pants }\end{array}$ & Statistical method & Effect size \\
\hline 1 Overall cognitive functioning & 1 & & Mean Difference (Random, 95\% Cl) & Subtotals only \\
\hline $\begin{array}{l}1.1>2-5 \text { years of supplemen- } \\
\text { tation }\end{array}$ & 1 & 5947 & Mean Difference (Random, 95\% Cl) & $0.04[-0.09,0.17]$ \\
\hline $\begin{array}{l}1.2>5-10 \text { years of supplemen- } \\
\text { tation }\end{array}$ & 1 & 2324 & Mean Difference (Random, 95\% Cl) & $0.12[-0.14,0.38]$ \\
\hline 2 Episodic memory & 2 & & Mean Difference (Random, 95\% Cl) & Subtotals only \\
\hline $\begin{array}{l}2.13-12 \text { months of supplemen- } \\
\text { tation }\end{array}$ & 1 & 124 & Mean Difference (Random, 95\% Cl) & $33.17[-28.12,94.46]$ \\
\hline $\begin{array}{l}2.2>2-5 \text { years of supplemen- } \\
\text { tation }\end{array}$ & 1 & 5942 & Mean Difference (Random, 95\% Cl) & $-0.01[-0.05,0.03]$ \\
\hline $\begin{array}{l}2.3>5-10 \text { years of supplemen- } \\
\text { tation }\end{array}$ & 1 & 2324 & Mean Difference (Random, 95\% Cl) & $-0.01[-0.07,0.05]$ \\
\hline 3 Executive function & 1 & & Mean Difference (Random, 95\% Cl) & Subtotals only \\
\hline $\begin{array}{l}3.1>2-5 \text { years of supplemen- } \\
\text { tation }\end{array}$ & 1 & 5942 & Mean Difference (Random, 95\% Cl) & $-0.02[-0.33,0.29]$ \\
\hline $\begin{array}{l}3.2>5-10 \text { years of supplemen- } \\
\text { tation }\end{array}$ & 1 & 2324 & Mean Difference (Random, 95\% Cl) & $-0.22[-0.65,0.21]$ \\
\hline 4 Speed of processing & 1 & & Mean Difference (Random, 95\% Cl) & Subtotals only \\
\hline $\begin{array}{l}4.13-12 \text { months of supplemen- } \\
\text { tation }\end{array}$ & 1 & 127 & Mean Difference (Random, 95\% Cl) & $\begin{array}{l}-14.71[-57.22 \\
27.80]\end{array}$ \\
\hline
\end{tabular}

Analysis 5.1. Comparison 5 Complex multivitamin versus control, Outcome 1 Overall cognitive functioning.

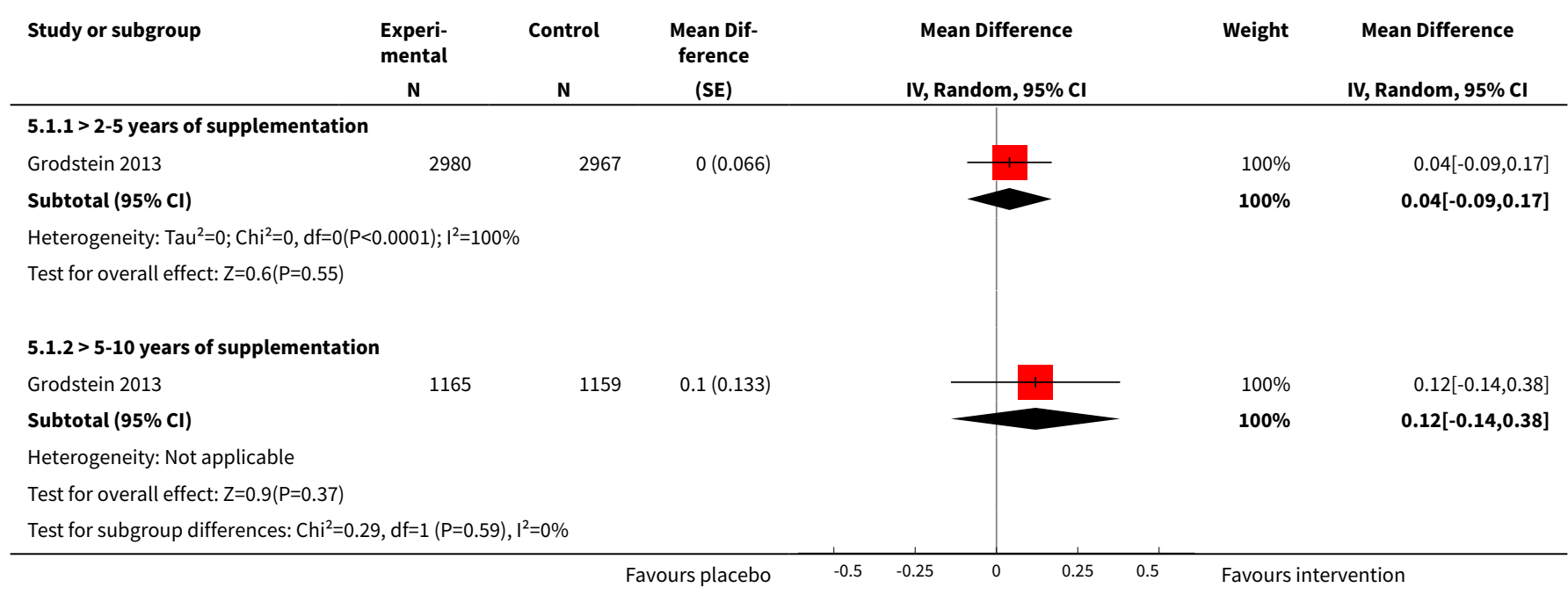


Analysis 5.2. Comparison 5 Complex multivitamin versus control, Outcome 2 Episodic memory.

\begin{tabular}{|c|c|c|c|c|c|c|}
\hline \multirow[t]{2}{*}{ Study or subgroup } & $\begin{array}{l}\text { Favours } \\
\text { multivi- } \\
\text { tamins }\end{array}$ & Control & $\begin{array}{l}\text { Mean Dif- } \\
\text { ference }\end{array}$ & Mean Difference & \multirow[t]{2}{*}{ Weight } & \multirow{2}{*}{$\begin{array}{c}\text { Mean Difference } \\
\text { IV, Random, } 95 \% \mathrm{CI}\end{array}$} \\
\hline & $\mathbf{N}$ & $\mathbf{N}$ & (SE) & IV, Random, $95 \% \mathrm{CI}$ & & \\
\hline \multicolumn{7}{|c|}{ 5.2.1 3-12 months of supplementation } \\
\hline Cockle 2000 & 65 & 59 & $33.2(31.27)$ & & $100 \%$ & $33.17[-28.12,94.46]$ \\
\hline \multicolumn{5}{|l|}{ Subtotal $(95 \% \mathrm{Cl})$} & $100 \%$ & $33.17[-28.12,94.46]$ \\
\hline \multicolumn{7}{|c|}{ Heterogeneity: Not applicable } \\
\hline \multicolumn{7}{|c|}{ Test for overall effect: $Z=1.06(P=0.29)$} \\
\hline \multicolumn{7}{|c|}{ 5.2.2 $>2-5$ years of supplementation } \\
\hline Grodstein 2013 & 2978 & 2964 & $-0(0.02)$ & & $100 \%$ & $-0.01[-0.05,0.03]$ \\
\hline Subtotal (95\% Cl) & & & & & $100 \%$ & $-0.01[-0.05,0.03]$ \\
\hline \multicolumn{7}{|c|}{ Heterogeneity: Not applicable } \\
\hline \multicolumn{7}{|c|}{ Test for overall effect: $Z=0.49(P=0.62)$} \\
\hline \multicolumn{7}{|c|}{$5.2 .3>5-10$ years of supplementation } \\
\hline Grodstein 2013 & 1165 & 1159 & $-0(0.031)$ & & $100 \%$ & $-0.01[-0.07,0.05]$ \\
\hline Subtotal $(95 \% \mathrm{Cl})$ & & & & & $100 \%$ & $-0.01[-0.07,0.05]$ \\
\hline \multicolumn{7}{|c|}{ Heterogeneity: Not applicable } \\
\hline \multicolumn{7}{|c|}{ Test for overall effect: $\mathrm{Z}=0.33(\mathrm{P}=0.74)$} \\
\hline \multicolumn{7}{|c|}{ Test for subgroup differences: $\mathrm{Chi}^{2}=1.13, \mathrm{df}=1(\mathrm{P}=0.57), \mathrm{I}^{2}=0 \%$} \\
\hline & & Favour & dtivitamins & $\begin{array}{ll}0.1 & 0.2\end{array}$ & Favours & rol \\
\hline
\end{tabular}

\section{Analysis 5.3. Comparison 5 Complex multivitamin versus control, Outcome 3 Executive function.}

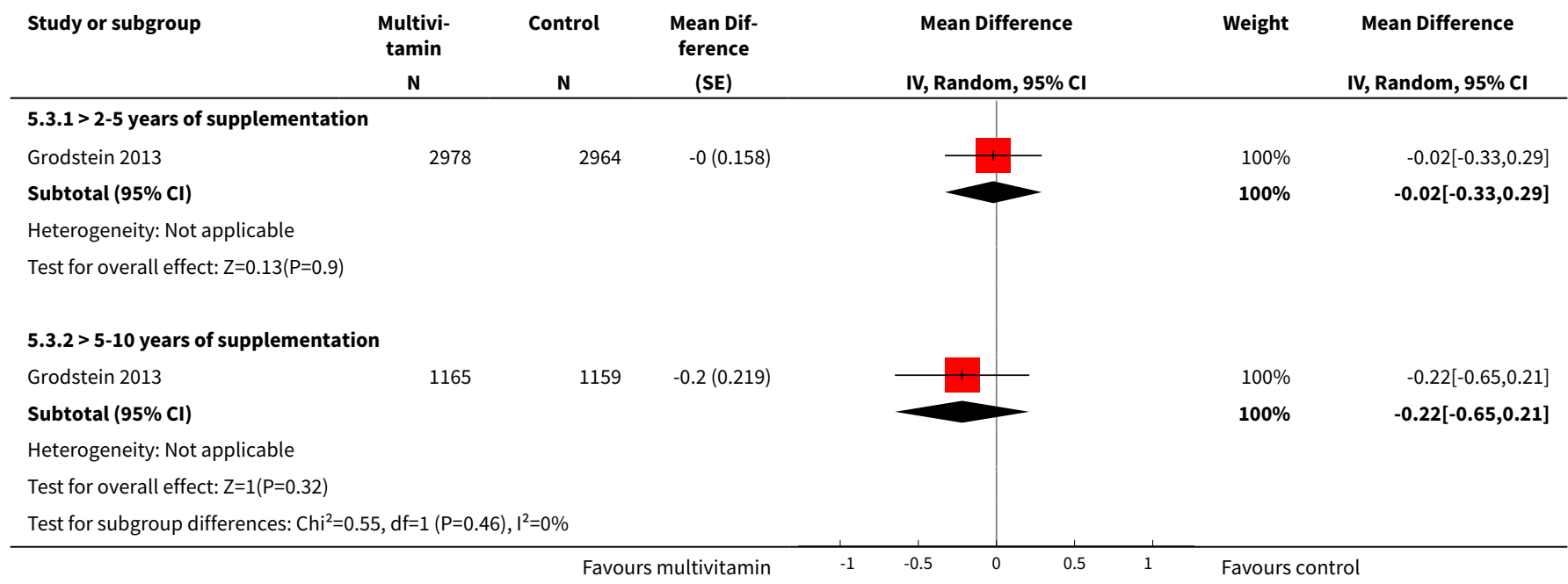


Analysis 5.4. Comparison 5 Complex multivitamin versus control, Outcome 4 Speed of processing.

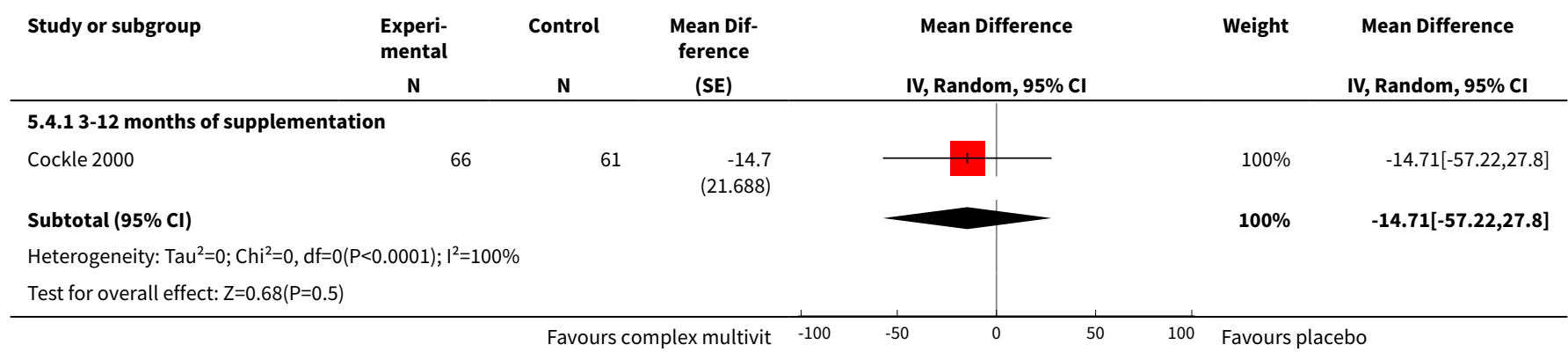

\section{APPENDICES}

\section{Appendix 1. Biological plausibility of vitamins and minerals}

\begin{tabular}{lll}
\hline Supplement* & Route & Biological plausibility \\
\hline Vitamins & & \\
\hline Vitamin A & antioxidant; & $\begin{array}{l}\text { Carboxylic form of Vitamin A known as all-trans retinoic acid has been shown } \\
\text { to have memory restorative function and it may be attributed to its an- } \\
\text { ti-cholinesterase, anti-oxidative and anti-inflammatory potential (Sodhi 2013). } \\
\text { Vitamin A and ß-carotene may also inhibit the formation, extension and desta- } \\
\text { bilising effects of beta-amyloid fibrins. Plasma or cerebrospinal fluid concen- } \\
\text { anti-cholinesterase; } \\
\text { beta-amyloid inhibition of vitamin A and beta-carotene have been reported to be lower in AD } \\
\text { patients, and increased Vit A/beta carotene concentrations have been clinical- } \\
\text { ly shown to slow the progression of dementia (Ono 2012). }\end{array}$ \\
\hline
\end{tabular}

Vitamin D neuronal activity

Vitamin D receptor (VDR) and 1, alpha-hydroxylase, the terminal calcitriol-activating enzyme, are distributed throughout both the foetal and adult brain. This is thought to play a role in brain development and critical brain functions (McCann 2008). Significant correlation between serum 25(OH)D levels and cognitive scores were reported in DeLuca 1975 and Przybelski 2007.

\begin{tabular}{ll} 
Vitamin E & $\begin{array}{l}\text { Vitamin E consists of a group of tocopherols and tocotrienols. Apart from lipid } \\
\text { beta-amyloid inhibition } \\
\text { antioxidant activity, other functions include membrane stabilisation by form- } \\
\text { ing complexes with the products of lipid hydrolysis (Wang 2000). It has been } \\
\text { shown that the antioxidant and free radical scavenging activity of Vitamin E in- } \\
\text { hibits amyloid beta protein induced neuronal cell death and may have impli- } \\
\text { cation in prevention and treatment of Alzheimer's dementia (Behl 1992). }\end{array}$ \\
\hline
\end{tabular}

Vitamin $\mathrm{K} \quad$ neuronal activity

Vitamin $\mathrm{K}$ participates in the synthesis of sphingolipids. Sphingolipids participate in important cellular events such as proliferation, differentiation, senescence, and cell-cell interactions. Sphingolipid metabolism has been linked to age-related cognitive decline and neurodegenerative diseases such as Alzheimer's disease (Ferland 2012). A cross-sectional study found correlations between higher serum phylloquinone concentration and better cognitive scores in tests evaluating episodic verbal memory among healthy older adults (Ferland 2013).

\begin{tabular}{|c|c|c|}
\hline Thiamine & neuronal activity & $\begin{array}{l}\text { Thiamine is required as a cofactor in the cellular production of energy and } \\
\text { enhances normal neuronal activities (Osiezagha 2013). Rats with an episode }\end{array}$ \\
\hline
\end{tabular}



ments (Langlais 1995).

\begin{tabular}{|c|c|c|}
\hline $\begin{array}{l}\text { Riboflavin } \\
\text { (Vitamin B2) }\end{array}$ & neuronal activity & $\begin{array}{l}\text { Riboflavin (7,8-dimethyl-10-ribityl-isoalloxazine) is water-soluble. Symptoms } \\
\text { of neurodegeneration and peripheral neuropathy in riboflavin deficiency have } \\
\text { been documented in animal studies, but not observed in humans. Subclini- } \\
\text { cal riboflavin deficiency may contribute to increased concentrations of plas- } \\
\text { ma homocysteine and may be associated with increased risk of cardiovascular } \\
\text { disease and impaired handling of iron (Powers 2003). }\end{array}$ \\
\hline
\end{tabular}

\begin{tabular}{|c|c|c|}
\hline $\begin{array}{l}\text { Niacin } \\
\text { (Vitamin B3) }\end{array}$ & $\begin{array}{l}\text { vascular: } \\
\text { anti-inflammatory }\end{array}$ & $\begin{array}{l}\text { Niacin is a water-soluble precursor cofactor essential for the formation of } \\
\text { dozens of enzymes. Niacin decreases atherosclerosis development mainly by } \\
\text { reducing LDL cholesterol. It also has modest HDL-cholesterol-raising and an- } \\
\text { ti-inflammatory effects (Kühnast 2013). }\end{array}$ \\
\hline
\end{tabular}

Niacin deficiency causes pellagra. Its neuropsychiatric symptoms are similar to those in Alzheimer's disease or vascular dementia (Amanullah 2010).

Vitamin B6
(Pyridoxine, pyridoxal,
pyridoxamine, Pyridox-
al 5' phosphate (PLP)
and pyridoxamine 5'
phosphate (PMP), Pyri-
doxine 5'-phosphate
(PNP))

homocysteine;

neuronal activity

Vitamin B6 is a group of water-soluble compounds (vitamers). Pyridoxal 5' phosphate (PLP) and pyridoxamine 5' phosphate (PMP) are the active coenzyme forms of vitamin B6 (ODS 2014).

Vitamin B6 has many important brain functions such as biosynthesis of neurotransmitters (GABA, dopamine, noradrenaline, serotonin), receptor binding, macronutrient metabolism, and gene expression. In a study looking at low plasma B6 levels predicting cognitive decline and depression in at-risk individuals, low PLP status was seen as a risk factor for cognitive decline and depression in at-risk populations (Scott 2013).

$\begin{array}{ll}\text { Folic Acid } & \text { antioxidant; } \\ \text { (Vitamin B9) } & \text { homocysteine; neu- } \\ & \text { ronal activity }\end{array}$

Folate is a cofactor and promotes the remethylation of homocysteine -- an amino acid that can induce DNA strand breakage, oxidative stress, and apoptosis. Folate is required for normal development of the nervous system, playing important roles regulating neurogenesis and programmed cell death. Folate deficiency and its resultant increase in homocysteine levels has been linked to several neurodegenerative conditions, including stroke, Alzheimer's disease, and Parkinson's disease (Mattson 2003).

\begin{tabular}{ll}
\hline Vitamin B12 & homocysteine; \\
& \\
(cobalamins: & neuronal activity \\
cyanocobalamin, & \\
hydroxocobalamin, & \\
methylcobalamin, hy- & \\
droxocobalamin) &
\end{tabular}

Vitamin B12 acts as a coenzyme in metabolism of amino acids and fatty acids required for the synthesis of nucleic acids, erythrocytes, and in the maintenance of myelin (Pawlak 2014). Lower vitamin B12 status has been associated with increased rates of cognitive decline and dementia (Clarke 2007b; O'Leary 2012).
Pantothenic acid (PA) is a component of coenzyme $A$, an essential cofactor in fatty acid oxidation, lipid elongation, and fatty acid synthesis (Kelly 2011). This may have an indirect effect in cognition.

(Vitamin B5)

energy; metabolism

\section{Biotin}

energy; metabolism

(Vitamin H)
Biotin is also known as Vitamin $\mathrm{H}$ and is part of the $\mathrm{B}$ complex group of vitamins. They act as cofactors in carboxylase enzymes, fatty acid, and amino acid metabolism. This may have an indirect effect in cognition.

Vitamin C antioxidant




\section{Minerals}

Calcium neuronal activity

Calcium ions regulate a number of physiological processes including neuronal gene expression and the neuronal secretion of neurotransmitters (Delage 2014; Dolphin 2012). Supplementation with calcium together with vitamin $D$ was found to have no significant association with incident cognitive impairment (Rossom 2012).

Ozawa 2012 concluded that, in the general Japanese population, higher selfreported dietary intakes of potassium, calcium, and magnesium reduced the risk of all-cause dementia, especially Vascular Dementia (VaD). The proposed mechanism was through the reduction of of vascular risk factors.

\section{Chromium}

energy production; metabolism.
Chromium is needed for energy production and has been found to promote the effect of insulin involved in metabolism and storage of protein, carbohydrates and lipids within the CNS (Anderson 1997; Institute of Medicine 2011; Ozawa 2012). Chromium is involved in metabolism of nucleic acid, which is needed to build DNA, the genetic material in cells; and promotes synthesis of cholesterol and fatty acids needed for brain function. It may lower LDL cholesterol and triglyceride levels, raise HDL cholesterol levels and reduce high blood pressure (Preuss 1997), hence may affect vascular risk factors.

Insulin resistance is implicated in the pathophysiological changes associated with Alzheimer's disease, and pharmaceutical treatments that overcome insulin resistance improve memory function in subjects with mild cognitive impairment $(\mathrm{MCl}$ ) and early Alzheimer's disease. Chromium $(\mathrm{Cr})$ supplementation improves glucose disposal in patients with insulin resistance and diabetes. A double-blind RCT suggested that supplementation with Chromium picolinate can enhance cognitive inhibitory control and cerebral function in older adults at risk for neurodegeneration (Krikorian 2010). An additional study reported a positive correlation between cognitive function and serum chromium levels (Smorgon 2004).

Copper antioxidant

Copper is a component of an antioxidant enzyme called superoxide dismutase that protects cells from damage by harmful free radicals. Copper is necessary for a healthy nerve system and taste sensitivity (Institute of Medicine 2011).

Copper may promote non-amyloidogenic processing of amyloid precursor protein (APP) and thereby lower the A $\beta$ production in cell culture systems, and it increases lifetime and decreases soluble amyloid production in APP transgenic mice (Borchardt 1999). In Alzheimer patients, a decline of $A \beta$ levels in CSF is reported in adults in the treatment group (Kaden 2011).

\section{lodine}

neuronal development and structure. lodine is needed for the synthesis of thyroid hormones which, in turn, are needed for the myelination of the central nervous system. lodine is necessary for the normal development of the brain. A deficiency of this mineral during critical periods of development in gestation can lead to intellectual disability and neurodevelopmental problems (Bath 2013a). Positive association was found between maternal iodine status and child IQ at age 8 years and reading ability at age 9 years (Bath 2013b).

Iron is needed for development of oligodendrocytes and numerous enzymes that synthesise neurotransmitters such as noradrenaline, serotonin, and dopamine. It is important for production of the haemoglobin in red blood cells (Delage 2014; Institute of Medicine 2011). Regression analysis showed that non-anaemic iron-deficient adolescent girls who received iron performed better on a test of verbal learning and memory than girls in the control group (Bruner 1996) 
(Continued)

Magnesium energy, metabolism
Magnesium is involved in hundreds of enzyme reactions, including protein synthesis. It plays a role in energy production; can improve insulin sensitivity in diabetics; helps regulate blood sugar level; and regulates neuro-muscular transmission.

Higher self-reported dietary intakes of potassium, calcium, and magnesium have been reported to reduce the risk of all-cause dementia, especially VaD, in the general Japanese population (Ozawa 2012).

Manganese is needed to synthesise fatty acids and cholesterol, and metabolise carbohydrates and proteins. It is important for energy production. It promotes utilisation of other key nutrients like vitamin B1 (thiamine), biotin, choline, ascorbic acid, and vitamin E (Delage 2014).

Manganese is needed for glucose metabolism, which helps regulate blood glucose. It is needed to make manganese superoxide dismutase (MnSOD), one of the key antioxidants that protects cells from free radical damage, and so helps maintains healthy nerves. It works synergistically with the B-complex vitamins to generate an overall feeling of well-being (Institute of Medicine 2011).

\begin{tabular}{|c|c|c|}
\hline Molybdenum & metabolism & $\begin{array}{l}\text { Molybdenum promotes normal cell function; and functions as a cofactor for } \\
\text { three essential enzymes that play a vital role in carbohydrate metabolism, util- } \\
\text { isation of iron, sulphite detoxification, and uric acid formation (Delage 2014; } \\
\text { Institute of Medicine 2011). }\end{array}$ \\
\hline
\end{tabular}

Phosphorus metabolism, neuronal Phosphorus is needed for metabolism of carbohydrates and fats to produce structure and function. energy and is involved in the production of ATP required for growth and repair of cells and tissues; it is needed to make cell membranes. It helps the body utilise the B-complex vitamins that support proper muscle and nerve function (Delage 2014; Institute of Medicine 2011).

Potassium nerve transmission.

\begin{abstract}
Potassium is involved in regulating nerve transmissions and muscle contractions. It helps the body handle sodium and so reduces the risk of high blood pressure (Berr 2012). It has been found to lower the risk of stroke and ischaemic heart disease. Potassium is needed for synthesis of protein from amino acids (Delage 2014; Institute of Medicine 2011).
\end{abstract}

Higher self-reported dietary intakes of potassium, calcium, and magnesium reduce the risk of all-cause dementia, especially $\mathrm{VaD}$, in the general Japanese population (Ozawa 2012).

Selenium is an important antioxidant especially in combination with vitamin $\mathrm{E}$, in the central nervous system and other body tissues (Delage 2014; Mehdi 2013; Rahman 2007).

Low selenium levels were found to be associated with poorer cognitive function (Berr 2012; Smorgon 2004). Supplementation with selenium has been associated with improved overall health, reducing oxidative stress and reducing the risk of dementia (Mehdi 2013).

Sodium is essential for regulating muscle contractions, nerve transmissions essential for normal CNS physiological mechanisms and homeostasis (Delage 2014; Institute of Medicine 2011).

$\begin{array}{ll}\text { Zinc } & \text { antioxidant } \\ & \text { neuronal activity }\end{array}$

Zinc is a constituent of the antioxidant enzyme superoxide dismutase that helps reduce the harm from free radicals. Zinc regulates cell division and synthesis of genetic cell DNA. It is essential for reproduction, repair, and normal growth within the CNS (Delage 2014). 
Zinc is found in high levels in the brain where it performs catalytic, structural and regulatory roles in cellular metabolism. Zinc is bound to proteins but free zinc is present in synaptic vesicles and performs a role in neurotransmission mediated by glutamate and gamma-aminobutyric acid (GABA). Short-term deficits of zinc have been shown to impair certain measures of mental and neurological function while long-term deficits of zinc, especially during gestation, result in malformation or deficits in attention, learning, memory and neuropsychological behaviour (Institute of Medicine 2011).

Zinc was found to be capable of reducing post-ischaemic injury to a variety of tissues and organs through a mechanism that might involve the antagonism of copper reactivity. Although the evidence for the antioxidant properties of zinc is compelling, the mechanisms are still unclear (Powell 2000).

\footnotetext{
or minerals are eligible as well.

\section{Footnotes}

$A \beta$ : Amyloid $\beta$ Protein

AD: Alzheimers' Disease

APP: amyloid precursor protein

ATP: Adenosine triphosphate

CNS: central nervous system

Cr: Chromium

CSF: CerebroSpinal Fluid

DNA: DeoxyriboNucleic Acid

GABA: Gamma-AminoButyric Acid

HDL: high-density lipoproteins

IQ: Intelligence quotient

LDL: Low-density lipoprotein

MCI: Mild Cognitive Impairment

MnSOD: manganese superoxide dismutase

PLP: Pyridoxal 5' phosphate

PMP: pyridoxamine 5' phosphate

PNP: Pyridoxine 5'-phosphate

VaD: Vascular Dementia

VDR: Vitamin D receptor

25(OH)D: serum hydroxyvitamin D
}

* Only orally-administered supplements taken at any dose for at least 12 weeks are considered. Supplements that combine vitamins

\section{Appendix 2. Sources searched and search strategies}

\begin{tabular}{lll}
\hline Source & Search strategy & Hits retrieved \\
\hline $\begin{array}{l}\text { ALOIS (www.medi- } \\
\text { cine.ox.ac.uk/alois) }\end{array}$ & Basic search: VIT & Dec 2014: 254 \\
$\begin{array}{lc}\text { (Date of most recent } \\
\text { search: 25 January }\end{array}$ & Jul 2015: 0 \\
[Studies within ALOIS are coded VIT if the intervention is a vitamin or mineral] & Mar 2016:2 \\
& Aug 2016:0 & Mar 2017: 3 \\
& Jan 2018: 1 \\
\hline
\end{tabular}


(Continued)

MEDLINE In-process and other non-indexed citations and MEDLINE 1950-present (Ovid SP)

(Date of most recent search: 25 January 2018)
1. exp *Vitamins/

Dec 2014: 1320

2. exp *Minerals/

3. exp *Dietary Supplements/_Jul 2015: 53

4. Calcium Carbonate/

5. vitamin ${ }^{\star} . t i, a b$.

6. cholecalciferol.ti,ab.

7. ergocalciferol.ti,ab.

8. toxiferol.ti,ab.

9. retinol.ti,ab.

10. "retinoic acid".ti,ab.

11. Vitamin A/

12. Vitamin B 12/

13. Vitamin D/

14. Vitamin E/

15. "beta-carotene".ti,ab.

16. "alpha-carotene".ti,ab.

17. "gamma-carotene".ti,ab.

18. "beta-cryptoanthin".ti,ab.

19. thiamine.ti,ab.

20. riboflavin.ti,ab.

21. niacin.ti,ab.

22. nicotinamide.ti,ab.

23. pantothenic.ti,ab.

24. pyridoxine.ti,ab.

25. pyridoxal.ti,ab.

26. pyridoxamine.ti,ab.

27. biotin.ti,ab.

28. "folic acid".ti,ab.

29. Folic Acid/

30. cyanocobalamin.ti,ab.

31. methylcobalamin.ti,ab.

32. "l-ascorbic acid".ti,ab.

33. "ascorbic acid".ti,ab.

34. ascorbate.ti,ab.

35. Ascorbic Acid/

36. phylloquinone.ti,ab.

37. phytomeadione.ti,ab.

38. phytonadine.ti,ab.

39. mineral ${ }^{\star} . t i, a b$.

40. multivitamin*.ti,ab.

41. "diet* supplement ${ }^{\star}$. .ti,ab.

42. calcium.ti,ab.

43. Calcium/

44. iron.ti,ab.

45. zinc.ti,ab.

46. sodium.ti,ab.

47. potassium.ti,ab.

48. phosphorus.ti,ab.

49. magnesium.ti,ab.

50. chloride.ti,ab.

51. sulphur.ti,ab.

52. mangansese.ti,ab.

53. cobalt.ti,ab.

54. selenium.ti,ab.

55. copper.ti,ab.

56. iodine.ti,ab.

57. fluoride.ti,ab.

58. or/1-57

59. *Aging/

60. Aged/ 
(Continued)

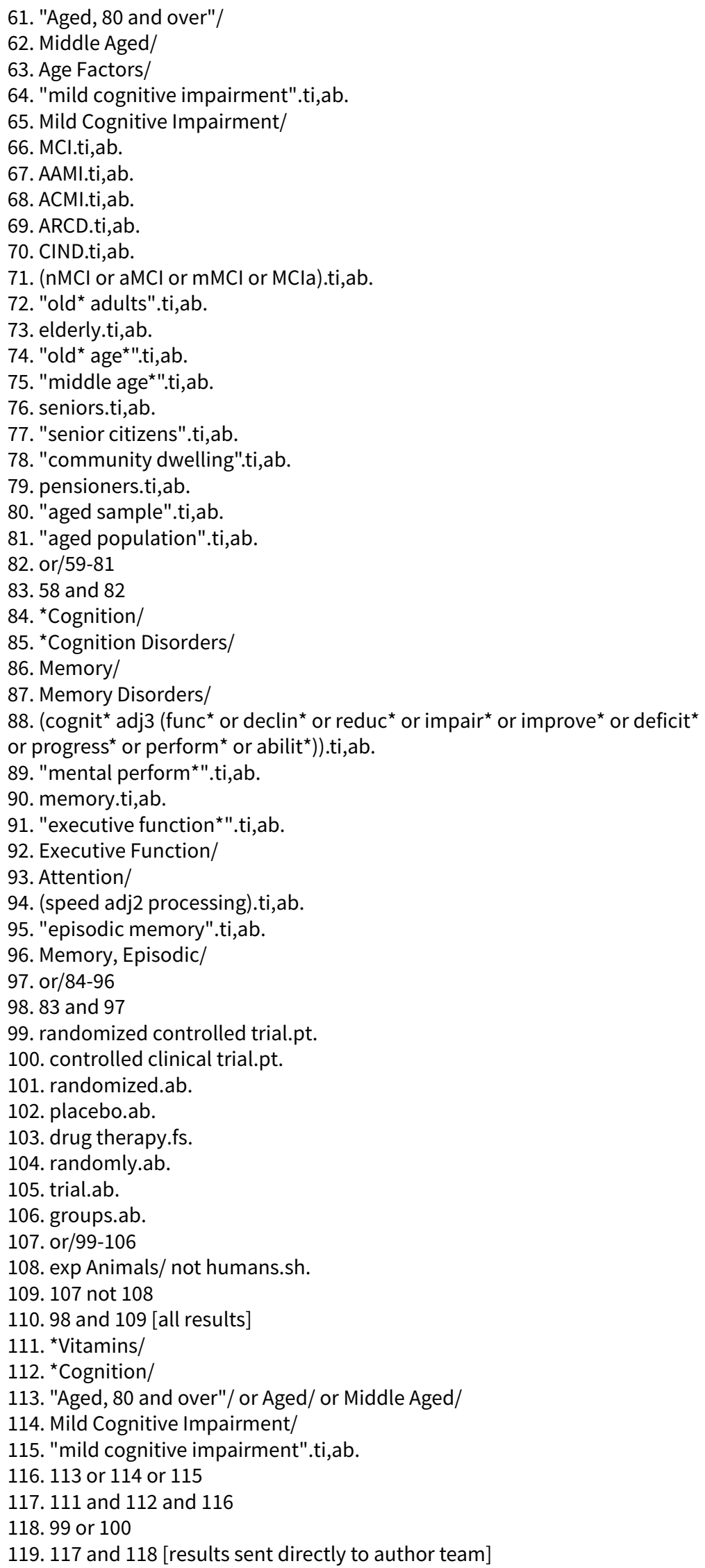


120. 110 not 119 [results minus those sent directly to author team. These results will be screened by the 'crowd']

\begin{tabular}{|c|c|c|}
\hline \multirow{32}{*}{$\begin{array}{l}\text { Embase } \\
\text { 1974-24 January } 2018 \\
\text { (Ovid SP) } \\
\text { (Date of most recent } \\
\text { search: } 25 \text { January } \\
2018 \text { ) }\end{array}$} & 1. exp *vitamin/ & Dec 2014: 1275 \\
\hline & 2. exp *mineral/ & Jul 2015: 114 \\
\hline & 3. exp diet supplementation/ & Mar 2016: 184 \\
\hline & 4. calcium/ & Aug 2016: 94 \\
\hline & 5. vitamin*.ti,ab. & Mar 2017: 257 \\
\hline & 6. mineral*.ti,ab. & Jan 2018: 250 \\
\hline & 7. cholecalciferol.ti,ab. & \\
\hline & 8. ergocalciferol.ti,ab. & \\
\hline & 9. toxiferol.ti,ab. & \\
\hline & 10. retinol.ti,ab. & \\
\hline & 11. retinal.ti,ab. & \\
\hline & 12. "retinoic acid".ti,ab. & \\
\hline & 13. vitamin $\mathrm{D} /$ & \\
\hline & 14. vitamin B complex/ or vitamin B group/ & \\
\hline & 15. vitamin $\mathrm{D} /$ & \\
\hline & 16. vitamin K epoxide reductase/ or vitamin K group/ & \\
\hline & 17. colecalciferol/ or calcitriol/ or calcitriol derivative/ & \\
\hline & 18. ascorbic acid/ & \\
\hline & 19. vitamin supplementation/ & \\
\hline & 20. "beta-carotene".ti,ab. & \\
\hline & 21. beta carotene/ & \\
\hline & 22. "alpha-carotene".ti,ab. & \\
\hline & 23. alpha carotene/ & \\
\hline & 24. "gamma-carotene".ti,ab. & \\
\hline & 25. gamma carotene/ & \\
\hline & 26. "beta-cryptoanthin".ti,ab. & \\
\hline & 27. thiamine.ti,ab. & \\
\hline & 28. thiamine/ & \\
\hline & 29. riboflavin.ti,ab. & \\
\hline & 30. riboflavin/ & \\
\hline & 31. niacin.ti,ab. & \\
\hline & 32. nicotinic acid/ & \\
\hline
\end{tabular}


33. nicotinamide.ti,ab.

34. pantothenic.ti,ab.

35. pyridoxamine.ti,ab.

36. pantothenic acid/

37. pyridoxamine/

38. biotin.ti,ab.

39. biotin/

40. "folic acid".ti,ab.

41. folic acid/

42. cyanocobalamin.ti,ab.

43. cyanocobalamin/

44. methylcobalamin.ti,ab.

45. "l-ascorbic acid".ti,ab.

46. "ascorbic acid".ti,ab.

47. phylloquinone.ti,ab.

48. phytonadine.ti,ab.

49. phytomeadione.ti,ab.

50. multivitamin*.ti,ab.

51. "vitamin* supple*".ti,ab.

52. "diet* supplement ${ }^{\star} " . t i, a b$.

53. calcium.ti,ab.

54. iron.ti,ab.

55. iron/

56. zinc.ti,ab.

57. zinc/

58. sodium.ti,ab.

59. sodium/

60. potassium.ti,ab.

61. citrate potassium/ or potassium/ or clavulanate potassium/ or diclofenac potassium/

62. phosphorus.ti,ab.

63. phosphorus/

64. magnesium.ti,ab.

65. magnesium/

66. chloride.ti,ab. 


\section{7. chloride/}

68. sulphur.ti,ab.

69. mangansese.ti,ab.

70. cobalt.ti,ab.

71. cobalt/

72. selenium.ti,ab.

73. selenium/

74. copper.ti,ab.

75. copper/

76. iodine.ti,ab.

77. fluoride.ti,ab.

78. fluoride/

79. or/1-78

80. aging/

81. aged/

82. middle aged/

83. mild cognitive impairment/

84. "mild cognitive impairment".ti,ab.

85. MCl.ti,ab.

86. AAMI.ti,ab.

87. ACMI.ti,ab.

88. ARCD.ti,ab.

89. CIND.ti,ab.

90. ( $\mathrm{nMCl}$ or $\mathrm{aMCl}$ or $\mathrm{mMCl}$ or $\mathrm{MCla}) . t i, a b$.

91. "middle age*".ti,ab.

92. "old* age*".ti,ab.

93. "old adults".ti,ab.

94. "community dwelling".ti,ab.

95. "senior citizens".ti,ab.

96. seniors.ti,ab.

97. pensioners.ti,ab.

98. "aged sample".ti,ab.

99. "aged population".ti,ab.

100. or/80-99 
101. exp cognition/

102. cognition disorders/

103. episodic memory/ or memory/

104. memory disorder/

105. dementia/

106. Alzheimer disease/

107. dement ${ }^{\star} . t i, a b$.

108. alzheimer ${ }^{\star} . t i, a b$.

109. cognition.ti,ab.

110. cognitive.ti,ab.

111. or/101-110

112. 79 and 100 and 111

113. randomized controlled trial/

114. controlled clinical trial/

115. placebo.ab.

116. (random* adj2 divide*).ti,ab.

117. (random* adj2 allocate*).ti,ab.

118. trial.ab.

119. "double-blind*".ti,ab.

120. "single blind*".ti,ab.

121. or/113-120

122. 112 and 121

123. *Cognition/

124. exp *vitamin/ or exp *vitamin supplementation/

125. exp *mineral/ or exp *mineral supplementation/

126. (vitamin* or mineral*).ti.

127. 124 or 125 or 126

128. exp *aging/

129. (elderly or "middle age*" or "old" adults" or $\mathrm{MCl}$ or "mild cognitive impairment").ti.

130. exp *middle aged/

131. 128 or 129 or 130

132. 123 and 127 and 131

133. 113 or 114

134. 132 and 133

Vitamin and mineral supplementation for maintaining cognitive function in cognitively healthy people in mid and late life (Review) 


\section{PsycINFO}

1806-January week 2 2018 (Ovid SP)

(Date of most recent search: 25 January 2018)

\section{1. exp Aging/}

Dec 2014: 202

2. exp Cognitive Impairment/

Jul 2015: 15

3. "cognit* impair*".ti,ab.

Mar 2016: 10

4. MCl.ti,ab.

Aug 2016: 0

5. AAMI.ti,ab.

Mar 2017: 14

6. ACMI.ti,ab.

Jan 2018: 9

7. ARCD.ti,ab.

8. CIND.ti,ab.

9. $(\mathrm{nMCl}$ or $\mathrm{aMCl}$ or $\mathrm{mMCl}$ or $\mathrm{MCla}) . \mathrm{ti}, \mathrm{ab}$.

10. "old* age*".ti,ab.

11. elderly.ti,ab.

12. "middle age*".ti,ab.

13. "old* adults".ti,ab.

14. seniors.ti,ab.

15. "senior citizens".ti,ab.

16. "community dwelling".ti,ab.

17. pensioners.ti,ab.

18. or/1-17

19. exp Cognition/

20. exp Dementia/

21. 19 or 20

22. randomi?ed.ti.

23. (randomly adj2 allocat $\left.{ }^{\star}\right) \cdot a b$.

24. (randomly adj2 divide*).ab

25. RCT.ti,ab.

26. "double-blind*".ti,ab.

27. "single blind*".ti,ab.

28. "randomi?ed trial".ab.

29. "randomi?ed control* trial".ab.

30. "random allocation".ab.

31. "controlled clinical trial".ti,ab.

32. or/22-31

33. exp Vitamins/ 


\section{4. exp Dietary Supplements/}

35. vitamin*.ti,ab.

36. mineral*.ti,ab.

37. calcium.ti,ab.

38. Calcium/

39. $\exp$ Ascorbic Acid/

40. exp Folic Acid/

41. "folic acid".ti,ab.

42. cholecalciferol.ti,ab.

43. ergocalciferol.ti,ab.

44. toxiferol.ti,ab.

45. retinol.ti,ab.

46. retinal.ti,ab.

47. "retinoic acid".ti,ab.

48. "beta-carotene".ti,ab.

49. "alpha-carotene".ti,ab.

50. "gamma-carotene".ti,ab.

51. "beta-cryptoanthin".ti,ab.

52. thiamine.ti,ab.

53. riboflavin.ti,ab.

54. niacin.ti,ab.

55. nicotinamide.ti,ab.

56. pantothenic.ti,ab.

57. pyridoxine.ti,ab.

58. pyridoxal.ti,ab.

59. pyridoxamine.ti,ab.

60. biotin.ti,ab.

61. "folic acid".ti,ab.

62. cyanocobalamin.ti,ab.

63. methylcobalamin.ti,ab.

64. "l-ascorbic acid".ti,ab.

65. "ascorbic acid".ti,ab.

66. ascorbate.ti,ab.

67. phylloquinone.ti,ab. 


\section{8. phytomeadione.ti,ab}

69. phytonadine.ti,ab.

70. multivitamin*.ti,ab.

71. "diet supplement*".ti,ab.

72. iron.ti,ab.

73. zinc.ti,ab.

74. sodium.ti,ab.

75. potassium.ti,ab.

76. phosphorus.ti,ab.

77. magnesium.ti,ab.

78. chloride.ti,ab.

79. sulphur.ti,ab.

80. mangansese.ti,ab.

81. cobalt.ti,ab.

82. selenium.ti,ab.

83. copper.ti,ab.

84. iodine.ti,ab.

85. fluoride.ti,ab.

86. 18 or 21

87. or/33-85

88. 86 and 87

89. 32 and 88

90. exp *Vitamins/

91. (vitamin ${ }^{\star}$ or mineral $\left.{ }^{\star}\right)$.ti.

92.90 or 91

93. exp ${ }^{*}$ Cognition/

94. (cognition or cognitive).ti.

95.93 or 94

96. (elderly or "middle age*" or "old* adults" or $\mathrm{MCl}$ or "mild cognitive impairment").ti.

\subsection{2 and 95 and 96}

98. (randomised or randomised or RCT or trial).ti.

99. 97 and 98

100. 89 not 99 
(Continued)

\section{CINAHL (EBSCOhost) \\ (Date of most recent search: 25 January 2018)}
S1 (MM "Vitamins+")
Dec 2014: 493
S2 (MM "Minerals+")
Jul 2015: 7
S3 (MH "Dietary Supplements") OR (MH "Dietary Supplementation") OR (MH
Mar 2016: 35
"Dietary Carbohydrates") OR (MH "Dietary Fiber") OR (MH "Sodium, Dietary")
OR (MH "Dietary Fats") OR (MH "Dietary Proteins") OR (MH "Dietary Sucrose")
Aug 2016: 15
S4 TX vitamin*
Mar 2017: 24
S5 TX mineral*
Jan 2018: 23

S6 TX "diet* supple*”

S7 (MH "Fatty Acids") OR (MH "Fatty Acids, Omega-6") OR (MH "Fatty Acids, Unsaturated") OR (MH "Trans Fatty Acids") OR (MH "Fatty Acids, Monounsaturated") OR (MH "Fatty Acids, Saturated") OR (MH "Fatty Acids, Essential")

S8 TX "fatty acid*"

S9 (MH "Vitamin A")

S10 (MH "Vitamin B12") OR (MH "Vitamin B Complex") OR (MH "Thiamine") OR (MH "Riboflavin") OR (MH "Pyridoxine") OR (MH "Carnitine")

S11 (MH "Folic Acid")

S12 (MH "Ascorbic Acid")

S13 (MH "Vitamin D") OR (MH "Cholecalciferol") OR (MH "Ergocalciferols") OR (MH "Calcitriol")

S14 (MH "Vitamin E") OR (MH "Pantothenic Acid")

S15 (MH "Vitamin K") OR (MH "Osteocalcin")

S16 TX "beta-carotene"

S17 TX "alpha-carotene"

S18 TX thiamine

S19 TX riboflavin

S20 TX niacin

S21 TX pantothenic

S22 TX nicotinamide

S23 TX pyridoxine

S24 TX pyridoxal

S25 TX biotin

S26 (MH "Calcium")

S27 TX calcium

S28 TX iron

S29 (MH “iron”)

S30 (MH "Zinc")

S31 TX zinc

Vitamin and mineral supplementation for maintaining cognitive function in cognitively healthy people in mid and late life (Review) 


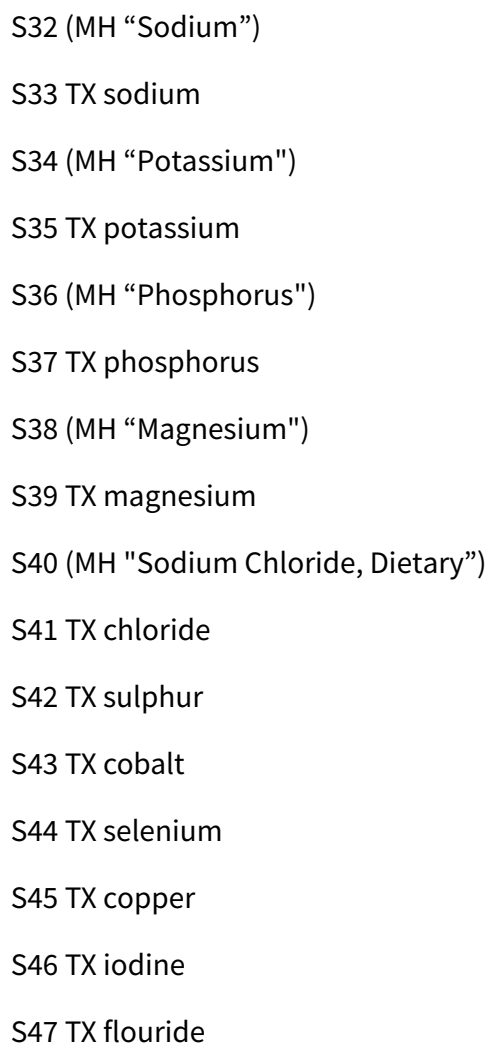


S64 S49 OR S50 OR S51 OR S52 OR S53 OR S54 OR S55 OR S56 OR S57 OR S58 OR S59 OR S60 OR S61 OR S62 OR S63

\section{S65 S48 AND S64}

S66 (MH "Cognition") OR (MH "Cognition Disorders") OR (MH "Delirium, Dementia, Amnestic, Cognitive Disorders")

\section{S67 TX cognition}

S68 TX memory

S69 (MH "Memory") OR (MH "Memory Disorders") OR (MH "Memory, Short Term")

S70 TX "executive function"

S71 TX "cognitive* declin*"

S72 TX "cognitive* improv"”

S73 TX "cognitive deficit*"

S74 TX "mental perform*"

S75 TX dementia

S76 TX alzheimer*

S77 (MH "Dementia+")

S78 S66 OR S67 OR S68 OR S69 OR S70 OR S71 OR S72 OR S73 OR S74 OR S75 OR S76 OR S77

\section{S79 S65 AND S78}

S80 (MH "Randomized Controlled Trials")

S81 AB randomly

S82 AB placebo

S83 AB groups

S84 AB RCT

S85 TX "double blind*"

S86 TX "single blind*"

S87 TX "controlled clinical trial"

S88 TI randomised

S89 TI randomized

S90 S80 OR S81 OR S82 OR S83 OR S84 OR S85 OR S86 OR S87 OR S88

S91 S79 AND S90

ISI Web of Science
[includes: Web of
Science (1945-present);
BIOSIS Previews (1926-
present); MEDLINE
(1950-present); Jour-

("mild cognitive impairment" OR elderly OR "age* subjects" OR "old* adult*" OR "middle age*" OR MCI) AND TOPIC: ("randomly allocated" OR "random allocation" OR randomised OR randomized OR RCT OR "controlled trial" OR "double blind" OR "single blind") AND TOPIC: (vitamin* OR mineral* OR "diet* suppl*" OR "ascorbic acid" OR "folic acid" OR iron OR calcium OR sodium OR

Dec 2014: 932

Jul 2015: 34

Mar 2016: 100

Aug 2016: 43 
(Continued)

nal Citation Reports]; BIOSIS Previews

(Date of most recent search: 25 January 2018)

\section{LILACS (BIREME)}

(Date of most recent search: 25 January 2018) zinc OR potassium OR magnesium OR cobalt OR copper OR iodine) AND TOPIC: (cognition OR dementia OR memory OR "executive function" OR alzheimer ${ }^{\star}$ )

Timespan: All years.

Search language=Auto
Mar 2017: 67

Jan 2018: 55 cognition OR "mild cognitive impairment" OR elderly OR "aged subjects" OR "older adults" OR "middle aged" [Words] and randomly OR randomised OR randomized OR RCT OR "controlled trial" [Words] and vitamin OR vitamins OR mineral OR minerals OR "fatty acid" OR "folic acid" [Words]
Dec 2014: 28

Jul 2015: 0

Mar 2016: 0

Aug 2016: 1

Mar 2017: 0

Jan 2018: 0

Dec 2014: 395

Jul 2015: 10

Mar 2016: 50

Aug 2016: 48

Mar 2017: 90

Jan 2018: 54

\#6 elderly

\#7 "old* adults"

\#8 "old*age*"

\#9 "old* sample"

\#10 senior citizens

\#11 pensioners

\#12 seniors

$\# 13 \# 1$ or \#2 or \#3 or \#4 or \#5 or \#6 or \#7 or \#8 or \#9 or \#10 or \#11 or \#12

\#14 MeSH descriptor: [Cognition] explode all trees

\#15 MeSH descriptor: [Dementia] explode all trees

$\# 16$ cognit*

\#17 memory

\#18 "executive function*"

\#19 processing

\#20 "mental perform*"

\#21 dement ${ }^{*}$

\#22 alzheimer*

$\# 23 \# 14$ or \#15 or \#16 or \#17 or \#18 or \#19 or \#20 or \#21 or \#22

\#24 MeSH descriptor: [Vitamins] explode all trees 
\#25 MeSH descriptor: [Minerals] explode all trees

\#26 vitamin *

\#27 mineral ${ }^{\star}$

\#28 "ascorbic acid"

\#29 "folic acid"

\#30 MeSH descriptor: [Fatty Acids] explode all trees

\#31 zinc or iron or calcium or sodium or potassium or magnesium or cobalt or copper or selenium or iodine or flouride or chloride

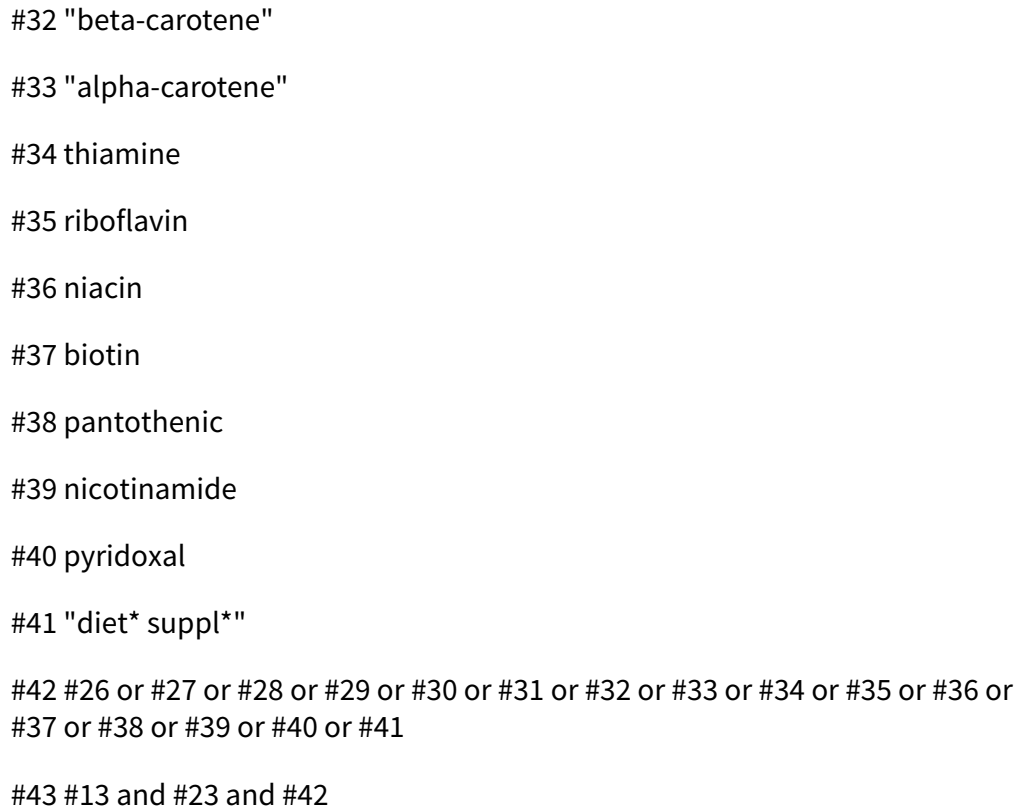

Clinicaltrials.gov (www.clinicaltrials.gov)

In Intervention studies: [intervention] vitamin * OR mineral ${ }^{\star}$ OR "diet* suppl*" OR "ascorbic acid" OR "folic acid" OR iron OR calcium OR sodium OR zinc OR potassium OR magnesium OR cobalt OR copper OR iodine AND [condition]: cognition OR "mild cognitive impairment" OR elderly OR "aged subjects" OR "older adults" OR "middle aged"

Trial Status: all

Jul 2015: 0

Mar 2016: 2

Aug 2016: 0

$\operatorname{Mar} 2017: 6$

Jan 2018: 8

\section{ICTRP Search Portal \\ (http://apps.who.int/tri- alsearch) (includes: Australian New Zealand Clinical Trials Reg- istry; ClinicalTrilas.gov; ISRCTN; Chinese Clini- cal Trial Registry; Clini- \\ dia; Clinical Research Information Service - Republic of Korea; Ger- man Clinical Trials Reg-}

In Intervention studies: [intervention] vitamin * OR mineral ${ }^{*}$ OR "diet ${ }^{*}$ suppl*" OR "ascorbic acid" OR "folic acid" OR iron OR calcium OR sodium OR zinc OR potassium OR magnesium OR cobalt OR copper OR iodine AND [condition]: cognition OR "mild cognitive impairment" OR elderly OR "aged subjects" OR "older adults" OR "middle aged"

Dec 2014: 25

Trial Status: all

Jul 2015: 0

Mar 2016: 2

Aug 2016: 0

$\operatorname{Mar} 2017: 4$

Jan 2018: 2 
(Continued)

ister; Iranian Registry

of Clinical Trials; Japan

Primary Registries Net-

work; Pan African Clin-

ical Trial Registry; Sri

Lanka Clinical Trials

Registry; The Nether-

lands National Trial

Register)

(Date of most recent

search: 25 January

2018)

TOTAL before de-duplication

Dec 2014: 5071

Jul 2015: 233

Mar 2016: 496

Aug 2016: 304

Mar 2017: 631

Jan 2018: 522

TOTAL: 7257

TOTAL after de-duplication

Dec 2014: 3451

Jul 2015: 200

Mar 2016: 399

Aug 2016: 208

Mar 2017: 522

Jan 2018: 431

TOTAL: 5211

TOTAL after first assessment by the Crowd and CDCIG information specialists

Dec 2014: 448

Jul 2015: 81

Mar 2016: 70

Aug 2016: 45

$\operatorname{Mar} 2017: 43$

Jan 2018: 38

TOTAL: 725

\section{Appendix 3. Definitions of design, patient and intervention characteristics as applied in the stratified analyses exploring between trial variations in intervention effect}




\begin{tabular}{ll}
\hline Item & Definition \\
\hline Bias-related characteristics* & \\
\hline $\begin{array}{l}\text { Concealment of allocation } \\
\text { (avoiding selection bias) }\end{array}$ & $\begin{array}{l}\text { The guidance from the Cochrane Handbook for Systematic Reviews of Interventions (Higgins 2011) } \\
\text { will be used to judge bias related to sequence generation and concealment of allocation using the } \\
\text { two Cochrane 'Risk of bias' items. From these, the statistician will derive a single variable to be } \\
\text { used in the stratified analysis: allocation concealment will be judged at low risk of bias if the inves- } \\
\text { tigators responsible for patient selection were unable to suspect before allocation which treatment } \\
\text { was next. Concealment will downgraded to high risk of bias if there is evidence of inadequate se- } \\
\text { quence generation. }\end{array}$ \\
\hline
\end{tabular}

Blinding of patients and personnel (avoiding performance bias)
Low risk of bias will be judged if:

- a credible sham procedure was used; or if a placebo supplement or pill was used that was reported to be identical in appearance to the experimental intervention and the specific outcome or group of outcomes is/are likely to be influenced by lack of blinding

- blinding is absent or suboptimal and the specific outcome, such as mortality, is not likely to be influenced by lack of blinding
Blinding of outcome assessment (avoiding detection bias)
For self-reported/partner-reported outcomes:

Low risk of bias will be judged if:

- self-reported outcomes were assessed AND blinding of patients was considered adequate AND there was no information to suggest that there was an investigator involved during the process of outcome assessment; OR if blinding of investigators performing the outcome assessment was reported AND an attempt to blind patients was reported For other outcomes:

Outcome assessment was considered to be blinded if the outcome assessment was reported to be blinded.
Statistical analyses (avoiding attrition bias)

\section{For continuous outcomes}

Low risk of bias will be judged if:

- at least $90 \%$ of the patients randomised were analysed AND the difference in percentage of participants not analysed was $5 \%$ or lower across trial arms

- for trials using imputations to handle missing data: the percentage of participants with missing data did not exceed $20 \%$ AND the difference in percentage of participants with imputed data was $10 \%$ or lower across trial arms AND applied imputation methods were judged to be appropriate For binary outcomes of rare events

Low risk of bias will be judged if:

- the event rate is low (e.g. incidence of dementia) AND at least $95 \%$ of the patients randomised were analysed AND there is no evidence of differential reasons for missing data that may alter the estimate AND the rate of missing data does not exceed the expected event rates

For binary outcomes of non-rare events

Low risk of bias will be judged if:

- at least $90 \%$ of the patients randomised were analysed AND the difference in percentage of participants not analysed was $5 \%$ or lower across trial arms AND there is no evidence of differential reasons for missing data that may alter the estimate AND the rate of missing data does not exceed the expected event rates A large trial will be defined by a sample size calculation for the primary outcome.

Trial Size

Follow-up duration
For the cognitive outcomes, we will group studies according to these follow-up cut-offs to describe immediate results (up to 12 weeks), short-term (up to 1 year), medium-term ( 1 to 2 years) and longer-term results (more than 2 years). For the secondary outcome all-cause dementia, only outcome data at 1 year of follow-up or longer will be considered and therefore the grouping will include short-term (1 year), medium-term (up to 2 years) and longer-term results (more than 2 years).

Treatment-related characteristics 
(Continued)

Treatment duration

The minimum treatment duration of 3 months is considered short-term, 3 to 12 months as medium-term, and 12 months for long-term.

Dose of treatment

Treatment will be analysed as high dose versus low dose according to previously reported cut-offs.

Mechanisms of action of the supplements ${ }^{\star *}$

Supplements postulated to share a main mechanism of action in preventing development of dementia, including:

- Antioxidant properties - affecting superoxide dismutase (vitamin A, C, D, E, selenium)

- Regulation/lowering levels of homocysteine: vitamins B12, folate and B6

Participant-related characteristics

Cognition-related criteria

No risk of deficiency versus at risk of deficiency for the type of vitamin and minerals investigated (e.g. presence of malabsorptive diseases, malnutrition, comorbidities or concomitant medications, and ethnicity (Vitamin D))

* The descriptions depicted in this Table are in addition to the guidance provided by Cochrane (Higgins 2011).

** Knowledge of possible mechanisms of actions is evolving, and we will consider other possible subgroups for data analysis as new information arises during the development of the review.

Appendix 4. Composition of Centrum Silver ${ }^{\circledR}$ used in Grodstein 2013

\begin{tabular}{|c|c|}
\hline Vitamin A (IU) & $5000^{*}$ \\
\hline Vitamin C (mg) & 60 \\
\hline Vitamin D (IU) & 400 \\
\hline Vitamin E (IU) & 45 \\
\hline Vitamin $\mathrm{K}(\mu \mathrm{g})$ & 10 \\
\hline Thiamin (mg) & 1.5 \\
\hline Riboflavin (mg) & 1.7 \\
\hline Niacin (mg) & 20 \\
\hline Vitamin B6 (mg) & 3 \\
\hline Folic Acid ( $\mu \mathrm{g})$ & 400 \\
\hline Vitamin B12 $(\mu \mathrm{g})$ & 25 \\
\hline Biotin $(\mu g)$ & 30 \\
\hline Pantothenic Acid (mg) & 10 \\
\hline Calcium (mg) & 200 \\
\hline Iron (mg) & 4 \\
\hline
\end{tabular}




\begin{tabular}{|c|c|}
\hline Phosphorus (mg) & 48 \\
\hline lodine ( $\mu \mathrm{g})$ & 150 \\
\hline Magnesium (mg) & 100 \\
\hline Zinc (mg) & 15 \\
\hline Selenium ( $\mu g$ ) & 20 \\
\hline Copper (mg) & 2 \\
\hline Manganese (mg) & 3.5 \\
\hline Chromium ( $\mu \mathrm{g})$ & 130 \\
\hline Molybdenum ( $\mu \mathrm{g}$ ) & 160 \\
\hline Chloride (mg) & 72.6 \\
\hline Potassium (mg) & 80 \\
\hline Boron $(\mu \mathrm{g})$ & 150 \\
\hline Nickel ( $\mu \mathrm{g})$ & 5 \\
\hline Vanadium ( $\mu \mathrm{g})$ & 10 \\
\hline Silicon (mg) & 2 \\
\hline
\end{tabular}

\section{WHAT'S NEW}

\begin{tabular}{lll}
\hline Date & Event & Description \\
\hline 7 January 2019 & Amended & First author affiliations updated \\
\hline
\end{tabular}

\section{CONTRIBUTIONS OF AUTHORS}

Completion of the protocol: Rutjes AWS, Al-Assaf AS, Denton DA, Abraham RP, Chong LY, Anderson J, Malik MA, Tabet N Completion of the searches: Noel-Storr A

Screening of references: Di Nisio M, Al-Assaf AS, Denton DA, Abraham RP, Chong LY, Anderson J, Malik MA, Rutjes AWS, Tabet N, Martinez G, McCleery J

Acquisition of data: Di Nisio M, Al-Assaf AS, Vernooij RWM, Rutjes AWS, Martinez G, McCleery J

Risk of bias and GRADE assessments: Di Nisio M, Vernooij RWM, Rutjes AWS, Martinez G, McCleery J

Statistical analysis: McCleery J, Martinez G

Overall interpretation of data: McCleery $\mathrm{J}$

Manuscript preparation: McCleery J, Rutjes AWS 


\section{DECLARATIONS OF INTEREST}

Rutjes AWS: Dr. Rutjes declares partial funding by a grant for the project 'OPERAM: OPtimising therapy to prevent Avoidable hospital admissions in the Multi-morbid elderly' supported by the European Union's Horizon 2020 research and innovation programme under the grant agreement No 6342388, and by the Swiss State Secretariat for Education, Research and Innovation (SERI) under contract number 15.0137.

\section{Denton DA: none known}

Di Nisio M: Di Nisio declares consultancy fees from Daiichi Sankyo, Bayer, and Aspen and participation to advisory boards for Daiichi Sankyo, Bayer, Pfizer outside the submitted work. M Di Nisio declares partial funding by a grant for the project 'OPERAM: OPtimising therapy to prevent Avoidable hospital admissions in the Multi-morbid elderly' supported by the European Union's Horizon 2020 research and innovation programme under the grant agreement No 6342388, and by the Swiss State Secretariat for Education, Research and Innovation (SERI) under contract number 15.0137

Chong LY: none known

Abraham RP: none known

Al-Assaf AS: none known

Anderson JL: none known

Malik MA: none known

Vernooij RWM: none known

Martinez G: none known

Tabet N: N Tabet reports I receive honorarium and consultation fees from the pharmaceutical industry

McCleery J: none known

\section{SOURCES OF SUPPORT}

\section{Internal sources}

- No sources of support supplied

\section{External sources}

- NIHR, UK.

This review was supported by the National Institute for Health Research, via a Cochrane Programme Grant to the Cochrane Dementia and Cognitive Improvement group. The views and opinions expressed therein are those of the authors and do not necessarily reflect those of the Systematic Reviews Programme, NIHR, NHS or the Department of Health

- SERI \& Horizon 2020, Other.

The authors AR and MdN are partially funded by a grant for the project 'OPERAM: OPtimising therapy to prevent Avoidable hospital admissions in the Multi-morbid elderly' supported by the European Union's Horizon 2020 research and innovation programme under the grant agreement No 6342388, and by the Swiss State Secretariat for Education, Research and Innovation (SERI) under contract number 15.0137. The opinions expressed and arguments employed herein are those of the authors and do not necessarily reflect the official views of the EC and the Swiss government.

\section{DIFFERENCES BETWEEN PROTOCOLANDREVIEW}

There are a number of significant differences between this review and its protocol.

Published protocols anticipated the production of two reviews with distinct populations: cognitively healthy people in midlife (40 years to 65 years; Denton 2015) and in late life (> 65 years). However, it became apparent that many studies straddled this arbitrary age boundary so that it was not possible logically to assign them to one review rather than the other. Therefore, it was decided to produce a single review covering participants in mid- and late-life.

The protocols specified that participants should have been cognitively assessed at baseline. Again, this criterion would have led to exclusion of a large amount of potentially informative data and was dropped in favour of a more pragmatic approach. If a study stated 
that participants were cognitively healthy or if they were a large population sample with no cognitive inclusion criteria, then they were assumed to be eligible.

The protocol specified only three time points for grouping outcomes: 12 weeks to 1 year, 1 to 2 years and $>2$ years. However, we considered that the very wide variation in durations of follow-up justified further subdivisions at 5 and 10 years. Particularly in the middle-aged and 'young' elderly, trial durations as short as 2 years are unlikely to be able to detect effects on the trajectory of age-related cognitive decline.

Appendix 3 described a stringent method for assessing blinding. In practice, we adopted a more flexible approach and for multicentre studies with generally rigorous methods, we accepted trial authors' statements about blinding of participants and investigators in the absence of further detail.

\section{INDEX TERMS}

\section{Medical Subject Headings (MeSH)}

*Dietary Supplements; Antioxidants [administration \& dosage]; Ascorbic Acid [administration \& dosage]; Calcium [administration \& dosage]; Cholecalciferol [administration \& dosage]; Cognition [ ${ }^{\star}$ drug effects] [physiology]; Cognitive Dysfunction [ ${ }^{\star}$ prevention \& control]; Copper [administration \& dosage]; Dementia [prevention \& control]; Folic Acid [administration \& dosage]; Minerals [ ${ }^{\star}$ administration \& dosage]; Randomized Controlled Trials as Topic; Selenium [administration \& dosage]; Vitamin A [administration \& dosage]; Vitamin B 12 [administration \& dosage]; Vitamin B 6 [administration \& dosage]; Vitamin E [administration \& dosage]; Vitamins [ ${ }^{\star}$ administration \& dosage]; Zinc [administration \& dosage]; beta Carotene [administration \& dosage]

\section{MeSH check words}

Adult; Aged; Humans; Middle Aged 